\title{
LOCATION OF ACTIVE FAULTS USING GEOMORPHIC INDICES IN ERODED LANDSCAPES, SOUTH TARANAKI, NEW ZEALAND
}

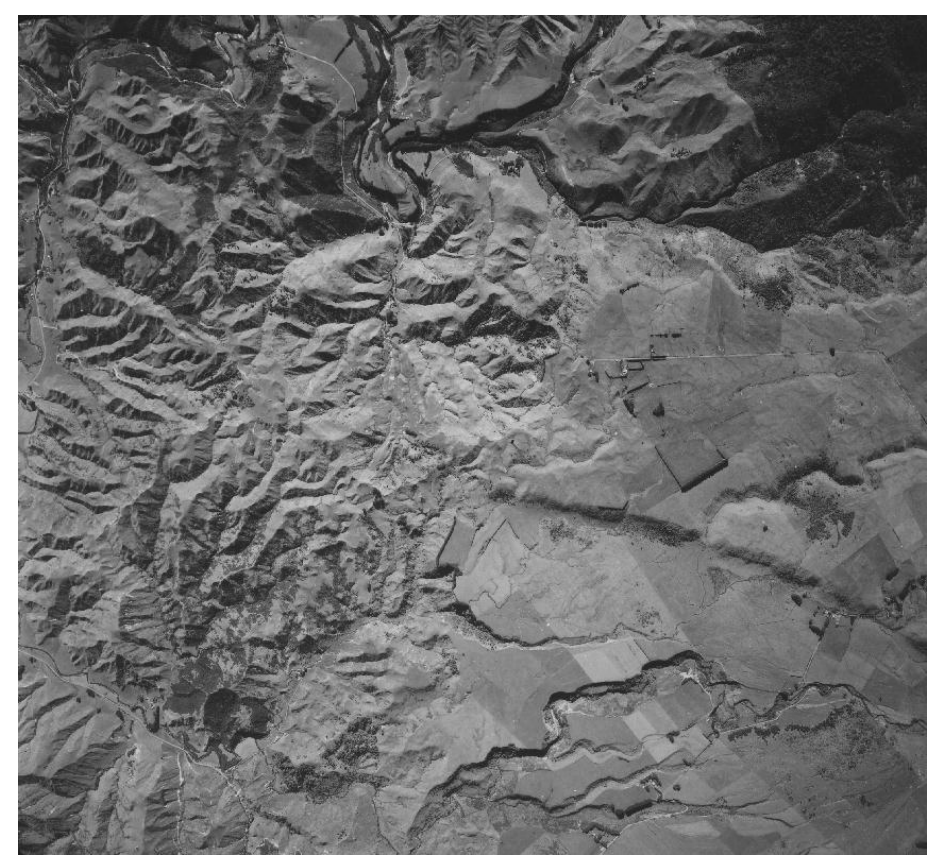

William Francis Ries

A thesis submitted to Victoria University of Wellington in partial fulfilment of the requirements for the degree of Master of Science in Physical Geography

School of Geography, Environment and Earth Sciences,

Victoria University of Wellington

May 2013 


\section{Abstract}

The South Taranaki region has a number of active faults that show surface expression in the younger and harder materials near the coast and central volcanoes of the North Island, but these traces finish abruptly inland when they cross into older, heavily eroded, mudstone and sandstone.

Current methods to locate surface evidence of active faults (i.e. geomorphic interpretation of stereographic aerial photography) are not fully successful in this region. Erosion occurs here at a greater rate than surface rupture of faults which causes the removal of surface expression, and/or dense tree cover obscures surface expression. International studies of tectonic activity in eroded landscapes have identified geomorphic indices as useful reconnaissance tools to locate active faults.

This research applies geomorphic indices to the Taranaki region for the first time. Four indices are tested; stream length-gradient index, stream channel sinuosity, hypsometry and drainage basin asymmetry. Results are obtained by applying the indices to four freely available national Digital Elevation Models (DEMs) of differing resolutions. This allowed comparison between DEMs, providing the ability to test DEM quality and at what scale geomorphic indices could be applied to these freely available data.

Results show that the geomorphic indices used can identify changes to the equilibrium state at a catchment and stream channel scales. However, the myriad of physical processes occurring at a range of temporal scales within this area make identification of a tectonic signature a challenging task. Conclusive examples of tectonic processes are evident and analysis suggests that these examples are likely to be due to recent or large fault ruptures. There are many areas where a tectonic influence to the equilibrium state of a stream or catchment can be inferred. These areas could then be targeted for detailed geophysical or ground based geological studies. Furthermore, the comparison of results from the four DEMs highlights a range of issues with DEM collection methods and resolution.

This study concludes that geomorphic indices can provide an effective method to locate evidence of recent and large faulting events. However, this type of analysis is hindered by the resolution of available digital elevation data. 


\section{Acknowledgments}

I would like to acknowledge all of my friends, family, and colleagues that have helped me throughout this project. A special thanks to my supervisors Dr Mairead de Roiste and Dr Pilar Villamor. I would also like to acknowledge the late Dr Nick Preston, his love of geomorphology is hopefully expressed somewhere within these pages. 


\section{Table of Contents}

Abstract

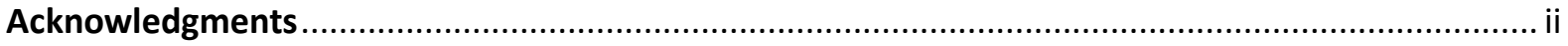

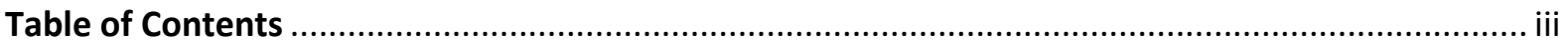

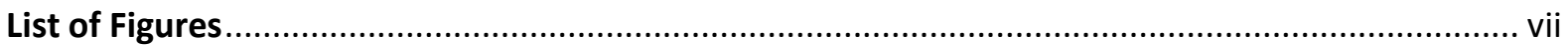

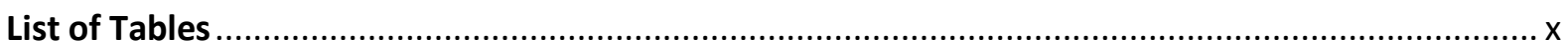

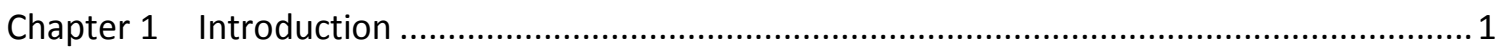

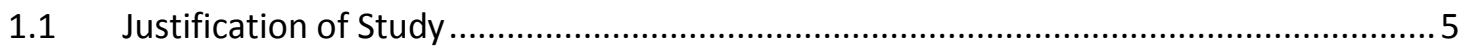

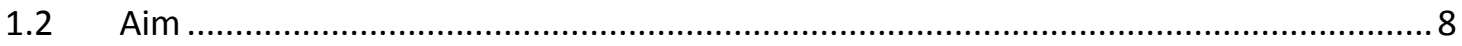

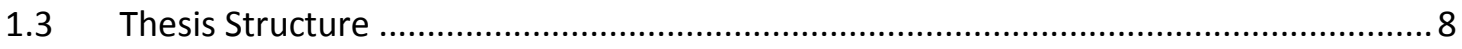

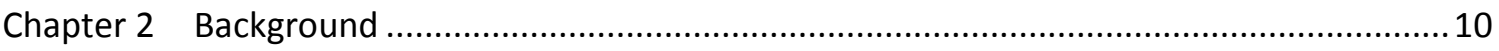

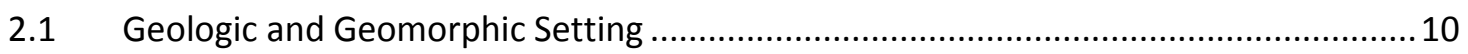

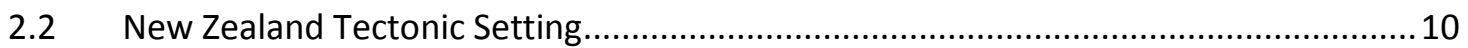

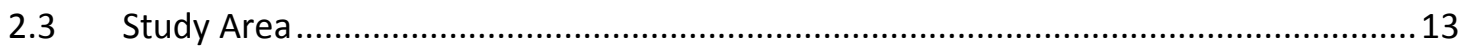

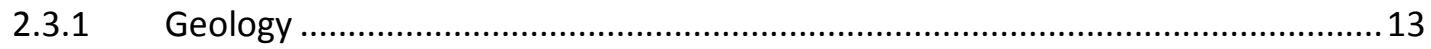

2.3.2 Tertiary - Pleistocene Mudstones, Limestones and Sandstones...........................14

2.3.3 Volcanic Rocks and Volcanic Derived Alluvium ................................................... 15

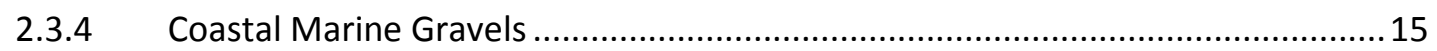

2.3.5 Active Faults in and Around the Study Area .................................................... 16

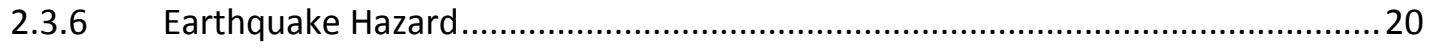

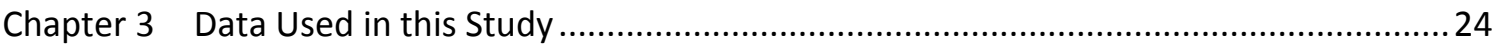

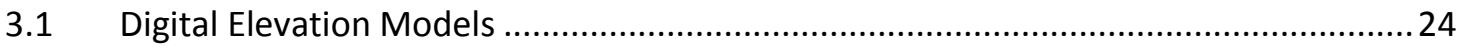

3.1.1 Issues with DEMs derived from contour data..................................................2

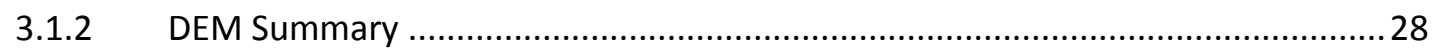

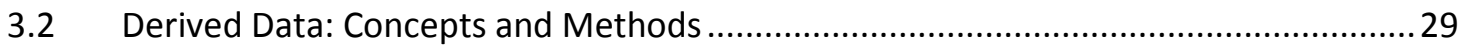

3.2.1 Correcting a DEM for hydrological modelling .....................................................29

3.2.2 Stream and Catchment extraction ..................................................................... 32 


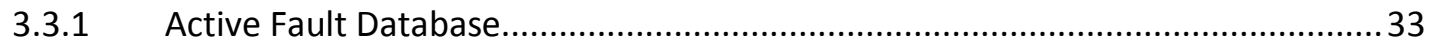

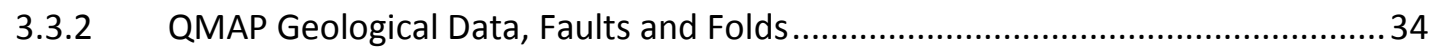

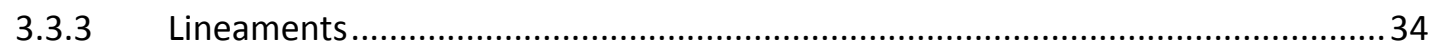

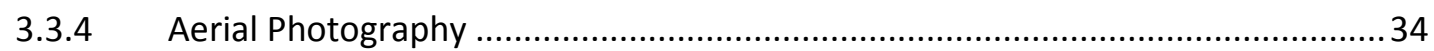

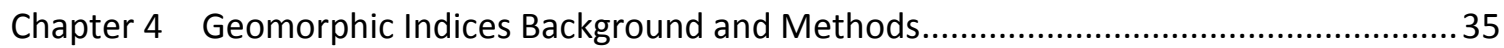

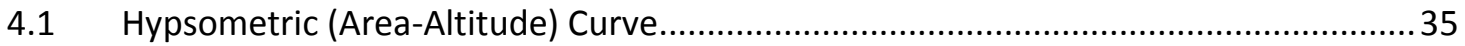

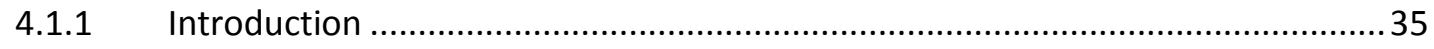

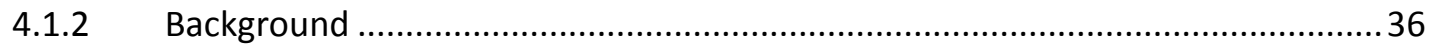

4.1.3 Summary of Literature: Hypsometric Curve ....................................................40

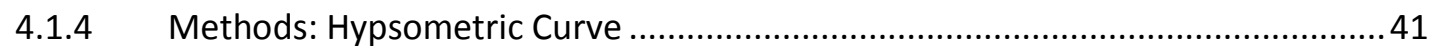

4.2 Stream Length Gradient Index: Concepts and Methods......................................... 42

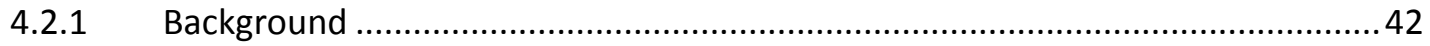

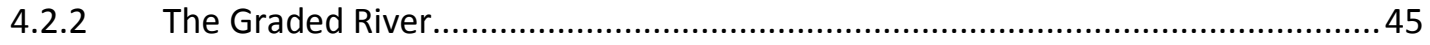

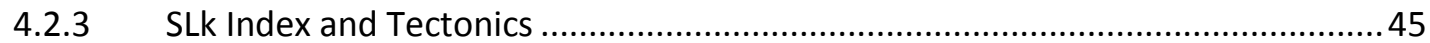

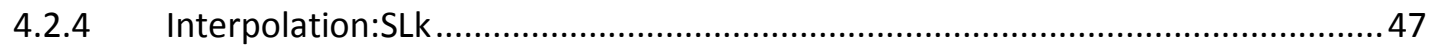

4.2.5 Summary of SLk and Application of the Index to the Taranaki Region.................47

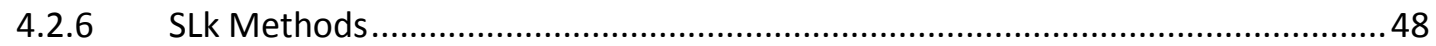

4.3 Sinuosity Index: Concepts and Methods............................................................... 50

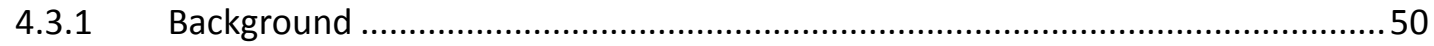

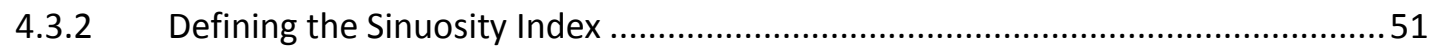

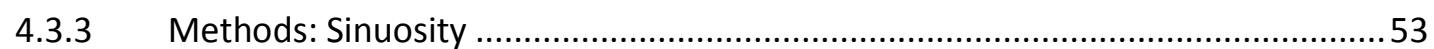

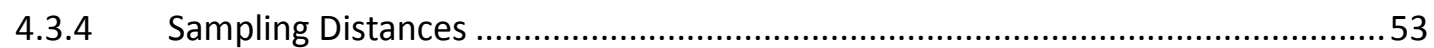

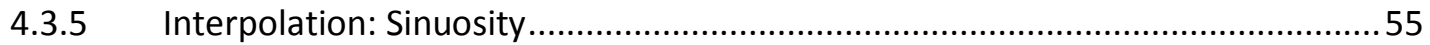

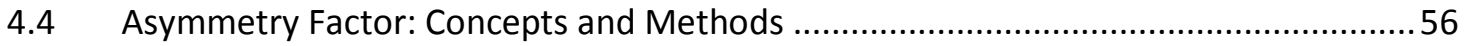

4.4.1 Defining Basin Asymmetry Parallel to the Trunk Stream ....................................57

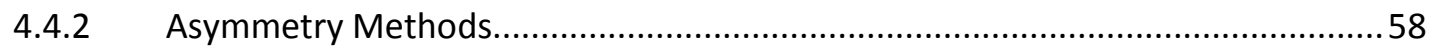

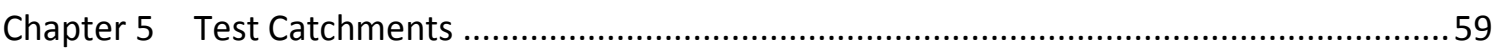


5.1 Test catchments: Geology, Active Tectonic Structures and Stream Profile

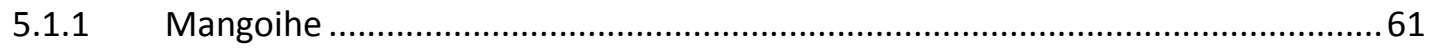

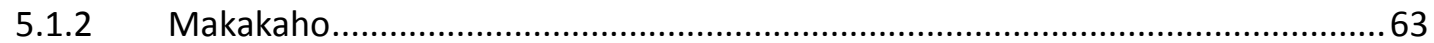

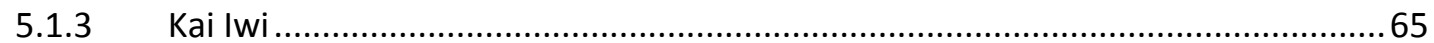

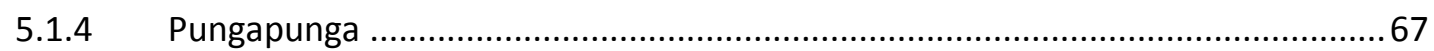

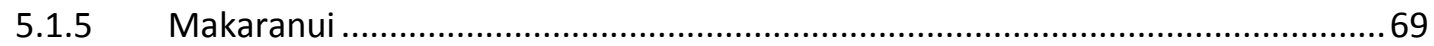

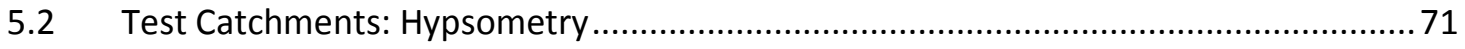

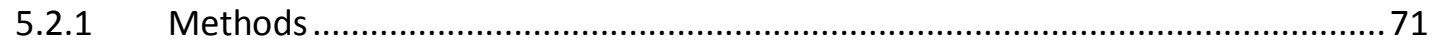

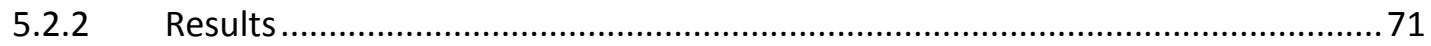

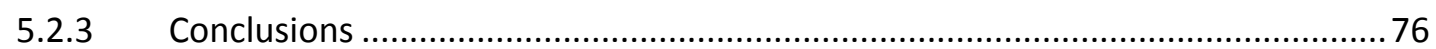

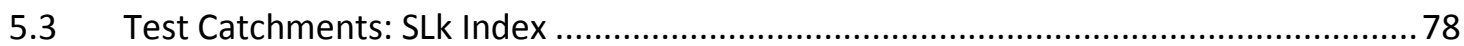

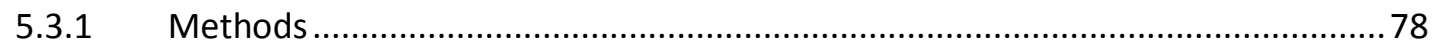

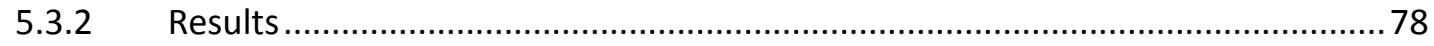

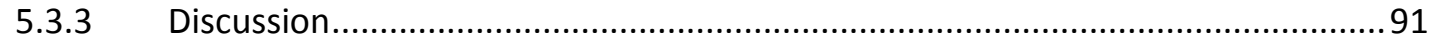

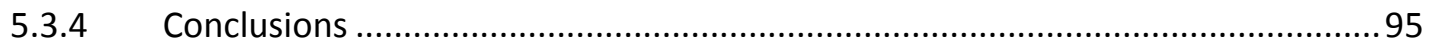

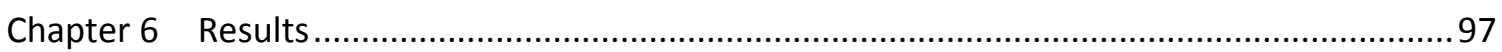

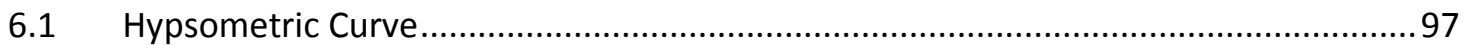

6.2 Stream Length Gradient Index (SLk Index) ................................................................ 101

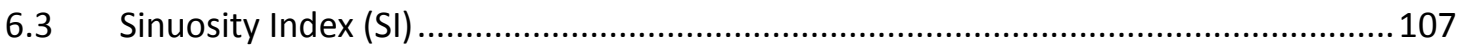

6.3.1 DEM Horizontal Resolution and Sinuosity ....................................................... 108

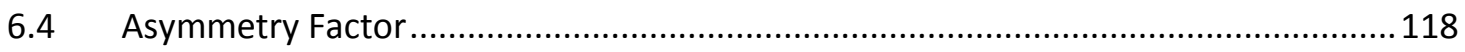

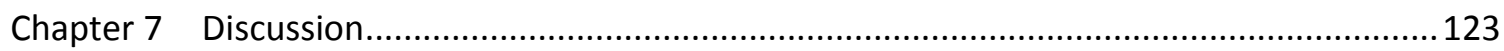

7.1 Appropriateness of DEM Data for Geomorphic Index Analysis ...................................123

7.2 Interpretation of Fault Activity from Analysis of Geomorphic Indices .......................125

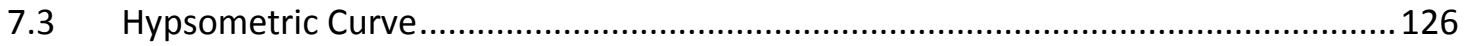

7.4 Stream Length Gradient Index and Sinuosity Index and Asymmetry ........................127

7.5 Implications for Seismic Hazards in the Wanganui Region .......................................129

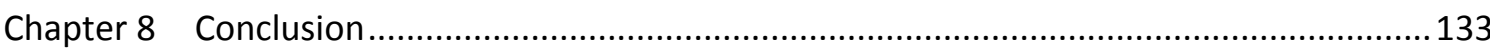




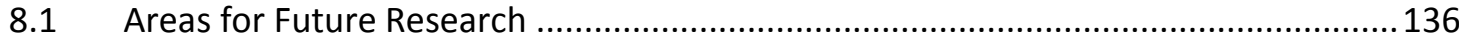

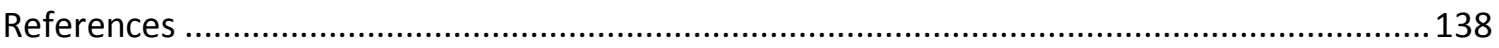

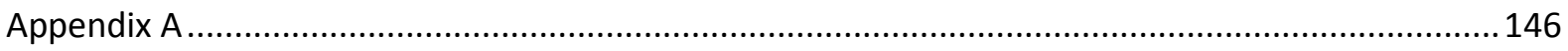

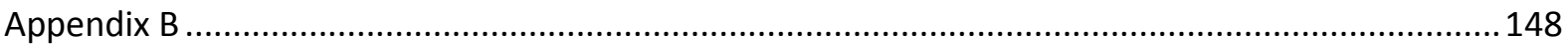

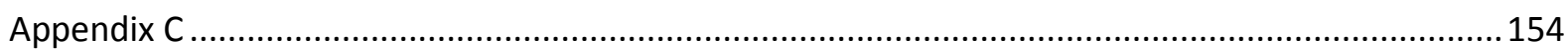

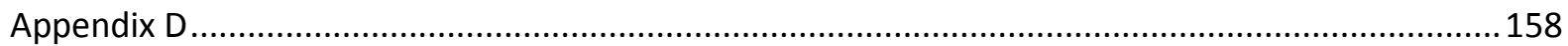




\section{List of Figures}

Figure 1-1. Mapped active faults. The red lines represent mapped traces of active faults in New Zealand. Source: GNS active fault database.

Figure 1-2. The Greendale fault is over $100 \mathrm{~km}$ from the Alpine Fault (surface expression of the plate boundary)

Figure 1-3. Map derived from the 2010 NSHM showing peak ground acceleration expected with a 475 year return period for Class $C$ sites.

Figure 1-4. 1:1 million geology of the Taranaki region. Red lines are active faults from the AFDB. At location A faults are preserved in the harder volcanic lithology .................................................... 6

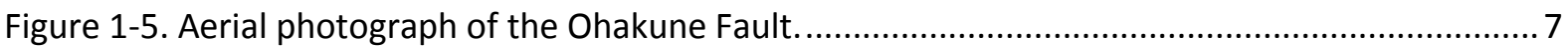

Figure 2-1. Tectonic domains as described by Berryman (1994) ...................................................... 11

Figure 2-2. The study area (black box) with mapped active (red lines) and inactive (black lines) faults from Qmap Taranaki and the AFDB.

Figure 2-3. Location of the three main regions that surround the study area where mapped faults have been investigated. 16

Figure 2-4. Mapped active fault traces in the Waverley fault zone. .17

Figure 2-5 Mapped active fault traces in the southern Taupo volcanic zone. 18

Figure 2-6. Mapped active fault traces of the Taranaki rift. .20

Figure 2-7. Earthquake hypocentres greater than Mw 3 post 1950 from GNS Science earthquake catalogue.

Figure 2-8. Earthquake hypocentres greater than Mw 3 post 1950 at a depth less than $40 \mathrm{~km}$ from GNS Science earthquake catalogue.

Figure 3-1. The four DEMs used in this study displaying a hillshade model of a bend in the Whanganui River, showing the difference between cell sizes. .25

Figure 3-2. A terracing effect can easily be seen in the hillshade model of the Otago $15 \mathrm{~m}$..............28

Figure 3-3. This figure visually shows the method used to correct a DEM for sinks and peaks...........30

Figure 4-1. The hypsometric curve is produced by calculating the percentage of area and plotting it

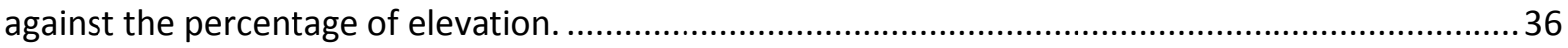

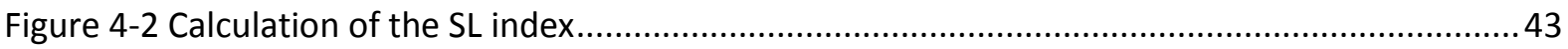

Figure 4-3 The process used to join stream network segments to allow for SLk calculations. .49

Figure 4-4. Block diagram showing the interactions between faulting and the sinuosity of an alluvial stream. .51

Figure 4-5. The sampling method used to calculate sinuosity in this study. .52 
Figure 4-6. Sinuosity calculations are made by dividing the stream into reaches at a user defined distance, this distance is then divided by the straight line distance between the start and end point of the reach.

Figure 4-7. The average SI vales for a range of sampling distances provides an idea of the optimal sampling distances to use to ensure the variation of sinuosity is captured. .55

Figure 4-8. Cross section and plan view of an idealised catchment and drainage network. .56

Figure 4-9. The asymmetry classifications and colour coding for catchments used in this study........58 Figure 5-1. The location of the five test catchments representing the range of geology within the study area. 60

Figure 5-2 A) Geology of the Mangoihe catchment. 62

Figure 5-3 A) Geology of the Makakaho catchment. 64

Figure 5-4. A) Kai Iwi geology showing the 7 mapped remnant marine terraces that overlie Tertiary sandstone, mudstone and limestone. .66

Figure 5-5. A) The geology of the Pungapunga catchment. .68 Figure 5-6. A) The Makaranui catchment represents the recent volcanic material within the study area. .70

Figure 5-7. Hypsometric curves of the five test catchments calculated from the four DEMs .72 Figure 5-8. The Mangoihe catchment SLk values, plotted for each DEM at sampling distances of $500 \mathrm{~m}$ and $750 \mathrm{~m}$.

Figure 5-9 The Mangoihe catchment SLk values, plotted for each DEM at sampling distances of $1000 \mathrm{~m}$ and $1500 \mathrm{~m}$.

Figure 5-10 The Makakaho catchment SLk values, plotted for each DEM at sampling distances of 500 $\mathrm{m}$ and $750 \mathrm{~m}$.

Figure 5-11. The Makakaho catchment SLk values, plotted for each DEM at sampling distances of $1000 \mathrm{~m}$ and $1500 \mathrm{~m}$.

Figure 5-12. The Kai Iwi catchment SLk values, plotted for each DEM at sampling distances of $500 \mathrm{~m}$ and $750 \mathrm{~m}$..

Figure 5-13. The Kai Iwi catchment SLk values, plotted for each DEM at sampling distances of $1000 \mathrm{~m}$ and $1500 \mathrm{~m}$. .86

Figure 5-14. The Pungapunga catchment SLk values, plotted for each DEM at sampling distances of $500 \mathrm{~m}$ and $750 \mathrm{~m}$.

Figure 5-15. The Pungapunga catchment SLk values, plotted for each DEM at sampling distances of $1000 \mathrm{~m}$ and $1500 \mathrm{~m}$. .88 
Figure 5-16. The Makaranui catchment SLk values, plotted for each DEM at sampling distances of $500 \mathrm{~m}$ and $750 \mathrm{~m}$.

Figure 5-17 The Makaranui catchment SLk values, plotted for each DEM at sampling distances of $1000 \mathrm{~m}$ and $1500 \mathrm{~m}$.

Figure 5-18 Frequency distributions for the Kai Iwi catchment obtained from the four DEMs used in this study. .91

Figure 6-1. The hypsometric curves for the $733^{\text {rd }}$ order catchments within the study area...............98

Figure $6-2.3^{\text {rd }}$ order catchments displaying hypsometric shape.....................................................99

Figure 6-3. Density skewness and the hypsometric integral show a strong relationship. ................101

Figure 6-4. SLk index values for the study area interpolated from $500 \mathrm{~m}$ sample distance. ............. 104

Figure 6-5. Issues with DEM pixel size (horizontal resolution). ....................................................... 108

Figure 6-6. The sinuosity index values interpolated from a sample distance of $1500 \mathrm{~m}$..................110

Figure 6-7 Area 8 with the location of active faults inactive faults and lineaments. ........................ 115

Figure 6-8. Aerial photographic review of an area of high sinuosity has identified a previously

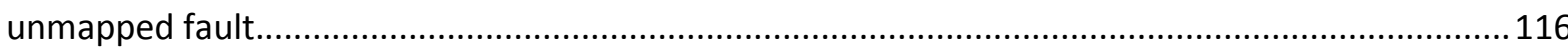

Figure 6-9. Asymmetry factor values for $4^{\text {th }}$ order catchment in the study area.............................. 119

Figure 7-1. The geometry of the fault rupture could affect which indices detect the fault...............128

Figure 7-2. Current mapped faults, folds and lineaments with the inferred traces from this study .131

Figure B-1. Upper - The sinuosity index values interpolated from a sample distance of $250 \mathrm{~m}$. LowerThe sinuosity index values interpolated from a sample distance of $250 \mathrm{~m}$ with active faults, inactive faults and lineaments.

Figure B-2. Upper - The sinuosity index values interpolated from a sample distance of $500 \mathrm{~m}$. Lower The sinuosity index values interpolated from a sample distance of $500 \mathrm{~m}$ with active faults, inactive faults and lineaments. .149

Figure B-3. Upper - The sinuosity index values interpolated from a sample distance of $750 \mathrm{~m}$. Lower The sinuosity index values interpolated from a sample distance of $750 \mathrm{Om}$ with active faults, inactive faults and lineaments. 150

Figure B-4 Upper - The sinuosity index values interpolated from a sample distance of $1000 \mathrm{~m}$. Lower - The sinuosity index values interpolated from a sample distance of $1000 \mathrm{~m}$ with active faults, inactive faults and lineaments...... .151 Figure B-5 Upper - The sinuosity index values interpolated from a sample distance of $1500 \mathrm{~m}$. Lower - The sinuosity index values interpolated from a sample distance of $1500 \mathrm{~m}$ with active faults, inactive faults and lineaments. 152 
Figure B-6. Upper - The sinuosity index values interpolated from a sample distance of $2000 \mathrm{~m}$. Lower - The sinuosity index values interpolated from a sample distance of $2000 \mathrm{~m}$ with active faults, inactive faults and lineaments

Figure C-1. Upper - The SLk index values interpolated from a sample distance of $500 \mathrm{~m}$. Lower - The SLk index values interpolated from a sample distance of $500 \mathrm{~m}$ with active faults, inactive faults and lineaments. .154

Figure C-2. Upper - The SLk index values interpolated from a sample distance of $750 \mathrm{~m}$. Lower - The SLk index values interpolated from a sample distance of $750 \mathrm{~m}$ with active faults, inactive faults and lineaments. .155

Figure C-3. Upper - The SLk index values interpolated from a sample distance of $1000 \mathrm{~m}$. Lower - The SLk index values interpolated from a sample distance of $1000 \mathrm{~m}$ with active faults, inactive faults and lineaments. 156

Figure C-4. Upper - The SLk index values interpolated from a sample distance of $1500 \mathrm{~m}$. Lower - The SLk index values interpolated from a sample distance of $1500 \mathrm{~m}$ with active faults, inactive faults and lineaments. 157

Figure D-1. Upper - The asymmetry factor values for $3^{\text {rd }}$ order catchments. Lower - The asymmetry factor values for $3^{\text {rd }}$ order catchments with active faults, inactive faults and lineaments .158

\section{List of Tables}

Table 1. Slip rate calculated by Villamor and Berryman (2006) for faults in the STVZ.

Table 2. Slip rates and magnitudes calculated for faults in the Taranaki Rift by Townsend et al. (2010)

Table 3. Large earthquakes that have been felt in Wanganui City since 1840. The Richter magnitudes as well as the Mercalli maximum values are shown .21

Table 4. Statistical Moments and the associated geomorphic meaning. Taken from (Luo, 2000) .......39

Table 5. The average statistical moment of all $3^{\text {rd }}$ order catchments. ............................................. 100

Table 6. Asymmetry factor values for $4^{\text {th }}$ order catchments 120

Table 7. The four DEMs used in this study and their recommended use with the four geomorphic indices.

Table 8. Estimated Magnitudes (Mw) for new fault traces or fault traces modified in this study.....130 


\section{Chapter 1 Introduction}

Large shallow earthquakes that rupture the Earth's surface pose a great risk to human life, buildings, and infrastructure. The majority of large earthquakes occur close to plate boundaries of the Earth's crust. New Zealand straddles the Pacific and Australian plate boundary and is subject to frequent large earthquakes. These earthquakes commonly occur along a pre-existing fault within the Earth's crust weakened by past ruptures (Burbank and Anderson, 2001). Where these faults rupture the Earth's surface, characteristic tectonic landforms such as fault scarps can be identified (Keller and Pinter, 1996; Burbank and Anderson, 2001). By studying characteristic tectonic landforms, insight can be gained into location, magnitude, and frequency of past earthquake events. Identifying and understanding tectonic landforms is, therefore, important for the accurate location of active faults and the quantification of earthquake hazards. The Active Fault DataBase (AFDB), compiled and maintained by GNS Science, contains mapped fault traces within New Zealand that are thought to have ruptured in the last 125,000 years (Figure 1-1). The data are obtained from published research conducted by the scientific community and GNS commercial reports. This AFDB is used to provide locations to calculate fault avoidance zones. These zones can be used to mitigate against loss of life and infrastructure damage from future surface rupturing events. The database also contains the information used to characterise fault sources for the National Seismic Hazard Model (NSHM), an important base for the National Building code (Stirling et al., 2002). The interpretation of aerial photography is the most commonly used method to find evidence of the location of past surface rupture events (Berryman, 1990; Villamor and Berryman, 2006; Villamor et al., 2007; Langridge et al., 2010). Paleoseismic trenching of these features then provide detailed information on co-seismic fault displacement and rupture frequency. The most prominent faults (faults that have ruptured recently and/or frequently) are generally easy to map (i.e. have good geomorphic expression) and thus are well documented in scientific literature (Pillans, 1983; Berryman, 1990; Pillans, 1990; Berryman and Beanland, 1991; Pillans, 1994; Townsend, 1998; Burbank and Anderson, 2001; Litchfield and Jongens, 2006; Villamor and Berryman, 2006; Langridge et al., 2007; Villamor et al., 2007; Begg and Mouslopoulou, 2010; Langridge et al., 2010; Little et al., 2010; Barrell et al., 2011; Langridge et al., 2011; Villamor et al., 2011; Villamor et al., 2012; Litchfield et al., In Prep.). 


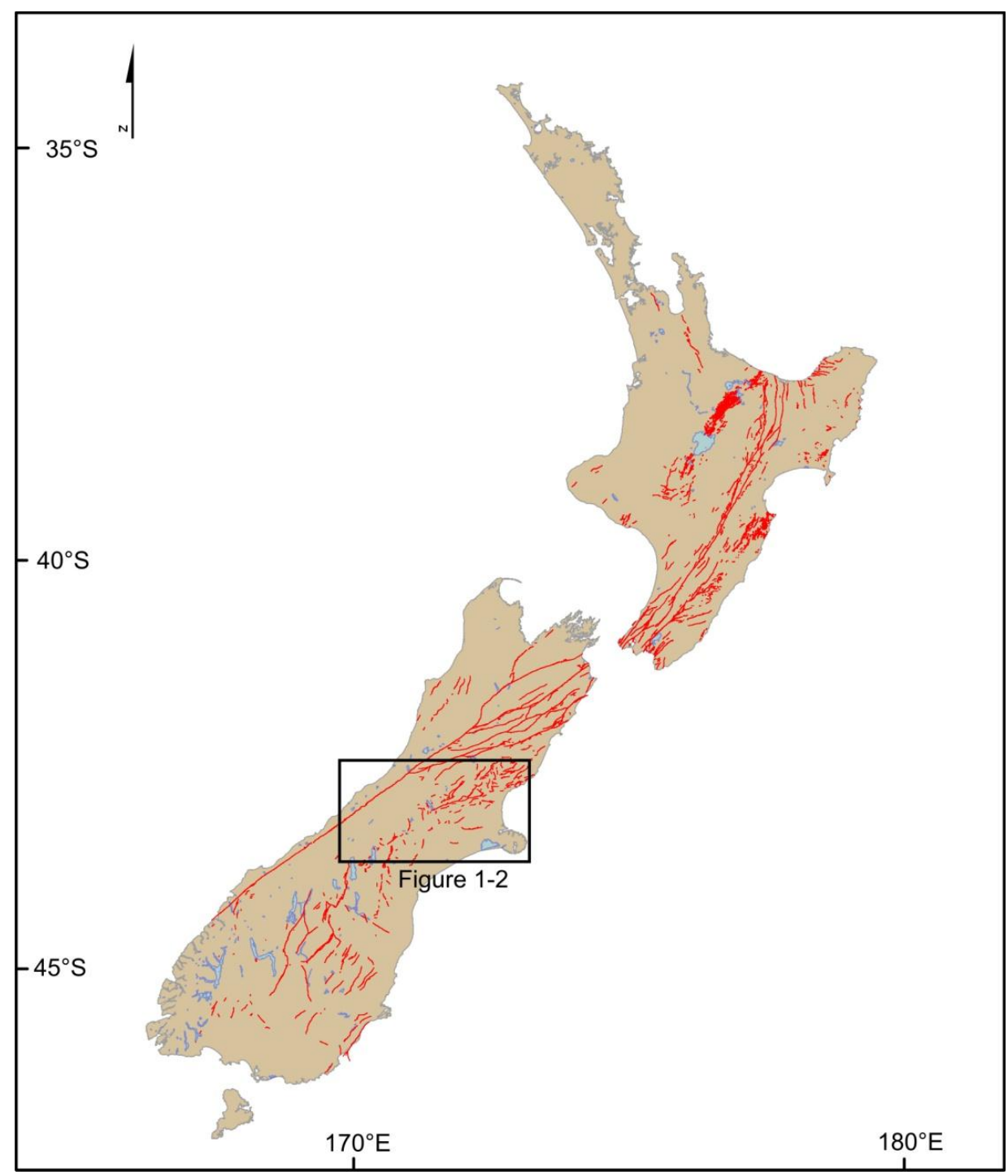

Figure 1-1. Mapped active faults. The red lines represent mapped traces of active faults in New Zealand. Source: GNS active fault database.

However, there are many areas of New Zealand where no faults have been mapped. This does not mean that large surface rupturing earthquakes have not occurred in these areas but instead may suggest the preserved or identifiable surface tectonic landforms may have been covered or removed from the landscape.

On the $4^{\text {th }}$ of September 2010, a large ground rupturing magnitude 7.1 earthquake occurred $50 \mathrm{~km}$ west of Christchurch, New Zealand (see Figure 1-2). This event occurred on previously unmapped faultlines, and from preliminary research it is estimated these faults were unlikely to have ruptured in the last $>8,000$ years (Villamor et al., 2012). The Darfield earthquake and aftershock sequence occurred in an area some distance from the Alpine fault (the surface expression of the Pacific and Australian plate boundary). These events caused substantial damage to Christchurch City and the 
surrounding area. No loss of life occurred from the September event. However, the large aftershock of magnitude 6.3 that occurred on February 222011 was centred closer to Christchurch City, killing 181 people. It was the second deadliest natural disaster in New Zealand's history (Quigley et al., 2012). This event highlights the possibility that many faults may exist in New Zealand within a similar distance from the plate boundary; not visible at the surface but still capable of producing a shallow earthquake greater than magnitude 6. In an opinion article published on the Seismological Society of America website (http://www.seismosoc.org/), Martin Reyners commented on the lessons from the Darfield earthquake and subsequent aftershocks. He states:

"Beware the tyranny of the obvious. At an active plate boundary such as New Zealand, it is easy to be seduced by prominent active fault traces (you can see the Alpine fault from space) and belts of high seismicity in the highest strain regions of the plate boundary. But we should not forget that regions further removed from the plate boundary still need to absorb measurable strain, and will eventually produce damaging earthquakes (albeit with long recurrence)."

The rupture of a large shallow earthquake can cause damage and loss of life through direct effects such as ground surface rupture and strong shaking close to the fault. These can cause damage and destruction of buildings and infrastructure leading to loss of life and economic loss. However, secondary effects, such as liquefaction, lateral spreading, landslides and flooding often cause more financial damage and have longer lasting impacts.

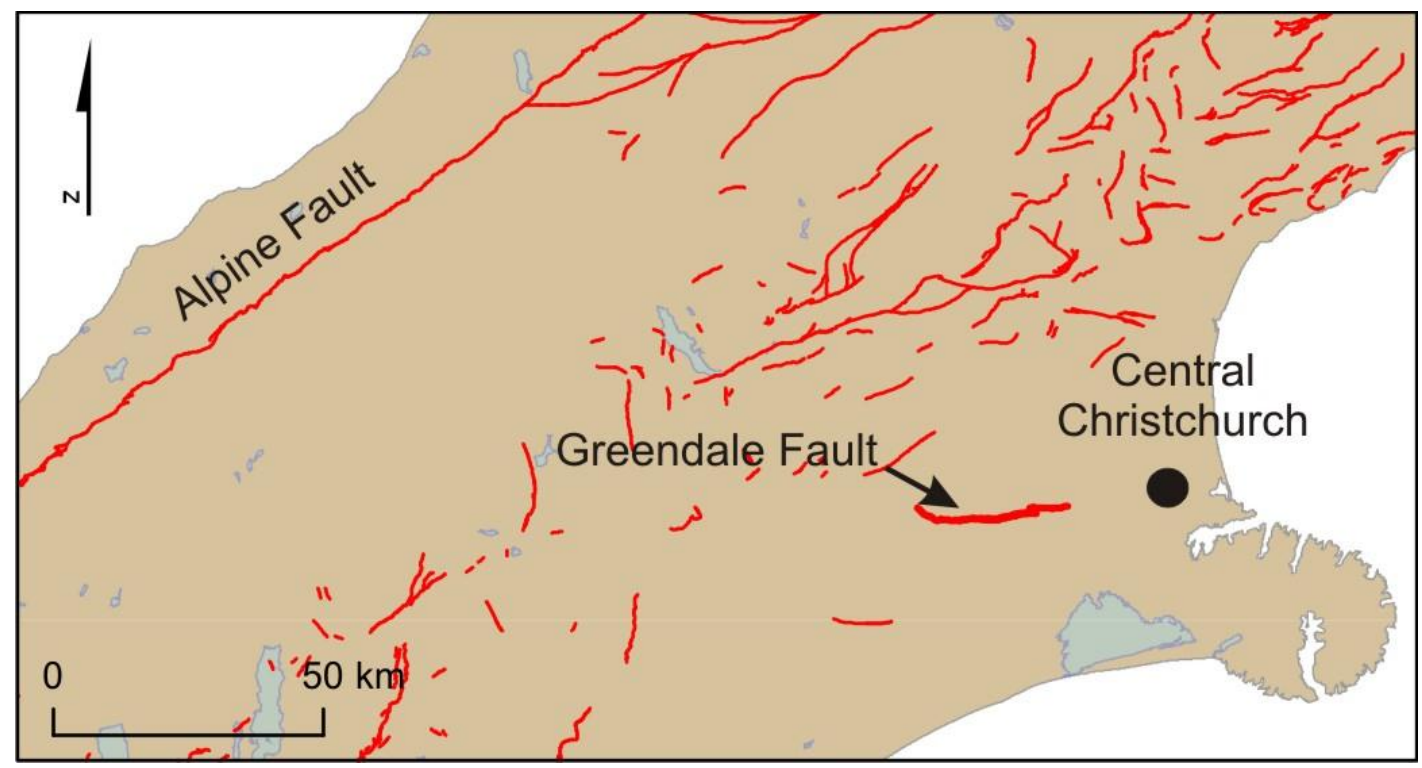

Figure 1-2. The Greendale fault is over $100 \mathrm{~km}$ from the Alpine Fault (surface expression of the plate boundary). The M 7.1 Darfield earthquake caused the rupture of the Greendale fault causing significant damage, mostly due to liquefaction. There was no loss of life from this event, however a M 6.3 aftershock on a fault closer to Christchurch, killed 181 people and caused significant damage to the city and the surrounding area. The fault rupture occurred on a previously unmapped fault. 
The Darfield earthquake produced an $\sim 29.5 \mathrm{~km}$ surface rupture that directly impacted several houses, buildings and infrastructure on or very close to the surface rupture (Van Dissen et al., 2011; Quigley et al., 2012; Villamor et al., 2012). The direct effects of this earthquake were minimal when compared to the damage from liquefaction covering an area $>50 \mathrm{~km}$ from the earthquake source, and damaging thousands of properties; some to the extent that rebuilding has been deemed too costly.

In areas of high relief, earthquakes can directly trigger and also pre-condition slopes to be more susceptible to large damaging landslides. Landslides induced by earthquakes often cause greater amounts of damage than the direct effect of ground shaking. The 1999 Chi-chi earthquake in Taiwan caused > 130 landslides during the main earthquake and subsequent aftershocks (Lin et al., 2006). These landslides were responsible for a large number of casualties, and extensive damage to buildings and infrastructure. Furthermore, large typhoon rainfall events during 2000 and 2001 triggered more landslides than previous larger rainfall events or the earthquake itself. Research by Lin et al. (2006) found the Chi-Chi earthquake not only triggered serious coseismic landslides but also partially transported material for reactivation, as well as, preconditioned slopes to fail through loss of cohesion and frictional strength of rock mass.

The NHSM places the South Taranaki region at the same level of risk as the Canterbury region (see Stirling et al. (2002) for details on methods used to calculate probabilistic hazard for regions of New Zealand). This suggests that there is potential for an earthquake of similar magnitude to the Darfield event within the South Taranaki region (see Figure 1-3).

The direct effect of an event of this size in South Taranaki region is unlikely to cause as much loss of life or direct shaking damage as occurred in Christchurch due to the lower population density. However, the secondary effects particularly, lateral spreading, liquefaction, landsliding, and flooding could be extremely damaging and costly to the New Zealand economy.

Wanganui's central business district is located on the banks of the Whanganui River. This extensive floodplain has been shown to be made up $>5 \mathrm{~m}$ of saturated silts and sands that would be very susceptible to lateral spreading and liquefaction. The city also contains a large number of historic buildings, that are not currently built to modern building standards, increasing the risk to loss of life if a large earthquake were to occur (WDC, 2011). 


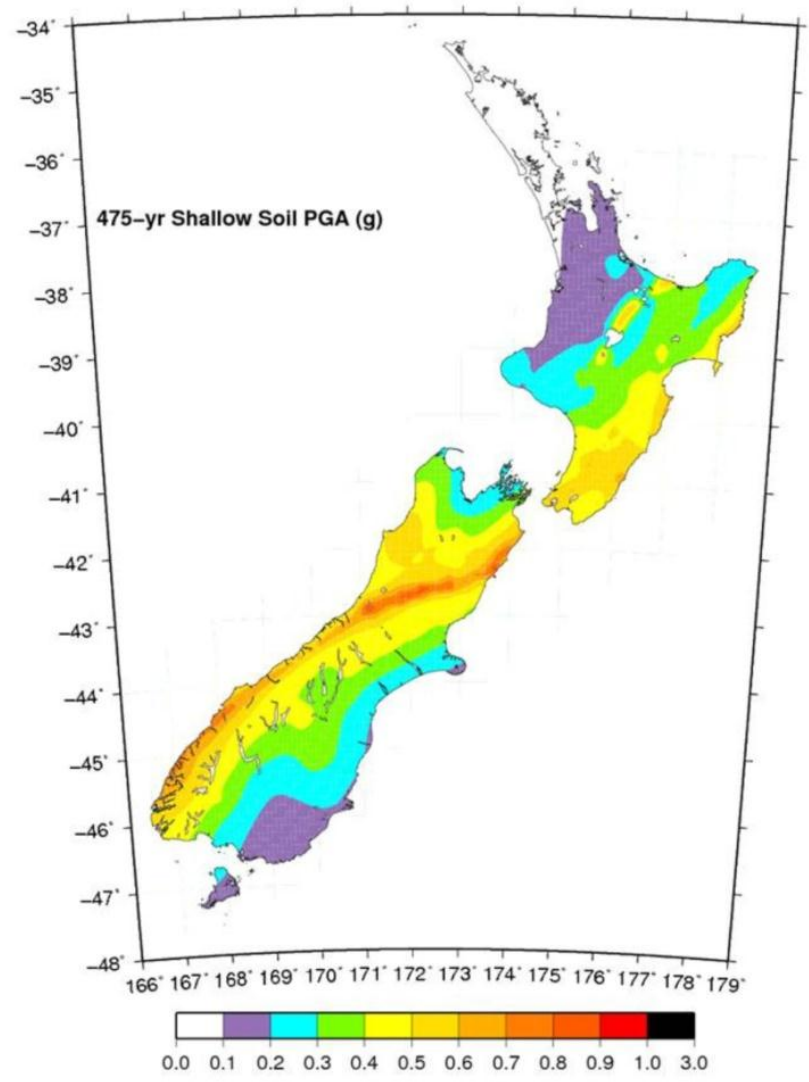

Figure 1-3. Map derived from the 2010 NSHM showing peak ground acceleration expected with a 475 year return period for Class $C$ sites. The Darfield earthquake occurred in the same modelled area to the study area for this study.

On a regional scale, a large earthquake is likely to cause a large number of landslides in the inland hill country. The soft marine derived sandstones, siltstones, and mudstones, which make up this area, are already highly susceptible to large landslides. A large earthquake is likely to increase the susceptibility as well as pre-condition many of the slopes to future rainfall events (Lin et al., 2006). The risk of flooding after a large earthquake is also likely to increase with an increased amount of sediment delivered to the fluvial network from the increased number of landslides. A large amount of this area is used for dairy, beef and sheep farming. Extensive flooding and landslides are likely to have long term financial impact on these industries (WDC, 2011).

\subsection{Justification of Study}

In the South Taranaki region there is evidence of recent surface fault rupture preserved in the volcanic deposits of the Taranaki volcano ring plain (Taranaki Rift) (Townsend et al., 2008), Ruapehu volcano ring plain (southern Taupo Rift) (Villamor and Berryman, 2006) (see Figure 1-4 location A) 
and in coastal gravel platforms to the south, (Townsend, 1998; Lamarche et al., 2005) (see Figure 1-4 location B).

While the geomorphic expression of the faults mentioned above is clear, fault traces have not been mapped in the inland, Tertiary - Pleistocene sediments. For example, the Ohakune fault (see Figure 1-5) has a prominent surface fault expression in the volcanic deposits of Ruapehu ring plain (Villamor and Berryman, 2006). However, evidence of this surface rupture ends abruptly when it crosses from

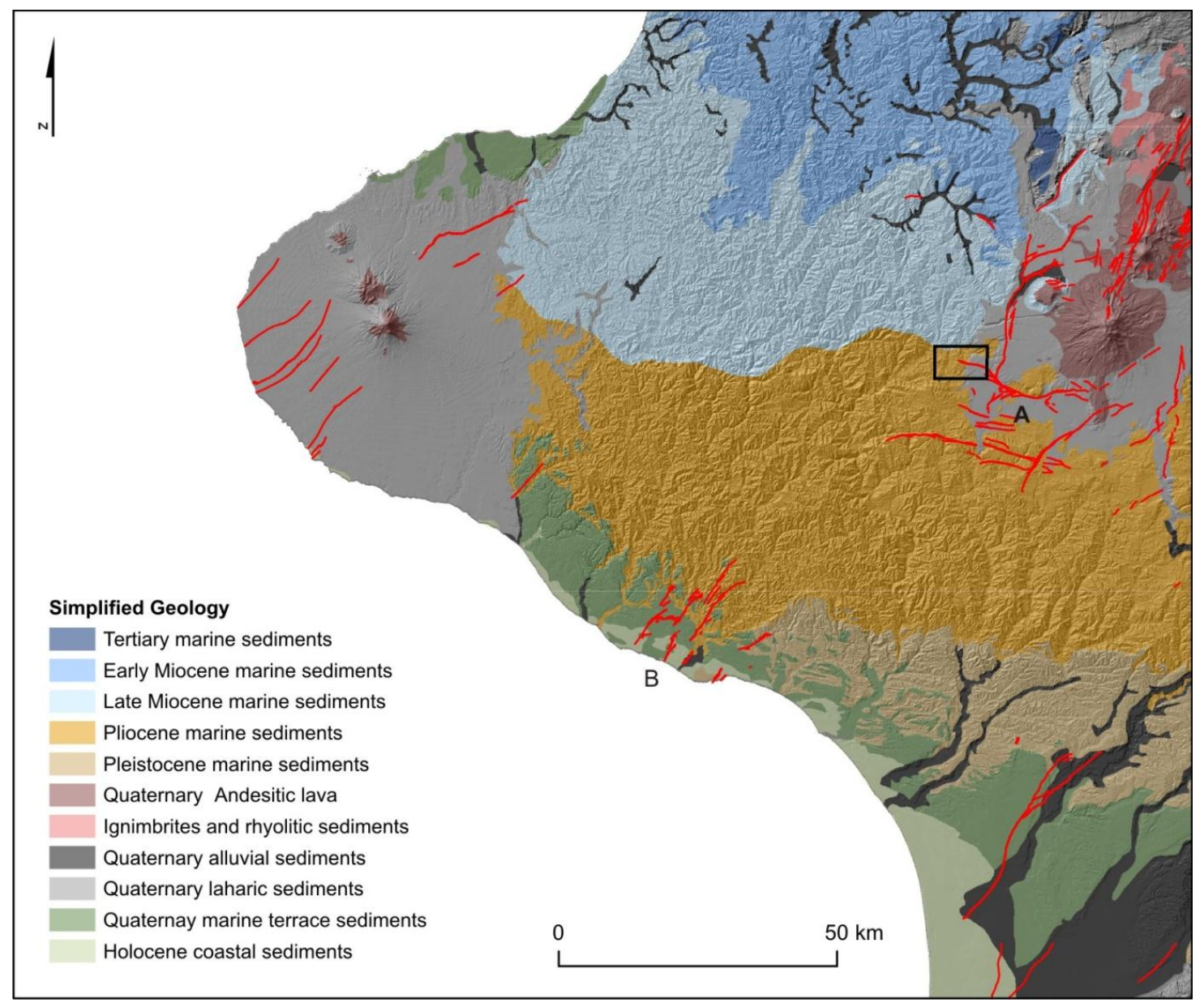

Figure 1-4. 1:1 million geology of the Taranaki region. Red lines are active faults from the AFDB. At location A faults are preserved in the harder volcanic lithology. At location $B$ faults are preserved in the gravels of uplifted marine terraces. The black box is the location of Figure 1-5.

younger, harder volcanic material to softer, Tertiary - Pleistocene, marine derived sandstone, siltstone, limestone, and mudstone. This sudden change could be the termination of the fault rupture. However, such an abrupt loss of scarp height is more likely to be caused by erosion of the surface trace from the softer material. 
Many methods have been developed to identify the location of active faults (Burbank and Anderson, 2001). These methods mostly use a combination of the interpretation of remotely sensed imagery (i.e. aerial photography, satellite photography), digital geomorphic data (i.e. DEM hillshades derived from, survey data, photogrammetry, RTK GPS, LiDAR, INSAR), geophysical images from seismic sources or ground penetrating radar, continuous GPS observations, and field observations (i.e. geological mapping, paleoseismic trenching of tectonic surface expression). Often these methods are combined to confirm observations or to provide further insight into the style of faulting and/or recurrence interval.

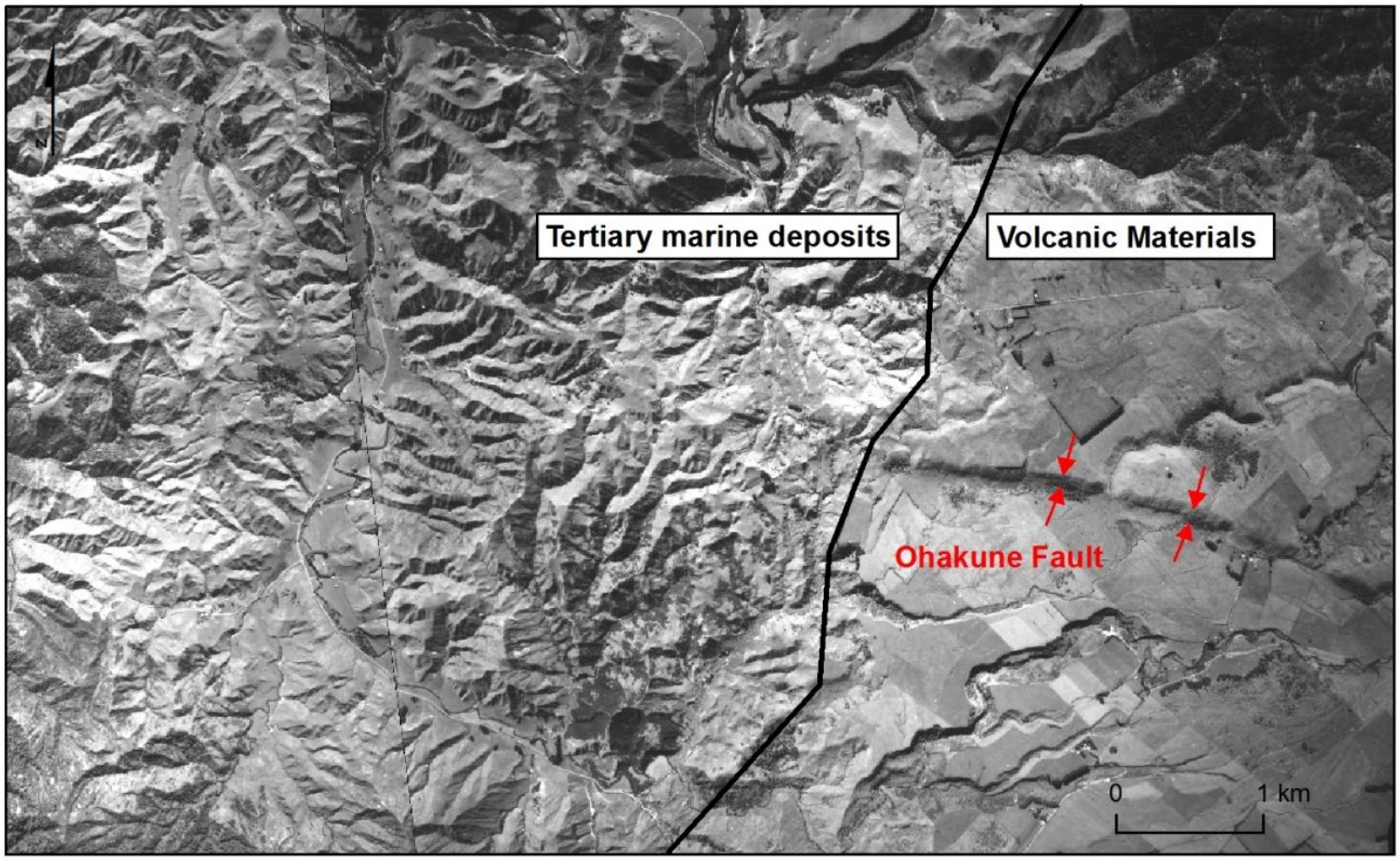

Figure 1-5. Aerial photograph of the Ohakune Fault. The Ohakune fault is a large normal fault with a scarp height of $3 \mathrm{~m}$. The fault scarp abruptly deminishes in height and surface expression where it crosses into the Tertiary materials of inland Taranaki.

The use of rivers as makers of large-scale deformation remains controversial, this is because rivers are not passive features of the Earth's surface, but dynamic features capable of independent lateral and vertical incision and discrete jumps as stream capture reorganises stream networks.

The erosion of a surface fault scarp may not remove all evidence of a past rupture from the landscape. Faulting not only produces landforms that are directly related to the surface rupture but also influences the wider landscape. Tectonic uplift, subsidence and tilting induce changes to erosion 
rates and affect the evolution of the fluvial system. A surface fault rupture, with vertical displacement can produce change in equilibrium state of the fluvial system. This change could be preserved in the landscape longer than it takes for erosion to remove the fault scarp. Cumulative displacements along a fault would likely increase the change to the geometry, equilibrium state and drainage geometry. Geomorphic indices can be applied to investigate and quantify a change to geometry and equilibrium.

\subsection{Aim}

The aim of this study is to assess whether evidence can be found of active faults in the erodible Tertiary-Pleistocene marine sediments within the Taranaki Region using geomorphic indices. This study focuses on quantifying if the fluvial network is affected by tectonic processes where no surface traces have been mapped (likely due to a lack of evidence because of erosion). This will be achieved by analysing and quantifying the morphology of catchments and streams (geometry and elevation distribution) with geomorphic indices supported by visual analysis and interpretation of GIS data. The study will use four indices that have proven to be useful in other tectonic environments worldwide, Stream Length gradient index (SL Index) (Hack, 1973; Chen et al., 2003; El Hamdouni et al., 2008; Troiani and Della Seta, 2008; Pérez-Peña et al., 2009b; Font et al., 2010; Pérez-Peña et al., 2010), Sinuosity Index (SI) (Ouchi, 1985; Holbrook and Schumm, 1999; Schumm et al., 2000), Asymmetry Factor (AF) (Cox, 1994; El Hamdouni et al., 2008; Lopez-Vicente et al., 2009; Dehbozorgi et al., 2010) and hypsometric curve (Ohmori, 1993; Willgoose and Hancock, 1998; Maroukian et al., 2008; Pedrera et al., 2009; Pérez-Peña et al., 2009a).

The desired outcome of this study is to provide a cost effective method to do reconnaissance of a large area where more detailed and costly methods could later be applied, such as, field studies, geophysical investigations and LiDAR surveys.

\subsection{Thesis Structure}

This study is divided into 8 chapters. Chapter 2 provides the background information for the geological and geomorphic setting of the study. By starting with New Zealand-scale tectonic processes the study area is put into context. The geology and earthquake hazard for this region is explained. Chapter 3 describes the geospatial data used in this study and provides a background of the collection methods and processing of these data. Chapter 4 provides a background on the development of the four geomorphic indices used in this study and introduces the methodologies for the application of these indices. Chapter 5 tests two of these indices to provide important 
information for the application of these indices at a catchment scale. Chapter 6 outlines the results for all four indices at a study area scale and includes preliminary discussion on the suitability of these indices to quantify tectonic landforms. Chapter 7 provides a discussion on the quality of the data used to calculate the geomorphic indices, the suitability of the indices to be applied to the study area, the interpretations of the anomalous geomorphic index values that were identified, and the implications of these findings to the earthquake hazard within the Taranaki region. The conclusions of the study are presented in Chapter 8 which also includes recommendations for future research. 


\section{Chapter 2 Background}

\subsection{Geologic and Geomorphic Setting}

This chapter describes the geologic and geomorphic setting for this study, and places it within a wider New Zealand context. New Zealand has been classified into tectonic regimes based on areas of tectonic activity with similar style and deformation. To do this, a review of these tectonic regimes will be undertaken to contrast and compare the tectonic activity in other regions of New Zealand with the tectonic activity within the south Taranaki study area. The rationale behind dividing New Zealand into a framework of tectonic provinces (tectonic terrains) relating to the style and amount of deformation is explained. The provinces are described along with the major historic earthquakes and mapped faults. The study area is defined. The study area is shown to be within an area of relatively low seismicity when compared to the provinces closer to the plate boundary. The study area is divided into 3 geological terrains based on the ability of these material to resist erosion; 1 ) Tertiary - Pleistocene mudstones, limestones and sandstones, 2) volcanic rocks and volcanic derived alluvium, and 3) coastal marine gravels and Quaternary alluvium. The mapped faults within the 3 geological terrains are reviewed and faulting styles are discussed. Fault rupture type is explained and related to characteristic landforms produced.

\subsection{New Zealand Tectonic Setting}

New Zealand is located on the boundary of the Pacific and Australian plates. In the North Island, the oceanic crust of the Pacific plate is obliquely subducted at $\sim 42-48 \mathrm{~mm} / \mathrm{yr}$ along the northeast trend of the Hikurangi margin (Figure 2-1). To categorise fault behaviour and characteristic styles of faulting, the region can be divided into tectonic regions (tectonic provinces) (Berryman and Beanland, 1991; Berryman, 1994) (see Figure 2-1).

\section{Hikurangi Subduction Zone}

In the east of the North Island, the Hikurangi subduction zone is defined by mostly reverse faulting and asymmetric folding due to a well-developed accretionary prism. The modern coastline coincides approximately with the highest accretionary ridge. Uplifted marine terraces preserved along this coast suggest significant vertical movement, as high as 3 or $4 \mathrm{~mm} / \mathrm{yr}$ (Berryman and Beanland, 1991). The $1931 M_{w} 7.9$ Hawke's Bay earthquake was along a large reverse fault thought to be within the accretionary wedge. This earthquake killed 256 people, the largest loss of life of any natural disaster in New Zealand. 


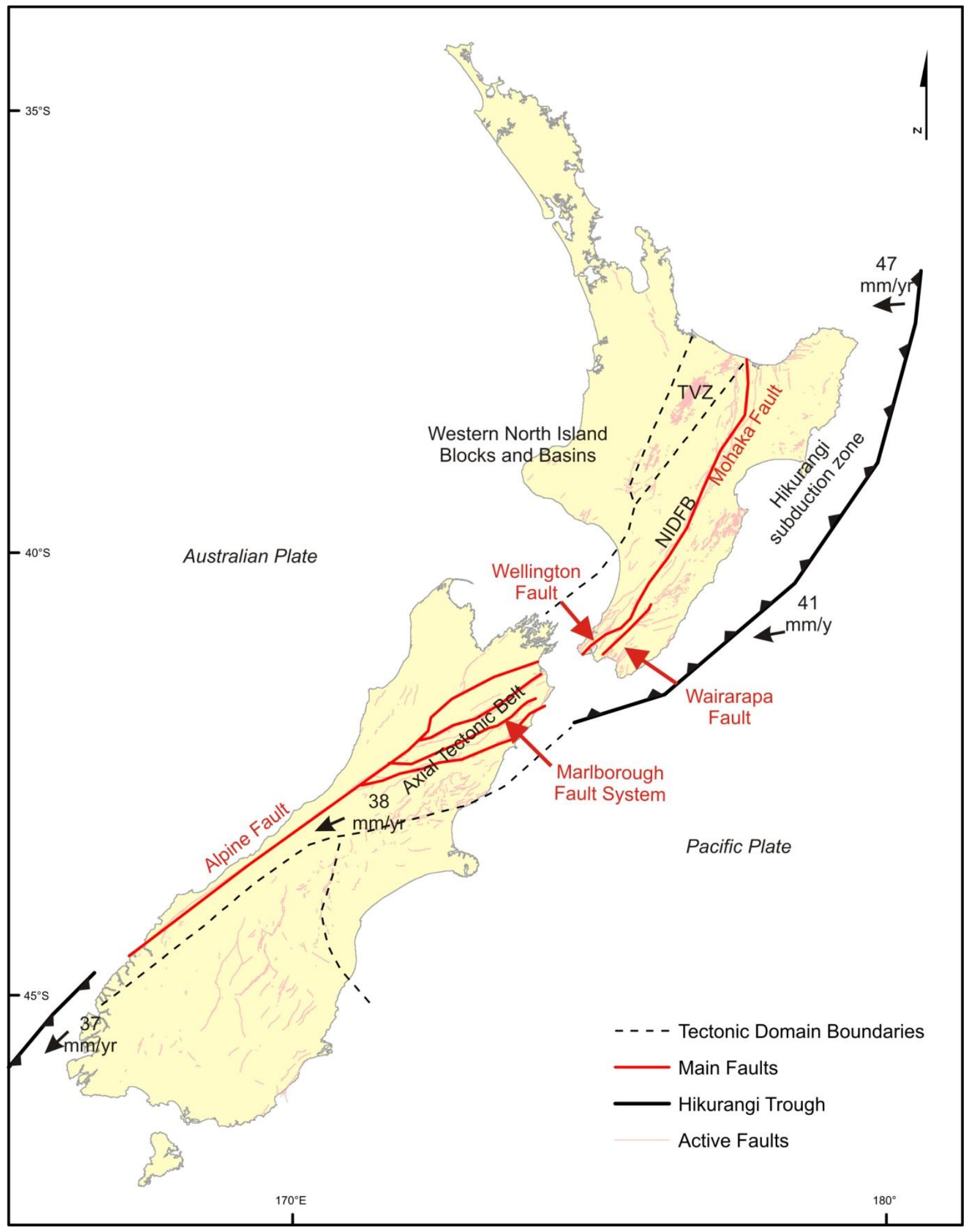

Figure 2-1. Tectonic domains as described by Berryman (1994). Red lines are generalised major faults. The dashed lines represent boundaries of the tectonic domains. NIDFB $=$ North Island Dextral Fault Belt, TVZ = Taupo Volcanic Zone. 


\section{Axial Tectonic Belt}

To the west of the Hikurangi subduction zone, and extending down the length of the South Island, is the Axial Tectonic belt (see Figure 2-1). The faults within this zone are thought to accommodate much of the relative motion between the tectonic plates (Berryman and Beanland, 1991). In the South Island, most of the displacement between the plates is accommodated along the Alpine fault (a large single strand dextral strike-slip fault with a major reverse component). The Alpine fault has a calculated slip rate of $25-45 \mathrm{~mm} / \mathrm{yr}$ (Cooper and Norris, 1994; Norris and Cooper, 2001; Sutherland et al., 2006; Langridge et al., 2010). The Alpine fault then splays into the Marlborough fault system, consisting of the Hope fault, Awatere fault, Clarence Fault and the Wairau fault. The majority of strain is then transferred across the Cook Straight onto a series of offshore faults of the Hikurangi Subduction Zone.

The remainder of the relative plate motion is accommodated by the dextral strike-slip faults that form the North Island Dextral Fault Belt (NIDFB). The Wairarapa fault has an average dextral slip of $15.5 \pm 1.4 \mathrm{~mm} / \mathrm{yr}$ (Rodgers and Little, 2006) and has produced the largest recorded earthquake in New Zealand. The $1855 \mathrm{M}_{\mathrm{w}}>8.1$ Wairarapa earthquake severely damaged Wellington and settlements within the Hutt Valley. Tilting of the landscape caused the uplift of land in and around Wellington that is now the central business district and State Highway 2.

Running parallel to the Wairarapa fault, and directly beneath Wellington City, is the Wellington fault. The Wellington fault has a slip rate of $4-8 \mathrm{~mm} / \mathrm{yr}$ (Berryman, 1990; Langridge et al., 2007; Little et al., 2010). A large earthquake along this fault has the potential to cause considerable loss of life and impact heavily on the economy (Langridge et al., 2007). Paleo-records from trenching surface fault scarps estimate a median recurrence interval of approximately 1145 years with the most recent event between 110 and 310 cal yr BP (Langridge et al., 2011). North of the Manawatu Gorge, the Wellington fault splays into the Ruahine fault and the Mohaka fault. Average Dextral slip for the Mohaka fault has been calculated at about $3 \mathrm{~mm} / \mathrm{yr}$ (Raub, 1987).

\section{Taupo Volcanic Zone}

To the west of the NIDFB is the back-arc basin of the Central Volcanic Region, referred to as the Taupo Volcanic Zone (TVZ), an area of high volcanic activity and closely spaced normal faulting. The deformation of the back-arc basin is distributed across many mostly normal short faults. The faults strike NE-SW, often in zones of many parallel strands accommodating the stretching and extension of the Taupo Rift. Historic and paleo records suggest that this area has non-characteristic fault behaviour, with a range of displacements and intervals between rupture events. The study area includes the Southern Taupo Volcanic Zone (STVZ). The termination of the STVZ is identified by a 
change from NE-SW trending faults to E-W trending faults. The E-W trending faults are large normal faults that have ruptured in recent history (Villamor and Berryman, 2006).

\section{Western North Island Blocks and Basins}

Further to the west is the Western North Island Blocks and Basins province. It is characterised as having relatively low levels of seismicity when compared to the other provinces. There are no historic records of large ground rupturing earthquakes within this region. However, there are historic reports of large earthquakes that have caused considerable damage to cities and towns within this region (e.g. Wanganui City, see WDC (2011) for details). This province has a small number of mapped active faults that displace the marine platforms to the south. Further to the west is the Taranaki rift, with numerous fault scarps preserved in the materials of the volcanic ring plain that can also be seen in offshore seismic surveys.

\subsection{Study Area}

The study area extends from eastern flanks of Taranaki volcano to the western flanks of Ruapehu volcano and then south of this line to the township of Marton. The main focus of the study is on areas where fault traces can no longer be mapped in the soft Tertiary - Pleistocene sediments of inland Taranaki (see Figure 2-2, location A and B). The area is mostly within the Western North Island Blocks and Basins province, but also extends into the STVZ.

\subsubsection{Geology}

The Taranaki region consists of gently dipping $\left(\sim 4^{\circ} \mathrm{N}-\mathrm{S}\right)$, sedimentary marine derived sandstone, mudstone and limestone, overlaid with volcanic deposits from the central volcanoes in the east and the Taranaki volcanoes to the west (Townsend et al., 2008). To the south, there is a flight of preserved marine terraces formed during Quaternary transgression of the coastline (Pillans, 1983). For this study, the geology of this region has been divided into three geological terrains based on the relative resistance of the materials to erosion. They are 1) Tertiary - Pleistocene mudstones, limestones and sandstones, 2) volcanic rocks and volcanic derived alluvium, and 3) coastal marine gravels. The materials of terrain 1 are weaker and highly susceptible to erosion when compared to terrains 2 and 3 (Fleming, 1953; Crozier and Pillans, 1991; Townsend et al., 2008). What follows is a description of the major geological units within each area. 


\subsubsection{Tertiary - Pleistocene Mudstones, Limestones and Sandstones}

Sedimentary basins formed during the cretaceous break-up of Gondwana are the main accumulation zones for a majority of the structure found within the study area. Over $8000 \mathrm{~m}$ of mudstones and

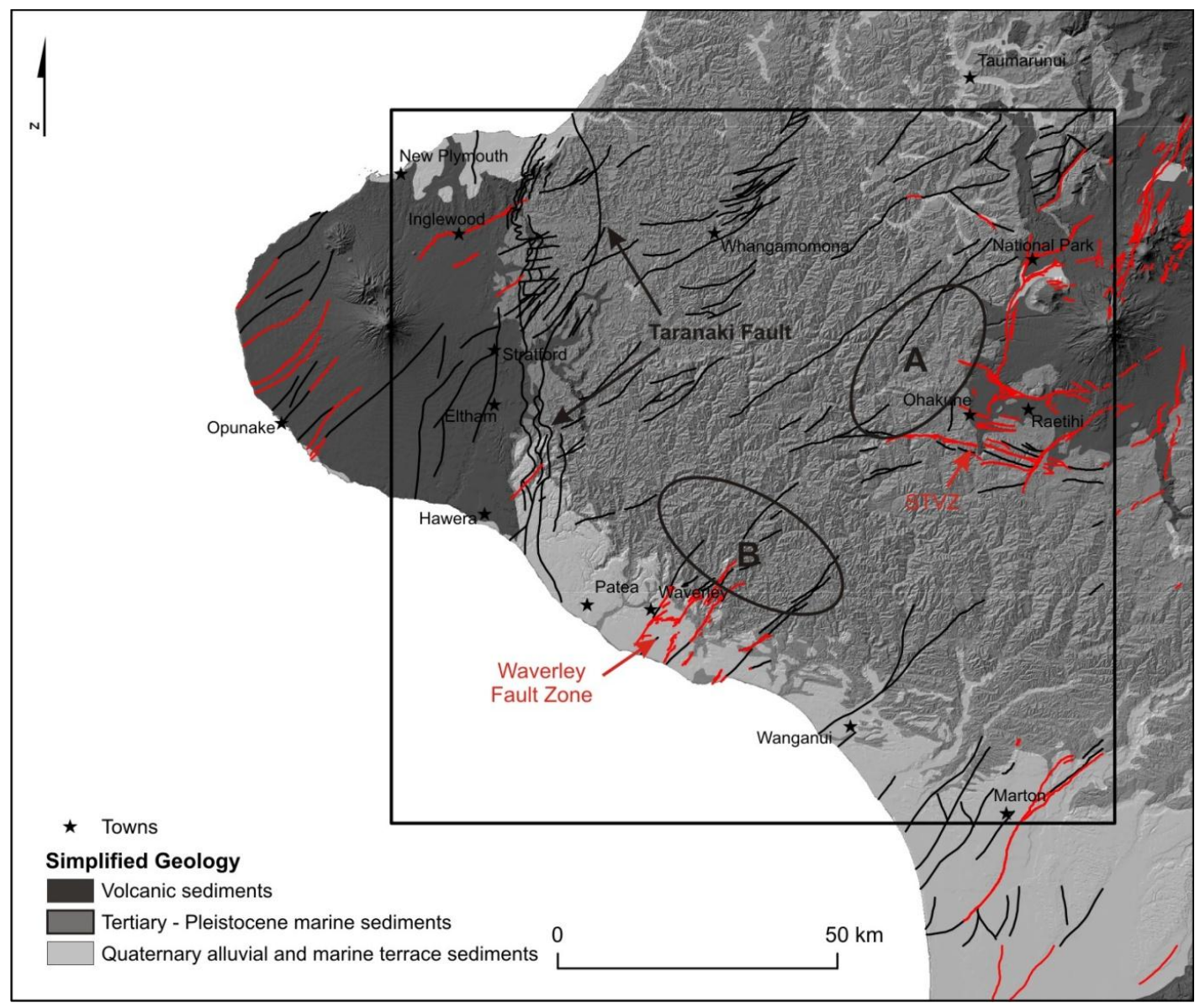

Figure 2-2. The study area (black box) with mapped active (red lines) and inactive (black lines) faults from Qmap Taranaki and the AFDB. The ellipses $A$ and $B$ show the location of the main focus for this study where mapped active fault traces are no longer visible due to erosion.

sandstones of Cretaceous and younger age are documented to the west of the Taranaki fault (see Figure 2-2). The merging of the King Country and Taranaki basins in the late Early Miocene caused the deposition of deep water Early to Middle Miocene sequences of mudstones and sandstones to accumulate (See Townsend et al. (2008) for detailed history and location of these basins). During the Late Pleistocene a period of progradation led to the formation of the modern continental shelf and slope system.

The main depocentre shifted southwards throughout the Neogene leading to the deposition of over $4000 \mathrm{~m}$ of material at the centre of the Wanganui Basin (Townsend et al., 2008). Most of the study area consists of sedimentary deposits from the Wanganui Basin since that time. Today these deposits are gently dipping to the south at $\sim 4^{\circ}$ and decrease in age from north to south. Recent 
volcanic deposits overlay these materials to the east (Tongariro Volcanic Centre) and to the west (Taranaki Volcanic Centre).

\subsubsection{Volcanic Rocks and Volcanic Derived Alluvium}

The rocks that make up the central volcanoes (e.g. Ruapehu, Tongariro and Ngauruhoe volcanoes) are primarily calc-alkaline, medium-K basic and acidic andesites. The ring plains of these volcanic cones comprise of a series of pyroclastic flows, breccias and tuff as well as small intrusive bodies. On the distal flanks of Ruapehu Volcano, there are a range of undifferentiated lahar deposits of undefined age (Townsend et al., 2008). However, their topographic elevation, as erosional remnants

above younger deposits indicates they represent some of the oldest deposits from Ruapehu Volcano. The most extensive lahar deposit is the Waimarino Formation. This massive, bouldery gravel and coarse, sandy fluvial gravel crop out around the Ruapehu ring plain. This formation is the result of successive aggradational pulses that formed laterally on the flanks of the volcano, and has since been reworked by fluvial processes.

In the west of the study area is the near-perfect andesitic stratovolcano of Mt Taranaki. The upper cone is mostly composed of lava and pyroclastic flow deposits interbedded with tephra and soils. The outer ring plain is composed of a series of lahar and debris avalanche material that extend into the western side of the study area. Two areas of Holocene swamp deposits occur around the town of Eltham caused by the collapse of an earlier Egmont Volcano around c. 28 ka that impeded drainage (Alloway et al., 2005). All of these units are less susceptible to erosion than the Tertiary Pleistocene mudstone, sandstones and limestones (Fleming, 1953; Crozier and Pillans, 1991; Townsend et al., 2008). For the purposes of this study, lavas, ignimbrites, lahar deposits and reworked volcanic material will be referred to as volcanic deposits.

\subsubsection{Coastal Marine Gravels}

A flight of Late Quaternary marine terraces are easily identifiable along the coast of the study area between Hawera and Wanganui, running in a northwest-southeast direction roughly parallel to the modern shoreline (Fleming, 1953; Pillans, 1983). To the southeast of Wanganui, extensive fluvial deposition has largely obscured the terraces. However, these terraces have been inferred and mapped by Fleming and Pillans. Chronology and nomenclature of these terraces is extensively outlined in Fleming (1953) and reviewed and improved between Hawera and Wanganui by Pillans (1983). The nomenclature and dates referred to for this study were taken from Pillans (1983). The terraces are a sub-horizontal wave-cut surface with a fossil sea cliff (strandline) at the most inland extent. The surfaces have as much as $12 \mathrm{~m}$ of marine sands, some with basal conglomerate and few 
with shell layers. Overlying the marine sediments are terrestrial deposits of peats, fluvial sediment, tephra, dune sand, loess and lahar debris. Pillans (1983) identified that the height of the present ground surface is not a good indication of wave cut surface height as the more recent deposits often completely cover the wave-cut surface, leaving a subtle topographic expression in the modern landscape.

\subsubsection{Active Faults in and Around the Study Area}

There are three main areas that have active faults mapped surrounding the study area, to the south east and west. These are the Waverley fault zone, the Taupo Rift and the Taranaki Rift, respectively. All of these zones contain normal faulting and have been active in the Holocene. There is evidence of multiple surface ruptures within the Holocene along some of the faults. Average rates of movement range from $0.1-2 \mathrm{~mm} / \mathrm{yr}$. Mapped fault scarps are only visible in the volcanic material of the ring plain of the central volcanoes, the ring plain of Taranaki volcano and the marine terrace near the coast. The preservation of the faults only in these areas suggests that the erosion rate TertiaryPleistocene may be greater than the aforementioned areas. Alternatively, the faults may not extend into the Tertiary-Pleistocene materials.

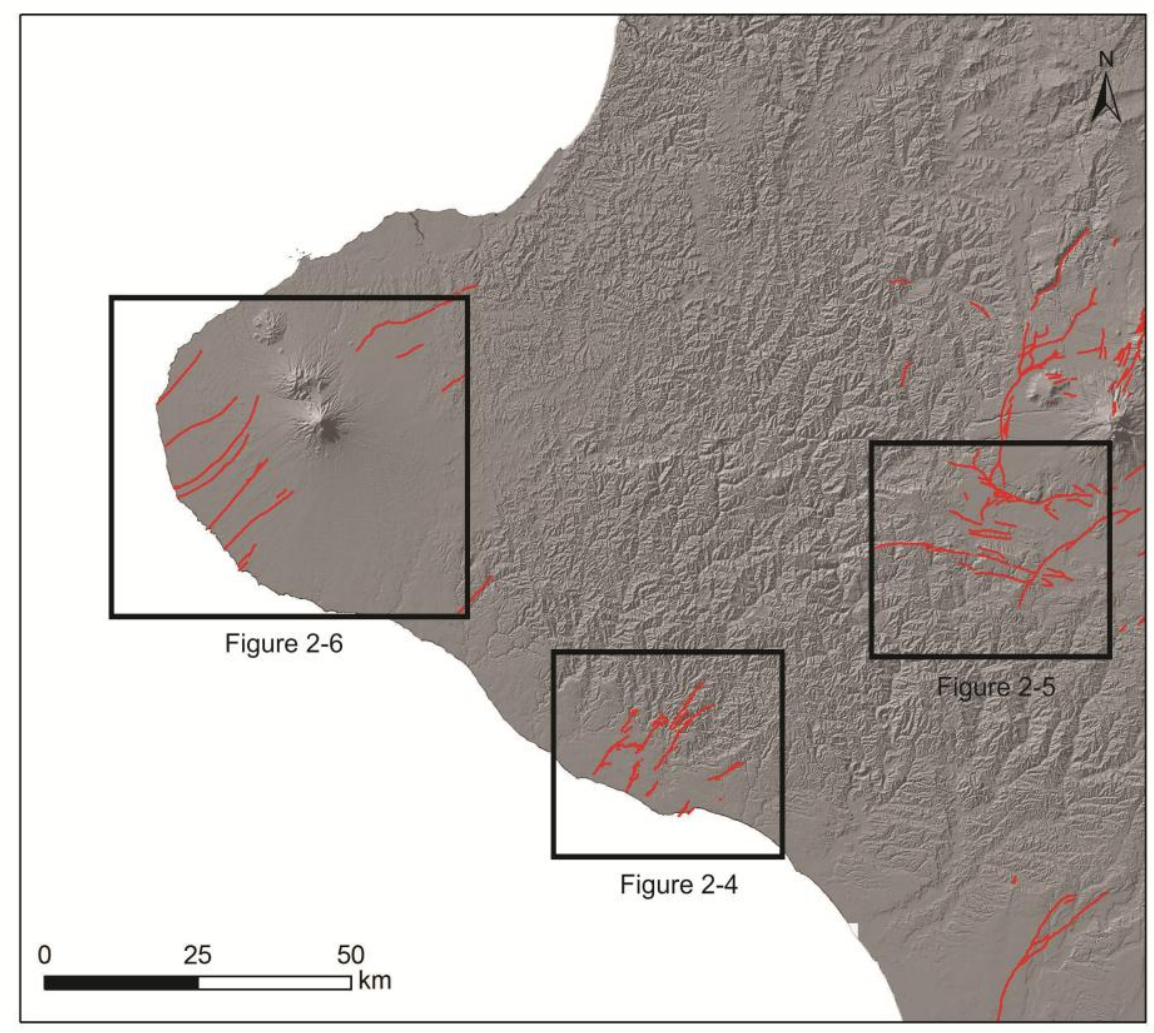

Figure 2-3. Location of the three main regions that surround the study area where mapped faults have been investigated. 


\section{The Waverley Fault Zone}

To the South there are a series of normal faults that have surface expression on the marine terraces (see Figure 2-4). The Waverley Fault Zone, located c. $40 \mathrm{~km}$ northwest of Wanganui, consists of clearly defined surface fault scarps preserved in the late Quaternary marine terraces. These southwest-northeast trending en echelon fault scarps extend for a distance of c. $8 \mathrm{~km}$ crossing the southeastern corner of Waverley Township (Townsend, 1998). A detailed study of this zone, including paleoseismic trenching of the southern section, revealed single event displacements of at least 1-2 m vertically (Townsend, 1998). Townsend (1998) concludes that the entire zone displays extensional normal faulting over the entire $8 \mathrm{~km}$ length, and estimates earthquake magnitudes from past events to have been on average M 6.3. The southern section was shown to have ruptured at least twice in the last 22500 years. An average recurrence interval for the southern section was calculated at $7000-11000$ years with no rupture evident within the last 1000 years. Townsend (1998) also suggests that flexural uplift around the margins of the South Wanganui Basin could explain the mechanism to forming this fault zone.

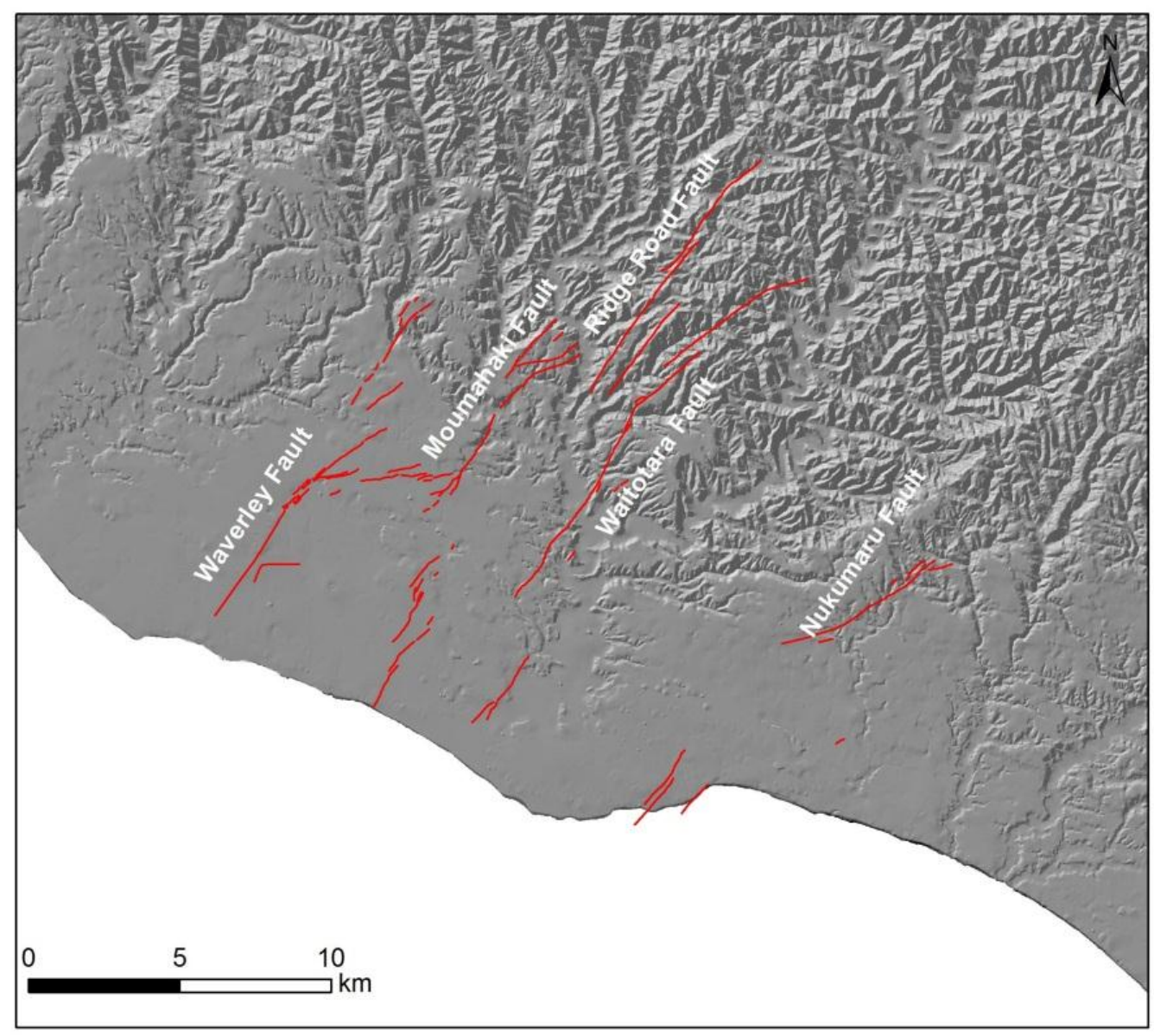

Figure 2-4. Mapped active fault traces in the Waverley fault zone. 


\section{Southern Termination of the Taupo Rift}

The Taupo rift is a zone of tectonic extension consisting of a series of closely spaced NE-SW trending normal faults. A series of E-W trending faults cross the NE-SW trending faults near the township of Ohakune extend into the study area, see Figure 2-5. These faults have been mapped in detail and displacement measurements calculated by Villamor and Berryman (2006). From north to south these faults are the Ohakune, Raetihi North, Raetihi South, Waipuna, and Oruakukuru Faults. Referred to in Villamor and Berryman (2006) as Ohakune-Raetihi fault set.

Exploratory trenches have revealed normal faulting on these structures with no substantial strikeslip motion. This is supported through observations of creeks crossing these faults with no lateral displacements. This series of faults predominantly dip to the south except for the Raetihi South Fault that dips to the north.

Displacement measurements calculated by Villamor and Berryman (2006) are outline in Table 1.

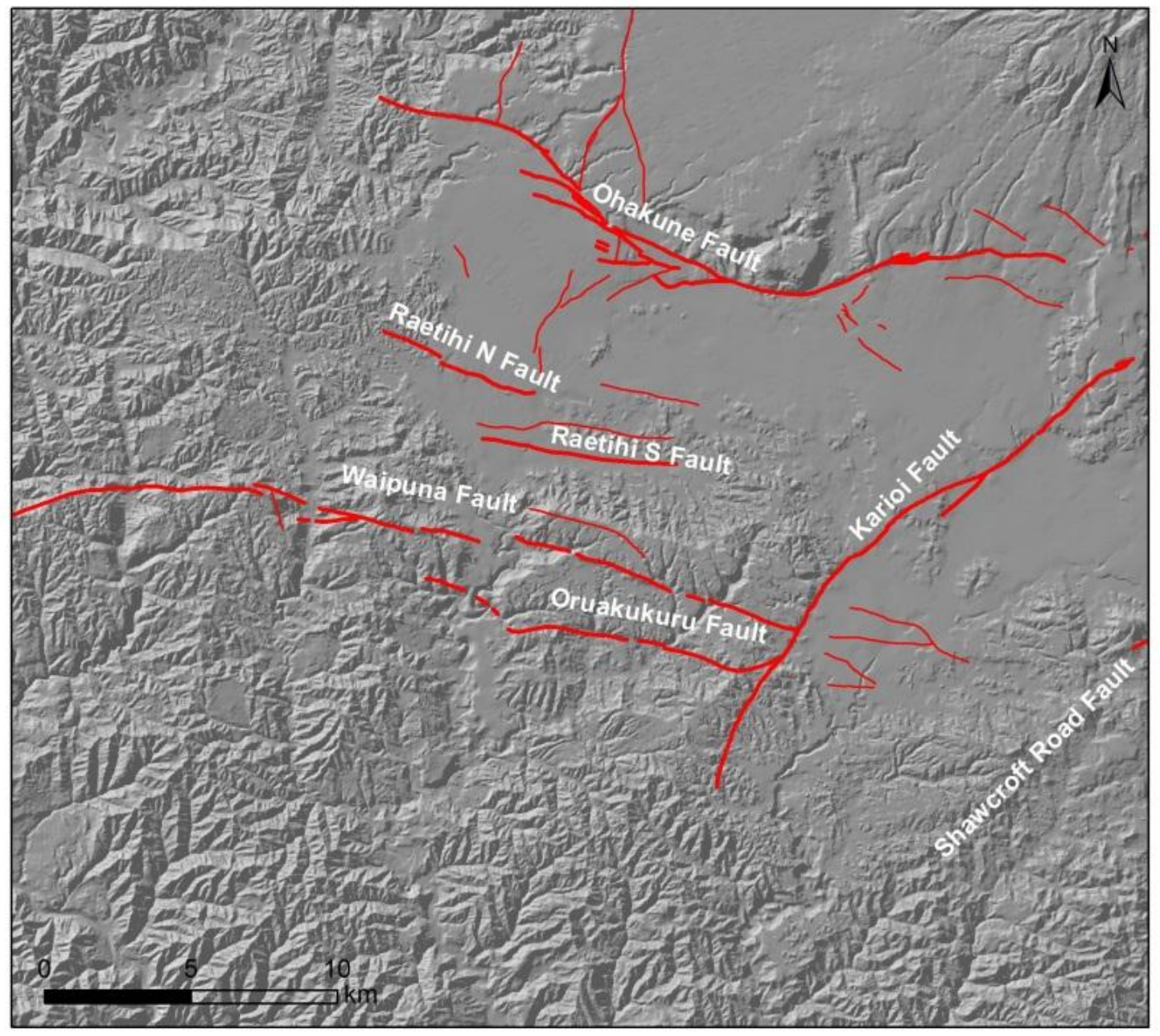

Figure 2-5 Mapped active fault traces in the southern Taupo volcanic zone 
Table 1. Slip rate calculated by Villamor and Berryman (2006) for faults in the STVZ.

\begin{tabular}{|l|l|r|r|}
\hline Fault & Age $(\mathrm{ka})$ & $\begin{array}{l}\text { Dip-slip } \\
\text { displacement }(\mathrm{m})\end{array}$ & $\begin{array}{l}\text { Rate of dip-slip } \\
\text { displacement (mm/yr) }\end{array}$ \\
\hline Ohakune & $18 \pm 3$ & 63 & 3.5 \\
\hline Raetihi N & $18 \pm 3$ & 8.5 & 0.5 \\
\hline Raetihi S & $18 \pm 3$ & 6.9 & 0.4 \\
\hline Waipuna & $<15$ & 1.2 & 0.4 \\
\hline Oruakukuru & $32 \pm 6$ & 23 & 0.7 \\
\hline Snowgrass & $<15$ & 5.8 & 0.55 \\
\hline Shawcroft Rd & $17.7 \pm 0.6$ & 11.5 & 0.7 \\
\hline Karioi & $26.5 \pm 0.2$ & 10.5 & 0.4 \\
\hline Wahianoa & $90 \pm 30$ & 23.1 & 0.3 \\
\hline
\end{tabular}

\section{Taranaki Rift}

The Taranaki rift is undergoing crustal extension in response to subduction of the Pacific Plate. Townsend et al. (2010) has mapped and calculated sliprates for 6 faults in this area. Paleoseismic trenches and radiocarbon dating these faults have shown all of these faults to be active in the Holocene. While the slip rates are relatively low Townsend et al. (2010) have estimated these faults are capable of producing $>$ M 6 earthquakes. The calculated sliprates and estimated magnitudes are outlined in Table 2.

Table 2. Slip rates and magnitudes calculated for faults in the Taranaki Rift by Townsend et al. (2010)

\begin{tabular}{|l|l|l|r|r|}
\hline Fault & $\begin{array}{l}\text { Single event } \\
\text { displacement }(\mathrm{m})\end{array}$ & $\begin{array}{l}\text { Recurrence } \\
\text { interval }(\mathrm{ka})\end{array}$ & $\begin{array}{l}\text { Maximum } \\
\text { rupture } \\
\text { length }(\mathrm{km})\end{array}$ & $\begin{array}{l}\text { Magnitude } \\
(\mathrm{Mw})\end{array}$ \\
\hline Rahotu & $0.3-1.2(0.75)$ & 6.7 & 20 & 6.5 \\
\hline Oaonui & $0.4-0.7(0.48)$ & $5.2-8.6(6)$ & 25 & 6.7 \\
\hline Kina & $0.4-0.8(0.6)$ & 2.6 & 30 & 6.8 \\
\hline Ihaia & $0.3-1(0.67)$ & $0.5-1.7(1.14)$ & 28 & 6.7 \\
\hline Kiri & $0.3-1(0.67)$ & $0.5-1.7(1.06)$ & 30 & 6.8 \\
\hline Pihama & $0.3-1.5(0.8)$ & $3-15(4.9)$ & 25 & 6.7 \\
\hline
\end{tabular}




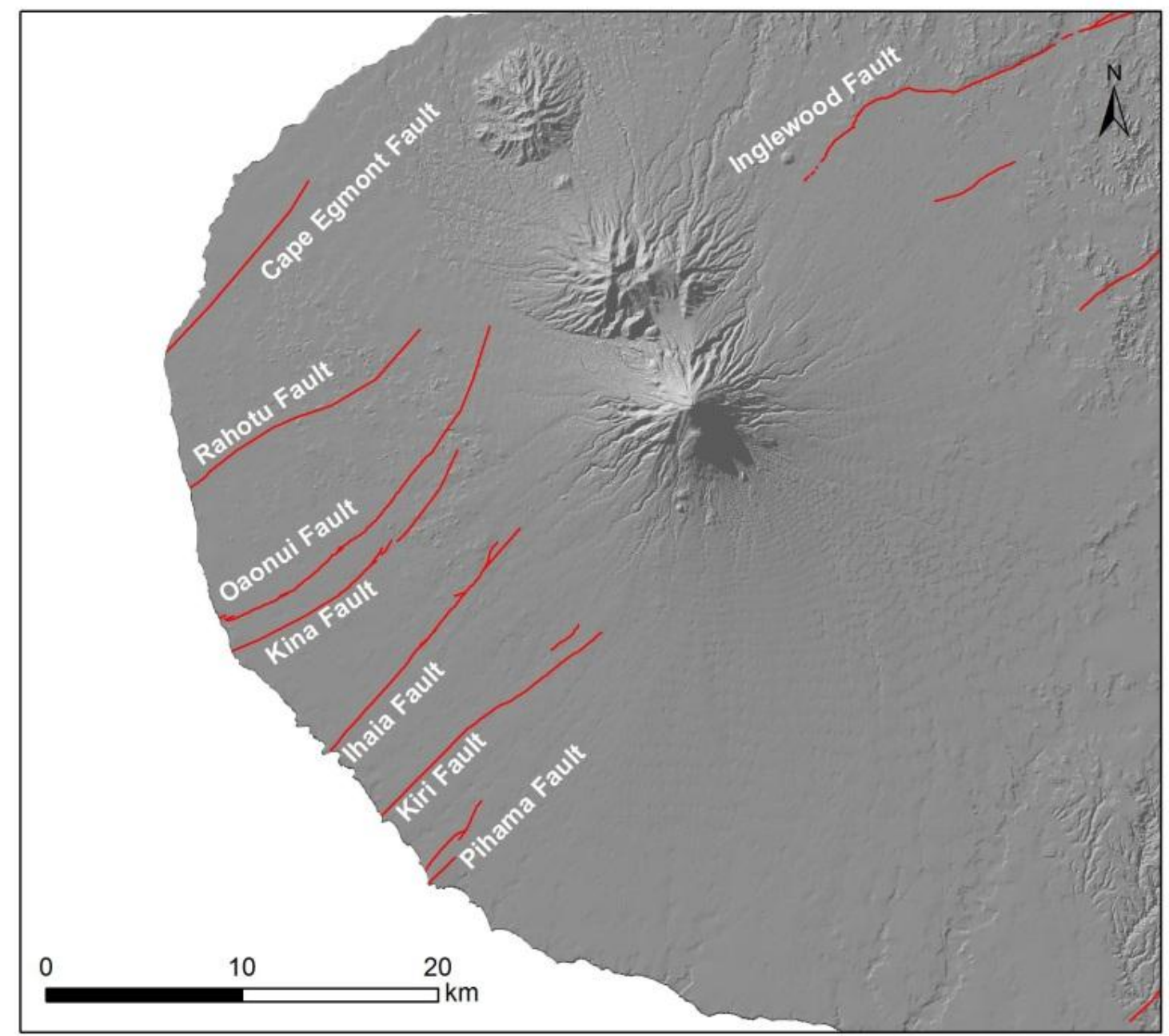

Figure 2-6. Mapped active fault traces of the Taranaki rift

\subsubsection{Earthquake Hazard}

Although the Taranaki region is located to the west of the plate boundary, surface rupture and associated ground shaking are significant hazards. Since written records (1840 AD) there have been at least 12 earthquakes greater than magnitude 5, a majority of these large earthquakes were deep (> $40 \mathrm{~km}$ ) (Townsend et al., 2008). The largest population centre within the study area is the city of Wanganui (see Figure 2-7). The effect of a large earthquake near this city has been shown to be potentially very damaging. Since 1840, there have been 5 earthquakes greater than MM 6 that have caused significant damage to Wanganui City (see Table 1 for details). A report commissioned by the Wanganui District Council states; "Wanganui can expect to experience a MM 9 earthquake every 270 years" (WDC, 2011 p. 2).

This short history is not an indication that shallow earthquakes do not occur in this region. As explained earlier, fault scarps (evidence of shallow medium to large magnitude earthquakes) can be 
found in the landscape, and research shows evidence of surface rupture on many of these faults within the last 125,000 years (Townsend et al., 2008). Another way to gain an insight into tectonic activity within a region is to measure the background seismicity. The location and depth of earthquake epicentres can provide an insight into tectonic activity of a region. Figure 2-7 shows the earthquake hypocentres for all earthquakes greater than magnitude 3 for all depths within the study area. This figure suggests there is a large amount of activity occurring within this region. However, a majority of the earthquakes occur at depths greater than $40 \mathrm{~km}$. Deep earthquakes in the Taranaki region (> 40-60 km), mostly occur along the subduction interface of the Pacific and Australian plates and below the brittle crust. Earthquakes at this depth cause little damage at the surface due to attenuation of the energy with distance from the epicentre. Figure 2-8 shows the distribution of earthquake hypocentres occurring at shallow depth $(<40 \mathrm{~km})$. Earthquakes occurring within the brittle crust have the potential to be very damaging at the surface. The distribution of shallow earthquakes can give some indication of tectonic activity within this section of the crust.

Table 3. Large earthquakes that have been felt in Wanganui City since 1840. The Richter magnitudes as well as the Mercalli maximum values are shown. The main damage from all of these earthquakes is extensive lateral spreading near the Whanganui River. Table from WDC (2011).

\begin{tabular}{|l|l|c|c|l|}
\hline Date & Epicentre & $\begin{array}{c}\text { Richter } \\
\text { magnitude }\end{array}$ & $\begin{array}{c}\text { Mercalli maximum } \\
\text { intensity }\end{array}$ & Earthquake effects in Wanganui \\
\hline 8 July 1843 & Wanganui & 7.5 & MM 9-10 & $\begin{array}{l}\text { Extensive lateral spread near the river. } \\
\text { Landslides. }\end{array}$ \\
\hline 16 Oct 1848 & Marlborough & 7.8 & MM 7 & $\begin{array}{l}\text { Minor lateral spread in river bed and } \\
\text { some wharf damage. }\end{array}$ \\
\hline 23 Jan 1855 & South Wairarapa & 8.2 & MM 8 & $\begin{array}{l}\text { Extensive lateral spread, extensive } \\
\text { wharf damage. Drainage of } \\
\text { lakes/swamps. }\end{array}$ \\
\hline Dec 1897 & Wanganui & 7.0 & MM 8 & $\begin{array}{l}\text { Loss of water supply, lateral spreading, } \\
\text { damage to wharves, minor ground } \\
\text { cracking in Glasgow Street. Greatest } \\
\text { damage to businesses in Victoria } \\
\text { Avenue. Landslides. }\end{array}$ \\
\hline 5 Mar 1934 & Pahiatua & 7.6 & MM 6-7 & $\begin{array}{l}\text { Aramoho and parts of Wanganui East } \\
\text { experience strong shaking. Fissuring of } \\
\text { river bank at Aramoho. Landslides. } \\
\text { Break in water main at foot of St John's } \\
\text { Hill. }\end{array}$ \\
\hline
\end{tabular}




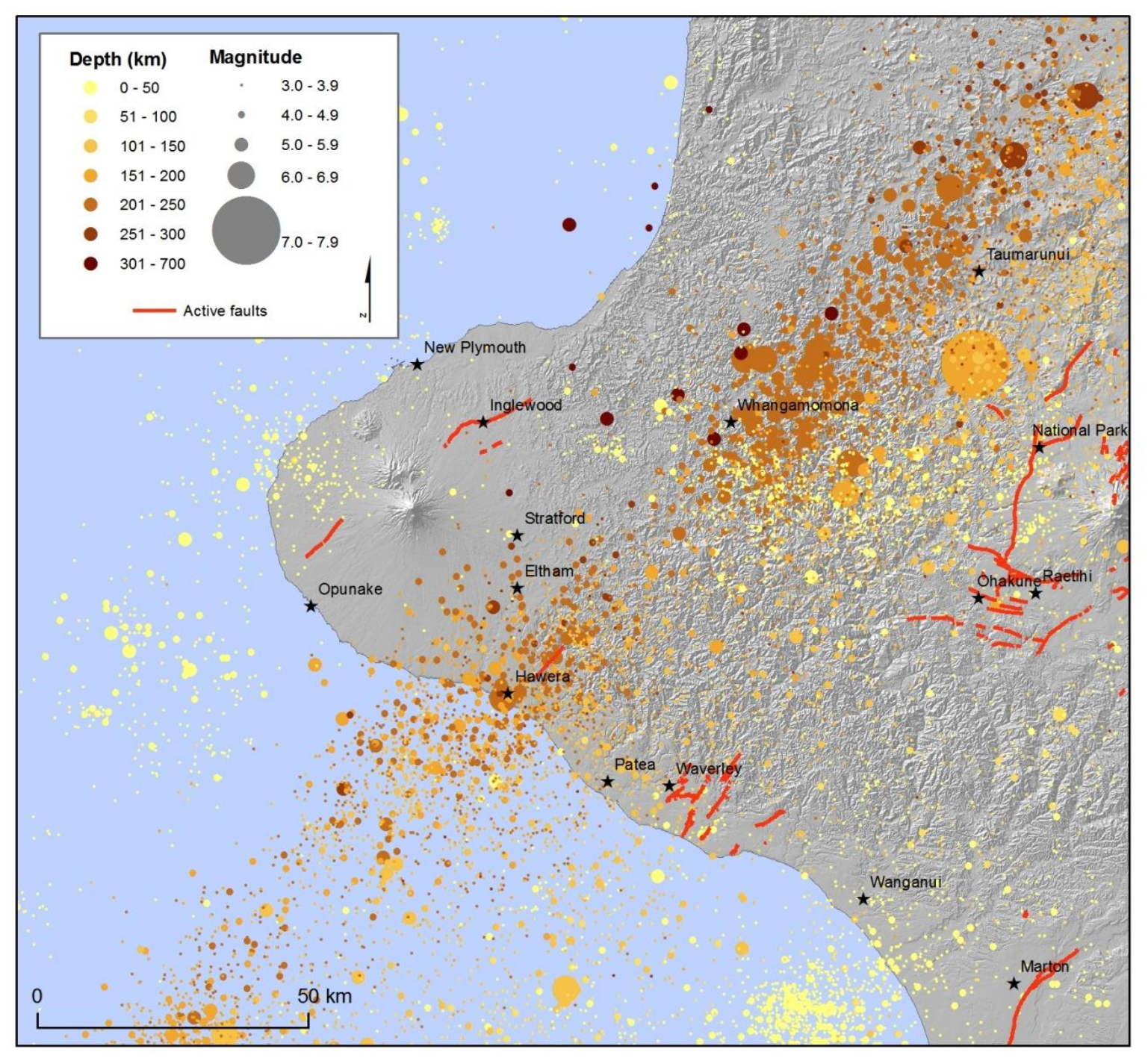

Figure 2-7. Earthquake hypocentres greater than Mw 3 post 1950 from GNS Science earthquake catalogue. Colour represents earthquake depth and size represents magnitude. Red lines are mapped active faults from the active fault database maintained by GNS Science. Stars are main population centres. The band of dark brown earthquakes running from $N E-S W$ shows earthquakes occurring at depth along the subducting plate. 


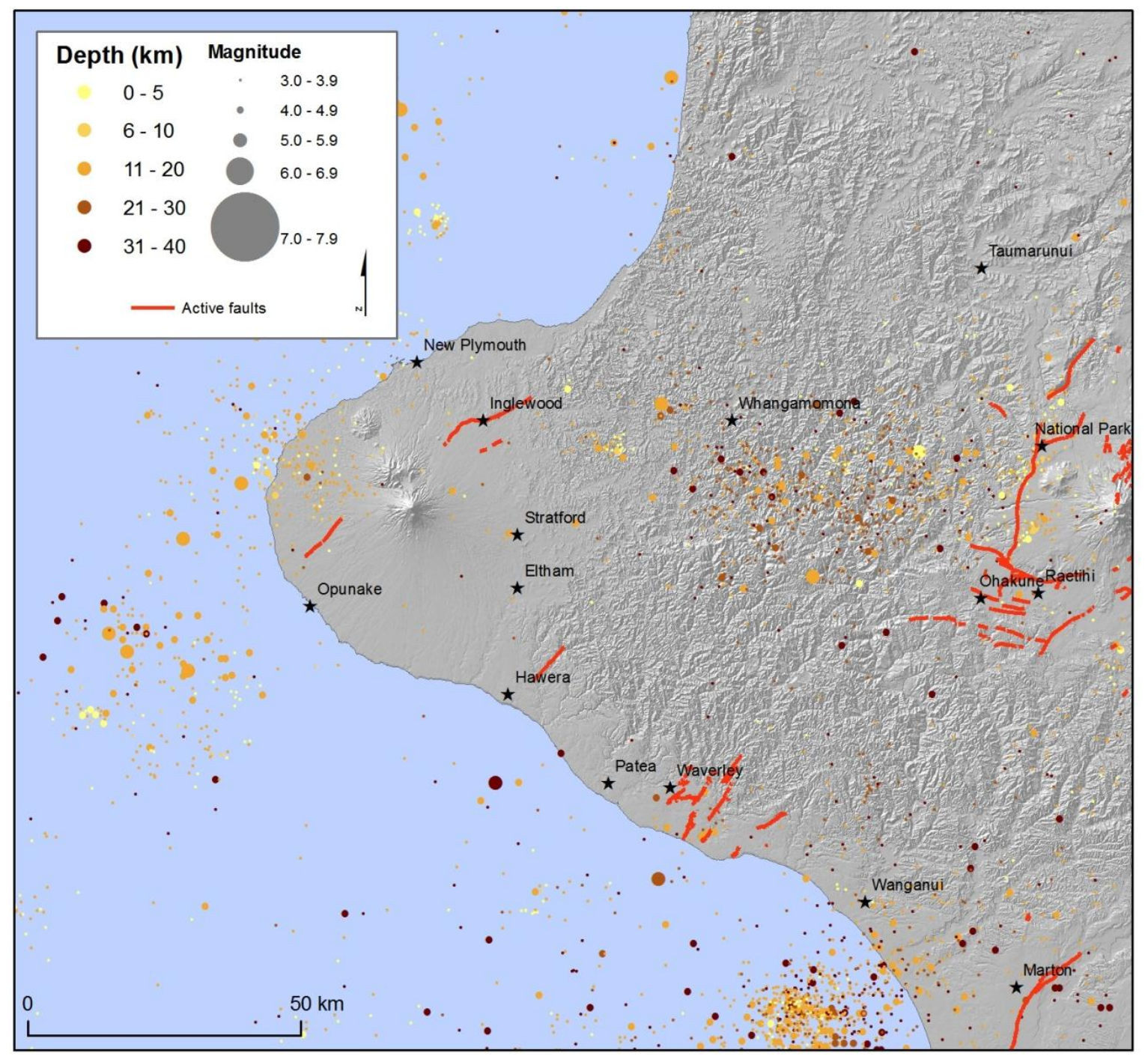

Figure 2-8. Earthquake hypocentres greater than Mw 3 post 1950 at a depth less than $40 \mathrm{~km}$ from GNS Science earthquake catalogue. Colour represents earthquake depth and size represents magnitude. Red lines are mapped active faults from the active fault database maintained by GNS Science. Stars are main population centres. 


\section{Chapter 3 Data Used in this Study}

The data used in this study can be broken into three types: 1) the base data (i.e. the four DEMs), 2) the derived data from DEMs (from which the geomorphic index values will be calculated), and 3 ) the datasets used to test the reasons for anomalous index values, e.g. geological maps, aerial photography and mapped faults, folds and lineaments. This section will describe these data focusing on resolution and methods used for their creation.

\subsection{Digital Elevation Models}

Digital Elevation Models (DEMs) are representation of the Earth's surface composed of a grid of equally sized cells or pixels, each containing a value for altitude above sea level. The most common method to produce these surfaces is to interpolate the required spatial extent from a collection of points that contain elevation attributes. The cell size of a DEM is a measure of the planar resolution of the DEM. The cell size should be directly related to the average number of points available to calculate the elevation value for each cell (Gyasiagyei et al., 1995; Wise, 2007; Gonga-Saholiariliva et al., 2011). This is calculated from the average spacing of the base point data, balancing interpolated elevation values while adhering closely to the original elevation information. Figure 3-1 shows the effect of cell size on the resolution of the four DEMs used in this study. It is beyond the scope of this study to review and comment on all of the methods used to produce DEMs. However, it is important to acknowledge the accuracy and precision of data collection, interpolation method and likely errors associated with each DEM used in this study. What follows is a description of the four DEMs used in this study. This will include a description of the data collection method, interpolation method and errors associated with each dataset.

\section{Shuttle Radar Topography Mission (SRTM)}

The Shuttle Radar Topography Mission (SRTM) collected elevation data during an 11-day mission in February 2000. The Space Shuttle Endeavour was fitted with two radar antennas, one located in the shuttle's payload bay and the other attached to a $60 \mathrm{~m}$ boom. This Interferometric Synthetic Aperture Radar (InSAR) configuration was used to collect elevation data of the entire landmass of the Earth between $60^{\circ} \mathrm{N}$ and $57^{\circ} \mathrm{S}$. These data were processed at $1 \operatorname{arc} \sec (\sim 30 \mathrm{~m})$ for the U.S.A. and $3 \operatorname{arcsec}(\sim 90 \mathrm{~m})$ for the rest of the world. The use of the InSAR also has the advantage of being able to collect data in all conditions, e.g. with cloud cover and during the night. 


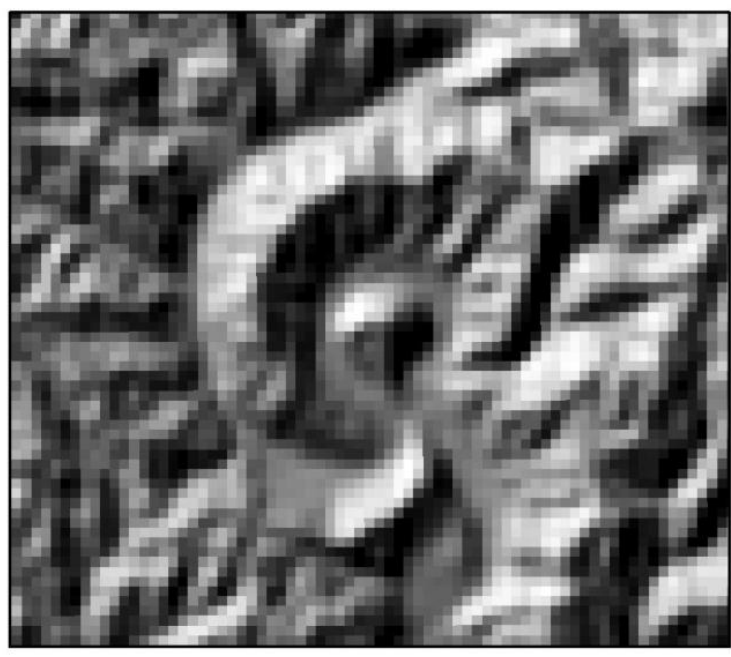

SRTM $90 \mathrm{~m}$

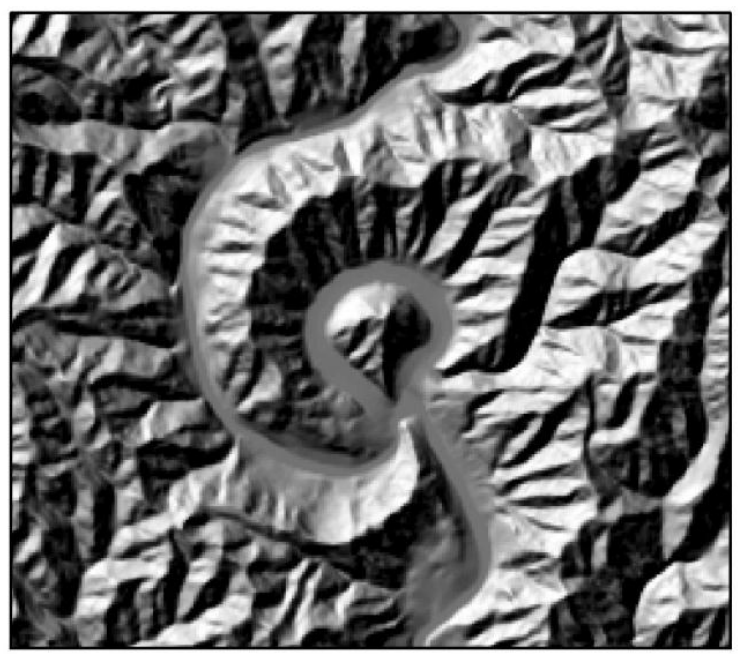

Landcare $25 \mathrm{~m}$

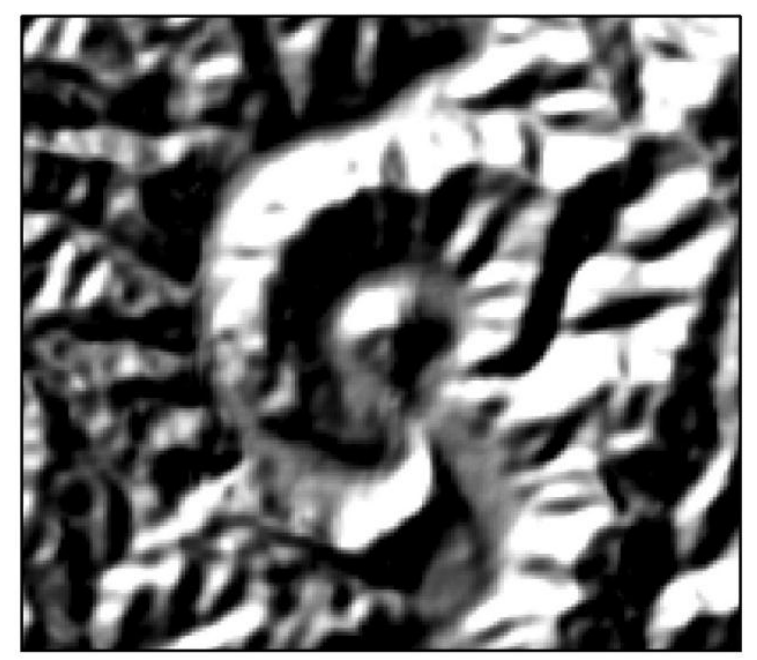

ASTER $30 \mathrm{~m}$

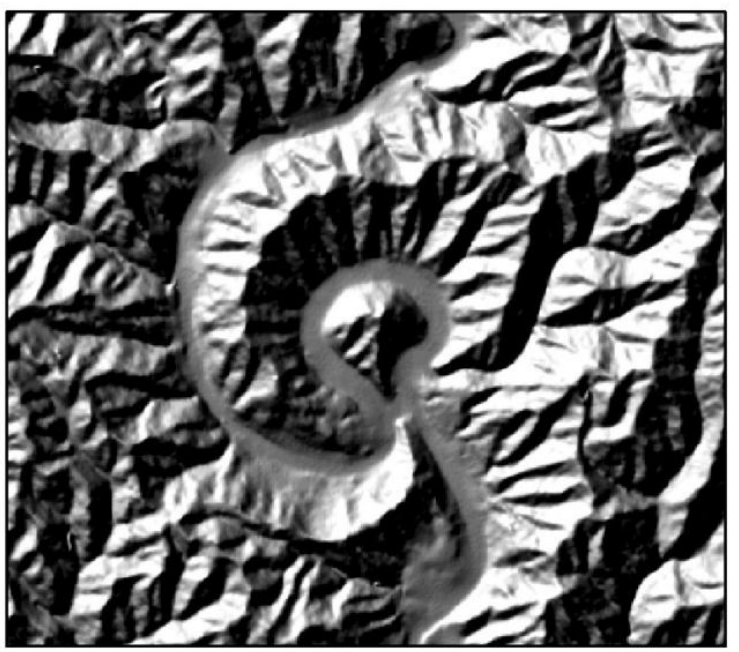

Otago $15 \mathrm{~m}$

Figure 3-1. The four DEMs used in this study displaying a hillshade model of a bend in the Whanganui River, showing the difference between cell sizes. The decrease in cell size improves the resolution of the landform.

The SRTM elevation data can contain voids where the angle of the radar beam and topography create shadows, producing areas where no elevation information is gathered. Furthermore, water bodies are poor reflectors of the radar signal, often causing voids. Manual editing of the raw data and interpolation of surrounding data points is used to provide approximations of surface elevations in these void areas. With the increasing use of SRTM data for scientific purposes (e.g. global hydrological modelling, disease vector modelling etc), datasets with voids removed and elevations already interpolated into a grid are becoming available and freely distributed though third party 
websites. However, these data often lack information on the techniques used to clean and fill elevation abnormalities. This lack of metadata is of concern, especially when these possible errors could produce potentially erroneous results and compound error in derived datasets. The SRTM data used for this study is Version 4, downloaded from http://srtm.csi.cgiar.org/. The Version 4 dataset was interpolated according to methods by Reuter et al. (2007). This data set has already had any large voids filled, using a New Zealand scale 100 m DEM from Geographx (http://www.geographx.co.nz/downloads.html). For information on methods and the algorithms used for void filling see Reuter et al. (2007).

\section{Advanced Spaceborne Thermal Emission and Reflection Radiometer (ASTER)}

Advanced Spaceborne Thermal Emission and Reflection Radiometer (ASTER) is an imaging instrument onboard the Terra satellite, a joint cooperative between the US National Aeronautics and Space Administration (NASA) and Japan's Ministry of Economic Trade and Industry (METI). The ASTER sensor collects a wide range of data such as surface temperature, reflectance, radiance and stereo high resolution imagery. Photogrammetry is used to calculate surface elevations from the imagery data captured by this sensor. The ASTER sensor uses simultaneous along-track stereo-pairs, which eliminate variations caused by multi-date stereo data acquisition. Overlapping images are used and a weighted average value is taken from multiple image pairs (referred to as stacking). In areas of little overlap, the averaging of elevation values between pairs of images can produce artefacts such as mole runs (i.e. positive curvilinear anomalies) and sinks and peaks can occur due to low stacking numbers (c.f. ASTER, 2009). One issue with using satellite stereo imagery is the necessary removal of any cloud cover present during collection during post-processing. It is almost impossible to acquire satellite imagery completely free of cloud. Therefore, imagery with the least amount of cloud is used and pixels identified as cloud cover are removed. This can produce large areas where elevation values need to be interpolated. Through the interpolation of these void areas, artefacts such as mole runs, sinks and peaks become more apparent. The aim of the ASTER Global DEM (GDEM) project was to produce a global coverage in a 1 arc second $(30 \mathrm{~m})$ resolution (ASTER, 2009). The initial GDEM1 dataset was released for scientific assessment in 2009. Building on feedback and analysis from the scientific community, issues such as sinks, peaks, and mole runs were greatly reduced in ASTER GDEM2 (released in 2011). The main improvement was the use of the SRTM and other freely available DEMs to fill in information where no ASTER data was available. The ASTER GDEM2 is a vast improvement on the initial release. However, this dataset still contains many of the issues listed above. Documentation assessing the accuracy of this dataset, advises a preliminary, study specific analysis to clarify if the ASTER data set is suitable for the intended 
purpose. With this in mind, any analysis using the ASTER DEM in this study will acknowledge that there is potential for erroneous values from underlying issues with the DEM.

\section{Landcare Research 25m (LC)}

Landcare has produced a National DEM of 1:50 000 with $25 \mathrm{~m}$ cell size, derived from the national TOPOBASE data. The TOPOBASE data was collected by Land Information New Zealand (LINZ) and consists of $20 \mathrm{~m}$ contours as well as surveyed spot heights. Version 2 of the LC DEM, released in 2002, uses an updated algorithm developed by David Giltrap (see Barringer et al. (2002) for details on the implementation of this algorithm). The main advantage of using this algorithm was to remove the flattening effect of valley bottoms often found in datasets of this kind (Barringer et al., 2002).

\section{Otago $15 \mathrm{~m}$}

This dataset was created at the School of Surveying at Otago University. It was also derived from the national TOPOBASE data, however, this DEM was interpolated at a $15 \mathrm{~m}$ cell size with the ANUDEM interpolation method. This interpolation method uses a 2-D thin plate spline and aims to generate a hydrologically correct DEM by removing spurious sinks in the surface (Columbus et al., 2011a; see Hutchinson (1989) for details on this process).

\subsubsection{Issues with DEMs derived from contour data}

There are many issues with using DEMs interpolated from contours in hydrological analysis. One of the major issues is a terracing effect caused by bias toward the contour values. This effect can often be seen in hillshade models of the DEM and is especially noticeable in areas of low relief with little elevation change where the contour values used for interpolation are spaced further apart (see Figure 3-2). Wise $(2000,2007)$ assessed the quality of hydrological data derived from DEMs 


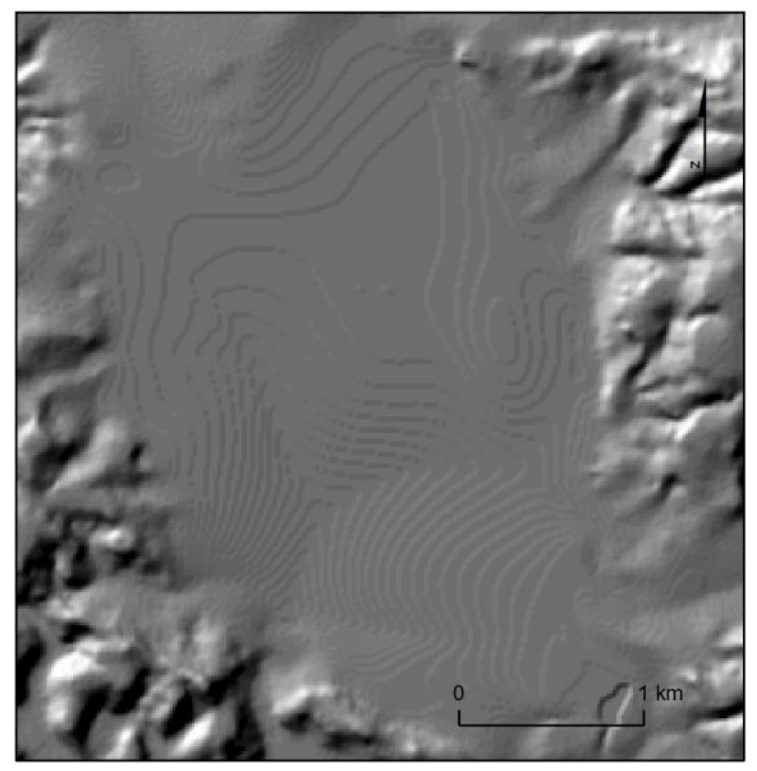

Figure 3-2. A terracing effect can easily be seen in the hillshade model of the Otago $15 \mathrm{~m}$.

interpolated from contour lines. He concludes that care should be taken to assess the quality of the DEM before use in hydrological modelling and that any results derived from these DEMs should always be checked to see if they appear reasonable.

\subsubsection{DEM Summary}

All of the four DEMs used in this study have advantages and disadvantages. From this review, it is noted that any data derived from a DEM needs to be used with caution. All results will need to be interpreted with the knowledge that an anomalous value could be due to an inherent error in the DEM creation process. The SRTM and ASTER DEMs have a low resolution (large cell size) and therefore these data might not be a suitable input for analyses requiring high horizontal precision. Furthermore, erroneous artefacts occur in both the SRTM and ASTER DEM. The LC and Otago DEMs are both derived from the same base elevation values but use different interpolation methods. The smaller cell size of both these DEMs could be useful where high horizontal precision is required. A bias toward the base contour data has been highlighted as a possible issue when deriving elevation data from these DEMs. 


\subsection{Derived Data: Concepts and Methods}

The following section describes the methods used to extract streams and catchments from the four DEMs, which will then be used to calculate the geomorphic index values. Both, methods used to produce these data sets as well as methods used to correct the DEMs for extraction of hydrological values, are outlined. Issues with using these standardised tools for hydrological modelling within a GIS are discussed.

\subsubsection{Correcting a DEM for hydrological modelling}

Due to the variety of data collection and interpolation methods used to produce the four DEMs, preprocessing to ensure hydrological correctness was performed on all of the datasets. The term 'hydrological correctness' is used here to describe the surface of the DEM which has been altered to ensure water flows downhill and best approximates the real life drainage in the extent covered by the DEM. Standard correction methods and the associated advantages/disadvantages have been widely discussed by a number of authors (Palacios-Vélez and Cuevas-Renaud, 1986; Gyasiagyei et al., 1995; Akar, 2009; Lopez-Vicente et al., 2009).

For this study it was important to ensure that the modelled drainage networks were, within the bounds of the native resolution of the DEM, as close to a real life representation as possible. Furthermore, elevation values were not overly altered to allow for accurate calculations of changes in elevation. As with any form of modelling, this required a certain level of compromise between the need for data accuracy and the ability to produce the best approximation of real life drainage network.

Of note for this study are artefacts that are produced during DEM data collection and interpolation, the removal of sinks and peaks from the datasets, and the representation of lakes in the datasets. What follows is a description of the methods used to correct the DEMs used in this study and a discussion of the implication of deriving values from these surfaces.

\section{Filling of Sinks}

Sinks are defined as a cell or cells where flow direction is undefined, whereas peaks are anomalous cells with a sudden change to a high value (Tarboton et al., 1991) (see also Figure 3-3). Sinks and peaks can be a natural part of the drainage network or be caused by errors produced during data collection or interpolation of the DEM. The removal of errors is necessary to ensure the downhill flow of water is modelled correctly and that the derived stream network does not have areas of 
internal drainage or is discontinuous. However, the removal of natural features such as towers, sinkholes and lakes might not be desired.

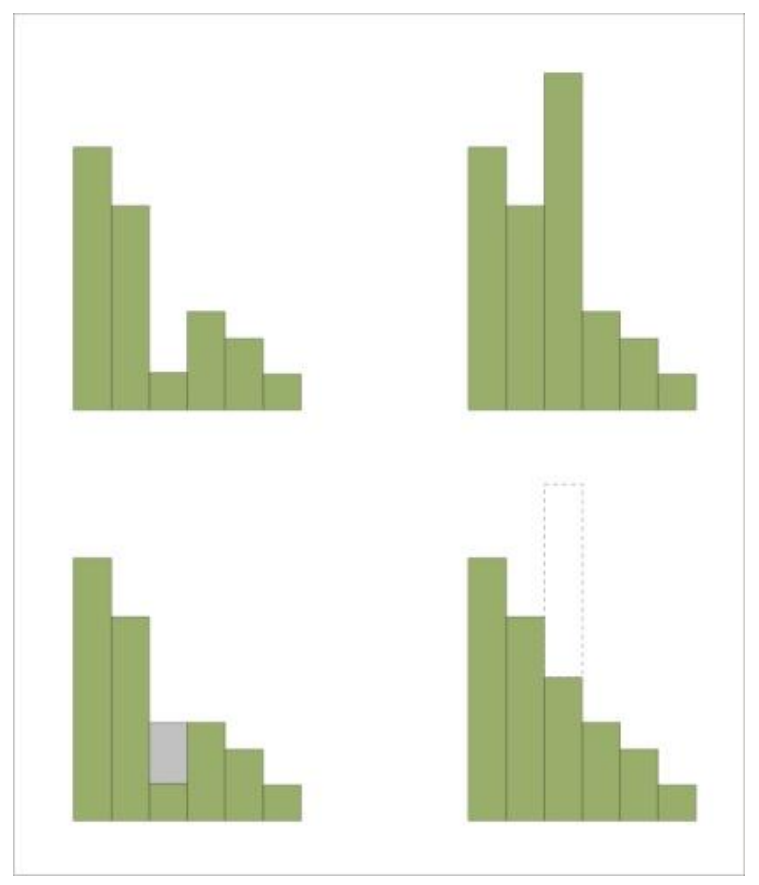

Figure 3-3. This figure visually shows the method used to correct a DEM for sinks and peaks. The bars represent elevation values within a DEM. When a sink or peak is detected elevation values for this cell are interpolated from the surrounding values (based on Tarboton et al., 1991).

For the best results all sinks and peaks should be individually analysed and a decision made whether they are an important landscape feature or an error. This method is often not possible due to the large extent of the DEMs and the time that would be involved with this type of analysis. To overcome the need to individually analyse every sink or peak, tools within a GIS environment have been developed to only remove sinks and peaks within a user defined tolerance. These tools are also especially useful for datasets were the DEM surface has a large number of undefined or 'NoData' values. These gaps in the DEM surfaces, most likely errors stemming from data collection or interpolation, can thus be interpolated from surrounding values.

In this study, sinks and peaks were corrected using the fill tool in the Hydrology toolbox of the ArcGIS 9.3.1 Spatial Analyst extension. The fill tool locates elevation values within a DEM that are greater than a specified $z$ tolerance and changes the value of the cell or cells to a value equal to the surrounding cells. For this study, cells that were filled by this tool were extracted to a raster layer and checked against topographic maps, hillshade models, satellite orthophotography and 
georeferenced aerial photography to ensure any features deemed important to this study were not removed.

\section{Lakes}

Lakes can also pose a problem when extracting a stream network from a DEM. How lakes are identified and represented depends on the data collection and interpolation method used for producing the DEM. The following explains how each of the DEMs used in this study represent lake elevation values and how these values were collected.

The Otago DEM and the SRTM DEM added lake heights prior to interpolation. For the SRTM DEM, the raw data natively contains cells that are classified as water. As part of the processing of the SRTM dataset for release to the public, water bodies were identified and corrected to the specification set out in Reuter et al. (2007). This set of guidelines defines lakes as a series of cells classified as a water return that has a length $\geq 600 \mathrm{~m}$ and a width $\geq 183 \mathrm{~m}$. This definition removes small lakes and ponds and any anomalous single cell water returns. Areas larger than the reference area are assigned values $1 \mathrm{~m}$ lower than the shoreline of the lake producing a continuous flattened surface. The outlet of the lake is assigned a value $1 \mathrm{~m}$ lower than the surface of the lake to ensure flow direction through the lake is achieved.

The Otago DEM uses lake extent and elevation data from the LINZ Topo250 map series to correct for elevations across a lake surface. This polygon shapefile was converted to a raster grid with elevation values from this layer assigned to the raster cells. This mask was then applied to the DEM. The process allowed for lakes to be represented as a flattened surface of constant elevation (Columbus et al., 2011b).

The documentation provided with the LC $25 \mathrm{~m}$ dataset does not mention the use of lake elevations prior to interpolation. However, based on visual inspection of the dataset, it appears that some form of elevation correction has been applied. It is assumed that LINZ Topo data was also used for correction. No inland water mask has been applied to the ASTER DEM and therefore lakes are represented as the elevations returned during data collection. To overcome the lack of lake elevations, the $z$ extent of the fill tool was left undefined to ensure all sinks were filled on this DEM. While the fill tool interpolates lake surfaces reasonably well, it can produce sudden changes in elevation within a lakes extent. Therefore any calculations from such areas were excluded from the analysis.

The largest lake within the study area is Lake Rotorangi. This lake is the only lake large enough to impact the hydrological extraction of a stream network. It is a manmade, $46 \mathrm{~km}$ long lake in a 
drowned river valley formed due to the construction of the $82 \mathrm{~m}$ tall Patea dam (built between 1979 and 1984) for electricity production (Trustpower Ltd., 2008). Subsequent analysis with geomorphic indices will show that this man-made structure creates very large anomalous values within the study area.

\subsubsection{Stream and Catchment extraction}

In this section the methods and tools used to extract stream networks and catchment boundaries from the hydrologically corrected DEMs are described. A series of hydrological tools from ESRI ArcGIS 9.3.1 and the Spatial Analyst Extension were used.

Once a DEM was corrected for elevation anomalies, the Flow Direction tool was used to produce a surface that represents the direction of flow based on the steepest direction of descent. An 8direction model, based on Jenson and Domingue (1988), was used. This model calculates the steepest descent from the centre cell in a $3 \times 3$ cell group. The distance is calculated from the cell centre to adjoining cell centres with lower elevation values. Any cell or cells in a diagonal direction have their distance calculated as $\sqrt{2} \times x$ Where $x=$ the cell size. Where this calculation produces two cells of equal value the neighbourhood is expanded until a direction of steepest descent is found (Jenson and Domingue, 1988). Values are then assigned a directional coding to indicate the direction of flow from each cell within the raster extent.

From the flow direction layer a surface of flow accumulation was calculated using the flow accumulation tool. This is achieved for each cell by determining the sum of the cells which flow into it. This is an iterative process as values of neighbouring cell will change with each pass. This calculation is repeated until two consequent iterations are identical.

The flow accumulation layer is used to define the drainage network by extracting values above a user defined threshold. In this study, the threshold was determined to be the value at which the heads of the streams matched the heads of the streams from the NZ Topo 50 maps. For each of the DEMs, this equated to c. $0.35 \mathrm{~km}^{2}$ of contributing flow accumulation area before a cell was classified as a stream.

Each of the stream networks were then classified into a stream order using the Strahler method (Strahler, 1952a). The stream networks were then converted from raster to vector format without generalisation. The resulting layer was line segments representing a stream network based on stream order. 
Catchments were derived from the four DEMs using the watershed tool in the Spatial Analyst toolset. This tool requires two layers, the flow direction layer (described above) and a series of user defined pour points. The first set of pour points was chosen by locating where stream channels terminate at the coast. The resulting layer is a raster representation of all cells that are upstream of a pour point. Delineated catchments were named after their main river. Pour points were then chosen at the lowest point of each stream based on stream order. Catchments were then derived for stream order. Orders 3 - 6 were calculated separately and named according to their main stream channel. Where the main channel name is the same, lower order catchment are identified by adding the preface 'upper'. The resulting layers are a representation of the catchments of a certain stream order. These layers allow for the analysis of each catchment based on the order of stream contributing to the catchment.

\subsection{Data Used for Testing Geomorphic Indices}

This section describes the data used to test the geomorphic index values. These data are compiled from a range of sources and therefore their accuracy and precision are important to acknowledge. In the following a description of how each dataset was collected and its resolution is given.

\subsubsection{Active Fault Database}

An active fault is defined as a fault that has ruptured repeatedly in the past, and whose history indicates that it is likely to rupture again (Jongens and Dellow, 2003; Litchfield and Jongens, 2006; Litchfield et al., In Prep.). The upper limit for a fault to be classified as active is evidence of rupture within the last 125000 years. The Active Fault Database (AFDB) is a GIS database that contains information on mapped active faults within New Zealand. The data contained within is a collaborative effort from researchers involved with the study of mapping and investigating surface expression of faults. GNS science maintains and updates these data from research and commercial reports conducted by their staff, universities, other Crown Research Institutes such as NIWA, and regional and local councils. Where the data are available, fault traces are attributed based on the classification in Jongens and Dellow (2003). As the mapped traces are a combination of data from a range of resolutions, it is important to recognise that the location of a mapped trace has some amount of error. These data were captured by manual digitisation from a variety of sources of differing quality and scale (generally at scales of $~ 1: 50000$ ) and are expected to have a locational accuracy of between +/- $100 \mathrm{~m}$ and +/- $250 \mathrm{~m}$. In many cases, surface traces of these faults have been mapped but paleoseismic trenching has not been undertaken to calculate slip rate or recurrence intervals. The AFDB does not currently contain information for active folds. 


\subsubsection{QMAP Geological Data, Faults and Folds}

The QMap series published by GNS is a comprehensive geological map series covering all of New Zealand at a scale of 1:250 000. These maps are published in paper and digital form. For this study, the digital versions of mapped geological units, active faults and folds and inactive faults and folds were used. The fault and fold information for these maps are sourced from the AFDB and published literature. To produce a map that can be printed at 1:250 000 these fault traces have been generalised. The Qmap fault data contain many faults, mostly around Taranaki volcano, that have yet to be added to the AFDB. Information on the attributes and collection methods for these data can be found in Nathan (1993), Rattenbury et al. (1994) and Ratternbury and Heron (1997). Qmap does not provide a rate of active of folds and the criteria for defining a fold active in Qmap is the same as the active fault database.

\subsubsection{Lineaments}

Often active and inactive faultlines provide a weakness in the geological structure that is exploited by the fluvial system creating linear valleys. Faultlines can also be express in the topography as a series of aligned ridge saddles. These features are often easily mapped from a hillshade model of a DEM. In areas of normal faulting, the four geomorphic indices provide an opportunity to test if these lineaments could be tectonic in origin, because of differential uplift either side of the lineament. The data used in this study was a layer of digitised lineament features from DEM hillshades and contour lines produced independently by Dr. Pilar Villamor and Dougal Townsend from GNS Science and added to by the author at a scale of 1:50 000 (Townsend et al., 2008).

\subsubsection{Aerial Photography}

Where available, stereoscopic aerial photography was used to check for surface expression of tectonic activity where the geomorphic indices provided strong evidence for their presence. The photographs used were captured in 1943 and 1956 at a resolution of 1:16 000 and 1:20 000. 


\section{Chapter 4 Geomorphic Indices Background and Methods}

This chapter provides the background for the four geomorphic indices used in this study i.e. hypsometric curve, basin asymmetry, stream length gradient index, and sinuosity. Each index is introduced separately with a brief history about the development of the index, the mathematical formula for its application, and a review of literature that uses the index for tectonic research. From this literature review, methods for how to apply each index in the study area are summarised.

\subsection{Hypsometric (Area-Altitude) Curve}

This section will describe the hypsometric curve and how it has been used to provide evidence of a change in the equilibrium state of a catchment, focusing on change in equilibrium state due to faulting. A brief history of the development of this geomorphic index is outlined to provide the background for the application of this index in the study of active tectonics. A review of literature explains how a typical catchment of homogeneous lithology will develop a distinctive S-shape hypsometric curve, when a balance between erosion and uplift has been obtained. Any deviation from the equilibrium shape is shown to be due to spatial variations in the amount of erosion occurring within the catchment. Spatial variation of the amount of erosion is a function of the physical properties of the catchment (i.e. geology, shape, and size) as well as the physical processes occurring within the catchment (i.e. erosion and tectonic activity). A catchment with uplift occurring faster than erosion is shown to develop a convex shaped hypsometric curve. Statistical moments of the hypsometric curve are explored to define a method for differentiating between catchments in equilibrium and disequilibrium.

\subsubsection{Introduction}

The hypsometric curve of a catchment describes the distribution of elevation within the catchment area. To produce a hypsometric curve, the proportion of total catchment height (percent height) is plotted against the proportion of total catchment area (percent area) (see Figure 4-1). The area under this curve is referred to as the Hypsometric Integral (HI) (a first order derivative of the hypsometric curve) and has been used as a method to quantify differences in the shape of hypsometric curves (Keller and Pinter, 1996). Using the HI, curves have been separated into 3 categories. $\mathrm{HI}$ values greater than 0.5 (greater than $50 \%$ of the area under the curve) equals a convex shape, $\mathrm{HI}$ less than 0.5 (less than $50 \%$ of total area under the curve) equals a concave shape, and $\mathrm{HI}$ of close to 0.5 mostly resemble an S-shape. These definitions of shape will be referred to throughout this study. 


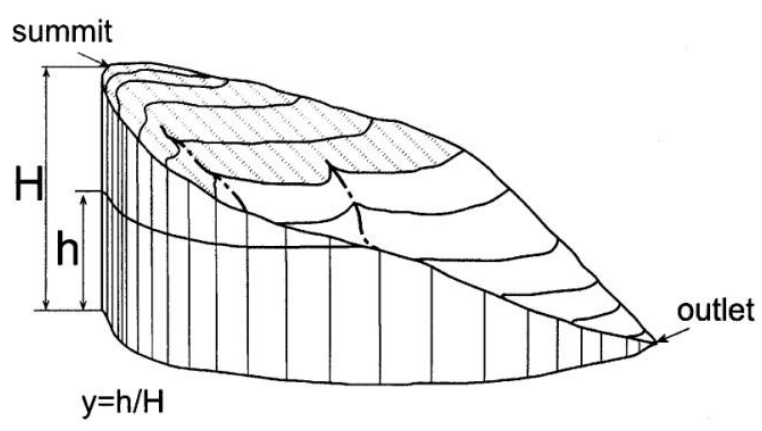

Perspective View

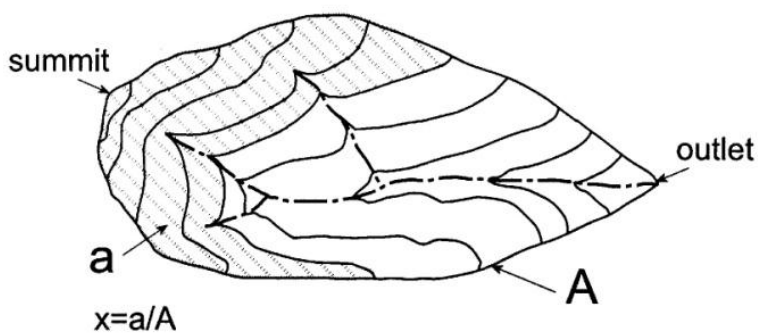

Top View

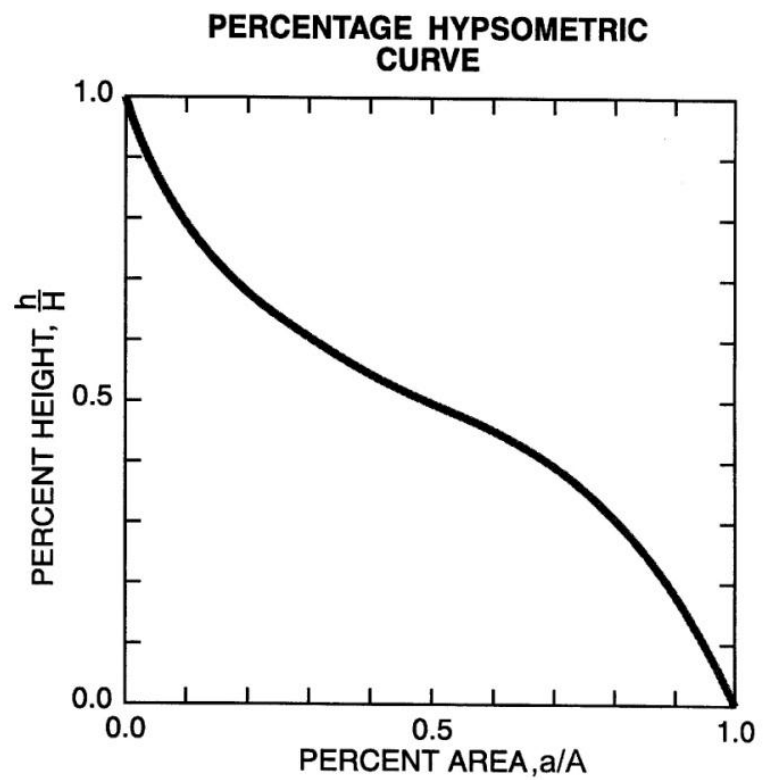

Figure 4-1. The hypsometric curve is produced by calculating the percentage of area and plotting it against the percentage of elevation. A catchment in equilibrium has been shown to have an S-shaped hypsometric curve. Figure from (Keller and Pinter, 1996).

\subsubsection{Background}

Since its inception in the $19^{\text {th }}$ century, the hypsometric curve and hypsometric integral have been used at a variety of scales and in a variety of environments as an efficient way of quantifying the form of the Earth's surface (Keller and Pinter, 1996). At a regional scale, the first use of hypsometry in geomorphology is credited to Langbein et al. (1947) using hypsometric analysis of selected catchments and relating it to the overall slope of a catchment.

Hypsometric analysis of a catchment as an indication of evolutionary stage was first proposed by Strahler (1952b). His research suggested differences in the shape of the curve and the value of the hypsometric integral are related to the degree of disequilibrium of erosive and uplifting forces. The geomorphic evolutionary model used to describe hypsometric shape in this early analysis was the 'geographical cycle' from Davis (1899) and was used to classify changes in hypsometric curve shape as stages in this evolution model. Strahler (1952b) suggested a catchment with a convex shape is in disequilibrium and assigned as youthful evolutionary stage. Basins with an S-shaped curve were considered to be in a state of equilibrium and in a mature stage of evolution. The final concave shape was termed the Monadnock phase representing a catchment that has reached a final mature 
stage with erosion reducing the catchment area to a peneplain with rock outcrops at the catchment divides.

Strahler's work introduced the hypsometric integral (the area under a hypsometric curve) as an empirical measurement of drainage basin evolution, suggesting a progressive decrease in this value as a proxy for a Davisian stage of landscape evolution. HI values of closer to 1 were shown to have a convex shape, $\mathrm{HI}$ values of $\sim 0.5$ were shown to have an S-shape and an $\mathrm{HI}$ values of close to 0 have a convex shape. This work was based on the thinking that the age (evolutionary stage) of a catchment could be determined by the shape of the hypsometric curve;

- $\quad$ convex $=$ disequilibrium $=$ young

- S-shape $=$ equilibrium $=$ mature

- $\quad$ concave $=$ disequilibrium $=$ old age

The discovery of plate tectonics has changed the fundamental thinking of relating hypsometric curve shape to a stage in a long term evolutionary model. The idea that through a long period of time a catchment will evolve through a series of predictable and predetermined stages is no longer valid. It is now realised that continual and sudden uplift needs to be allowed for (Keller and Pinter, 1996; Burbank and Anderson, 2001). For example, a large uplift event could change a single catchment from mature S-shaped to convex while other catchments nearby are unaffected. The catchment would be assumed to be young when in reality it is the same age as the other catchments. This does not mean that all of the early research is no longer valid. It does however require a slight change in thinking when interpreting the results from early research using hypsometric analysis. In areas of high tectonic activity the shape of a hypsometric curve cannot be used as an indication of age. However, it could be possible to use the hypsometric curve as an indication of equilibrium state but only where geology was more or less homogeneous.

Ohmori (1993) applied the $\mathrm{HI}$ and hypsometric curve to an area of Japan containing young mountainous regions and older depositional regions of mostly outwash plains. Changes in the hypsometric curve and $\mathrm{HI}$ were related to concurrent tectonics and denudation rather than evolutionary state of the catchment. Ohmori found that the drainage basins of Japan do not follow the evolutionary stages suggested by Strahler (1952b) but found these basin progress from concave, to S-shaped in accordance with an increase in mountain altitude. He highlights the assumption of the Davisian model of landscape evolution as the main reason that these results differ. This is reflected in the hypsometric integral values calculated in Ohmori's study. The youngest landscapes (i.e. the 
mountainous regions) have the lowest $\mathrm{HI}$ values and a concave shaped hypsometric curve. He concluded that this was due to the rapid uplift of the headwaters and substantially lower rates of uplift at the catchment outlet. Ohmori also recognised that many of the landscapes would have been undergoing fluvial incision prior to and during uplift, this would suggest that the fluvial system was already well developed prior to uplift causing channels to incise further into these predefined fluvial networks.

\section{Statistical Moments of the Hypsometric Curve}

The relationship between hypsometric integral as a method to classify hypsometric curves was investigated by Harlin (1978). Harlin highlighted issues with identifying the shape of a hypsometric curve from $\mathrm{HI}$ values. He noted that $\mathrm{HI}$ values of close to 0.5 could visually represent concave convex and S-shaped curves and therefore the $\mathrm{HI}$ value is only a rough estimate of the process occurring within a catchment. He proposed the use of statistical moments of the hypsometric curve and the statistical moments of the density function (first derivative of the curve) to better understand hypsometric shape. Using polynomial regression to fit low order $\left(2^{\text {nd }}\right.$ or $\left.3^{\text {rd }}\right)$ continuous polynomial function to percentage hypsometric curves, analysis of the statistical moments of the hypsometric curve, (skewness and kurtosis) and statistical moments of the distribution function of the polynomial fit (density skewness and density kurtosis) were suggested to provide a method to quantify differences in curve form, and therefore differences between basins with homogenous environment and lithological conditions. Skewness is the measure of the amount of asymmetry of the distribution of a dataset when compared to a normal distribution. Skewness is positive when the mean of the sample data is to the left of a normal distribution and negative when the mean is to the right of a normal distribution. Kurtosis measures how peaked the distribution is when compared to normal distribution. Kurtosis values $<3$ represent a flatter than normal distribution and kurtosis values $>3$ a distribution more peaked than a normal distribution. Harlin suggests that the $\mathrm{HI}$ alone is not enough to realise the true potential of the hypsometric method of quantitative landform analysis, and the statistical moment can provide a better insight.

Harlin's results suggest a relationship between the statistical moments of the hypsometric curve and physical processes occurring within the basin. He postulates that where change is rapid, density skewness and density kurtosis values will be higher. He recognises a critical change in hypsometric form from negative values of density skewness to positive values of density skewness. From observation of processes occurring in the studied basins he suggests density skewness values that are : 
1. Negative values indicate areas with very little development and therefore very little headwater erosion (convex shape).

2. Values equal to zero indicate an equal amount of change is occurring, or has occurred, this change is balanced between the upper and lower reaches (perfect S-shaped).

3. Positive values are attributed to accelerated forms of erosion in the upper reaches such as mass wasting (S-shaped $\rightarrow$ Concave).

Table 4. Statistical Moments and the associated geomorphic meaning. Taken from (Luo, 2000)

\begin{tabular}{|l|l|}
\hline Parameter & Meaning \\
\hline Integral (INT) & $\begin{array}{l}\text { Mass left after erosion (if in homogenous geology and } \\
\text { assuming block uplift) }\end{array}$ \\
\hline Skewness (SK) & Amount of headward erosion in upper reach of basin \\
\hline Density Skewness (DSK) & Rate of hillslope change \\
\hline Kurtosis (KUR) & Erosion on both upper and lower reaches of basin \\
\hline Density Kurtosis (DKUR) & Midbasin hillslope \\
\hline
\end{tabular}

Building on Harlin's research, Lou $(1998 ; 2000 ; 2002)$ used statistical moments of hypsometric curves within a GIS to differentiate between groundwater-sapping and fluvial landforms. Summarising Harlin's interpretation, he assigns physical meaning to hypsometric attributes (i.e. hypsometric integral, skewness, and kurtosis of the hypsometric curve and skewness and kurtosis of the probability function of the polynomial function fitted to the curve) (see Table 2).

Willgoose \& Hancock (1998) used the SIBERIA catchment evolution model to explore linkages between catchment process and hypsometry. From their study they suggest that hypsometry can be affected by the topological shape of the catchment. They suggest that an elongated catchment of the same area as a wider catchment will have a different hypsometric curve shape. By comparing the main drainage paths of modelled catchment they concluded that the amount of network branching (bifurcation) could explain the differences in hypsometric curve form. The amount of bifurcation could also explain the increased downward concavity of the toe of the hypsometric curve that occurs for a majority of catchments. A proportional increase of short and steep input from slope and fluvial processes at lower elevations could explain shape of this section of a hypsometric curve. Their model also suggests that catchments with the freedom to branch and form networks at lower elevations would increase the size of this toe. They conclude that Strahler's age association with hypsometric curve shape could be misleading as many of the changes to hypsometric shape can also be explained by change in catchment shape and drainage bifurcation. They highlight Strahler's monadnock (concave) shape as also a feature of very elongated catchments. 
Variations in catchment area have also been suggested to affect the shape of a hypsometric curve. Hurtrez et al. (1999) investigated differences in areas of catchments with similar lithology, uplift and climatic conditions, relating these to the shape of hypsometric curve and hypsometric integral. They found a relationship between the shape of the hypsometric curve and the area of the catchment. They noted that smaller basins were more likely to have a higher hypsometric integral and a convex shape. They concluded that this could be due to the smaller catchments being dominated by hillslope processes and therefore less erosion would be possible. Conversely they suggest as drainage area increases fluvial processes dominate and therefore a greater amount of erosion is possible. Hurtrez et al. (1999) also tested if DEM resolution (grid size) affects the shape of the hypsometric curve. They tested DEM resolutions of $20 \mathrm{~m}, 40 \mathrm{~m}, 100 \mathrm{~m}$ and $200 \mathrm{~m}$ on multiple drainage basins. By plotting and comparing the curves for a basin at all of these resolutions they concluded that variations of hypsometric curve shape did not differ significantly and therefore hypsometry is independent of resolution.

Many of the earlier studies have concluded that hypsometric analysis is hindered by the amount of time needed to manually extract elevation and area values. Perez-Pena, et al. (2009a) addressed this issue and have produced an extension for ESRI ArcGIS software to automatically extract hypsometric curves and their statistical moments from digital elevation data. CalHypso uses a DEM for elevations data and a polygon shapefile for area as inputs. This tool can calculate hypsometric curves and their statistical moments (based on Harlin (1978)) for multiple drainage basins. This tool dramatically increases the ease of extracting hypsometric data and allows for larger datasets to be analysed.

\subsubsection{Summary of Literature: Hypsometric Curve}

This review of literature involving the use of hypsometry as a method for landscape analysis has identified a multitude of factors that can influence the shape of a hypsometric curve (i.e. uplift, erosion, basin shape and area, bifurcation of stream channels and lithology). Variation in lithology within a catchment can cause variation in erosion and therefore a variation in hypsometric shape. The review has also identified methods to quantitatively describe hypsometric shape through analysis of the hypsometric integral and the statistical moments of the hypsometric curve, and therefore provide insight into the process occurring within the catchment.

Inferring a stage of landscape evolution to hypsometric curve shape has been shown to be problematic. Many of the early assumptions use a Davisian landscape evolution model that cannot be applied to modern thinking of landscape evolution. Unfortunately the young to old landscape evolution model still persists in recent literature (e.g. Ohmori, 1993; Hurtrez et al., 1999; Pérez-Peña 
et al., 2009a; Pérez-Peña et al., 2010). A majority of the literature identifies the main drivers of change to a hypsometric curve as erosion and uplift. If these two main drivers are equal, a drainage basin is thought to be in a state of dynamic equilibrium. An S-shaped curve is thought to represent this state. A convex shape has been widely interpreted as a catchment out of equilibrium. A large amount of elevation in the upper and middle reaches of a catchment are needed to produce a basin with a convex hypsometric curve. Uplift due to multiple fault ruptures can produce a change in elevation. Therefore a catchment with a convex shape could indicate multiple uplift events that occur at a frequency to produce uplift greater than the erosion rate.

The hypsometric integral can be used as a rough guide of equilibrium. However, due to the variety of shapes that can produce a similar hypsometric integral, this variable is not a robust measure. A perfect S-shaped catchment, in homogenous lithology and isotropically stable will have a $\mathrm{HI}$ of 0.5 , a skewness of 0 , a kurtosis of 3 , a density skewness of 0 , and a density kurtosis of 3 . If these values represent an equilibrium state of erosion and uplift, then catchments with statistical values that are vastly different from the equilibrium state are the most likely to have been effected by an increase in uplift or erosion. With this in mind, this study will compare hypsometric shape (convex, concave and $\mathrm{S}$-shaped) to statistical moments and try to ascertain the process that relate to these shapes and/or statistical moment values.

\subsubsection{Methods: Hypsometric Curve}

Hypsometric curves and their statistical moments were calculated using the Calhypso extension for ESRI ArcGIS developed by Pérez-Peña et al. (2009a). This extension is an efficient way of calculating multiple hypsometric curves using an integer DEM and a catchment polygon shapefile (see Section 3.2.2 for details on methods used to calculate catchment polygon shapefiles). The tool outputs a/A (percentage area) and $\mathrm{h} / \mathrm{H}$ (percentage height) data that can be plotted to produce the hypsometric curve. The hypsometric curves are then used to calculate the statistical moment. A polynomial is fitted to each curve and hypsometric integral, skewness, kurtosis, density skewness, and density kurtosis are calculated using the method outlined in (Harlin, 1978). These data were exported to a text file and used to attribute each catchment. The statistics for each curve were also exported to a spreadsheet to allow for further analysis. Initially five catchments were used to test if there is a difference between hypsometric curves and their statistical moments calculated from the four DEMs. The results from this analysis are outlined in chapter 5. Using information gained from the analysis of the five test catchment, catchments were extracted from all of the DEMs at the confluence of every $3^{\text {rd }}$ order and $4^{\text {th }}$ order stream and attributed with statistical moment data. These data were then compared to active faults, inactive faults, lineaments, and geological data. 


\subsection{Stream Length Gradient Index: Concepts and Methods}

This section will describe the Stream Length gradient index (SL index) and the Stream Length gradient index normalised by length (SLk index) and reviews its use to identify tectonic perturbation to the equilibrium state of a stream channel. Methods to normalise the SL index to compare between streams of varying length (using the graded river constant k) will be explained and investigated. The concept of a graded river is discussed and mathematical description of a graded river reviewed. The many issues with using stream channel data derived from digital data (DEMs) are discussed. The methods for interpolating SLk anomaly maps of an area greater than a catchment are reviewed. The main physical controls (i.e. geology, sediment load, local influence of major tributaries, and uplift/base level lowering at a local or regional scale) that produce high SLk values are summarised.

\subsubsection{Background}

The SL index is based on the conceptual model that streams, over time, will erode to an equilibrium elevation profile. Any deviation from this equilibrium state will indicate some perturbation that has affected the stream. By measuring the gradient of a stream profile at a constant distance, changes in gradient can be compared both within the stream and also compared between streams if they are normalised by length (Keller and Pinter, 1996; Burbank and Anderson, 2001). The SL index is a very useful tool for conducting large scale recognisance of areas where field data cannot be easily obtained (Keller and Pinter, 1996; Burbank and Anderson, 2001). There are many physical processes that can cause a high SL value. One of the aims of this study is to ascertain if a perturbation producing a high SL value is tectonic in origin. To accomplish this aim it is necessary to prove that tectonic influences are the most likely cause.

The SL index was first introduced by Hack (1973), who defined the SL index at a point in a river reach as follows:

$$
S L=\left(\frac{d h}{d l}\right) * L
$$

Where $\frac{d h}{d l}$ is the slope or gradient of a stream reach ( $d h$ is the change in elevation and $d l$ is the length of the reach) and $L$ is the channel length upstream from the midpoint of the reach to the river head (see Figure 4-2). 

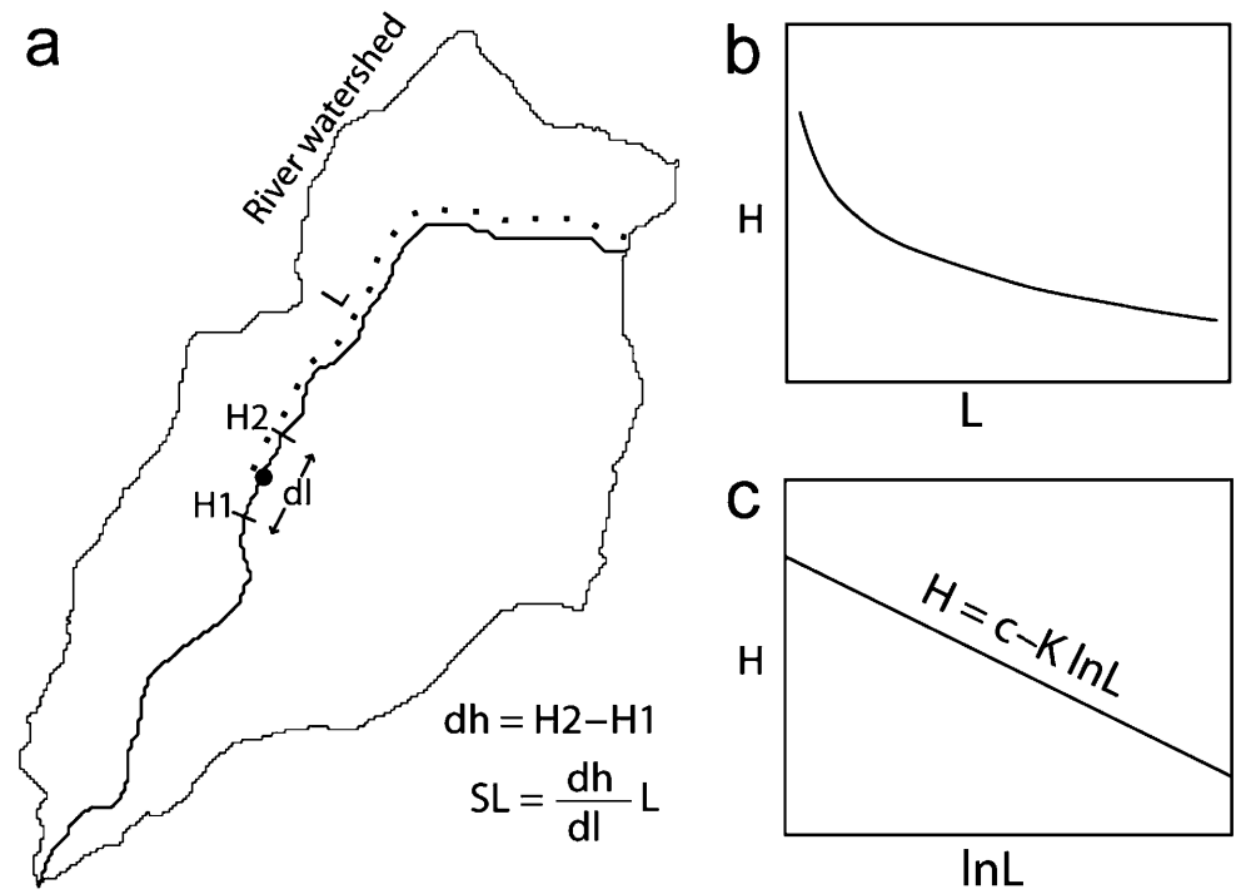

Figure 4-2 Calculation of the SL index from Keller and Pinter (1996). b. The semi-logarithmic shape of an ideal graded river. c. The ideal graded river is a straight line when a semi-logarithmic scale is applied to the distance from the stream head plotted on the $x$ axis.

Hack related changes in SL index values as generally corresponding to changes in bedrock or introduced sediment load. He also noted that base level lowering due to sea level change and tectonic events are likely to greatly affect SL values. He suggested that a catchment of homogeneous lithology and uniform shape will have values of the SL index that remain approximately the same, representing a stream in dynamic equilibrium that has eroded the stream bed to a logarithmic profile (Hack, 1973). Hack (1973) suggested this index could be used as a measure of competence of the stream to erode its bed and banks and therefore as a proxy for stream power. Stream power can be calculated using the simple equation:

$$
\Omega=\rho g Q S
$$

Where $\Omega$ is stream power, $\rho$ is the density of water $\left(100 \mathrm{~kg} / \mathrm{m}^{3}\right), g$ is acceleration due to gravity $(9.8$ $\left.\mathrm{m} / \mathrm{s}^{2}\right), Q$ is hydraulic discharge $\left(\mathrm{m}^{3} / \mathrm{s}\right)$ and $S$ is the channel slope. From this equation we are able to see that any increase in slope or discharge will increase stream power, therefore increasing the ability for the stream to erode its bed and banks. A typical stream will have a decreasing slope and increasing discharge downstream.

An alluvial stream that maintains a steady balance between erosion and deposition, i.e. a state of dynamic equilibrium, has been referred to as a graded river. The earliest literature describing the 
concept of a graded river is attributed to Mackin (1948), and was further refined by Leopold and Maddock (1953). They define a graded river as having slope and channel characteristics that are delicately adjusted over a period of years, with the available discharge providing the velocity to transport sourced materials. They also acknowledge that any change in the controlling characteristics will cause a displacement of this state of equilibrium to one that is able to absorb this change.

A graded river will develop a concave shape (Figure $4-2 b$ ) and therefore, if the $x$-axis of this profile is plotted using a semi-logarithmic scale, the profile will yield a straight line (Hack, 1973; Chen et al., 2003; Pérez-Peña et al., 2009b) (Figure 4-2c):

$$
H=C-k \ln (L)
$$

Where $\mathrm{H}$ is the elevation of the stream bed, $L$ is the length from the river head, $C$ is the elevation at the point of the river head, and $k$ is the slope of the line.

The derivation of this equation with respect to $L$ (Burbank and Anderson, 2001) can be used to calculate stream slope, $s$ :

$$
s=\frac{d h}{d l}=\frac{d(k \ln (L))}{d l}=\frac{K}{L}
$$

The parameter $\mathrm{k}$ can be seen as the product between slope and $l n$ stream length, and can be used to characterise a reach of a stream or its entire length, referred to as $K$ (Pérez-Peña et al., 2009b). The value of $K$, therefore, represents the equilibrium conditions of any given stream:

$$
K=C-\frac{h_{m}}{\ln L_{\mathrm{t}}}
$$

where $h_{\mathrm{m}}$ is the elevation at the mouth of the stream and $\mathrm{L}_{\mathrm{t}}$ is the total length of the stream (PérezPeña et al., 2009b).

Using the idea that $K$ represents the equilibrium condition of a stream, Pérez-Peña et al.(2009b) investigated the relationship between $K$ and $\Omega_{t}$ (total stream power). They found a strong relationship between $K$ and $\Omega_{t}$, and from these results recommend the use the parameter $K$ to normalise SL values allowing for comparison between streams of different length.

Therefore streams of differing length can be normalised by the parameter $K$, the SLk value at a point along a normalised stream can be calculated using the equation: $S L k=\left(\frac{d h}{d l} * L\right) * K$ 
For a full description of the derivation of the equations above see Hack (1973), Keller and Pinter (1996) Burbank and Anderson (2001) and Pérez-Peña et al. (2009b).

\subsubsection{The Graded River}

It has been shown that the perfect theoretical semi-logarithmic graded river is not commonly found in field based studies (Snow and Slingerland, 1987; Chen et al., 2003; Pérez-Peña et al., 2009b). However, research has shown three mathematical forms (i.e. exponential, logarithmic and power functions) can be used to provide the best approximation of a stream profile. Research into the fitting of particular mathematical analogues to graded river profiles has found the longitudinal profile shape is affected by controls on the equilibrium state of the river system (Snow and Slingerland, 1987). Snow and Slingerland (1987) investigated the fitting of exponential, logarithmic and power functions to modelled stream profiles and related physical processes to each shape. They concluded that no simple mathematical function could be used for all observed streams. However, they suggest; streams with a downstream increase in sediment and discharge are best explained with a power-function form, streams with a downstream reduction in sediment calibre are best described using a logarithmic form and profiles with low rates of sediment transport most closely approach pure exponential curves.

Most of the streams of the Taranaki area are alluvial and are characterised by streambeds and banks that are not able to resist erosion and often not able to transport all available material (i.e. transport limited). The river is essentially flowing over a bed of partially transported deposits (Fleming, 1953; Townsend et al., 2008). The sediment calibre for all of the streams within the study area also reduces downstream. It is therefore assumed, for this study, that stream profiles are likely to be best described by a logarithmic form.

\subsubsection{SLk Index and Tectonics}

Faults and changes in underlying geology can cause anomalous SLk values (Keller and Pinter, 1996; Burbank and Anderson, 2001). Chen et al. (2003) used a SLk analysis to investigate the along strike variation of morphotectonic features in the western foothills of Taiwan. They related SLk values derived from contour lines to mapped faults and geology. They note that the angle at which a stream intersects a geological structure is also likely to complicate the comparison of SL values between streams. They also suggest that stream order and stream length are very important to consider when comparing SL values between streams. They found large streams are able to incise at a rate equal to or greater than uplift or base level lowering. Therefore, large streams adjust quickly to maintain their longitudinal profile. They suggest that the incision rate is likely to be lower in 
higher order streams and, therefore, any tectonic disequilibrium is more likely to be preserved in lower order streams. Their analysis showed clear indication of anomalous SL values coinciding with changes in lithology and where mapped faults crossed stream channels at a high angle.

Contrary to the example above, Font et al. (2010) found that SL index values are not significantly influenced by changes in stream bed erodability (bedrock lithology). Their study was based in an intraplate area of Normandy, NW France. They used a GIS and contour data derived from a $50 \mathrm{~m}$ DEM and applied the SL index to stream profiles of $3^{\text {rd }}$ and $4^{\text {th }}$ order basins. The reason for only using low order basins is unclear, however, this method could remove the need to normalise the SL values, as most streams of this order would be a similar length.

Areas of low tectonic deformation (regional uplift of $0.05-0.28 \mathrm{~mm} / \mathrm{y}$ ), mostly characterised by folding, were investigated using the SLk index by Pedrera et al. (2009). Applying the SLk index to stream channels of the eastern Betic Cordillera, Spain, they found that active folds in areas of hard rock were detected. However, results from softer Neogene-Quaternary sedimentary sediments showed little variation of SLk values. They suggest that removal of any perturbation to the stream bed of the softer sediments is attributed to the combination of low levels of uplift and high erosion.

Early research using the SL index was only applied to a small number of streams due to limitations from the manual extraction of contour data from paper topographic maps. Therefore many of these studies were limited to catchment scale analysis. Since the advent of computers and GIS software the ability to extract data to calculate the SL index has greatly improved, and allowed for analysis of large areas providing a more complete picture of how this index works in a variety of environments. Many of the studies reviewed used contour lines as elevation values for SL index calculation. This can lead to a disparity between the number of points sampled at the head of the stream and the number of points sampled near the outlet (Chen et al., 2003; Pérez-Peña et al., 2009b). Contour lines become tightly spaced in the head waters causing more SL index points to be calculated. The converse is true in flat areas where contour lines become widely spaced. This sampling bias can be avoided by extracting SL values using a DEM and GIS software. SLk index calculations can be made at regular interval along a stream channel by extracting elevation values directly from a DEM and therefore remove this sampling bias (Pérez-Peña et al., 2009b). Both the Landcare and Otago DEMs are derived from contour line data so applying this method will not improve the data representation. However, in order to allow comparison between DEMs, from various collection methods, the equal distance method described above will be used. The results from the Landcare and Otago DEMs will need to be interpreted acknowledging the aforementioned bias. 


\subsubsection{Interpolation:SLk}

The SLk index has been used at larger than a single stream scale to produce SLk anomaly maps for an entire region. Pérez-Peña et al. (2009b) tested two methods for producing anomaly maps in the Granada basin, SE Spain. Their methods involved the interpolation of SL values as outlined in Keller and Pinter (1996) (using contour lines) and the interpolation of SLk values calculated at an equal spacing (with elevation values taken directly from the DEM). The SL anomaly map showed little correlation with mapped lithological boundaries and faults. This is mostly due to the anomalies in longer rivers having higher values, suggesting that values along short streams were not well represented. However, the SLk anomaly map produced a strong correlation with mapped structure. This relationship was tested using cross-validation and ordinary kriging. A small area with accurately mapped faults and lithological contacts was used to validate the relationship between anomalous SLk values and mapped structure. Using a defined Z-score absolute limit of values higher than 2 (obtained from the cross validation analysis), 38 anomalous values were mapped. They found $81 \%$ of the anomalous values were located within $150 \mathrm{~m}$ from a lithologic contact or fault.

\subsubsection{Summary of SLk and Application of the Index to the Taranaki Region}

As a broad classification the streams in the south Taranaki region are alluvial, however many of the streams have their headwaters in very hard volcanic materials. The transition between these materials is often abrupt and could potentially dramatically affect the elevation profile of the stream, producing large SLk values. From Snow and Slingerland (1987), it is expected the volcanic material will exhibit a stream elevation profile best described by a power function and the softer Tertiary - Pleistocene marine sediments a semi-logarithmic elevation profile. This change in elevation profile shape could cause issues when comparing streams with their headwaters in volcanic material with streams with their headwaters in the Tertiary - Pleistocene marine sediments.

The majority of the study area consists of interbeded mudstones and sandstones. It has been shown that when rock strength is very low lithological boundaries are unlikely to affect SLk values due to the stream eroding easily to a semi-logarithmic shape. It is therefore not expected that the SLk index will be greatly affected by the transition between materials within the Tertiary - Pleistocene marine sediments. The study area also contains occasional outcrops of limestone that could produce local high SLk values where the stream bed is confined by these materials. The uplifted marine terraces near the coast are unlikely to produce high SLk values due to a majority of the major channels eroding through these sediments to the underlying Pleistocene marine sediments. Near the coast a transition to recent Quaternary gravels and sands is likely to produce high SLk values. 
The Tertiary - Pleistocene marine sediments are highly susceptible to erosion therefore it is unlikely that evidence of low levels of tectonic uplift will be preserved in these materials. Of importance to this study are areas of high tectonic activity that show evidence of abnormal stream gradient where a channel crosses an active fault. A high SLK index value could indicate the landscape has not had time to adjust to a recent fault rupture, indicating a recent event or an old, very large event.

The large active faults near the central volcanoes are likely to extend into the Tertiary - Pleistocene materials, and could have sufficient vertical displacement to have affected the stream profile. Where a stream channel crosses perpendicular to the projected fault trace it is expected there will be high SLk values. The mapped fault traces on the south coast of the study area, mapped in the marine terrace deposits, strike in the same direction as the streams. It is therefore likely that streams that follow along a fault will produce low SLk values. Where multiple stream channels cross a fault and the lithology is uniform, these stream channels should show similar abnormal gradients due to the linear nature of fault rupture.

The review of literature pertaining to the application of SL index for identification of tectonic anomalies has identified some important lessons and assumptions that need to be acknowledged and utilised in this study.

- SL values need to be normalised by length to allow comparison between streams of differing length.

- The equilibrium state of a stream in the Tertiary - Pleistocene materials are assumed to fit a semi-logarithmic shape.

- Low levels of uplift at a regional scale are unlikely to be detected in material with high levels of erosion

\subsubsection{SLk Methods}

The same five catchments that were used to test hypsometric data were used to test the SLk index before applying the index to the entire study area. The main trunk stream for each of the five catchments was extracted from the stream networks derived from each of the four DEMs (see 3.2 Derived data, for methods used to extract a stream network). The output from the calculation of the stream networks contain individual line segments for each section of a stream based on Strahler order. To calculate the stream length for the SLk calculations, it was required to merge to stream paths from the outlet to the headwater based on Strahler order. This was achieved by identifying the main trunk stream following the stream order back from highest to lowest. Where it was unclear 
which channel was the main channel, a decision was made base on stream length, contributing drainage area and consultation with topographic maps (process outline in Figure 4-3).

The Convert Feature to 3D tool from the 3D Analyst Toolbox was used to apply elevation values from the filled DEMs to each of the main trunk streams. An automated SLk extraction tool (code written and developed by J.V. Pérez-Peña) was used to calculate SLk values. This tool uses the geometry contained within a $z$ aware shapefile (i.e a shapefile that contains elevation values) and a user defined distance to calculate SLk values.

A
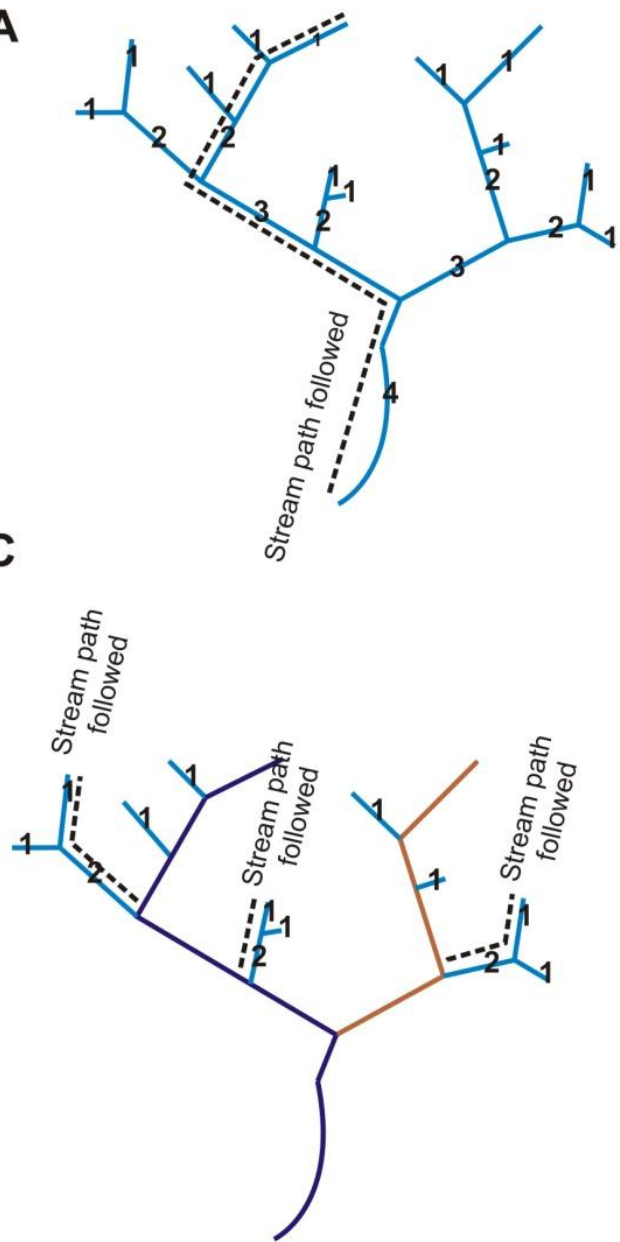

B

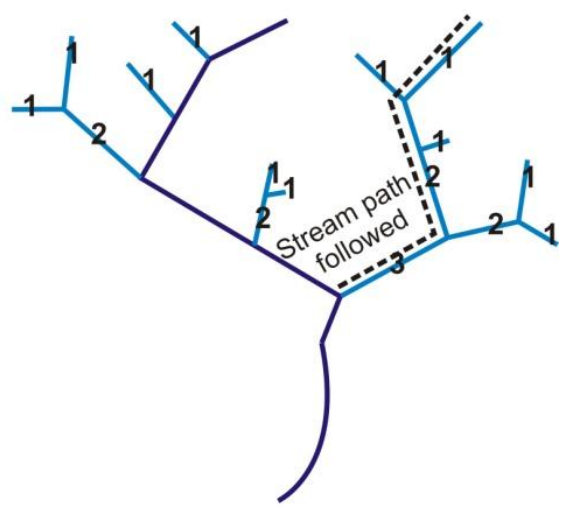

D

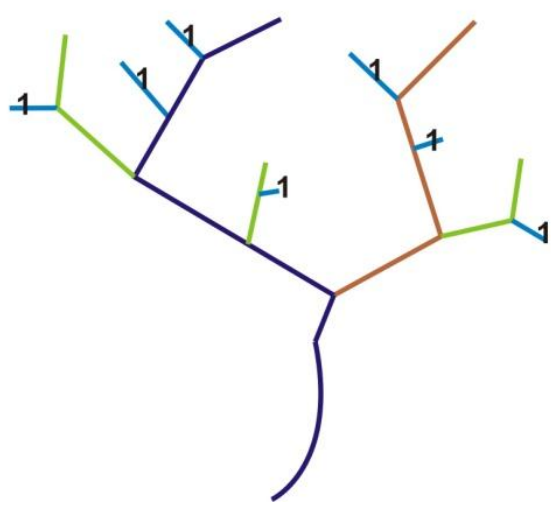

Figure 4-3 The process used to join stream network segments to allow for SLk calculations. The numbers are Strahler orders. Each time a stream was traced to its source the segments were merged. This allowed for length calculations so streams can be normalised.

The outputs are point files containing the attributes $\mathrm{dl}$ (change in length, which is the sample length), dh (change in height), $x$ and $y$ coordinates, I (length from stream head to the point), and SLk.

The above attributes were calculated for each of the trunk streams at $100 \mathrm{~m}, 250 \mathrm{~m}, 500 \mathrm{~m}, 750 \mathrm{~m}$, $1000 \mathrm{~m}$, and $1500 \mathrm{~m}$ sample spacing to test if sampling distance affects SLk values. The SLk values 
were also plotted on elevation profile graphs. The major lithological boundaries and mapped faults were also identified on the elevation profile to provide a method to visually assess if they influence SLk values. The results and discussion for the five test catchments are outlined below in Section 5.6. Using these results SLk values were then calculated for the entire study area, and SLk anomaly maps interpolated. These maps were then compared to mapped active faults, inactive faults, folds and lineaments. Results and discussion are outlined in Section 6.2.

\subsection{Sinuosity Index: Concepts and Methods}

This section will review and investigate if the sinuosity index can be used to identify tectonic perturbation to the stream channels within the study area. This index has been developed from fundamental studies that investigate the geomorphic patterns that have been shown to be inherent in alluvial channels. This index will be shown as a useful reconnaissance tool, identifying areas where high sinuosity values cannot be explained by either a change in lithology or increase in stream sedimentation. This provides areas where more focused techniques for fault identification can be applied. The analysis of this index is shown to be difficult due to the many processes that can influence the sinuosity of an alluvial river.

\subsubsection{Background}

Alluvial streams have been shown to maintain a quasi-equilibrium elevation profile of a semilogarithmic shape (Hack, 1960). Tectonic activity can directly or indirectly alter the equilibrium profile and the three dimensional length of the stream. As discussed earlier, one method for a stream to adjust back to an equilibrium profile is to erode the bed of the stream. Conversely, another way a stream can maintain an equilibrium profile, is to erode the banks of the channel, lengthening the stream. This erosion of the river bank increases sediment supply and reduces channel slope leading to an increase in sinuosity as the stream adjust to the increased length. Where a stream is able to erode its banks and a vertical fault rupture crosses a high angle, increased sinuosity is often observed (Schumm et al., 2000). This increase in sinuosity is caused by an increased in stream length and a decrease in stream power and is therefore the increased sinuosity is observed on the downthrown side of the fault (Ouchi, 1985; Keller and Pinter, 1996; Holbrook and Schumm, 1999) (see Figure 4-4).

Flume experiments confirm a similar response of alluvial rivers to anticlinal and synclinal folding. Ouchi (1985) conducted a series of flume experiments to investigate the response of alluvial rivers to slow tectonic moment. His methods involved observations of the fume channel form of three 
modelled sediment regimes (used to represent sediments similar to braided and meandering stream channels) to uplift and subsidence, simulated by changing the channel base level over time. Sinuosity was shown to occur downstream of the area uplifted or in the area of subsidence (Ouchi, 1985).

\subsubsection{Defining the Sinuosity Index}

Sinuosity has been defined by Schumm et al. (2000) as the ratio between the length of the channel $\left(L_{c}\right)$ and valley length $\left(L_{v}\right)$, and is also the ratio between valley slope $\left(S_{v}\right)$, and the gradient of the channel $\left(\mathrm{S}_{\mathrm{c}}\right)$ as follows:

$$
p=\frac{L c}{L v}=\frac{S v}{S c}
$$

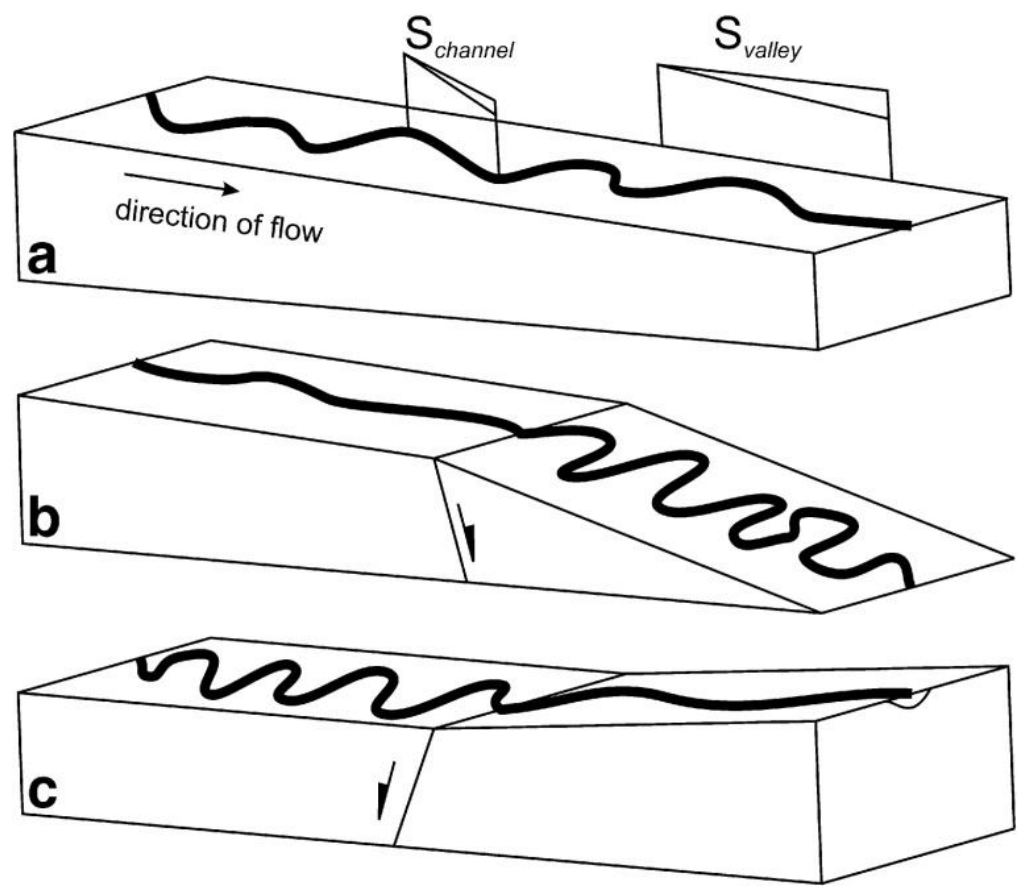

Figure 4-4. Block diagram showing the interactions between faulting and the sinuosity of an alluvial stream. Sinuosity increases on the downthrown side of the fault. (figure from (Schumm et al., 2000)) a. Shows a meandering alluvial stream without tectonic influences. $b$. A normal fault downthrown downstream will produce increase sinuosity downstream of where it crosses the fault c. a normal fault with the downthrown side upstream will produce increased sinuosity on the upstream side of the fault.

In the case of a stream with a $P=1$ the channel length and valley length are equal, and also valley slope and channel gradient are equal. Schumm's definition of sinuosity identifies that a valley is also sinuous, but at a much larger wave length than the stream. Furthermore, he acknowledges that the three dimensional length of the stream is important to consider when calculating sinuosity. 
For this study, an approach similar to a classic sinuosity index used by Leopold et al. (1964) was used to allow for sinuosity to be calculated automatically and efficiently within a GIS. This approach uses the ratio between the stream channel reach length and straight line between the start and end point of the reach. This method assumes that the valley length is relative to the straight line distance between two points along a stream. This assumption will not overly change the relative sinuosity values so long as the sample length is short enough to encompass the larger valley changes in direction. This is explained graphically in Figure 4-5.

The sinuosity of a stream reach for this study is therefore defined as the ratio between the length of a sampled stream reach $C_{1}$ and the straight line distance between the start and the end point of the sampled reach $\mathrm{C}_{2}$ as follows:

$$
S I=\frac{C_{1}}{C_{2}}
$$

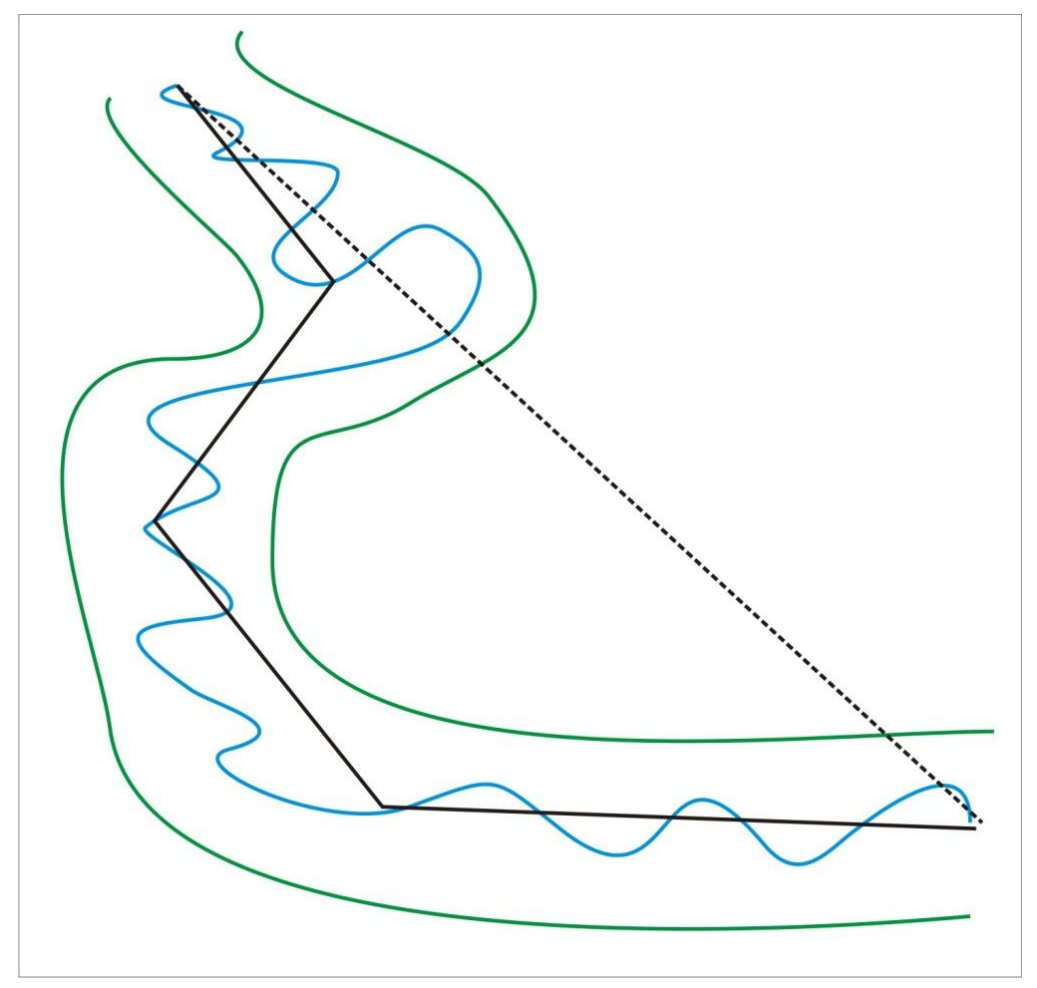

Figure 4-5. The sampling method used to calculate sinuosity in this study. The black line represents the sampling distance used in this study. The dashed black line represents how the length of the valley can be under represented if the sampling distance is too large. 


\subsubsection{Methods: Sinuosity}

A Visual Basic script (see Appendix A) was written to automatically measure sinuosity values at a user specified reach length. The script uses a line shapefile as input and first divides the line into segments based on the user specified reach length. The reach length is then divided by the straight line distance between the start and end points of the reach. The value is then assigned to a point exactly halfway along the reach length (see Figure 4-6).

\subsubsection{Sampling Distances}

A meandering stream follows a wave like pattern. An increase in wavelength is represented by the distance between meander bends. As discussed earlier there are many factors that can cause a stream to increase or decrease in sinuosity. The change from a straight to sinuous stream channel can occur abruptly or over distances of many kilometres. To ensure this transition and the complexity of a possible subtle change (e.g. from sinuous to straight to sinuous) is captured, it was deemed necessary to apply and test a range of sampling distances to the data.

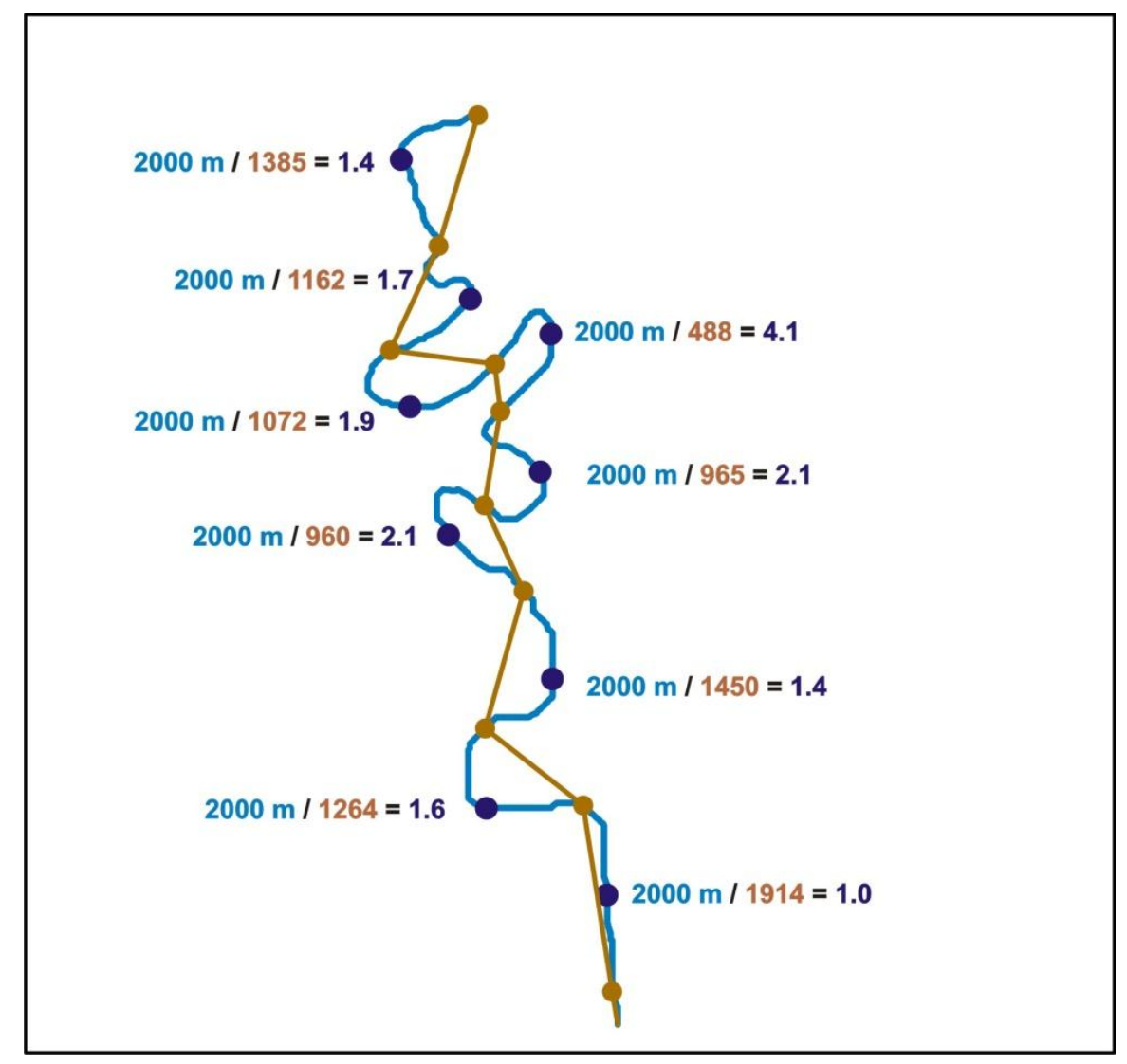

Figure 4-6. Sinuosity calculations are made by dividing the stream into reaches at a user defined distance, this distance is then divided by the straight line distance between the start and end point of the reach. The calculated index value is then assigned to a point halfway along the reach. 
The rational for this involved considering the likely outcome from the two ends of the scale of possible sampling distances. These two scenarios are as follows:

1. If the sampling distance was smaller than the distance between meander bends, the resulting sinuosity values would be close to 1 and therefore no meaningful data would be extracted.

2. If the sampling distance far exceeded the average distance between meander bends then the value assigned to the point on the stream may not represent the complexity need to locate the point at which the stream became sinuous. Furthermore, the sampling distance must also relatively represent changes in valley direction.

To provide an idea of the possible sample length range, the length between meander bends was assessed using the measure tool in ESRI ArcGIS. This showed that the dataset contained meander distances from $100 \mathrm{~m}$ in very small streams to greater than $1 \mathrm{~km}$ on the Whanganui River. To identify the optimal sampling distances to capture the variability of sinuosity, the sinuosity index was calculated at a range of sample distances between $100 \mathrm{~m}$ and $10000 \mathrm{~m}$. The mean sinuosity values were then calculated for each sampling distance and plotted against sample distance. Figure 4-7 shows, as sample distance increases, the average sinuosity index value increases steeply until flattening out around $7500 \mathrm{~m}$. This shape visually displays the two scenarios described above. Scenario 1 represented by the initial steep increase in the graph and scenario 2 represented by the flattening off at around $7500 \mathrm{~m}$. The section between these two zones provides the optimal sample spacing that is likely to capture all variability in sinuosity within the system. From this analysis, it was decided to use 6 sample distances of $250 \mathrm{~m}, 500 \mathrm{~m}, 750 \mathrm{~m}, 1000 \mathrm{~m}, 1500 \mathrm{~m}$ and $2000 \mathrm{~m}$ for sinuosity index calculations. 


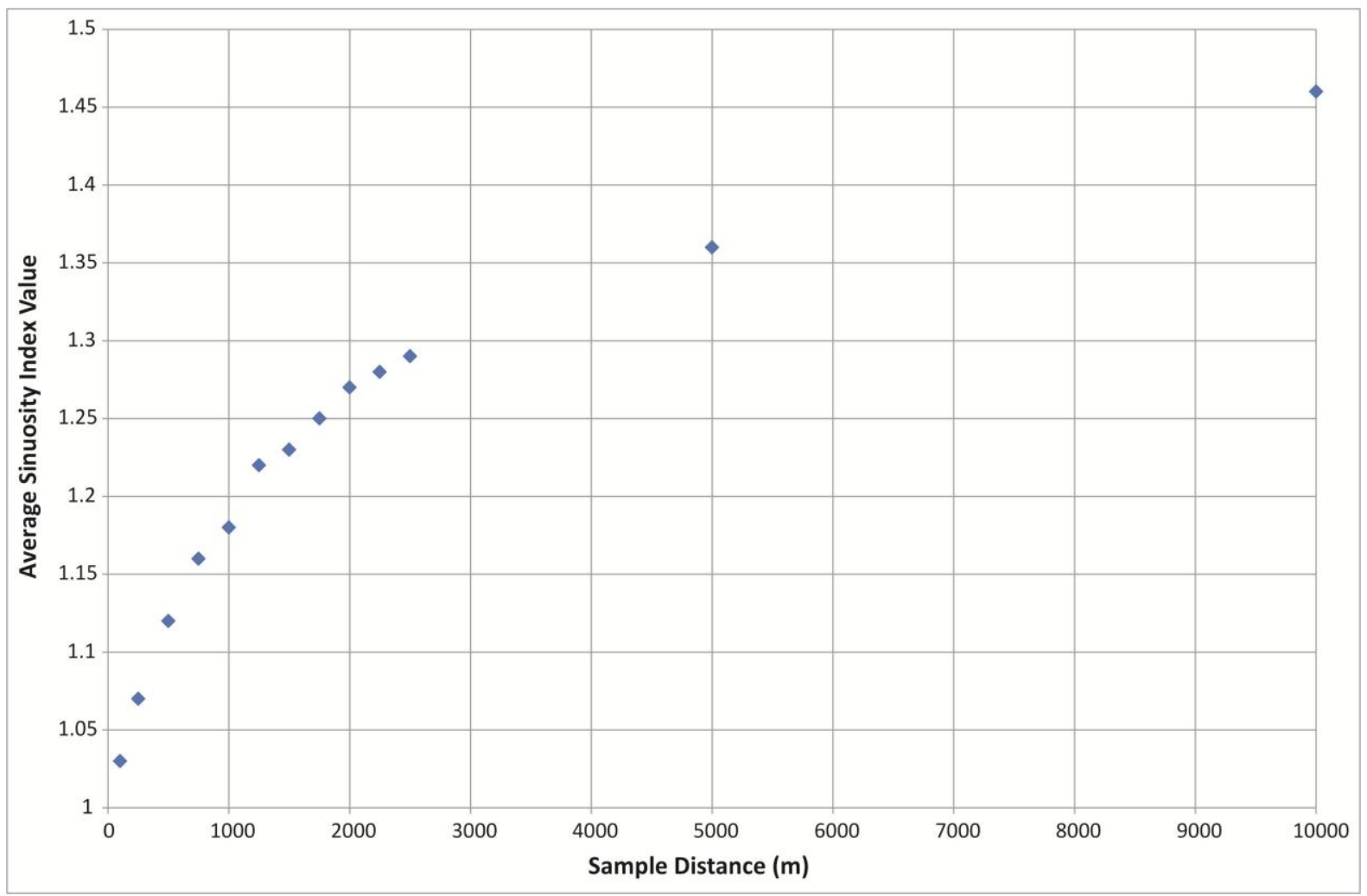

Figure 4-7. The average SI vales for a range of sampling distances provides an idea of the optimal sampling distances to use to ensure the variation of sinuosity is captured.

Sinuosity values were calculated at $250 \mathrm{~m}, 500 \mathrm{~m}, 750 \mathrm{~m}, 1000 \mathrm{~m}, 1500 \mathrm{~m}$ and $2000 \mathrm{~m}$. The resulting text files (containing the $X$ and $Y$ coordinated and the sinuosity values for a point along a stream channel) were converted into ESRI point shapefiles.

\subsubsection{Interpolation: Sinuosity}

The point files were then interpolated for the entire study area using IDW, with a minimum of 24 points and a search radius of $5000 \mathrm{~m}$. Values were classified into four categories using Jenks natural breaks. The top two categories represent areas of medium and high sinuosity. These data were then compared to mapped active faults, inactive faults, lineaments and geological polygons. 


\subsection{Asymmetry Factor: Concepts and Methods}

The primary effects of tectonics on the drainage network are local steepening or reduction of gradient or lateral tilting. The lateral (cross-basin) tilting of a stream network can be measured and when combined with a good understanding of geological and geomorphic processes can provide useful insight into the occurrence of tectonic processes (Schumm et al., 2000). A drainage network of a catchment that flows over homogenous strata that is not affected by tectonics will develop a symmetric dendritic pattern (Schumm et al., 2000). An asymmetric drainage pattern can be an indication of recent tectonic activity tilting the drainage network, past tilting of sedimentary rocks, an underlying change in lithology with differing bedding angle, drainage influenced by aeolian processes, or variable erosion due to aspect (Keller and Pinter, 1996; Schumm et al., 2000; Burbank and Anderson, 2001). All of these processes were considered when interpreting the asymmetry values in the study area. Figure 4-8 shows the effects of faulting causing lateral tilting on a drainage network.

Tectonic tilting, at a regional block and basin scale can cause high order catchments to become asymmetric. At a local scale, faulting and folding, causing localised uplift can tilt low order catchments, with the amount of tilt relative to the size and frequency of rupture along the local structure.

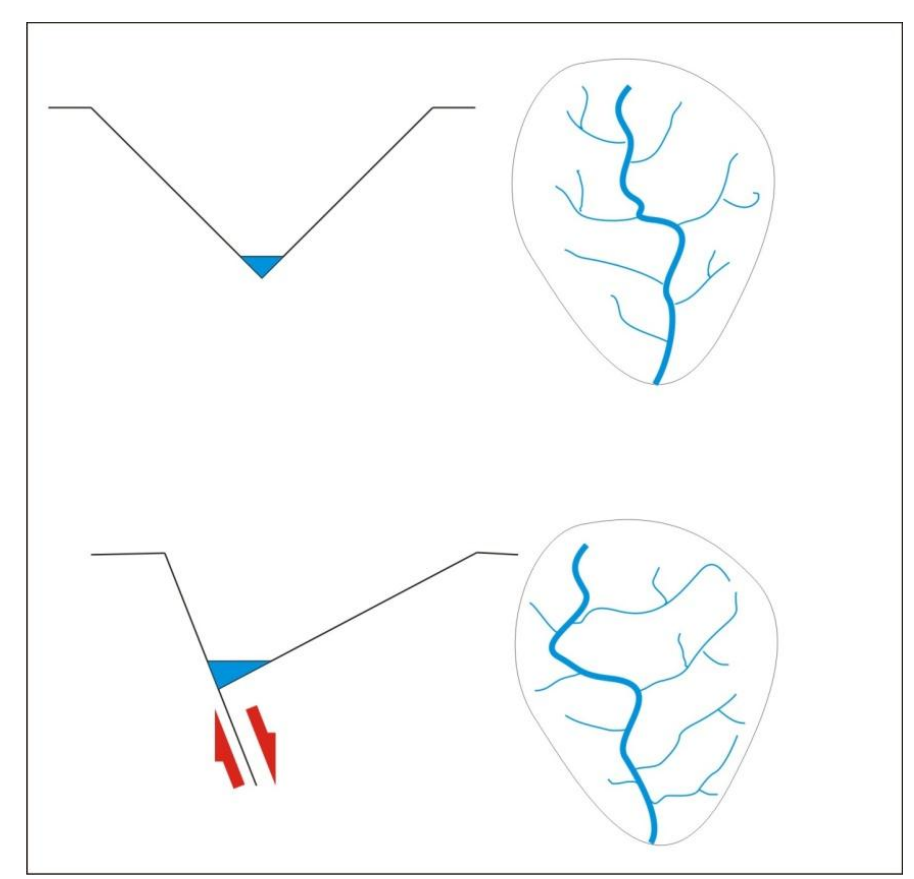

Figure 4-8. Cross section and plan view of an idealised catchment and drainage network. The drainage network will adjust to tilting through migration of the main trunk stream in the direction of tilt. 
To the south of the study area there is evidence of asymmetric drainage caused by four NE-SW trending active folds. The Mount Stewart - Halcombe, Pohangina, Fielding, and Marton anticlines influence the catchments of this region producing a series of asymmetrical drainage basins characterised by parallel drainage flowing to the NW to join a main trunk steam that is confined to the NW side of the catchment (Jackson et al., 1998). Using seismic reflection Melhuish et al. (1996) used seismic reflection to described the subsurface of the Mount Stewart-Halcombe anticline as 2 large, west dipping reverse faults, capable of producing an earthquake of M 6.5 - 7.

Jackson et al. (1998) investigated the drainage in more detail, differentiating between the impacts of localised and regional tilt on drainage networks. They studied the Mount Stewart-Halcomb anticline and also included analyses of the Pohangina, Feilding, and Marton anticlines. They noted that all four catchments are uplifted on the SE and have elongated, parallel, lower order, streams flowing on the interfluve surface to the NW. The structural contours of each anticline were used to provide data for the amount of vertical uplift and angle of tilt due to influences of local tectonic structure. These contour data were then compared to the horizontal offset amount of consequent streams to calculate a regional southward tilt of around $4 \times 10^{-8} \mathrm{rad} / \mathrm{yr}$ over the last c. 300,000 $\mathrm{yr}$. They attributed this tilt to migration of the Pilo-Pleistocene depocentre in the offshore Wanganui Basin.

The mapped active faults and folds in the south of the study area, strike in the same direction as the anticlines in the Manawatu region. Therefore, there is a possibility that this similar tectonic structure could be causing asymmetry of the catchments within the study area. The following methods were used to test asymmetry within the Taranaki region.

\subsubsection{Defining Basin Asymmetry Parallel to the Trunk Stream}

Where tilting of a catchment is mostly parallel to the main trunk stream, migration of the stream in the direction of the tilting is observed. To quantify and compare the amount of tilting between catchments, the area either side of the trunk stream can be calculated and related to the overall area of the catchment. This quantified percentage of basin area is referred to as the Asymmetry Factor (AF) and is defined as:

$$
A F=\frac{A R}{A T} \times 100
$$


where AR is the area of the basin to the right (facing downstream) of the trunk stream, and AT is the total area of the drainage basin.

\subsubsection{Asymmetry Methods}

Asymmetry was calculated for each $3^{\text {rd }}$ and $4^{\text {th }}$ order catchment within the study area (see 3.2.2 for details on catchment extraction from DEMs). The main trunk stream for each catchment was extracted from the stream networks that were calculated for the SLk index (see 4.2.6 for methods used to identify the main trunk stream). The head of each trunk stream was extended to the catchment boundary so that an area could be calculated either side of the stream. This was achieved by manually extending the headwater node of each stream following the angle from the last section of the stream. The catchment polygons were then split based on this trunk stream. Area was then calculated for each of these polygons and a percentage of total catchment area also calculated. These values were added as an attribute to each polygon. Figure 4-9 shows the classification and colour coding of the asymmetry of catchments. The catchments were classified into four categories, based on percentage of area either side of the main trunk stream, and applied the following colour coding; Green $=$ Symmetric, Blue $=$ Low Asymmetry, Yellow $=$ High Asymmetry, Orange $=$ Extreme Asymmetry. The darker hues of each colour represent the side of the main trunk stream with higher percentage of area and provide a visual method for identifying the direction of asymmetry. The result were displayed in a GIS and then analysed with mapped faults, folds, lineaments and geological polygons to test for tectonic influences on drainage symmetry (see Section 6.4 for results).

\section{Symmetric $\longrightarrow$ Asymmetric}
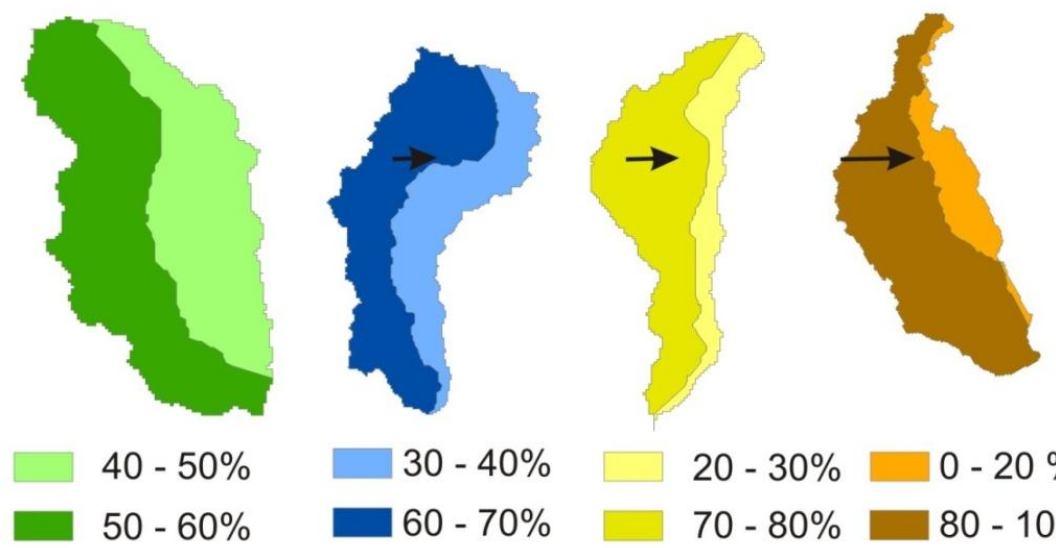

$$
\begin{aligned}
& 20-30 \% \\
& 70-80 \%
\end{aligned}
$$
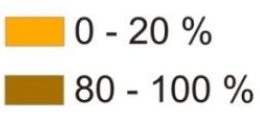

Tilt Direction

Figure 4-9. The asymmetry classifications and colour coding for catchments used in this study. The darker hues provide a visual method to identify the direction of asymmetry. 


\section{Chapter 5 Test Catchments}

Results from the hypsometric curve and SLk index can vary greatly depending on local and regional influences, such as changes in geology (i.e. changes in the resistance of rocks and sediments to erosion) and tectonic activity (Keller and Pinter, 1996; Burbank and Anderson, 2001). Furthermore, the base data (DEMs) used to calculate index values as well as the used sampling distances can cause erroneous results (Walcott and Summerfield, 2008). It is therefore necessary to test the effects of geology, tectonic activity, base data and sampling distance for representative catchments within the study area before proceeding to application of these indices at the study area scale.

The Hypsometric and SLk index are dimensionless values. Therefore this testing will also be used to identify the range of values and their sensitivity to tectonic activity. In this chapter, five chosen test catchments are introduced along with a detailed description of their geology and geomorphology. The results from the application of the hypsometric curve and SLk index to the test catchments are presented and discussed.

\subsection{Test catchments: Geology, Active Tectonic Structures and Stream Profile}

The test catchments were chosen to represent the varied geology within the study area and both the presence and absence of active faulting. Fourth order catchments were used as they cover an area large enough to capture processes occurring at a catchment and stream scale, allowing for a meaningful comparison between results from the two indices. To ensure that the selected catchments could test the effects of geology and faulting, a map of geological units from the QMap maps series (1:250 000 scale) and mapped active faults from the Active Fault Database (AFDB) was visually assessed and overlain with the boundaries of fourth order catchments.

Together with the description of the geology and tectonic structures of each catchment the stream profile (shape of the elevation profile of the stream) is also described. Snow and Slingerland (1987) fitted exponential, logarithmic and power functions to modelled stream profiles. Their research suggests the shape of an elevation profile is not easily described by only one mathematical form and that the mathematical form could be used to describe the processes effect the channel. The SLk index is calculated using a log function to represent a river in equilibrium. If a stream profile deviates from this semi logarithmic form then higher SLk values are calculated. Therefore, how well the stream profile fits a semi logarithmic form can be used as a quick visual indication of the equilibrium state of the stream channel. The stream profile of the main trunk stream for each test catchment 
was calculated by extracting elevation values from the ASTER DEM at $750 \mathrm{~m}$ intervals. This profile was then fitted with a semi logarithmic shape. Deviation from a semi logarithmic shape was compared to geological formation boundaries and active faults. Outlined below are the five catchments and a description of the geological units within each catchment (see Figure 5-1 for location of catchments). Unless specified, all geological formations and active faults are taken from Edbrooke (2005), Townsend et al. (2008), and Lee et al. (2011). A description of how the geology influences the stream elevation profile is also included.

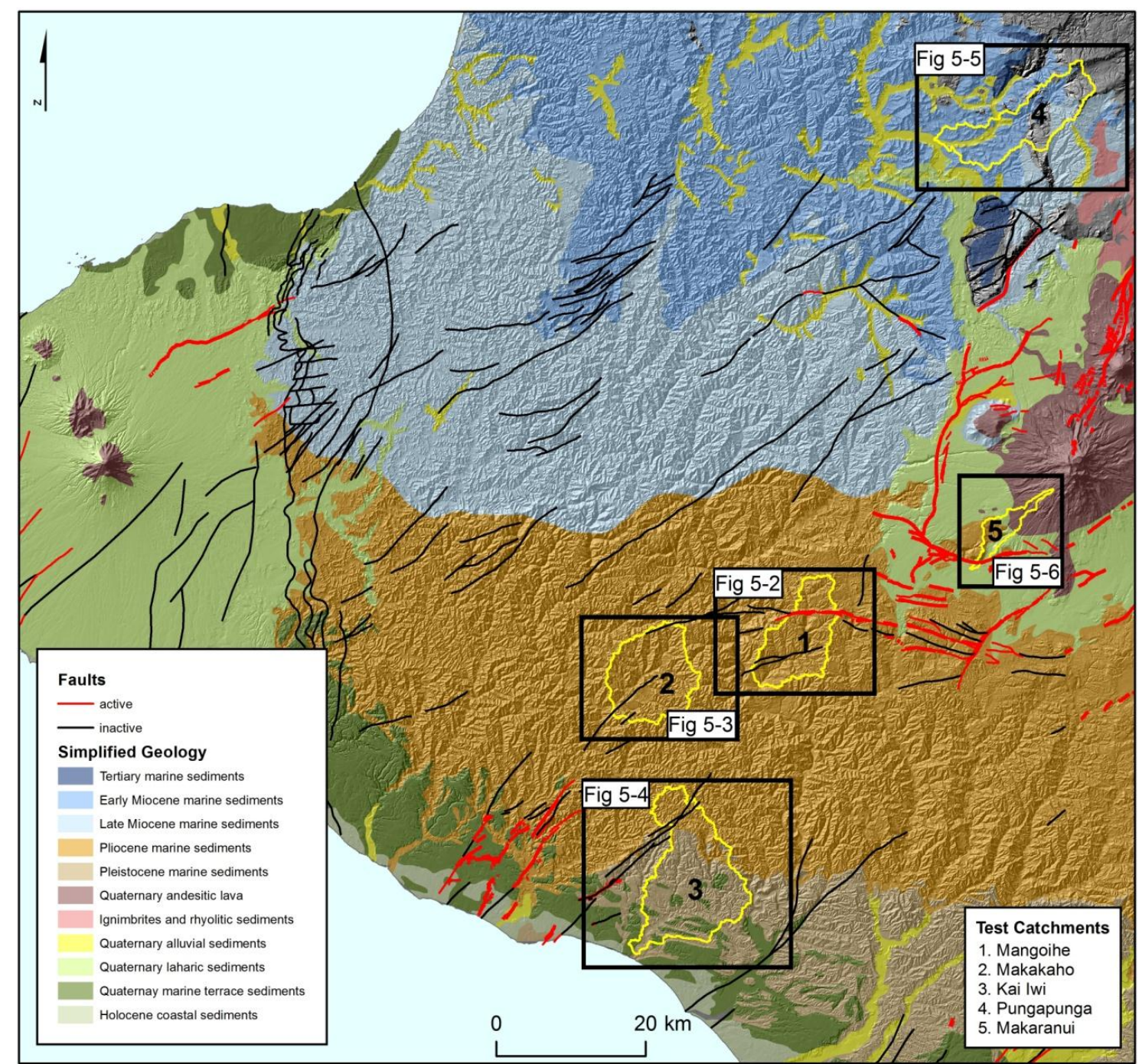

Figure 5-1. The location of the five test catchments representing the range of geology within the study area. Geology is from the 1:1.000,000 scale National Geology map. Red lines are mapped active faults from the GNS active fault database. 1. The Mangoihe catchment covers the transition from volcanic material to Tertiary - Pleistocene sediments. 2. The Makakaho catchment comprises of Tertiary - Pleistocene sediments and represents a catchment with homogenous but highly erodible strata. 3. The Kai Iwi catchment covers the transition between the Pleistocene materials and the marine gravels near the coast. 4. The Pungapunga catchment is the most varied and includes volcanic material, bedrock and miocene- Pleistocene sediments. 5. The Makaranui is entirely comprised of volcanic sediments. Two catchments, Mangoihe and Makaranui, contain a mapped fault trace that crosses perpendicular to the main channel. 


\subsubsection{Mangoihe}

The Mangoihe catchment transitions from Matemateaonga Formation sandstone into the Tangahoe mudstone. The Waipuna fault crosses the stream channel $\sim 6 \mathrm{~km}$ downstream (Location 1, Figure $5-2$ ). This fault is normal and is downthrown to the south. At $\sim 7.5 \mathrm{~km}$ downstream the main valley becomes confined within a transition zone between the Matemateaonga Formation sandstone and the Tangahoe mudstone (Location 2, Figure 5-2). The stream is constricted for a further $7 \mathrm{~km}$ before the Tangahoe mudstones become apparent (Location 3, Figure 5-2). There are a number of large landslides that encroach on the main trunk stream in the lower reaches. The profile of the Mangoihe stream clearly shows the change from harder to softer lithologies. The stream profile is convex in shape and therefore has the worst fit with the logarithmic shape $\left(R^{2}=0.72\right)$. There are large steps in the profile that appear to coincide with lithological boundaries. A change in slope occurs at $\sim 6 \mathrm{~km}$ downstream where the Waipuna fault crosses the channel. Another change of slope is evident at $\sim 15 \mathrm{~km}$. 

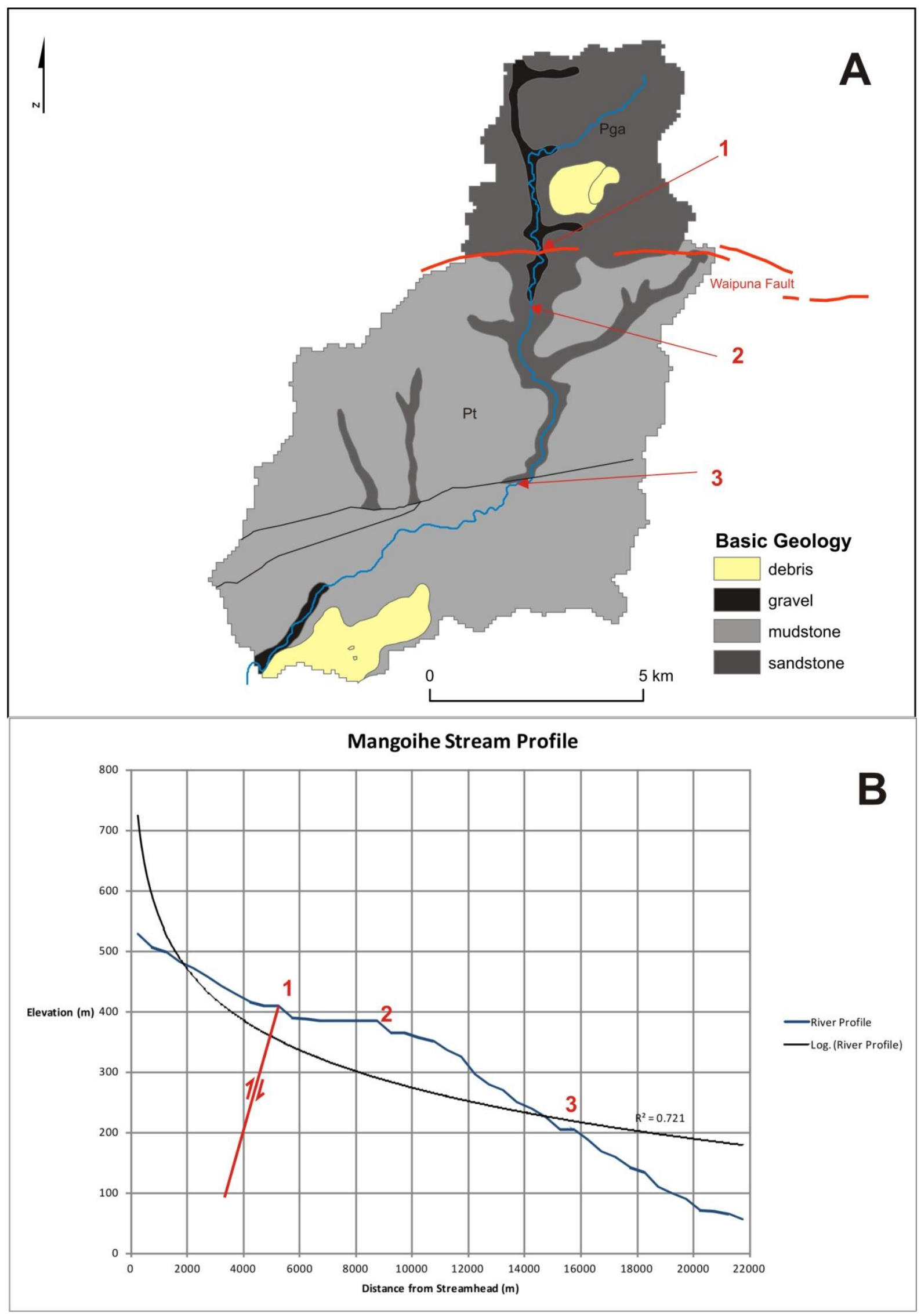

Figure 5-2 A) Geology of the Mangoihe catchment. The transition from Matemateaonga sandstone in the north to the highly erodible Tangahoe mudstone bounded by the Waipuna fault. Pga - Matemateaonga sandstone. Pt - Tangahoe mudstone. B) The stream profile of Mangaihe stream fitted with a logarithmic curve. 


\subsubsection{Makakaho}

The Makakaho catchment is representative of the inland central section of the study area. The catchment is $120 \mathrm{~km}^{2}$ and consists of mostly Pliocene Tangahoe mudstone in the north and Whenuakura Group sandstone to the south. The Tangahoe mudstones are very susceptible to erosion and the catchment has many large landslides that encroach on the main drainage network that do not appear to affect the stream profile. The stream profile (Figure 5-3) is the closest of the five test catchments to a logarithmic shape $\left(R^{2}=0.97\right)$. The Makakaho catchment is the most homogeneous catchment with regard to geology and this is apparent in the shape of the main trunk stream elevation profile. The mudstone that makes up the majority of this catchment is very soft and therefore is likely to erode quickly to this shape from any change to the stream channel. There is a break in slope $\sim 6 \mathrm{~km}$ (Location 1, Figure 5-3) downstream that coincides with the merging of a main tributary of the catchment. 


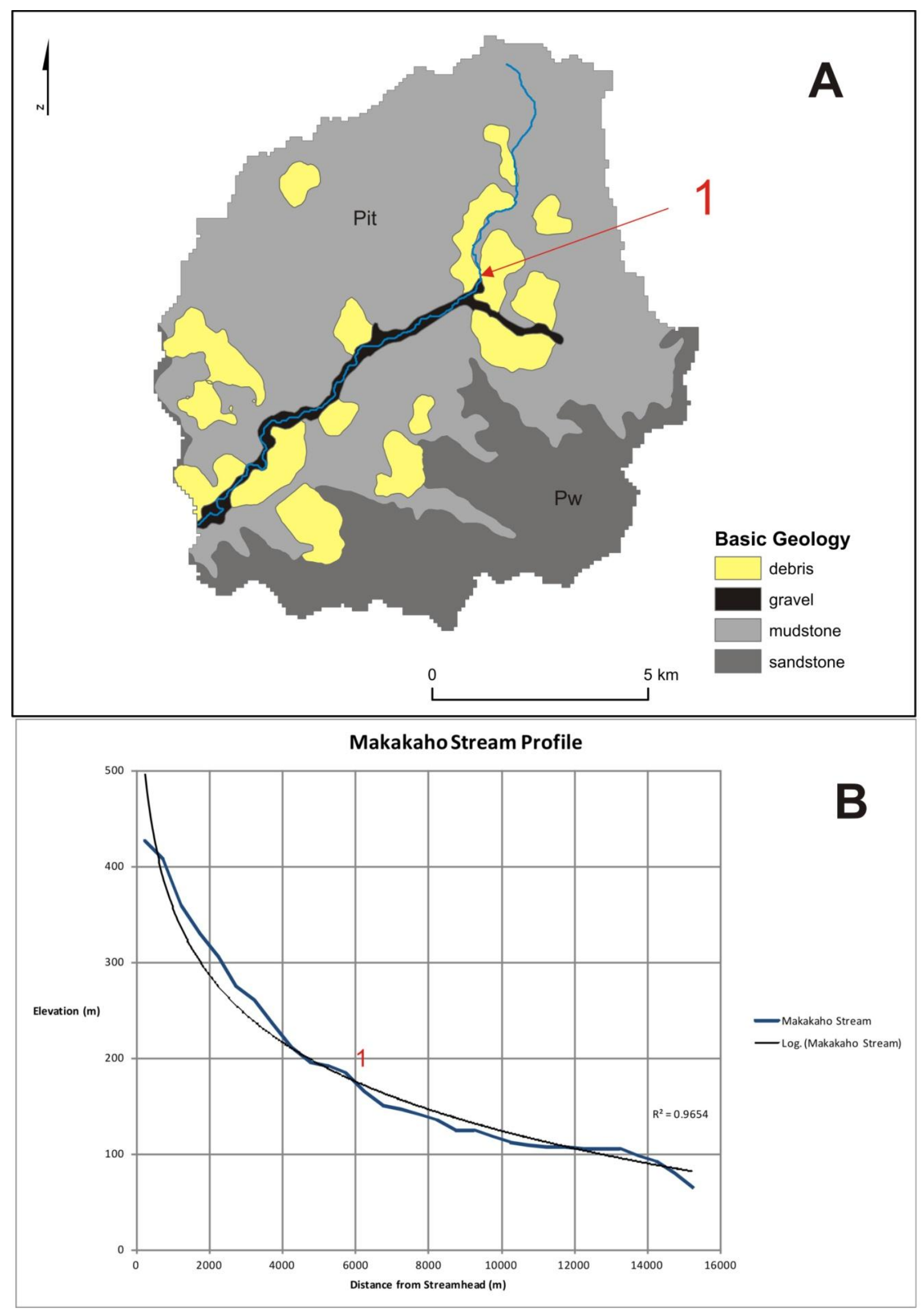

Figure 5-3 A) Geology of the Makakaho catchment showing the Makakaho stream flowing through mostly homogenous Tangahoe mudstone. Pit - Tangahoe mudstone, Pw - Whenakura Group sandstone. This catchment contains a number of large landslides shown in yellow. B) Makakaho stream profile from the ASTER DEM with elevations extracted every $750 m$. 


\subsubsection{Kai Iwi}

The Kai Iwi catchment is $190 \mathrm{~km}^{2}$ and represents Pleistocene sediments that have been covered by marine gravel platforms that extend along the southern coast of the study area. The headwaters of the Kai Iwi stream are Pliocene Paparangi Group sandstone consisting of thin pebbly shell beds and massive, well sorted sandstone. At $13 \mathrm{~km}$ downstream (Location 1, Figure 5-4) a transition occurs to the Pliocene Upper Okiwa Group mudstones which also contain some bioclastic limestone, sandstone, and massive siltstone. At $\sim 15 \mathrm{~km}$ the first of a series of seven mapped remnant marine platforms, consisting of shell beds, sand and marine gravels, are preserved in the surrounding hills. At $\sim 23 \mathrm{~km}$ (Location 2, Figure 5-4) the stream crosses into Pliocene Nukumaru limestone that consists of coquina limestone and sandstone ranging from pebbly to well sorted. At $\sim 34 \mathrm{~km}$ (Location 3, Figure 5-4) the stream enters Holocene alluvial river gravels surrounded by Pliocene Maxwell Group mudstone. The stream reaches the coast passing through a thin band of sand dunes that overlie Q2 Ohakean alluvial terrace deposits.

The locations of changes in lithology coincide with obvious steps in the Kai Iwi stream profile (Location 1, 2, and 3, Figure 5-4B). The transition from Paparangi Group sandstone to Upper Okiwa Group mudstones is clearly distinguishable in the profile. The locations of breaks in slope that are associated with individual marine terrace can be visually identified from the stream. These breaks in slope are the main contributing factor to the stream profile having a poor fit with a logarithmic shape $\left(R^{2}=0.82\right)$. 

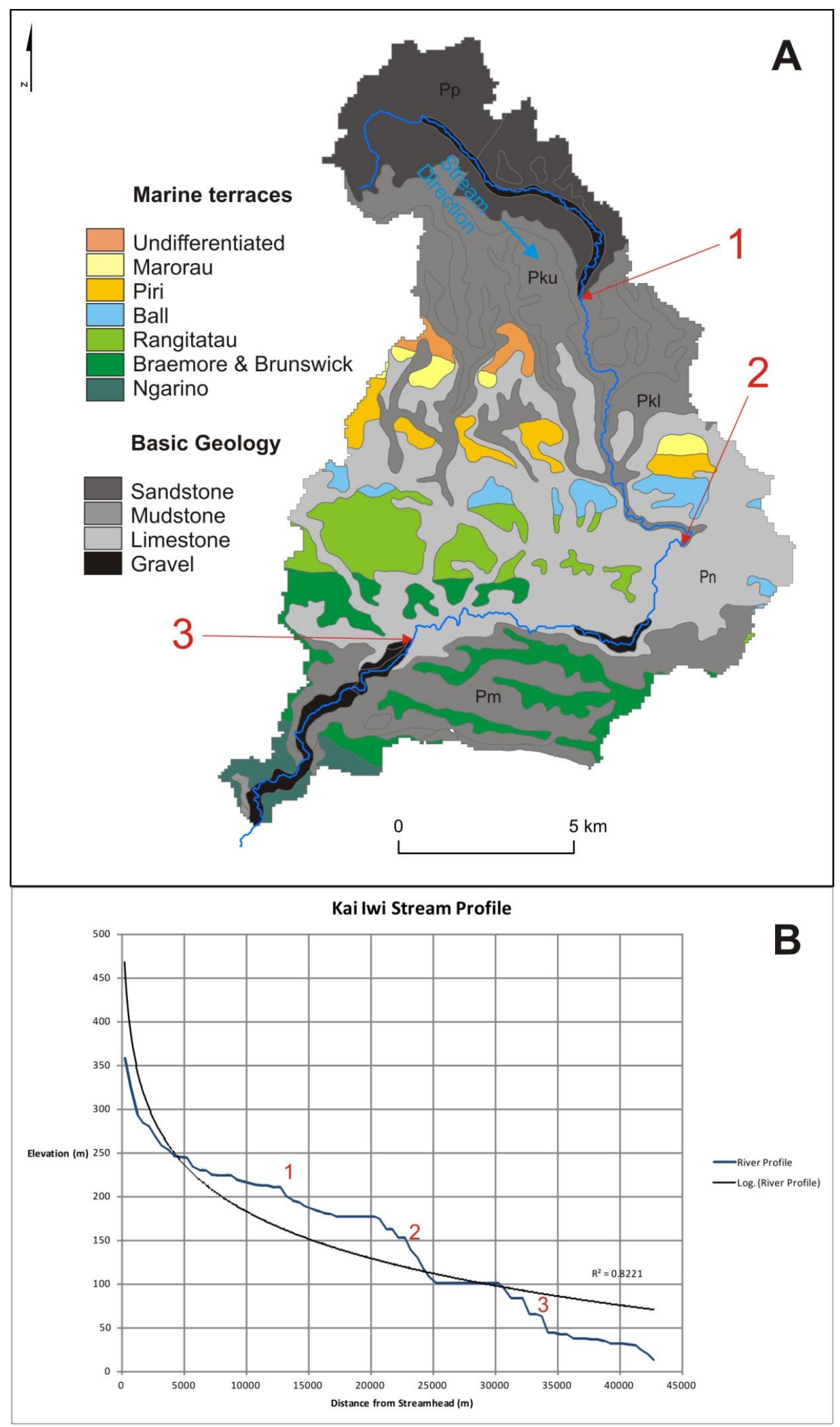

Figure 5-4. A) Kai Iwi geology showing the 7 mapped remnant marine terraces that overlie Tertiary sandstone, mudstone and limestone. Pp-Paparangi Group sandstone, Pku - Upper Okiwa Group mudstone, Pkl - Lower Okiwa Group mudstone, Pn - Nakumaru limestone, Pm - Maxwell Group Mudstone. B) The Kai Iwi stream profile from the ASTER DEM sampled at $750 \mathrm{~m}$. The location of changes in lithology are expressed as steps in the stream profile. 


\subsubsection{Pungapunga}

The Pungapunga catchment is located in the north-eastern section of the study area. This catchment has the most varied and complex geology of the five test catchments, transitioning from recent volcanic material, over a greywacke basement to younger sandstone overlain with laharic sequences. The headwaters are Pliocene Hauhungaroa Formation laharic conglomerate consisting of andesitic boulders and gravel with volcanic ash. At $\sim 4.7 \mathrm{~km}$ from the headwaters the stream crosses into the mid to late Miocene sandstone of the Otunui and Mangarara Formations. At $\sim 5.7 \mathrm{~km}$ the sandstone is covered by a $\sim 3 \mathrm{~km}$ section of Taupo Ignimbrite before flowing onto basement greywacke at $\sim 9 \mathrm{~km}$ downstream (Location 1, Figure 5-5). At $\sim 11 \mathrm{~km}$ downstream there is $2 \mathrm{~km}$ section that changes from Taupo Ignimbrite to greywacke and then onto a thin band of siltstone which is evident for $\sim 500 \mathrm{~m}$. At $\sim 14 \mathrm{~km}$ downstream the channel is bedded with Taupo Ignimbrite that overlies early Miocene mudstone of the Mahoenui Group (Location 2, Figure 5-5). At $18 \mathrm{~km}$ downstream (Location 3, Figure 5-5) the channel is then bedded with Holocene alluvium to the catchment outlet with Taupo and Oruanui Ignimbrite overlying Mahoenui mudstones in the surrounding source areas. There are small patches of Whakamaru (Q9) Ignimbrite also preserved in the hills surrounding the main channel. The stream profile (Figure 5-5) fits well with a logarithmic shape $\left(R^{2}=0.95\right)$ with the main deviation in the form of large step at $\sim 13 \mathrm{~km}$ downstream. This step coincides with a change in lithology from greywacke basement to younger and softer sandstones. 

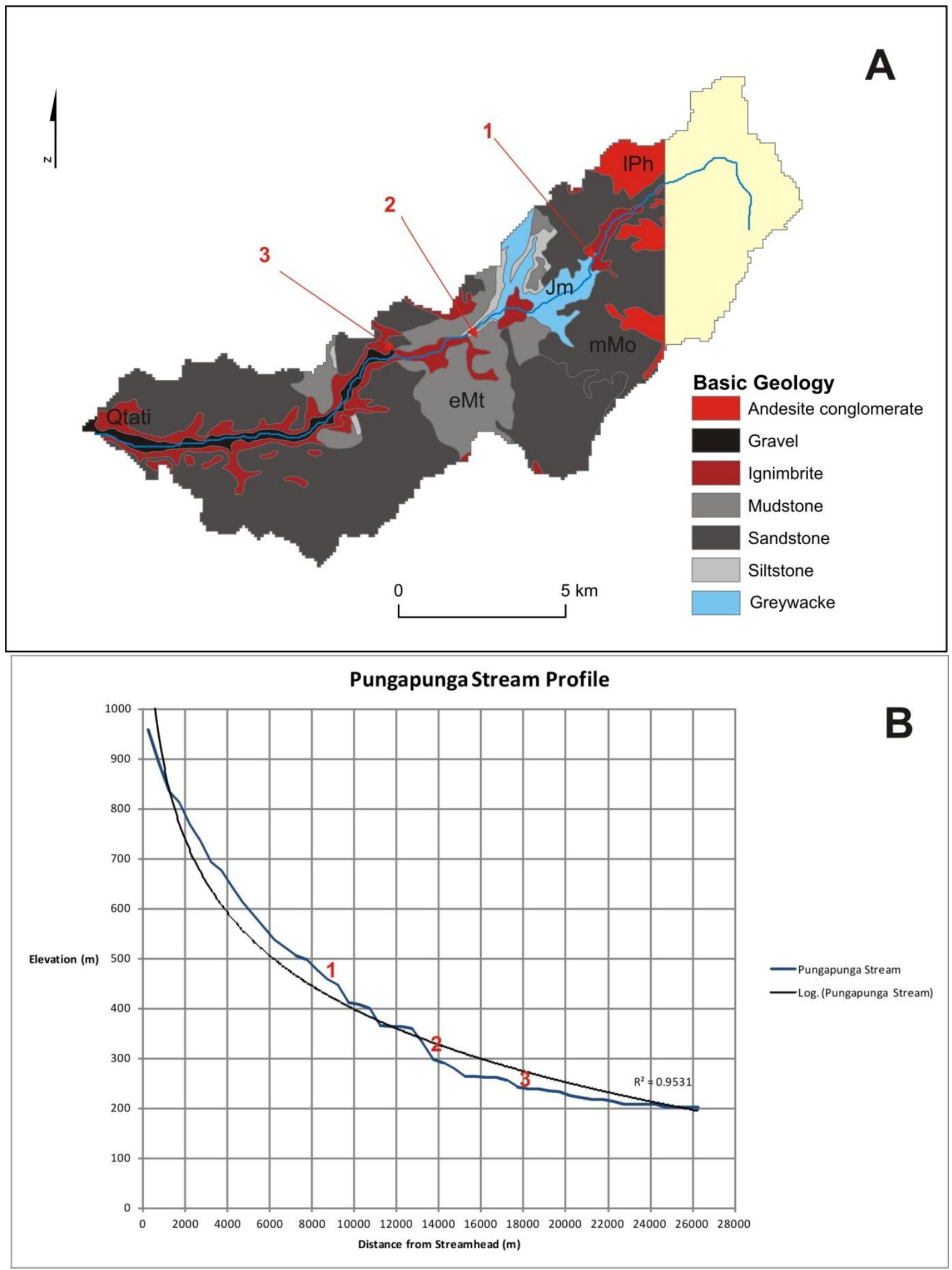

Figure 5-5. A) The geology of the Pungapunga catchment contains a varied mix of litholgies from recent volcanic deposits to Miocene and Pliocene sandstones and basement Greywacke. Detailed geological boundaries at the eastern end of the catchment from Lee et al (2011) were not available. IPh - Lahar deposits, mMo - Whangamomona sandstone, Jm-Manaia Hill sandstone, eMt- Mahoenui mudstone, Q1ati-Primary and reworked Taupo ignimbrite. B) The Pungapunga stream profile from the ASTER DEM sampled at $750 \mathrm{~m}$. The location of changes in lithology are expressed as steps in the stream profile. 


\subsubsection{Makaranui}

The Makaranui catchment, is with $25 \mathrm{~km}^{2}$, the smallest of the test catchments. It is located on the western flank of Ruapehu Volcano and represents recent volcanic geology. The headwaters are confined by andesitic lava until $~ 3.5 \mathrm{~km}$ downstream. The stream then crosses into a series of late Quaternary Lahar deposits consisting of massive to well bedded andesitic gravel and sand. This zone is also overlaid with fan deposits consisting of similar material. At $~ 7.7 \mathrm{~km}$ downstream (Location 1, Figure 5-6) the channel bed changes to undifferentiated fan gravel. At $\sim 10 \mathrm{~km}$ downstream the channel still flows over undifferentiated gravel but the surrounding source area changes to Whangamomona Group sandstones. At $14.7 \mathrm{~km}$ downstream (Location 2, Figure 5-6) the channel is crossed by the Ohakune fault. The Ohakune fault is normal and is downthrown to the south. Overall the Makaranui stream profile fits well with a logarithmic shape $\left(R^{2}=0.92\right)$. There is a large step in the stream profile at $\sim 7 \mathrm{~km}$ downstream (Location 1, Figure 5-6). This coincides with a change from harder volcanic materials to alluvial gravels. The Ohakune fault is also evident as a step in the stream profile near the catchment outlet. 

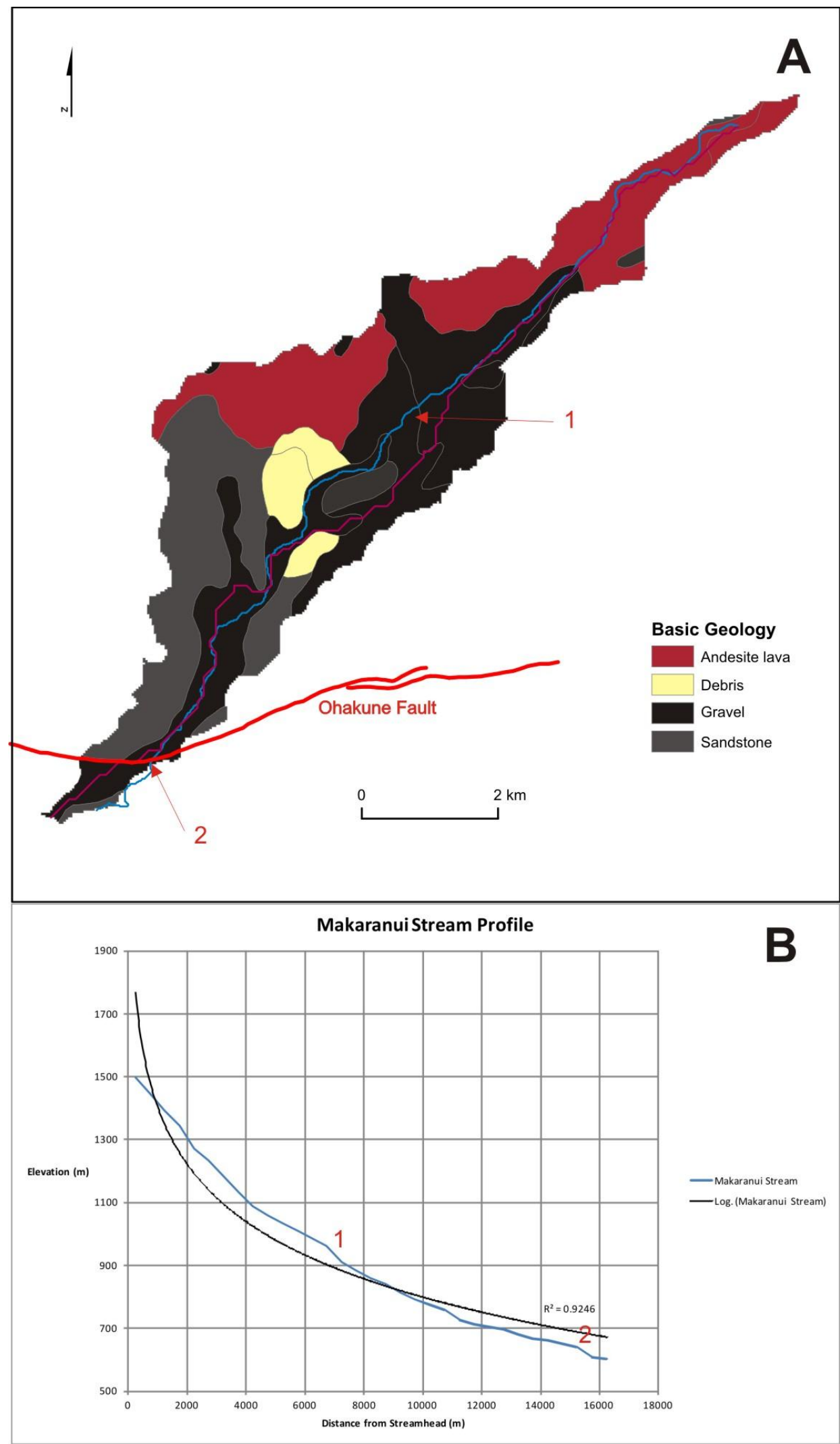

Figure 5-6. A) The Makaranui catchment represents the recent volcanic material within the study area. The blue line is the main channel delineated by the ASTER, LC and Otago DEMs. The pink line is the main channel delineated by the SRTM DEM. The differences in delineation of the STRM channel are likely to be caused by the horizontal resolution of the SRTM base data. B) The Makaranui stream profile fitted with a logarithmic shape, profile was extracted from the ASTER DEM at $750 \mathrm{~m}$ point spacing. 


\subsection{Test Catchments: Hypsometry}

\subsubsection{Methods}

The hypsometric curve for each of the test catchment was calculated using the methods outlined in 4.1.4. This process was completed for each of the four DEMs. For each catchment the results from the four DEMs were plotted on the same graph. The statistical moments for each curve were also calculated and compared between DEMs and then between catchments. The average values of each of the statistical moments were then used to compare differences between curves produced from different DEMs and to test the effects of geology and active faulting on hypsometric curve shape.

\subsubsection{Results}

Figure 5-7 shows that there is visually very little difference between the curves produced from the four DEMs and a significant difference when comparing curves between catchments. The statistical moments of each curve can be used to quantify the variation between catchments and provide an idea about the significance of the variation. To test if there is any significant variation between curves produced from the four DEMs, an average and standard deviation were calculated for each of the statistical moments calculated from each DEM for each catchment. There was no significant variation between DEM's for the same catchment, apart from the density skewness (Den SK) and density kurtosis (Den KUR) values in the Mangoine catchment and the SK and KUR values in the Makaranui catchment (see Figure 5-7). In both these cases the variation is due to anomalous values from the SRTM DEM.

The shape of the hypsometric curve has been used as a method to classify catchments (i.e. convex, S-shaped, concave; cf. Strahler, 1952b). The five test catchments visually display distinct changes of hypsometric curve shape. From most convex to S-shaped to concave the catchment rank as follows: Mangoihe, Makakaho, Kai Iwi, Pungapunga, and Makaranui.

The hypsometric integral ( $\mathrm{HI})$ has been used as a simple method to categorise and quantify the shape of hypsometric curves (i.e. values approaching $0=$ concave, close to $0.5=\mathrm{S}$-shaped, approaching 1 = convex). Values for the $\mathrm{HI}$ and other statistical moments of the hypsometric curve (skewness and kurtosis) and statistical moments of the distribution function of the polynomial fit (density skewness and density kurtosis) are shown in Figure 5-7. 


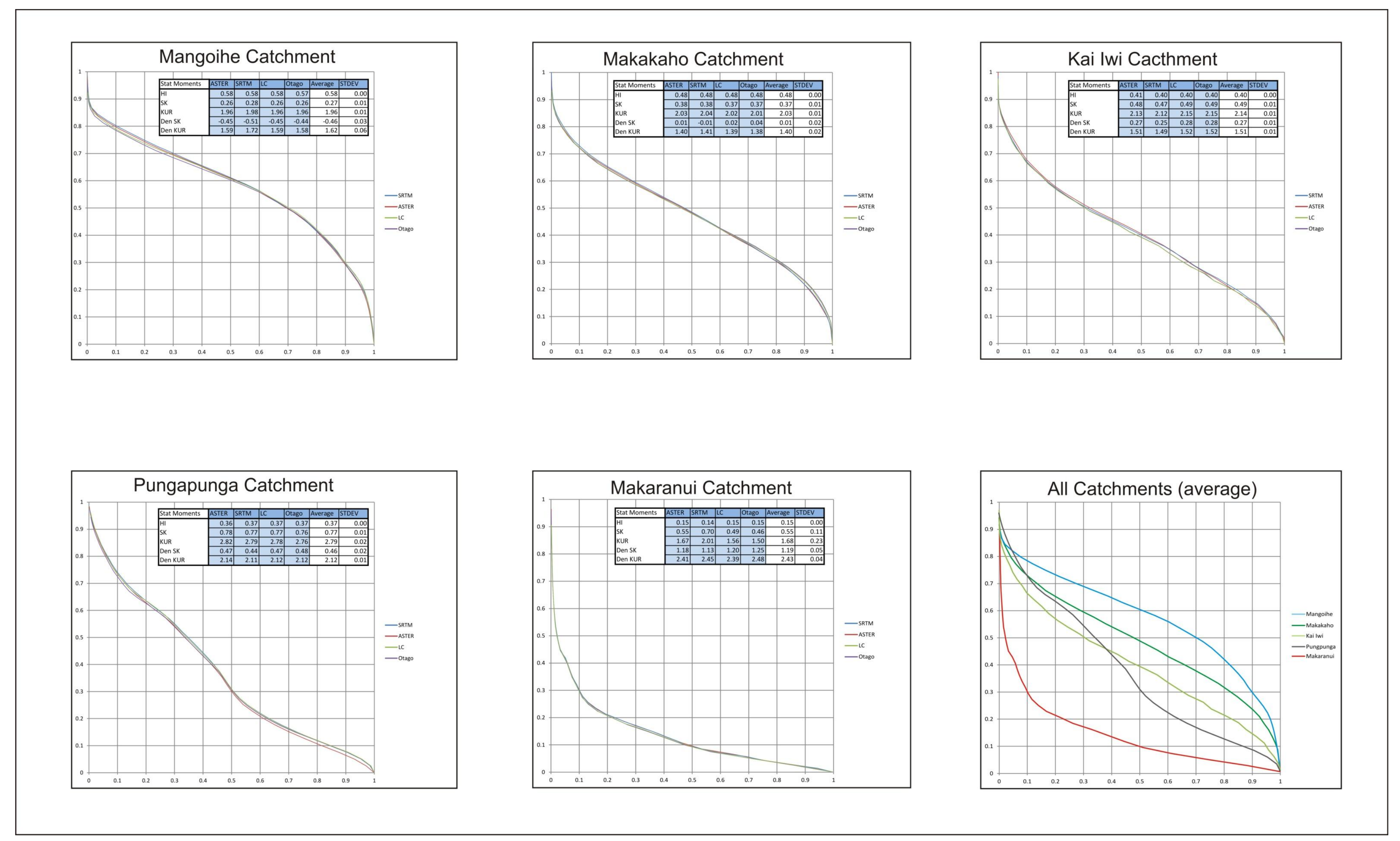

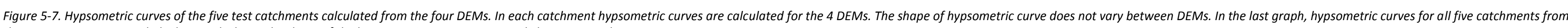
the ASTER DEM are compiled. This graph shows the shape of the hypsometric curve varies greatly between catchments. 


\section{Limitations of the Data}

The analysis of the variation in values derived from the four DEMs shows no significant difference between DEMs apart from some variation in the Makaranui and Mangoihe catchments. In both these cases, the variation is due to anomalous values from the SRTM DEM. The SRTM DEM has the largest grid size of $90 \mathrm{~m}$. When compared to the other DEMs, this dataset is a magnitude of resolution courser with at least nine cells from the other DEMs able to fit inside one cell of the SRTM DEM. The method to collect the SRTM data is also different from the other DEMs, i.e INSAR versus photogrammetry (cf. Section 3.1). The INSAR data collection method can produce voids in mountainous regions due to topography causing a shadowed area. This result, while not significant to the hypsometric analysis, highlights the necessity to be cautious when interpreting data derived from DEMs. The comparison between the four DEMs agrees with Walcott and Summerfield (2008) that DEM resolution does not influence hypsometric shape. However, this study has found some minor variation in mountainous areas mostly from the SRTM dataset. While this was only minor variation, it was prudent to exclude these data from further analysis.

\section{Hypsometric Curve, Statistical Moments and Landscape Processes}

Potential interpretations of the shape of the hypsometric curve as well as of values of its statistical moments in terms of landscapes processes affecting catchments were presented in Chapter 4. Of interest for this study is the assessment of whether faulting can influence these values. For example, a fault crossing a catchment may influence erosion in different parts of the catchment and thus influences any of the statistical moments (e.g. changes in the rate of slope change may be shown by Den SK; or changes in mid basin slope may be detected with DEN KUR). Similarly, large differences between adjacent catchments may be associated with tectonic activity, affecting these catchments in a different way (e.g. one catchment can be uplifted and the other can be subsiding). Some of these hypotheses are discussed below for each catchment.

The $\mathrm{HI}$ of the five test catchments decreases in value in accordance with a change in hypsometric shape from convex to concave, from 0.58 (Mangoihe catchment, most convex) through to 0.15 (Makaranui catchment, most concave). The inverse is true for the DEN SK values. With values increasing from -0.46 (convex) to 1.19 (concave). The other statistical moment do not appear to follow a simple pattern.

The Mangoihe catchment has the highest $\mathrm{HI}$ with 0.58 and is also the most convex in shape. There is only a slight increase of 0.08 away from the suggested equilibrium value of $\mathrm{HI}=0.5$. This slight increase could suggest an issue with using $\mathrm{HI}$ values as a method for classifying hypsometric curves. 
While the area under the hypsometric curve is close to half of the catchment area the amount of convexity in the lower reaches is not reflected in this value. However, the DEN SK of -0.46 could be an indication that this measure may be a better indicator of this convex shape. Without another convex catchment to compare with, it is impossible to say how sensitive this variable is to convexity.

The Mangoihe catchment has a large normal fault that crosses perpendicular to the main stream channel. The Waipuna fault has ruptured in recent history. Based on the fresh scarp displayed across highly erodible materials, the fault could have rupture in the last few thousand years (Villamor and Berryman, 2006). Accumulated fault ruptures could be the cause of the convex hypsometric curve shape, with increased relief north (upstream) of the fault. However, the catchment also has a sudden change in geology from Matemateaonga formation sandstone to Tangahoe mudstones. The Tangahoe mudstone is highly erodible compared to the Matemateaonga layers at the boundary (mainly sandstones). If the convex shape was only due to differential erosion, it would be expected that this catchment would still have an $\mathrm{HI}$ value less than 0.5 , since ongoing erosion would have reduced the material left to erode below this important threshold. Therefore it is suggested that the rupture of the Waipuna fault is likely to have caused the convex shape of the hypsometric curve in this catchment rather than a change in lithology.

Visually the Makakaho catchment has a near perfect S-shaped hypsometric curve. This is supported by the statistical moments $\mathrm{HI} 0.48$ and DEN SK of 0.01 . This catchment can be interpreted as a near perfect example of what has been suggested by Strahler (1952b, reg. HI) and Harlin (1978, reg. DEN SK) as a catchment in equilibrium. The geology of this catchment is the most homogeneous of the five catchments and also the most erodible. This suggests that any regional or local uplift is balanced by erosion. This catchment contains mostly the very weak and highly prone to erosion Tangahoe mudstone (Townsend et al., 2008). With this in mind, it is assumed that the time period for catchment comprised of this material to return to an equilibrium state is relatively quick.

The Kai Iwi catchment visually has an S-shape and a $\mathrm{HI}$ of 0.4 (Figure 5-7). The distribution of elevations around the mean for this catchment is slightly skewed toward lower elevations (SK $=0.49)$. This suggests there is more erosion occurring in the upper catchment or conversely uplift occurring in lower elevations. This catchment contains preserved marine terraces that indicate ongoing regional uplift.

One explanation of the slight increase in indicated erosion could be changes in the geology of the Kai Iwi catchment. The geology of the Kai Iwi catchment transitions from Paparangi Group sandstone and Upper Okiwa mudstone to Nukmaru limestone, Holocene alluvial deposits and marine terrace 
deposits overlying mudstone. The limestone, Holocene alluvial deposits and marines terrace all crop out in the lower reaches and are more able to resist erosion. This change in geology could explain the difference in proportional elevation distribution (skew) toward the lower reaches.

Kurtosis values of the hypsometric curve have been interpreted by Harlin (1978) to provide evidence of erosion/uplift in the mid reaches of a catchment. A high kurtosis value suggests a disproportionate amount of elevations in the middle reaches, either due to erosion in the upper and lower reaches or localised mid catchment uplift. A kurtosis value of 2.14 , slightly lower than a normal distribution, suggests an increase in the amount of erosion occurring in the mid reaches for the Kai Iwi catchment. Once again, this small deviation from normal could be due to small changes in the local geology.

The $\mathrm{HI}$ is a very simple measure, as it only measures the area under the curve and does not take into account the shape of the curve, i.e. it is theoretically possible to have an $\mathrm{HI}$ of 0.5 but a shape inverse of the common S-shape (Harlin, 1978; Luo, 1998; 2000; 2002). The Pungapunga catchment is in some ways an example of this. The shape of this curve is not easily visually categorised as it is somewhere between an S-shape and heading toward concave. The $\mathrm{HI}$ of 0.37 suggests that this catchment is out of equilibrium with erosion occurring faster than uplift. However the geology within this catchment is complex with a large amount of recent volcanic material in the head waters, soft mudstones and sandstone in the lower reaches with outcrops of basement greywacke and lahar deposits. The geology of this catchment suggests that rather than erosion dominating, the shape of the curve could be explained by the deposition of the volcanic material in the upper reaches. Relatively recent deposition occurring only in the upper reaches would increase the elevation explaining the convex shape of the upper section of the curve. The soft sandstones and mudstones of the lower reaches would have an increase in erosion explaining the more concave shape to the lower curve. The DEN SK of 0.46 suggests this catchment is half way between the Makakaho and Makaranui catchment making this catchment hard to categorise as either S-shape or concave.

The Makaranui catchment is the most concave and has the lowest $\mathrm{HI}(0.15)$ as well as the highest DEN SK (1.19). This shape of hypsometric curve was originally referred to as the Monadnock stage by (Strahler, 1952b) and used to describe a catchment that has eroded almost all available material leaving only a small amount of increased elevation at the catchment boundaries. The process within Makaranui catchment are opposite from Strahler's description with this catchment situated on the slopes of Ruapehu volcano. The mountainous geology explains the shape of the catchments hypsometric curve with a small percentage of very high elevation (mountainous headwaters) that 
abruptly flattens out (volcanic ring plain). This shape was also found by Ohmori (1993) in the mountainous regions of Japan.

The Marakanui catchment contains the Ohakune fault that crosses perpendicular to the main trunk stream near the outlet. There is no indication in the shape of the hypsometric curve to suggest the presence of this fault. This is likely due to the small amount of high elevations in the upper catchment obscuring the more subtle change in elevation due to faulting.

\subsubsection{Conclusions}

Application of hypsometry to the test catchments has shown the great influence of lithological changes on hypsometry values. For example, marine terraces are much less erodible than Pleistocene sediments to the north (Fleming, 1953). This contrast in resistance to erosion tends to dominate the hypsometry values. Also, in active volcanic edifices, the processes of edifice built up by volcanic eruptions in the upper reaches of the streams controls the hypsometric shape. Catchments within or straddling these regions need to be interpreted with care and may not be useful to identify active tectonics with hypsometric analysis.

If lithological changes are not present or cannot explain the calculated hypsometry values, the following processes which are related to active tectonic activity may be supported by hypsometric analysis:

1. Differential erosion on the upper or lower reaches of a stream can be caused by differential uplift across a fault that crosses the catchment.

If either the upper or lower reaches are undergoing more erosion relative to each other, the expected shape of the hypsometry curve would be concave - S-shaped. The HI and DEN SK could then be used to determine if the increased erosion is due to tectonic processes. Catchments with these ranges of shapes and very high $\mathrm{HI}$ or very negative DEN SK could be highlighted as potentially influenced by tectonics.

2. Different rates of uplift /subsidence can occur on adjacent catchments that are bounded by an active structure.

A catchment that is undergoing uplift, compared to the adjacent catchment that is subsiding, is expected to present a hypsometric curve with a more convex shape, a higher $\mathrm{HI}$ and a DEN SK close to 0 . 
The test catchments have not been able to identify if hypsometric analysis can be used as an indicator of tectonic activity. The myriad of process occurring within each catchment has made it difficult to isolate a single process as the main influence on a statistical moment or hypsometric shape. 


\subsection{Test Catchments: SLk Index}

\subsubsection{Methods}

The aim of testing the SLk index in a few catchments is to identify the most appropriate DEM and sampling distance for the production of a SLk anomaly map for the entire study area. The same five test catchments used to test the hypsometric curve are also used here to test the SLk index. The main trunk stream of each test catchment was extracted from the four DEMs using the methods outlined in Section 4.2.6. SLk values were calculated for the main trunk stream at sampling distances of $100 \mathrm{~m}, 250 \mathrm{~m}, 500 \mathrm{~m}, 750 \mathrm{~m}, 1000 \mathrm{~m}$ and $1500 \mathrm{~m}$ using the methods outlined in Pérez-Peña et al. (2009b). SLk values from each of the four DEMs and stream elevations were plotted against distance downstream and compared to geological boundaries from Townsend et al. (2008) and mapped active faults were extracted from the AFDB. The elevation profile of each stream was plotted together with the SLk values, and was produced by extracting height values from the DEM every 500 $\mathrm{m}$ downstream along the extracted trunk stream.

\subsubsection{Results}

The SLk results for each test catchment are presented below. The results from $100 \mathrm{~m}$ and $250 \mathrm{~m}$ sampling distances were removed from further analysis as the spacing was not appropriate for the resolution of the DEM data. The reasons why these plots are not used for further analysis are discussed later in Section 5.3.3.

The SLk values calculated at sampling distances greater than $500 \mathrm{~m}$ are displayed below in Figure 5-8 to Figure 5-17. Abrupt changes in SLk values have been correlated with the mapped active faults and geological boundaries with mixed success. There are some instances where abrupt changes in SLk values coincide with a geological boundary and/or active fault, and other cases where there is no correlation.

\section{Mangoihe}

In the Mangoihe catchment there is a positive correlation between the location of changes in SLk values and the location of geological boundaries but there is no correlation to mapped active faults. At $\sim 13 \mathrm{~km}$ downstream, over a $\sim 2 \mathrm{~km}$ distance downstream from the boundary between the Matemateaonga Formation sandstone and the Tangahoe mudstone there is a large increase in SLk value for all sampling distances and on all DEMs. At $\sim 7 \mathrm{~km}$ downstream the Waipuna fault does not coincide with an increase in SLk value at any sample distance or on any of the DEMs. 


\section{Makakaho}

The main trunk stream of the Makakaho catchment flows over homogeneous Tangahoe mudstone. Therefore there is very little change in SLk. There is one significant increase of SLk detected from the SRTM and ASTER DEMs at $13 \mathrm{~km}$ downstream near the outlet of the catchment. The LC and Otago DEMs also show a slight increase in SLk at this location.

\section{Kai Iwi}

The Kai Iwi stream profile visually reflects the underlying geology. The upstream reaches of this catchment have a limited amount of drainage area and therefore a limited amount of erosion has occurred. Headwater streams generally have low discharge and a steep slope and this is displayed in the stream profile, with the loss of over $100 \mathrm{~m}$ of elevation over $15 \mathrm{~km}$. At $\sim 15 \mathrm{~km}$ downstream the SRTM and ASTER DEMs show an increase and then a sudden decrease in SLk value leading up to the boundary between the Paparangi Group sandstone and the Okiwa Group mudstone. This increase is also noted on the LC and Otago DEMs but the increase is in the form of a series of peaks. The SLk values continue to increase until the boundary of the Nukumaru group limestone at $\sim 25 \mathrm{~km}$ where there is a sudden drop recorded in every DEM. At $~ 30 \mathrm{~km}$ downstream SLk values sudden increase with no change in geology. The boundary between the Nukumaru Group limestone and the alluvial terrace does not appear to coincide with any increase in SLk value.

\section{Pungapunga}

The Pungapunga stream profile is almost logarithmic except for step at $13 \mathrm{~km}$ downstream, which is remarkable given the complicated geology along the stream bed. The large SLk spike at $\sim 13 \mathrm{~km}$ coincides with the transition between Manaia Hill Sandstone and Te Kuiti Group siltstone. SLk values remain approximately equal for the Holocene alluvium.

\section{Makaranui}

When comparing the Makaranui stream profiles extracted from the four DEMs it was noted that the SRTM DEM had produced a stream that flowed in a different location to the streams extracted from the other three DEMS. The hillshade model for the area showed the SRTM dataset contained obvious elevation anomalies. It has been documented that the SRTM DEM contains anomalous elevation values in mountainous regions due to shadow effects during the collection of the raw data. From the Hillshade model, it appears that part of the SRTM DEM of the Makaranui catchment contains an area with these anomalous elevations and this has caused the algorithm used to extract stream data to find a different path than the other three DEMs (see Figure 5-6). Therefore the SLk values from the SRTM DEM will be excluded from analysis. Results from the other three DEMs show 
that there is a subtle increase in SLk values at the boundary between andesite and Quaternary lahars. Two more pronounced increases in SLk are located close to the boundary between Quaternary lahars and the "Undifferentiated Quaternary fan gravel" and at the catchment outlet in close proximity to the Ohakune Fault.

The following figures show the SLk values, main geological formations and stream elevation profiles for each of the test catchments. The scale for the SLk values varies between figures. 

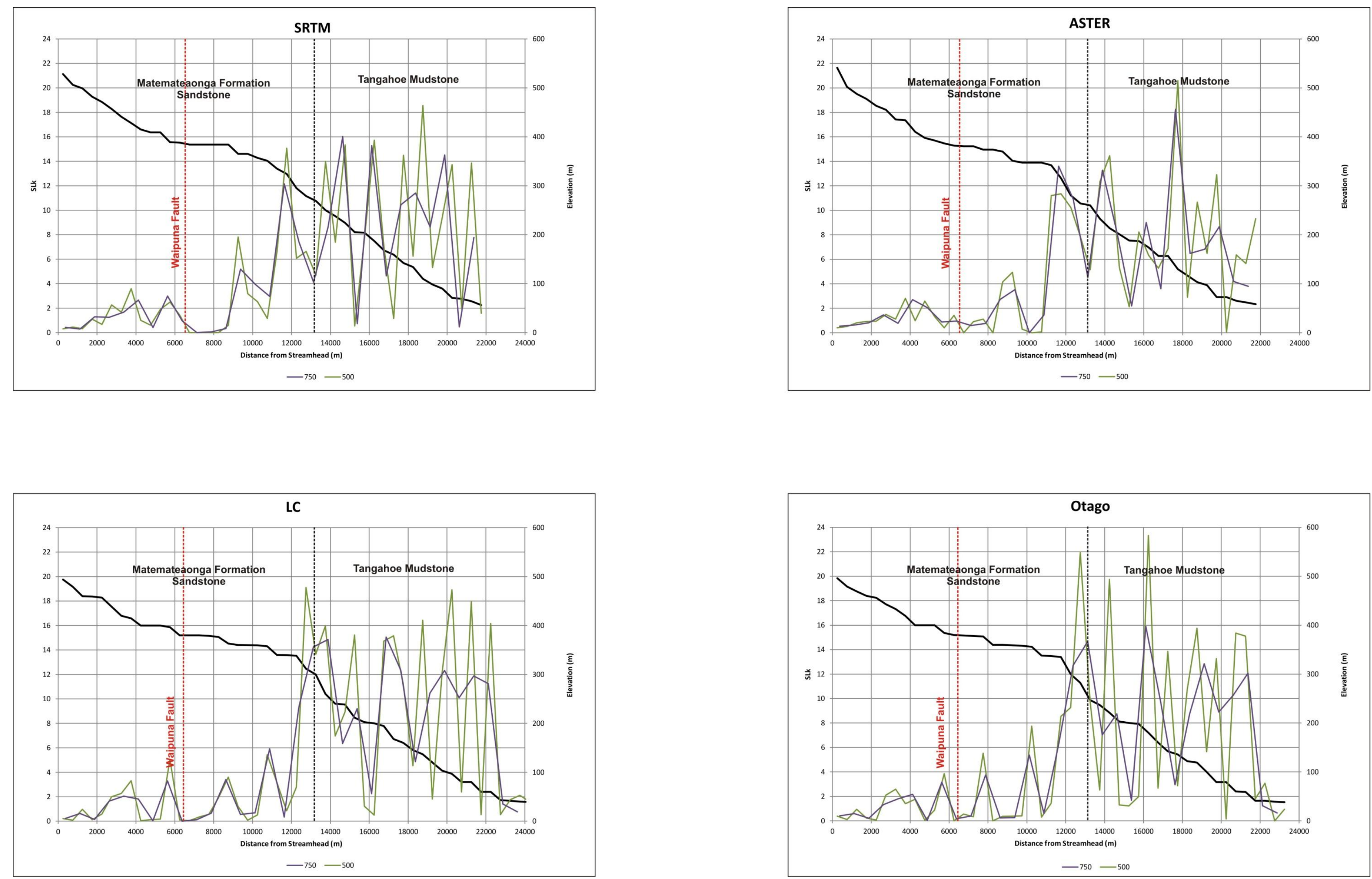

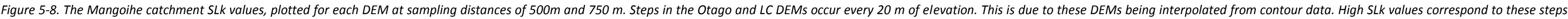
There is no clear relationship between high SLk values and the mapped Waipuna fault. There is a sudden increase in SLk values where the stream crosses into the Tangahoe mudstones. 

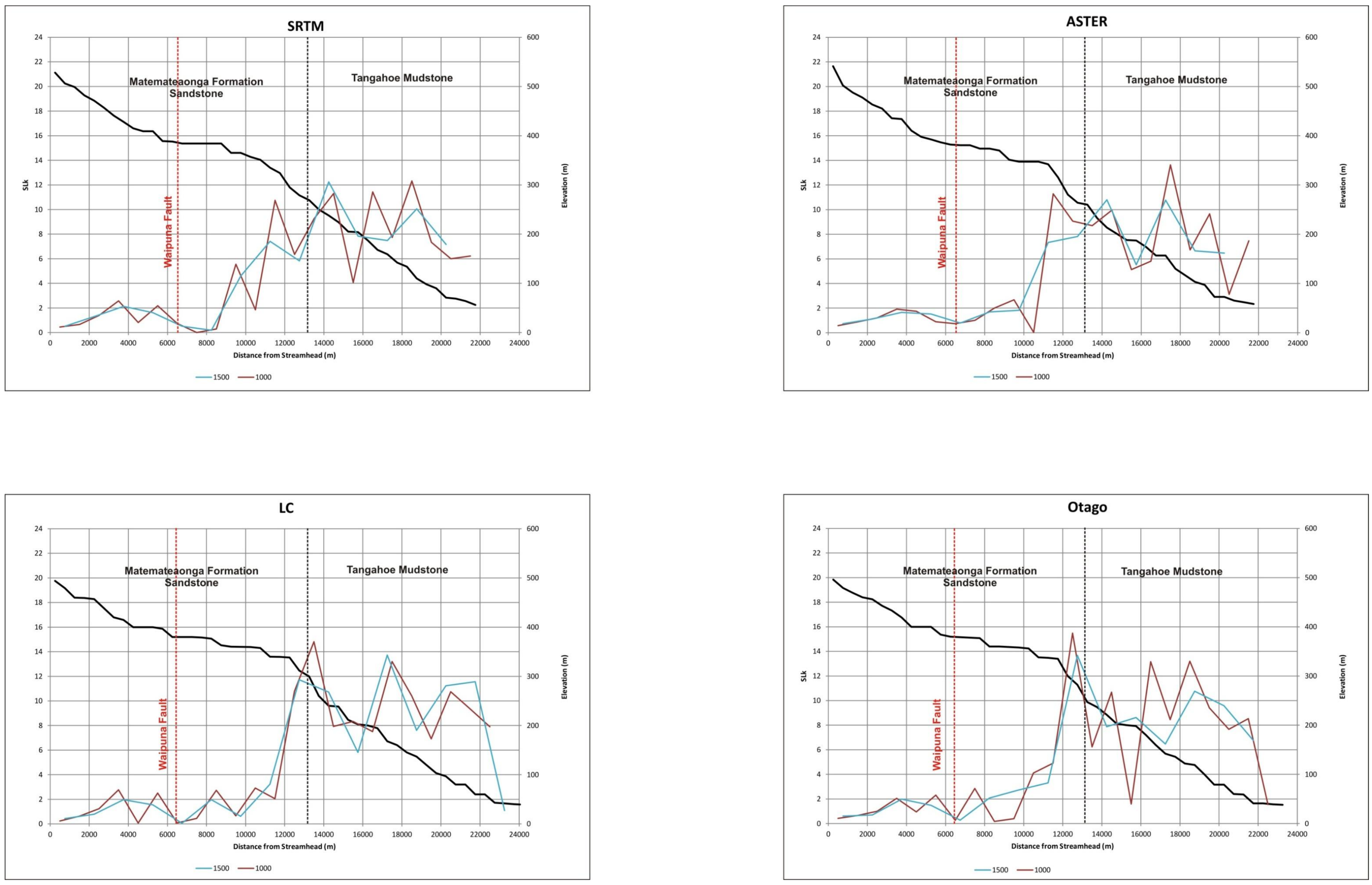

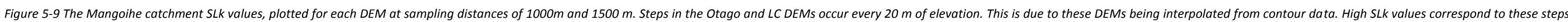
There is no clear relationship between high $S L k$ values and the mapped Waipuna fault. There is a sudden increase in SLk values where the stream crosses into the Tangahoe mudstones 

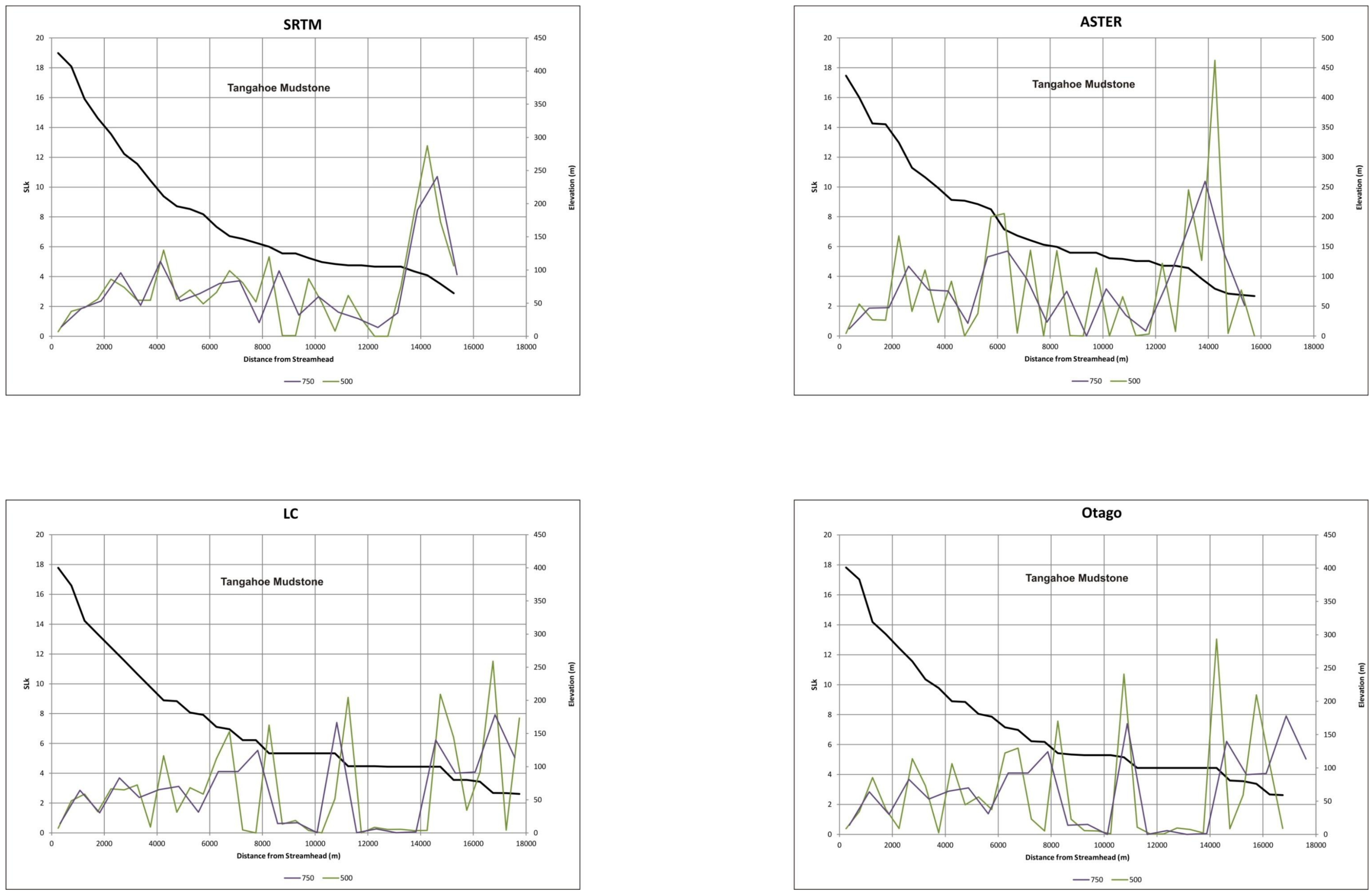

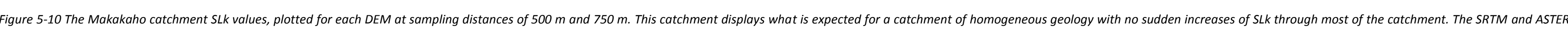
$D E M s$ do have an increase toward the catchment outlet. This is suggested to be an influence of the convergence of a higher order stream increasing erosion at the outlet. 

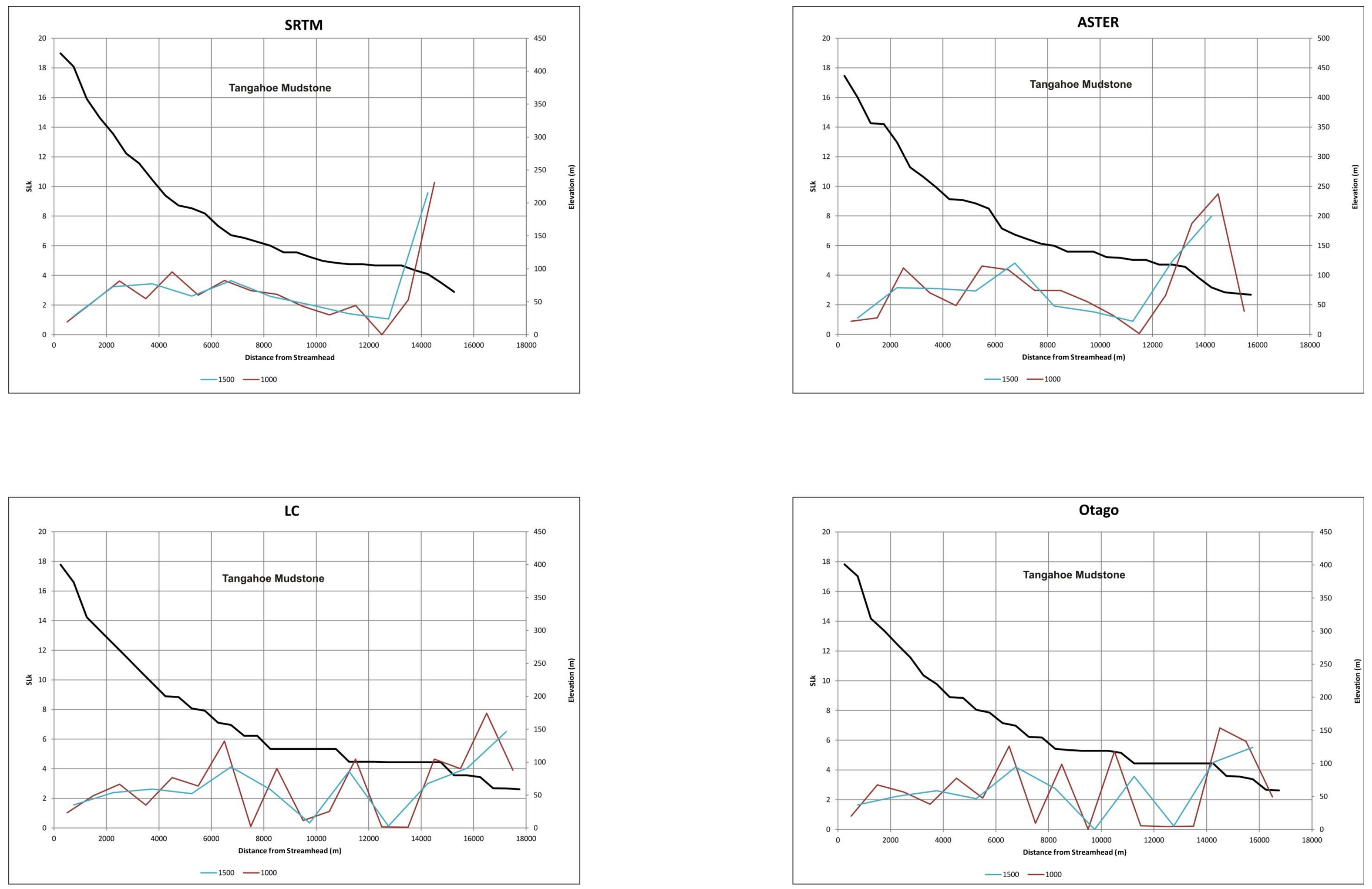

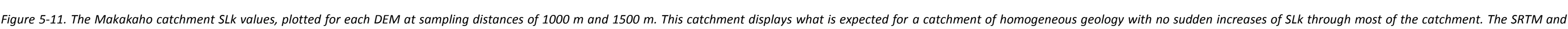
ASTER DEMS do have an increase toward the catchment outlet. This is suggested to be an influence of the convergence of a higher order stream increasing erosion at the outlet. 

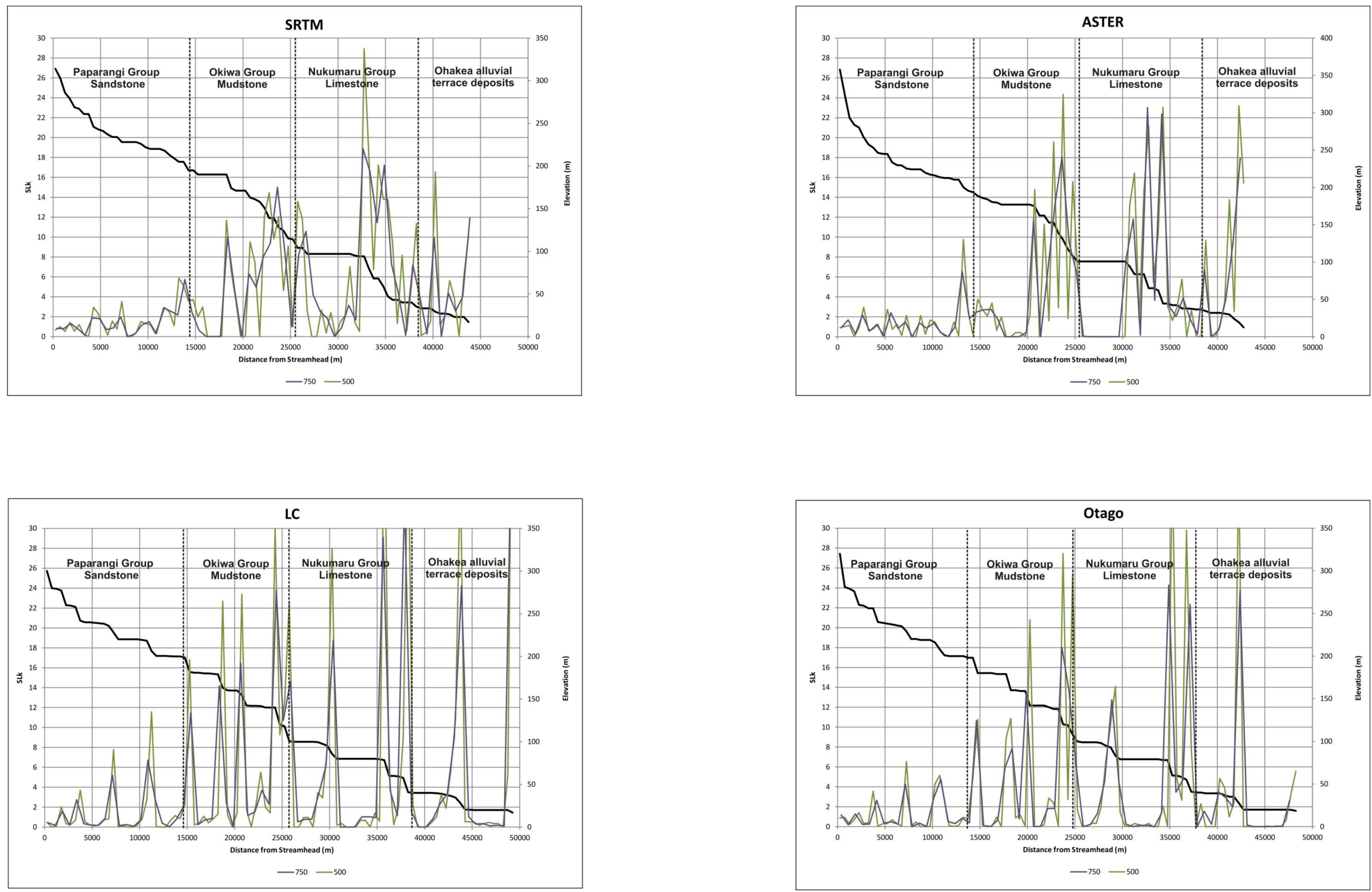

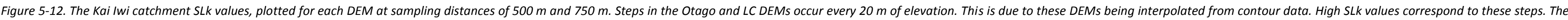
SRTM and ASTER graphs both identify low SLk values possibly corresponding to marine platforms preserved though out his catchment. The $750 \mathrm{~m}$ and $1000 \mathrm{~m}$ sampling distances best capture these changes to lower SLk values. 

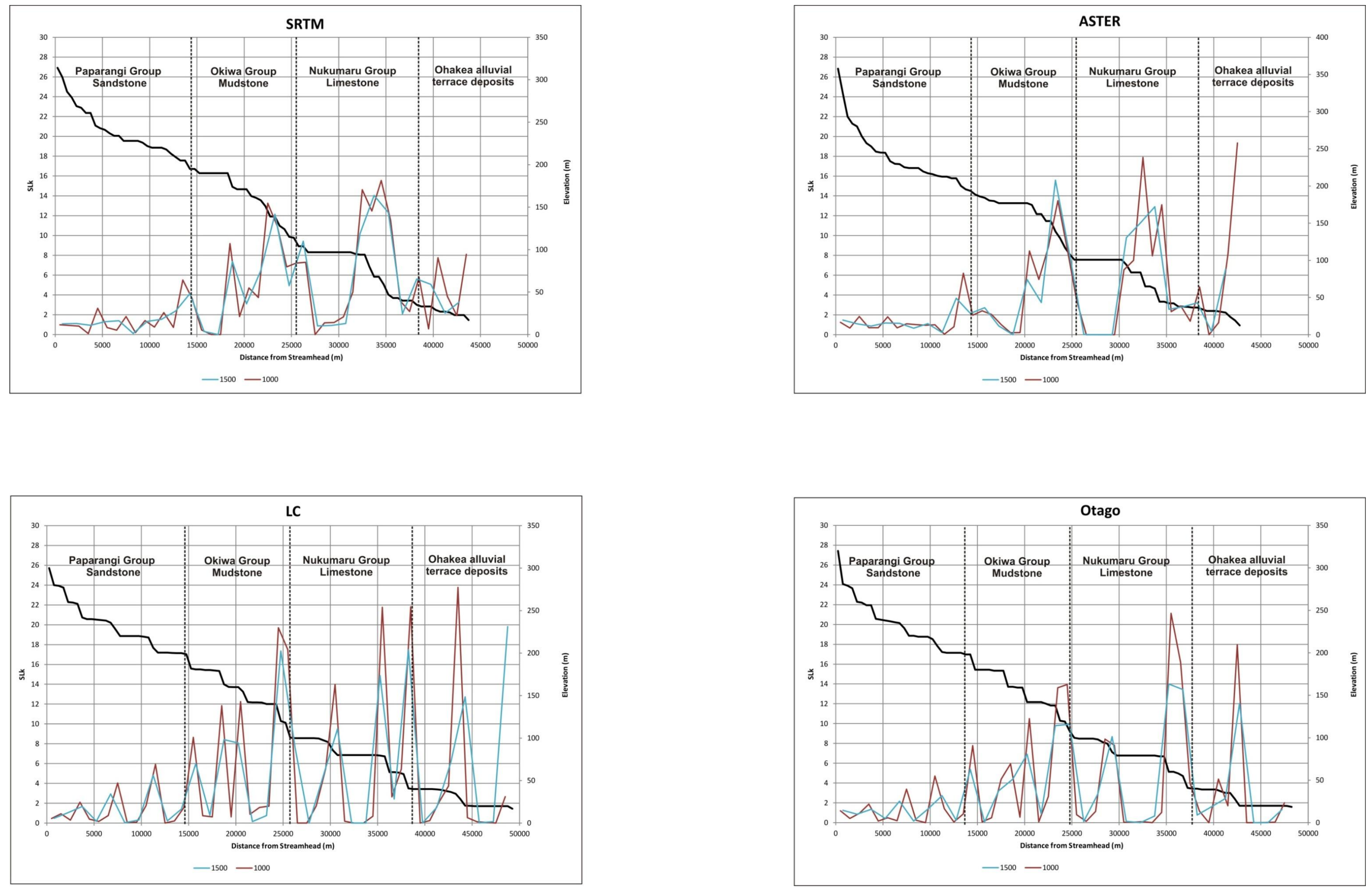

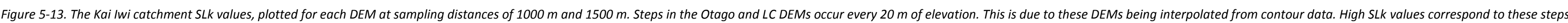
The SRTM and ASTER graphs both identify low SLK values possibly corresponding to marine platforms preserved though out his catchment. The $750 \mathrm{~m}$ and $1000 \mathrm{~m}$ sampling distances best capture these changes to lower SLK values. 

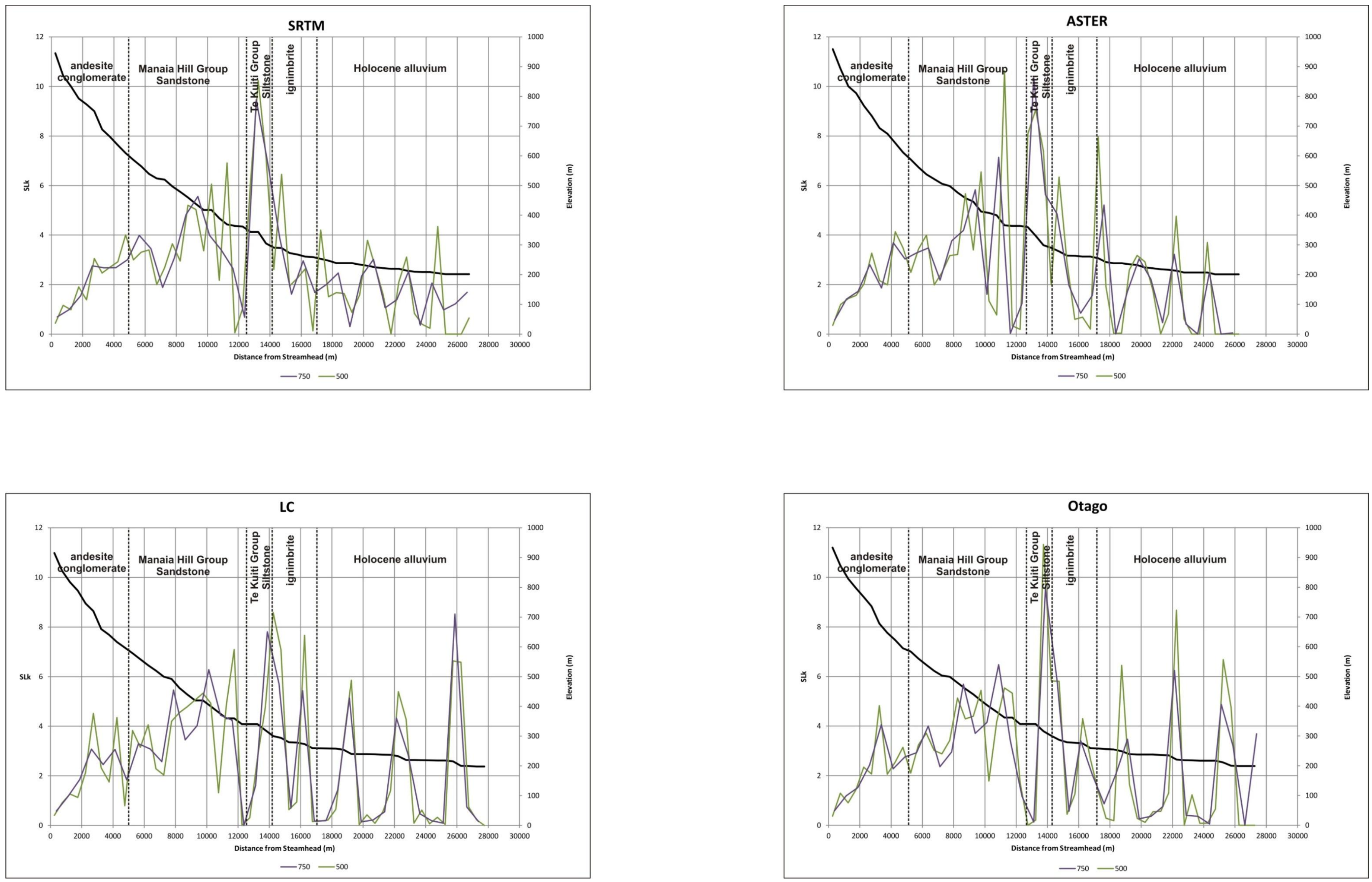

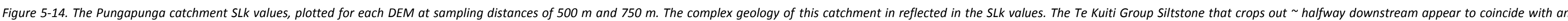
increase in SLk. 

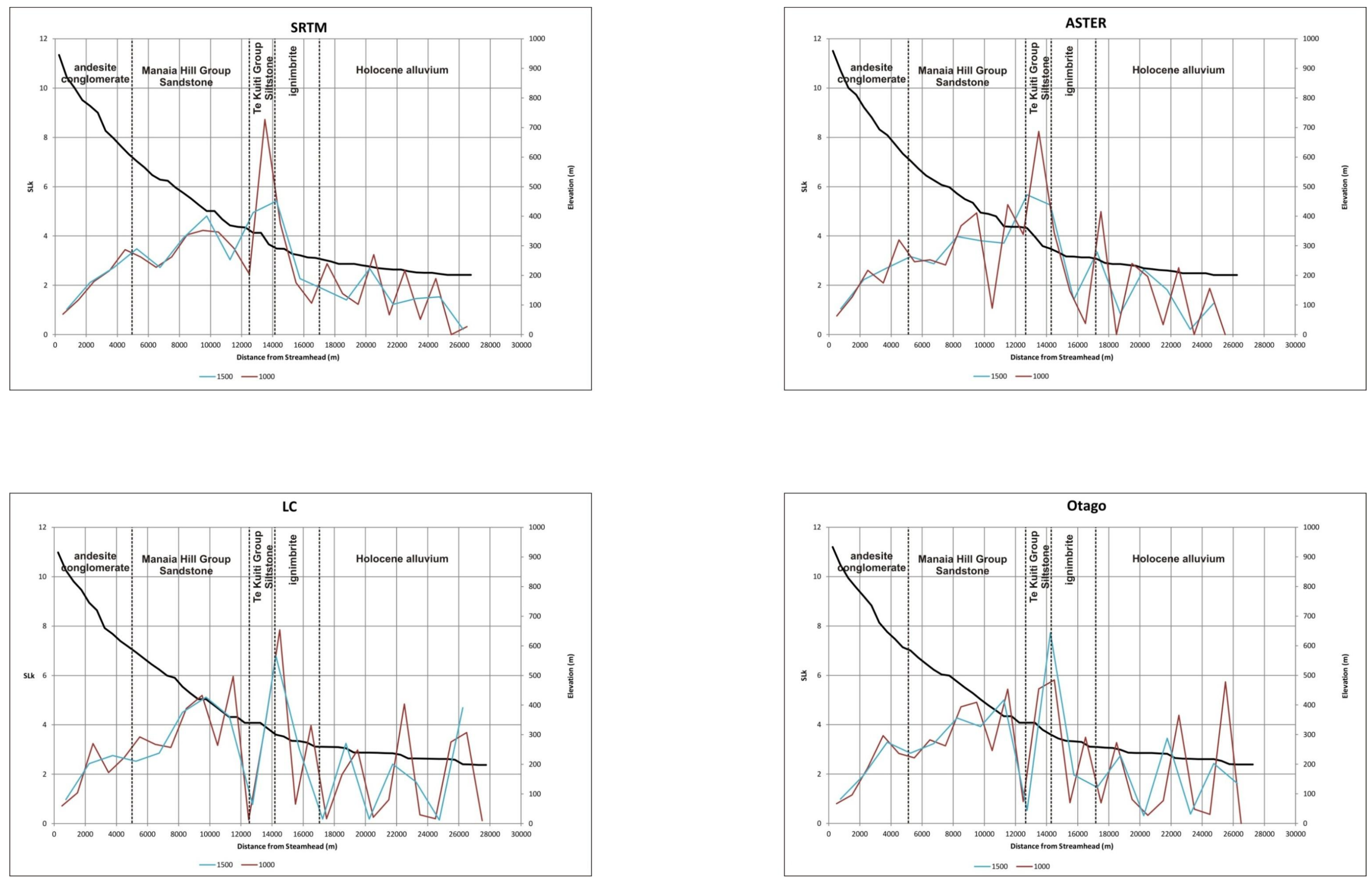

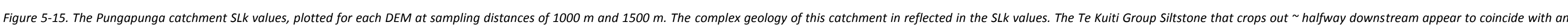
increase in SLk. 

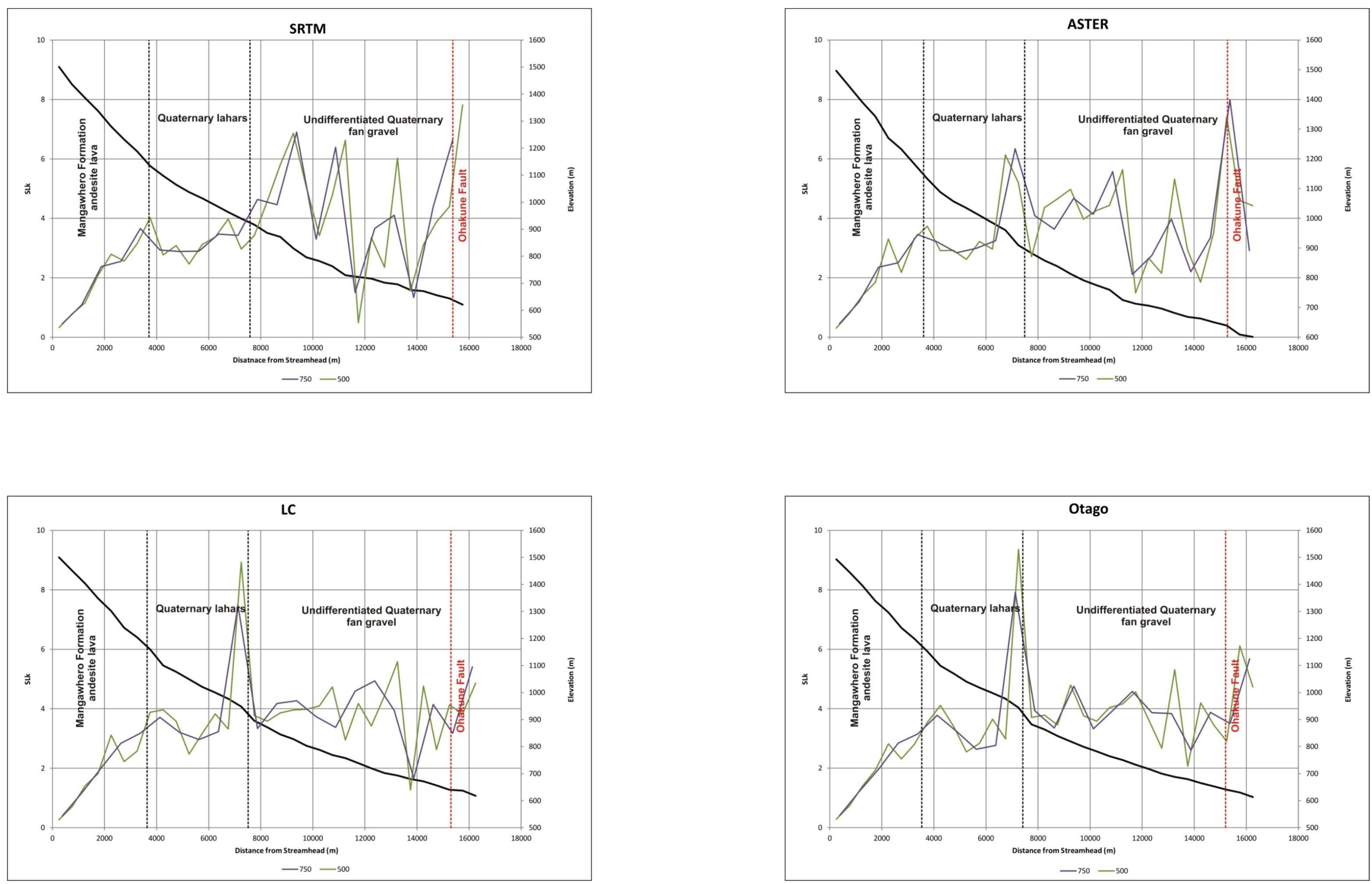

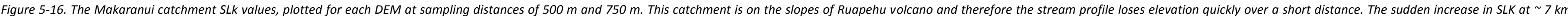
downstream is attributed to a sudden change in slope where the stream flows on to the volcanic ring plain. There is a suggestion that the Ohakune fault increases SLk, however this could also a feature of a stream profile where it joins another large stream. 

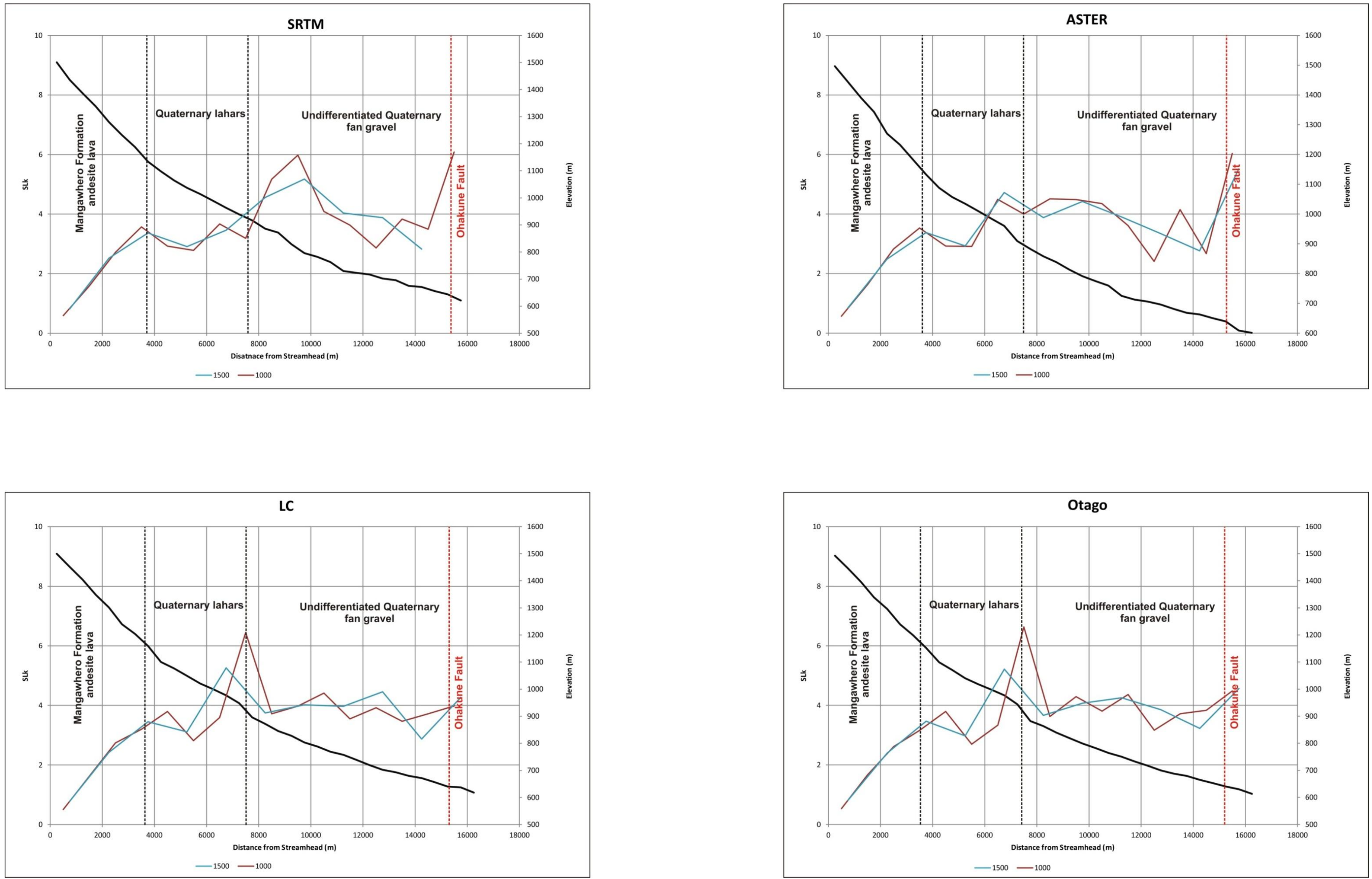

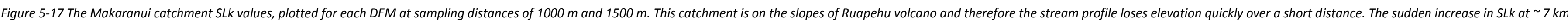
downstream is attributed to a sudden change in slope where the stream flows on to the volcanic ring plain. There is a suggestion that the Ohakune fault increases SLk, however this could also a feature of a stream profile where it joins another large stream. 


\subsubsection{Discussion}

\section{DEM Interpolation Error}

Visually the stream profiles for most of the test catchments derived from the LC and the Otago datasets look stepped compared to the SRTM and ASTER stream profiles. These steps appear to coincide with a $20 \mathrm{~m}$ change of elevation and therefore it is possible that the method used to build the DEMs (extracted from $20 \mathrm{~m}$ contours) could produce these erroneous abrupt changes in elevation. To visually assess the difference between contoured and non contoured DEMs the frequency of elevations (i.e. the number of cells that contain a certain elevation value) for each test catchment was plotted for each of the DEMs. The example below (Figure 5-18) shows the Kai Iwi catchment. In this example, distinct peaks in the distribution at regular $20 \mathrm{~m}$ interval can be observed in the Otago (Figure 5-18 A) and the LC DEMs (Figure 5-18 B) but not the ASTER (Figure 5-18 C) or SRTM (Figure 5-18 D) DEMs. This was the case for each of the test catchments, except for the Marakanui catchment where the interpolation was better, due to the high slopes and simple geomorphic shapes of the landscape (volcano cone and ring plain).

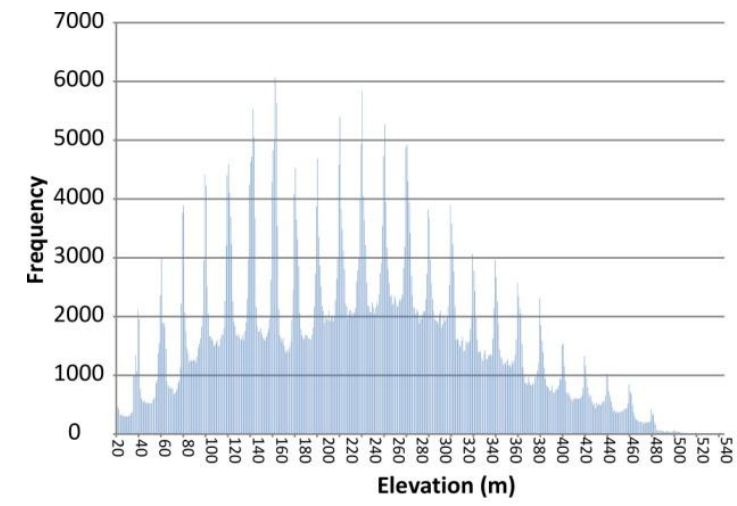

A. Otago $15 \mathrm{~m}$

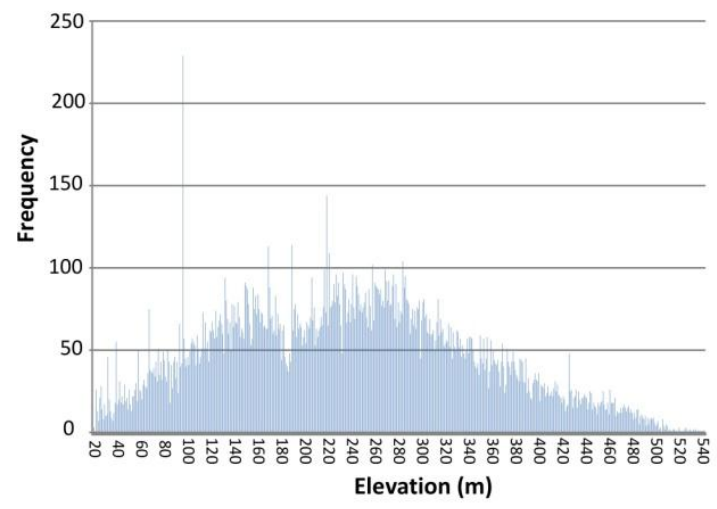

C. Aster $30 \mathrm{~m}$

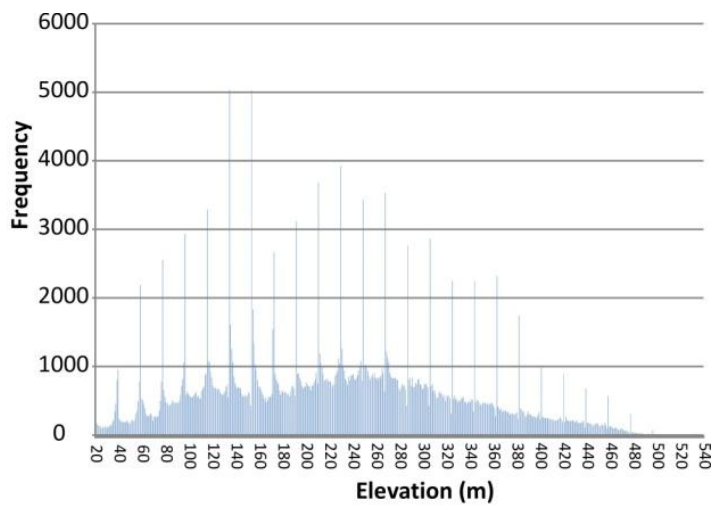

B. LC $25 \mathrm{~m}$

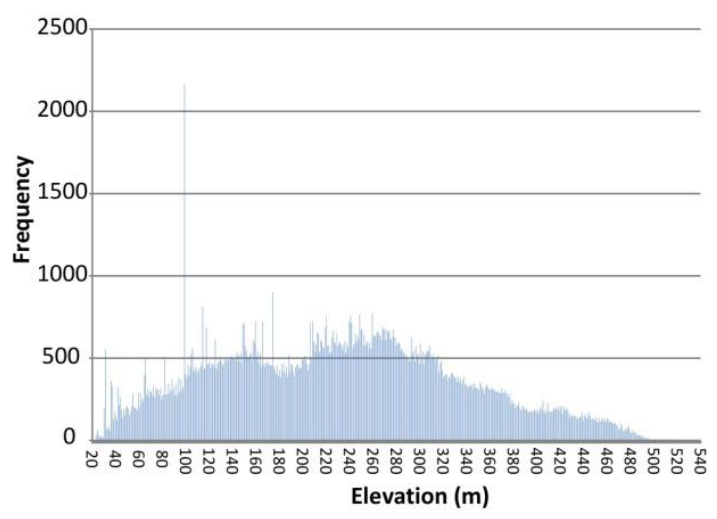

D. SRTM $90 \mathrm{~m}$

Figure 5-18 Frequency distributions for the Kai Iwi catchment obtained from the four DEMs used in this study. The DEMs interpolated from contour lines display a spike in elevation frequency every $20 \mathrm{~m}$. 
Traditionally the SLk index has been calculated using contour lines. Keller and Pinter (1996) outlined a methodology designed to work with large scale topographic maps (1:50 000 to 1:250 000). This methodology uses the equidistance contour intervals as the dh therefore causing the distance between sample points to increase downstream. This leads to clustered SLk values near the headwaters and where elevations change over a short distance and large intervals between points in areas of little elevation change. The method outlined in Pérez-Peña et al. (2009b) and applied here, uses an equal distance downstream and the elevations are extracted at that distance from the DEM. This methodology overcomes issues with sampling distribution but as this study has shown, can only be used with DEMs not derived from contour lines.

\section{SLk Index and Sampling Distance}

The sampling distance used to calculate the SLk index needs to be such that the signature of the landscape process of interest is captured in the dataset produced. For example, the deformation zone for a fault can range from very small for a single event (meter scale) surface rupture through to very large (kilometre scale) for a large number of accumulated events. A fault that has ruptured many times can produce a large area of deformation and through time this zone is increased further as the stream erodes back toward the stream head. The relative elevation increase from the rupture event is not lost, rather it is just spread out over a longer distance as the stream attempts to erode the bed and banks to a semi-logarithmic elevation profile. Paleo-earthquake investigations of many of the faults in this region show the size of a vertical single event displacement to be in the range of 0.1 - 1m (Pillans, 1983; Townsend, 1998; Villamor and Berryman, 2006; Townsend et al., 2008; Townsend et al., 2010). As mentioned earlier, multiple events along the same fault could produce large scarps but only if the amount of uplift is greater than the amount of erosion occurring between uplift events. Therefore, the sample distance for the SLk index needs to be such that it will capture changes in elevation from recent fault rupture through to elevation change that that have been smoothed out through time. To ensure this change in slope is detected the sampling distance therefore needs to be between $1 \mathrm{~m}$ and $1 \mathrm{~km}$.

The elevation data for the SLk calculations are obtained directly from the DEMs and therefore the resolution of these data also limits the minimum sampling distance for SLk calculations. The largest cell size of the DEMs used is $90 \mathrm{~m}$ and consequently limits the minimum sampling distance to $90 \mathrm{~m}$ in order to allow for comparison between DEMs. However, this value is still too small if a stream crosses a $90 \mathrm{~m}$ cell in any direction other than the four primary directions. The distance of the diagonal for a $90 \mathrm{~m}$ square is $127.3 \mathrm{~m}$ therefore the $100 \mathrm{~m}$ sampling used previously should not be 
used when comparing results between DEMs. For any calculation of SLk, a change in elevation of at least two grid cells is required. The minimum sampling distance is hence $254.6 \mathrm{~m}$ ( 2 x 127.3).

The smaller sampling distances should capture recent vertical displacements. The larger sampling distances should capture vertical displacements that may have been smoothed out through time. With a large sampling distance, there is a chance that subtle changes in slope may not be detected. With a small sampling distance, there is a chance that the change in slope could be broken into a series of smaller values and therefore not be noticeable. The $1500 \mathrm{~m}$ and $1000 \mathrm{~m}$ sampling distances are somewhat smoothed and oversimplify the more subtle changes in slope. The $500 \mathrm{~m}$ and $750 \mathrm{~m}$ sampling distances locate all of the changes in slope, but appear also to reflect underlying issues with the DEMs.

\section{SLk Index and Geology/Faulting}

There is an overall trend for SLk values to increase when a stream crosses a geological boundary and the material downstream of the transition is more easily erodible. The best example of changes in lithology causing an increase in SLk is the Mangoihe catchment because of the simplicity of the geology and good correlation between the geologic boundary and the increase in SLk. In this catchment, the transition from Matemateaonga sandstone to Tangahoe mudstone coincides with a large increase in SLk. The increase in SLk is directly related to the increase in slope of the stream profile due to the stream being more able to incise into the bed and banks because of the more easily erodible Tangahoe mudstone.

Other catchments also show correlation between lithological changes and increases in SLk values. The Kai Iwi catchment reflects the influence of the lithology with a complex geology correlating with presence of several SLk spikes. Also the Marakanui catchment shows changes in SLk associated with the boundary between andesitic lavas and Quaternary lahars and between lahars and "Undifferentiated Quaternary fan gravel". The definition of this latter formation in Townsend et al. (2008) is not clear and thus it is not possible to interpret the cause for this increase in SLk but it is likely that the "Undifferentiated Quaternary fan gravel" may contain sediments that are more erodible than the Quaternary lahars (e.g. more distal fine-grained lahars and alluvium).

The location of the maximum peak of the SLk increase does not always exactly coincide with the lithological boundary. For example in the Mangoihe catchment, the mapped geological boundary occurs $4000 \mathrm{~m}$ downstream of where the SLk values start to increase. The distance between the boundary and the increase in SLk can be explained by the resolution of the geological mapping. The maps used are compiled at a 1:250,000 scale and not all individual beds within a formation are 
mapped. Layers are also dipping to the south at $\sim 4^{\circ}$ causing the boundary in the stream to be downstream (south) of where it has been mapped due to the stream eroding though overlying geology ( $V$ shape of dipping layers in valleys). The scale of the geological maps used does not include the detailed shape of the boundary. Also knick-point retreat can affect the exact location of the high SLk values.

Where the geology of a catchment is homogeneous, the SLk value should remain approximately equal as the stream erodes the bed and banks to semi-logarithmic shape. The Makakaho catchment is a good example with homogenous geology and SLk values remaining low apart from a large increase at $\sim 14 \mathrm{~km}$ downstream near the catchment outlet detected in the ASTER and SRTM DEMs. As there is no geological boundary mapped nearby, geology is ruled out as an explanation for this sudden increase in SLk value. The proximity to the catchment outlet could be causing this increase in SLk. The confluence of this stream to a stream with more stream power would cause erosion upstream of the catchment outlet and therefore increase stream bed slope causing an increase in SLk. Alternatively, active faulting could potentially be the cause for high SLk at this location and should be further explored.

Active faulting seems to correlate with an SLk increase in proximity to the Ohakune Fault in the Marakaui catchment. The high SLk can be either associated with activity of the Ohakune fault or with the intersection with another stream. Displacement of the fault is evident by a $3-20 \mathrm{~m}$ high, well preserved fault scarp on Quaternary alluvial surfaces (Villamor and Berryman, 2006) and thus it is possible that displacements of the stream bed are preserved and have influenced the SLk values. However, since the Ohakune fault is very close to the outlet of the stream, it is also possible that elevated SLk values are a consequence the intersection with another stream, similar to the situation described above for the Makako catchment.

In the Mangoihe catchment at $\sim 7 \mathrm{~km}$ downstream, the Waipuna Fault crosses perpendicular to the main trunk stream. However, there is no corresponding increase in SLk. The Waipuna fault has a clear scarp of $\sim 1 \mathrm{~m}$ in height preserved in erodible mudstone suggesting that the last rupture should have occurred relatively recently (perhaps in the last $<2000$ years). The lack of SLk in association with such a recent rupture suggests that faulting events older than that of the Waipuna fault are unlikely to be detected using the methods for SLk outlined in this study if the fault ruptures through highly erodible materials. 


\subsubsection{Conclusions}

The analysis of the SLk index on the main trunk stream of the test catchments has identified the following important results:

\section{Limitations of the DEMS Used}

While correlations between SLk and geological processes have been attempted with the four DEMs and sampling distances between 500 and $1500 \mathrm{~m}$, all four of the DEMs are not suitable for SLk analysis at the resolution range required to assess presence of active faulting. While they may be suitable to assess large scale displacements (i.e. accumulated displacement), the resolution of the DEMs is not detailed enough to assess recent ruptures.

The SRTM DEM has the largest cell size and therefore the lowest resolution. Due to the $90 \mathrm{~m}$ cell size SLk values calculated from the SRTM DEM is likely to miss smaller scale and subtle changes in elevation. The ASTER DEM has a better resolution but also has many documented issues with artefacts produced during interpolation. These artefacts could also produce high SLk values making it very difficult to ascertain if anomalous value are due to faulting/geology. However, the ASTER DEM does provide some useful results that could be used for analysis of tectonic processes at a large scale, so long as the results are interpreted with caution to avoid interpreting random errors from the production of the DEM as a SLk anomaly.

The stepped nature of stream profiles extracted from LC and Otago DEMs produces high SLk values at every contour interval (i.e. every $20 \mathrm{~m}$ ). This makes it almost impossible to differentiate between high SLk values due to contour bias and geology/faulting. Because this error is systematic it is possible to smooth the DEM to remove the bias toward contour values. However, any removal of data could potentially also remove an increase in elevation due to faulting.

Therefore, it is important to highlight that:

- Otago and LC DEMs will be excluded from the regional scale analysis and the production of SLk anomaly maps. DEMs interpolated from contour data are fraught with issues when used in hydrological research (Wise, 2000; 2007). These errors are compounded when SLk index data is derived from these datasets with the methods used in this study.

- Sampling distances need to be significantly greater than the cell size of the DEM to ensure changes in elevation occurring over a large distance are identified.

- The ASTER and SRTM DEM are the preferred DEMs for SLk analysis but contain artefacts that could potentially produce high SLk values. 
- The ASTER DEM will be the focus of a majority of SLk analysis acknowledging that a high SLk value could be due to errors within the dataset.

- The SRTM data will be used with the knowledge that the resolution is unlikely to be sufficient to capture any small changes in elevation.

- All sampling distances will be used to produce point data for interpolation of regional SLk anomaly maps. There is not a single value of sampling distance that provides a balance to avoid sampling anomalies while still identifying the mapped structure.

- All of the sampling distances should be used in the final interpretation of results to insure all possible SLk anomalies that could be attributed to faulting are captured.

\section{Influence of Lithological Changes and Active Faulting in SLk Values}

At the resolution achieved with the use of existing DEMs and sampling distances selected, the following correlations have been observed:

- Increase in SLk values is generally associated lithological boundaries where materials with different resistance to erosion are in contact.

- The exact location of the lithological boundary may be a few kilometres off the location of the corresponding SLk anomaly at the resolution of this study. Large sampling (>500 m) and the simplified mapping on the 1:250:000 geological scale maps (simplified boundary geometries and not all individual units within Formations being mapped) can explain this discrepancy.

- It is possible that active faulting may correlate with high SLk in areas of sediments/rocks that are resistant to erosion (e.g. Ohauke fault displacing laharic deposits). However, SLk may not be the appropriate geomorphic index to explore active faulting in the less resistant materials (i.e. recently active Waipuna Fault displacing the Matemateaonga mudstone sand sandstones).

Taking into account the limitations of the SLk values, interpretations of the SLk maps below will be undertaken with care. The main focus will be in identifying areas where important changes in SLk along streams cannot be explained by lithological changes, and in areas where other geomorphic indices may suggest presence of active faulting. 


\section{Chapter 6 Results}

This chapter contains the results of the four geomorphic indices (i.e. hypsometric curve, stream length gradient index, asymmetry factor, and sinuosity index). Each of the indices has individual results presented at the study area scale, and in the case of the hypsometric curve and SLk index the results are also compared to results from the test catchments.

\subsection{Hypsometric Curve}

Hypsometric curves and their statistical moments were calculated for $733^{\text {rd }}$ order catchments, using the methods outlined in Section 4.1.4. The comparison between test catchment hypsometric curves (see Figure 5-7 and discussion in Section 5.2.2), showed no significant difference in the shape of hypsometric curves extracted from the four DEMs. Therefore, any of the four DEMs could have been used for this analysis. The results below are calculated from the ASTER DEM.

The $\mathrm{HI}$ has traditionally been used as one method to classify hypsometric curves. In this study it was noted that a large number of curves classified using $\mathrm{HI}$, when assessed visually, did not fit the expected shape. $\mathrm{HI}$ is a measure of the area under a hypsometric curve and has been shown to provide a rough guide to the shape of the curve. As the area under the curve decreases the shape becomes increasingly concave. Conversely, as the area under the curve increases the curve becomes increasingly convex. The main discrepancy noted by this study occurred with $\mathrm{HI}$ values of S-shape and concave curves. The simple nature of this metric is not adequate to easily differentiate between these two shapes. The observation that the HI could not be used to differentiate between S-shape and concave curves also led to the observation that many, visually, S-shape curves also have a low HI. This has led the author to consider a fourth category for classification. The S-shaped/concave category (see Figure 6-1, grey coloured curves) has been included in this study to describe a curve that is S-shaped in the upper reaches but in concave in the lower reaches. With this in mind, the hypsometric curves were visually grouped into 4 categories; convex, S-shaped, S-shaped/concave and concave, see Figure 6-1

The statistical moments for each catchment, along with the hypsometric shape, were then analysed and compared to geological boundaries from Townsend et al. (2008) and Edbrooke (2005), mapped faults extracted from the GNS AFDB and Townsend et al. (2008) and lineaments layer described in 3.3. The 3rd order catchments are displayed in Figure 6-2. 


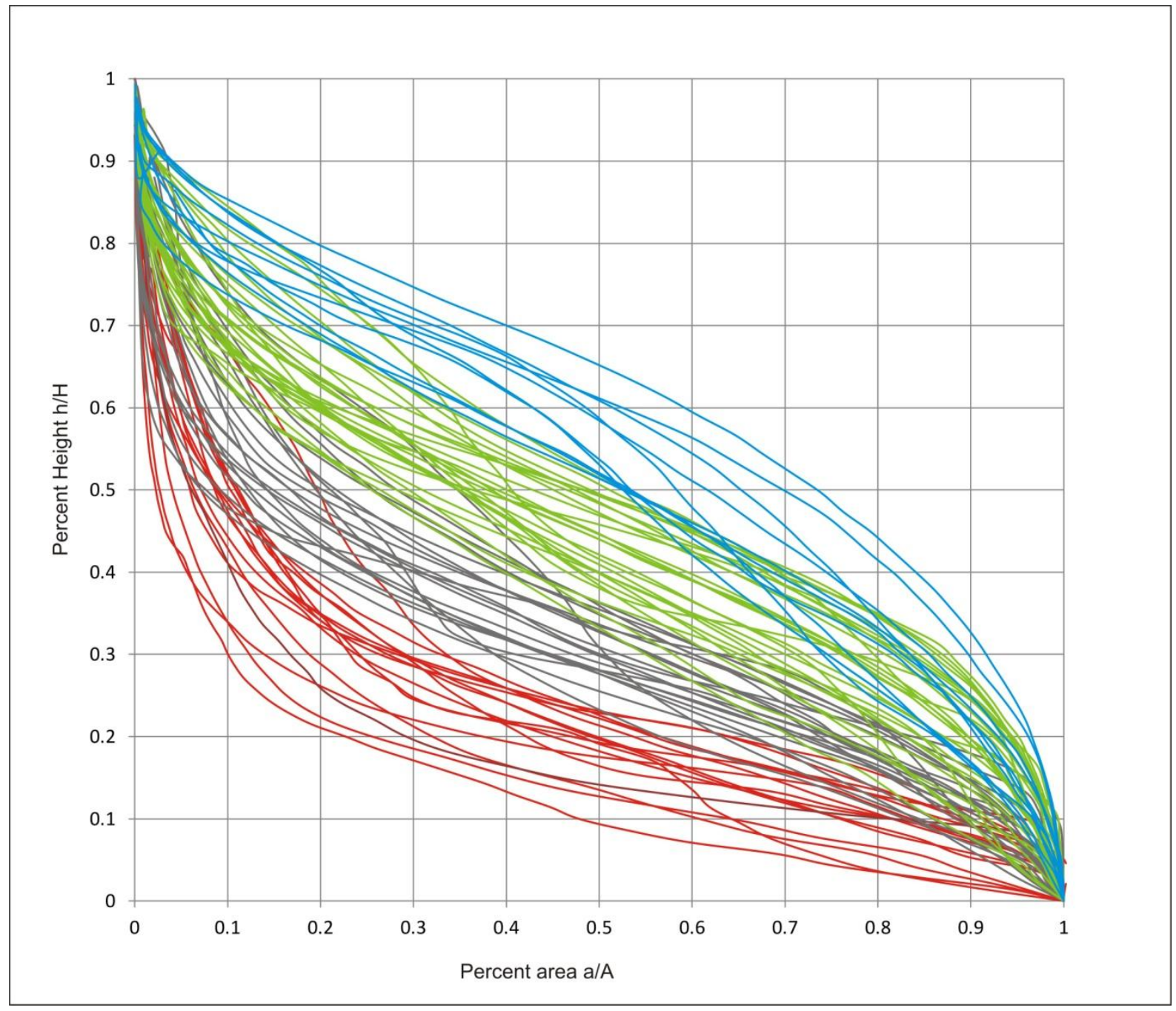

Figure 6-1. The hypsometric curves for the $733^{\text {rd }}$ order catchments within the study area. The colours of the curves represent the following classifications; Blue = Convex, Green = S-shaped, Grey = S-shaped/Concave, Red=Concave 

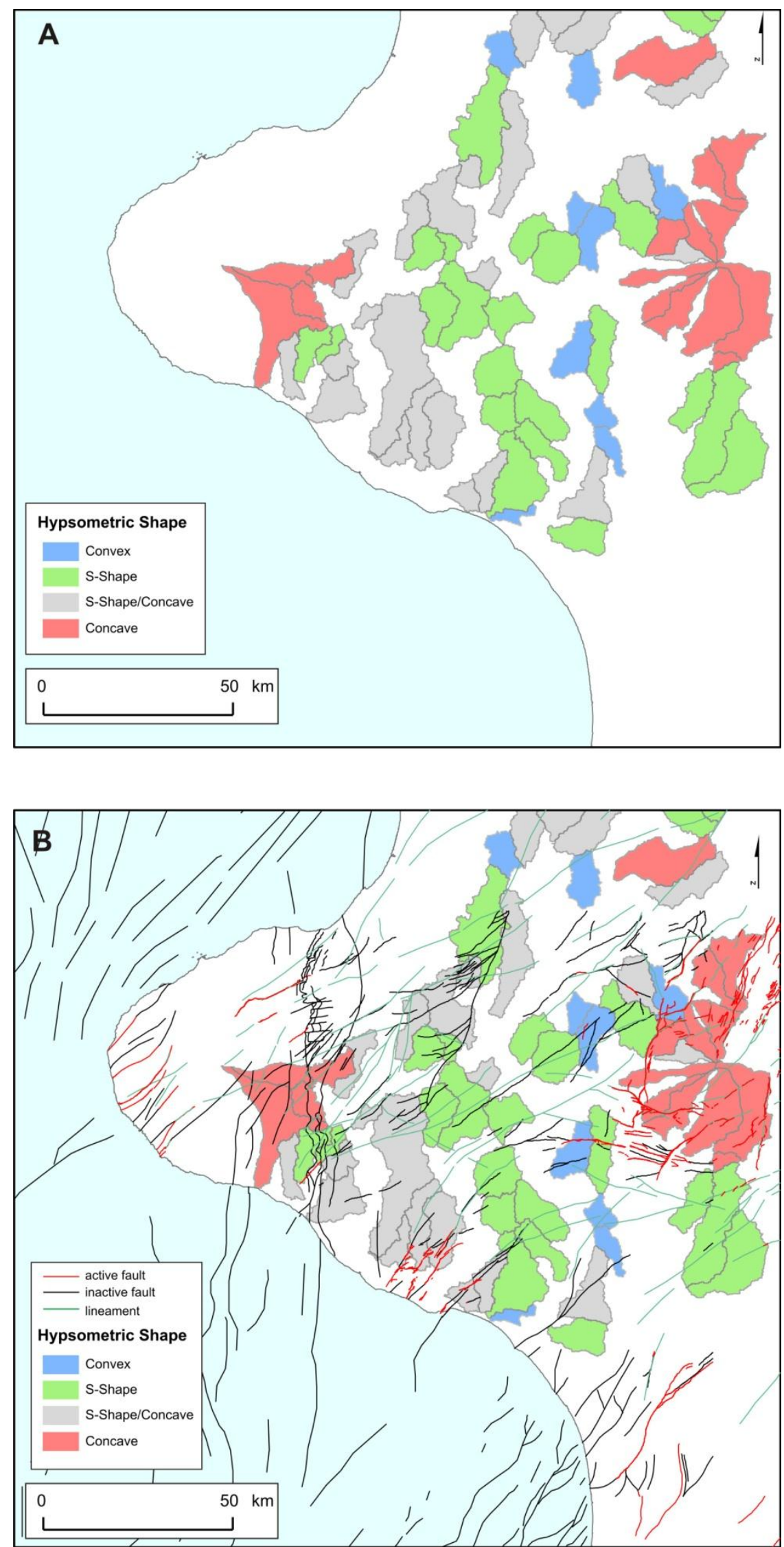

Figure 6-2. $3^{\text {rd }}$ order catchments displaying hypsometric shape. The colours of the catchments represent the following classifications; Blue = Convex, Green = S-shaped, Grey = S-shaped $/$ Concave, Red $=$ Concave . 
There is no easily discernible relationship between the mapped active faults and the shape of the hypsometric curves calculated for third order catchments. For example, the Waipuna fault crosses two adjacent catchments, one classified as convex and one classified as S-shaped. These catchments are also of approximately the same area and with similar geology. The catchments near the coast, which are crossed by the Waverly fault zone, are all classified as S-shaped/concave. With such little correlation it is almost impossible to say with any certainty that hypsometry can be used in the Taranaki region to identify tectonic processes. Geology has been identified as influencing catchment shape. The comparison of geology and catchment shape showed no easily discernible relationship for the convex, S-shaped or S-shaped/concave. The concave catchments do appear to be effected by geology, with all catchments from this group being located on the slopes of the Ruapehu, Tongariro and Taranaki volcanoes and containing volcanic materials.

The literature refers to hypsometric curves either being convex, S-shaped or concave. Often these classifications are not defined quantitatively and therefore there is some confusion between studies as to what defines a catchment as convex, S-shaped or concave (Strahler, 1952b; Luo, 1998; Willgoose and Hancock, 1998; Luo, 2000; 2002; Pérez-Peña et al., 2009a). This makes it hard to compare results between studies. Strahler (1952b), loosely used the hypsometric integral to quantify catchment shape i.e. $\mathrm{HI}>0.5=$ convex,$<0.5$ concave and around 0.5 as S-shaped. Much of the recent literature uses this method of classification. However, often these studies are only comparing between a few catchments, and are only interested in relative change between catchments. Therefore, a precise classification is not required. Many studies have identified geomorphic processes occurring within catchments and relate those processes to the shape of the hypsometric curve and the HI (i.e. Strahler (1952b), Ohmori (1993)). However, if the catchment shape is to be used to identify processes occurring within a catchment, the hypsometric shape first needs to be quantitatively defined. This study provides a chance to investigate a large sample of catchments over a wide range of geology and therefore presents an opportunity to quantify the shape first and then use the shape to identify the processes occurring within the catchment. Table 5 shows the averages for all statistical moments grouped by shape.

Table 5. The average statistical moment of all $3^{\text {rd }}$ order catchments. The average area for the convex catchment is smaller compared to the other groups.

\begin{tabular}{|l|c|c|c|c|c|c|c|}
\cline { 2 - 8 } \multicolumn{1}{c|}{} & $\mathrm{n}$ & Mean HI & Mean SK & Mean KUR & Mean DEN SK & Mean DEN KUR & Mean Area \\
\hline Convex & 9 & 0.54 & 0.37 & 2.08 & -0.33 & 1.68 & 66.16 \\
\hline S-Shaped & 25 & 0.45 & 0.41 & 2.07 & 0.07 & 1.45 & 123.81 \\
\hline S-Shaped/Concave & 23 & 0.34 & 0.52 & 2.12 & 0.54 & 1.70 & 104.77 \\
\hline Concave & 16 & 0.23 & 0.66 & 2.14 & 1.11 & 2.59 & 102.58 \\
\hline
\end{tabular}




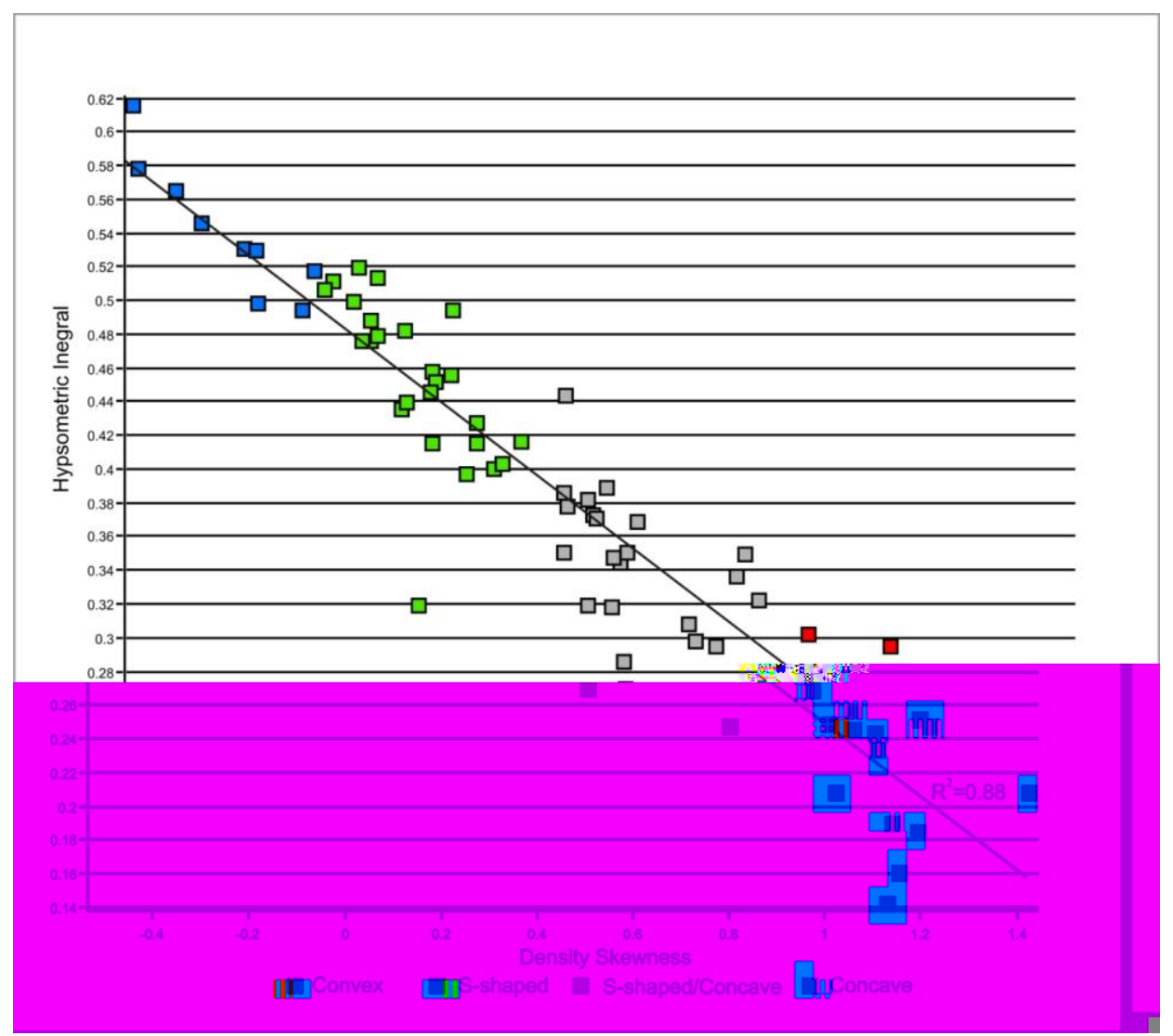

Figure 6-3. Density skewness and the hypsometric integral show a strong relationship. This shows density skewness could be used as another method to classify hypsometric curve into shape catagories.

Luo (2000) proposes that density skewness might provide a method to quantify shape. Figure 6-7 shows a comparison between density skewness and $\mathrm{HI}$ for all catchments and colour denotes the visually classified shape. There is a strong relationship $\left(R^{2}=0.88\right)$ between these two variables. This supports the suggestion by Luo (2000) that Den SK could be used as another method to classify the shape of the hypsometric curve. It is uncertain if the Den SK provides a better method for the classification of catchments than the HI. It is beyond the scope of this study to investigate this further but this result could provide and interesting study for future research.

\subsection{Stream Length Gradient Index (SLk Index)}

The test catchments have shown that the SLk index did not provide a clear indication of tectonic activity in the Taranaki region at a catchment scale, mainly because of the lack of active traces in the Tertiary countryside to be used as test areas. However, SLk changes did coincide with lithology changes, and thus areas of homogeneous lithology which may show changes in SLk are worth further investigation for fault activity. Also, the test catchments did not cover a large enough area to detect 
regional scale activity. With this in mind a region scale analysis was undertaken with the knowledge that any results will need to be carefully interpreted, as there are many other processes that can produce high SLk values. It was discovered from the test catchments that the LC and Otago DEMs were not suitable for SLk analysis. This was due to the issues with anomalous SLk values produced from interpolation of the DEMs from contour data. Furthermore, the test catchment also identified that a sample spacing greater than $500 \mathrm{~m}$ was required if the SRTM DEM was to be used. With this knowledge, the SLk index was calculated for all third order streams from the ASTER and SRTM DEMs at $500 \mathrm{~m}, 750 \mathrm{~m}, 1000 \mathrm{~m}$ and $1500 \mathrm{~m}$ using the methods outlined in Section 4.2.6. These point layers were then used to interpolate a raster surface of SLk index values for the study area. The SLk raster layers were then visually compared to geological boundaries from Townsend et al. (2008) and Edbrooke (2005), mapped faults extracted from the GNS AFDB and Townsend et al. (2008) and lineaments layer described in Section 3.3.

The SRTM SLk maps were compared to the ASTER SLk maps at each of corresponding sampling distances. The SRTM maps showed very similar areas of high SLk, but the areas identified were not as well defined as the ASTER maps. This distinct lack of detail was attributed to the resolution of the SRTM data, i.e. $90 \mathrm{~m}$ cell size compared to $30 \mathrm{~m}$. Therefore, it was decided to exclude these maps from further analysis.

The interpolated SLk maps provide a way to categorise area of low and high SLk. The SLk index is a dimensionless value and therefore break values for each category needed to be decided upon. All of the distributions of the SLk values are skewed toward low values. Therefore, a method to identify the break limits for each class of SLk was required. The interpolated SLk maps from the 4 sample distances were visually assessed using a range of methods for classifying values. The Jenks' Natural Breaks method was eventually used. The Jenks' method of classification was used as it reduces the variance within a class while maximising variance between classes and therefore is well suited for skewed distributions of dimensionless values (Jenks, 1967). Jenks' method is disadvantaged in that classes for each sampling distance will contain different ranges of SLk values. Consequently, this method does not allow for direct comparison between layers but is very useful in defining categories for break values. Three classes were used and defined as low, medium and high SLk. The four maps that were used to identify these results can be found in Appendix C.

The same areas of high SLk are detected at all of the sampling distances with the possibility that more detail could be interpreted at lower sample distances. The $500 \mathrm{~m}$ sampling distance was chosen to display the results, however, all of the sampling distances were referred to during analysis. 
The areas of high SLk were grouped into six areas that contain anomalous SLk values that are of interest to this study (see Figure 6.2). What follows, is a brief description of the six areas and an interpretation of the likely process that caused them, i.e. geological boundary or tectonic structure. The results of this analysis are discussed and will be compared to results from the other indices in Chapter 7. 

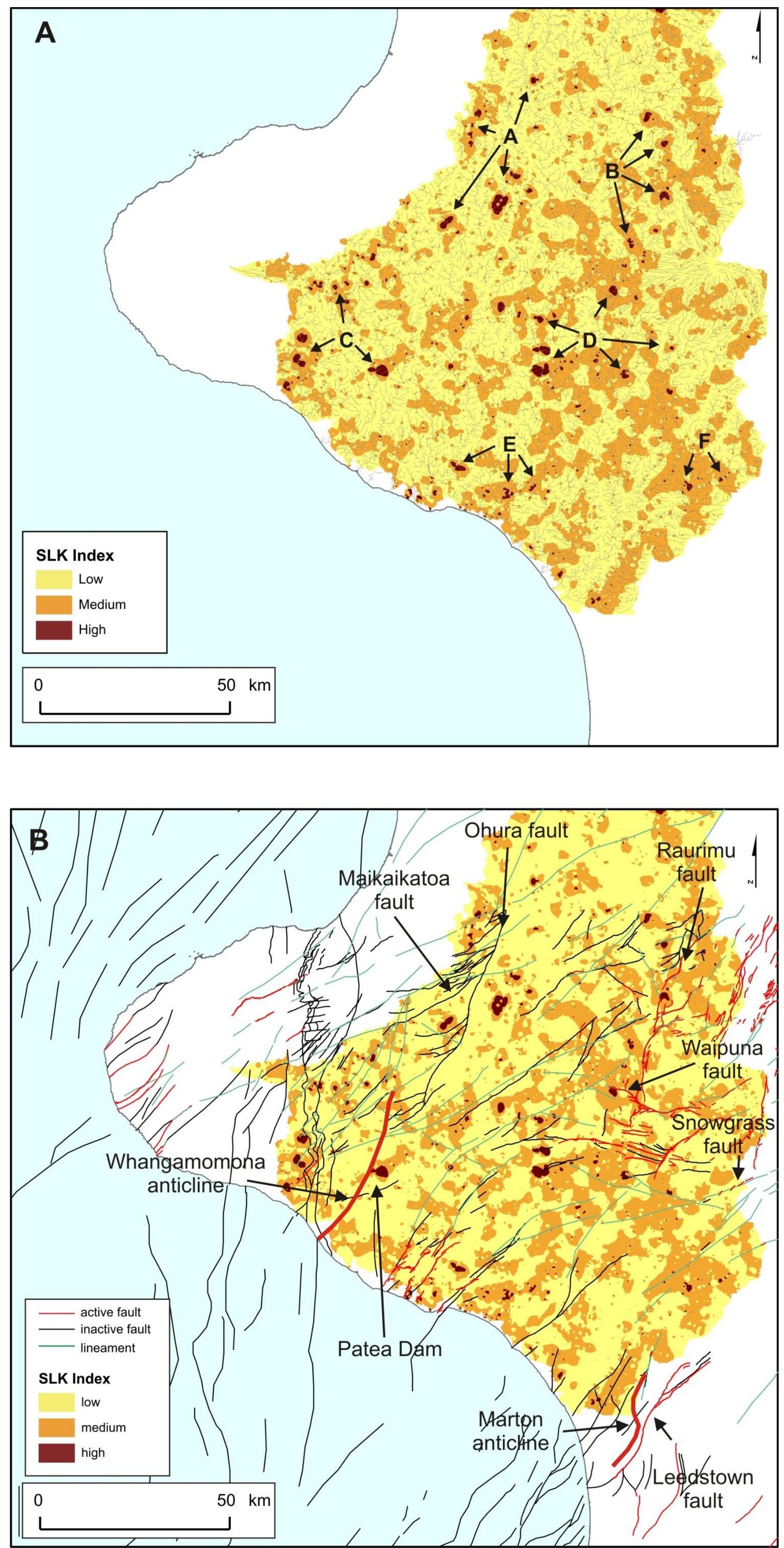

Figure 6-4. SLk index values for the study area interpolated from $500 \mathrm{~m}$ sample distance. A. The 6 areas of high SLk values with the $3^{\text {rd }}$ order streams used in this analysis. B. The 6 areas of high SLk with active faults, inactive faults and lineaments. 


\section{Area A}

This area contains the Ohura fault and other NE-SW trending inactive faults. There are high SLk values to the north west of the Ohura fault that correspond to where the streams cross these inactive structures. However the faults are also boundaries for changes in geology. The complexity of the geology makes it hard to suggest the SLk values are fault driven. To the south west, the high SLk value corresponds to inactive fault structure and there is no change in geology. The large anomaly to the east does not correspond to any mapped structure or geological boundary. The aforementioned area of high SLk will be discussed further in Chapter 7.

\section{Area B}

All of the anomalous SLk values in this area, apart from one to the south, correspond to where streams cross mapped tectonic structures. The anomalies to the north intersect structures that have been mapped as inactive. The anomalies to the south correspond to the N-S trending Raurimu fault. The Raurimu fault is a large normal fault that is downthrown to the east and the streams cross this structure flowing to the west. Due to the geometry of this fault, the apparent high SLk values would not be expected.

\section{Area C}

In the north of this area, anomalous values are associated with a series of parallel valleys that have been mapped as lineaments. These valleys are also the transition from volcanic deposits, mostly Ngeare formation, into the softer Matemateaonga formation sandstone. The presence of volcanic sediments in these valleys is thought to be causing the high SLk values. To the south-west, the largest SLk value of the entire study area can be found. It is located directly on the Patea hydroelectric dam. The anomalies to the south-east are all associated to the transition from volcanic sediments to marine terrace deposits. The SLk analysis for this area shows no evidence for active faulting.

\section{Area D}

In this area high SLk values partly correspond to the eastern mapped extent of the Ohakune and Waipuna faults. The high values to the south are located on top of unnamed, inactive traces. The anomalies also correspond to the boundary of Matemateaonga formation sandstones and mudstones then into Tangahoe mudstone. The Mangoihe test catchment showed an increase in SLk crossing this geological boundary and therefore it is likely that similar processes are occurring in this 
area. However the proximity of Area $D$ to large active faults that have ruptured recently warrant further investigation and will be discussed in more detail in Chapter 7.

\section{Area $\mathbf{E}$}

This area comprises the boundary of the Plio-Pleistocene marine sediments and a series of uplifted marine terraces. All high SLk values correspond to this transition or where the stream crosses onto a lower terrace. The highest values are found where the stream crosses from Pilo-Pliestocene materials onto the marine terrace deposits. This area is similar to the Kai Iwi test catchment and SLk anomalies in this area are not thought to be tectonically driven.

\section{Area F}

This area contains a series of anomalous SLk values that run parallel to a mapped NE-SW trending lineament. There is also an anomaly associated to a change from Plio-Pleistocene materials and marine terrace deposits. This anomalies trend NE-SW along strike with many of the nearby mapped active faults i.e. the Leedstown fault and the Snowgrass fault. 


\subsection{Sinuosity Index (SI)}

Streams from this region adjust relatively quickly to any change in elevation due to the relative weak competency of the underlying geology. A majority of the streams in this region are alluvial and meandering. A vertical change to the stream bed causes a change in stream power and therefore the ability of the stream to transport sediment changes. Where the stream power decreases, deposition occurs and where stream power increases, erosion occurs. This adjustment, through erosion and deposition, can then influence stream geometry (Schumm et al., 2000). A vertical change to a stream bed will also increase the length of the stream. A stream will adjust by progressively eroding material on the upthrown side and depositing material on the downthrown side of the perturbation. Alternatively, and often occurring in conjunction with stream bed erosion, a stream will erode the banks. The erosion of the banks and on longer time scales the valley walls increases the overall stream length which in turn increases the sinuosity of the stream. Therefore streams that are sinuous are most likely to occur in areas where a stream is relatively unconfined or where the stream bed is harder to erode.

As discussed earlier in Section 4.3, there are many reasons for an increase in stream sinuosity. However, for this study only three main drivers are considered: 1 ) changes in the competence of the geological formations along a river stream (i.e. location of mapped geological boundaries), 2) a large sediment supply, and 3) interaction with a fault or fold. These three very simple criteria are unfortunately not mutually exclusive, i.e. a fault could be the boundary for a change in the underlying geology. Furthermore an increase in sediment supply can also shift a stream from a meandering form to a braided form. Therefore, the information gained from interpolated sinuosity maps will not provide a definitive identification of tectonics as the main cause of sinuosity, but results will identify areas where sudden changes in sinuosity values between multiple streams are apparent. In particular, where the change in sinuosity is linear across multiple streams, a change in geology or a tectonic structure can be inferred. Therefore the sinuosity of a stream, used in conjunction with an understanding of alluvial stream processes and other geomorphic indices, could provide supporting evidence for possible fault rupture as the main cause of the perturbation to the stream pattern. These areas can then be highlighted for more detailed investigations.

The interpolated sinuosity Index maps are similar to the SLk index maps described in Section 6.2. The point data used to interpolate the sinuosity Index has the same properties as the point data used to interpolate the SLk index, i.e. they are dimensionless values and the distributions are also skewed toward low values. Therefore, the same method as used to display the SLk data was also used for 
sinuosity data, i.e. Jenk's (1967) natural breaks with three categories of low, medium and high. Appendix 3 contains maps showing the 4 sampling distances displayed, using the above method.

\subsubsection{DEM Horizontal Resolution and Sinuosity}

Originally it was planned to calculate sinuosity values from the four stream networks derived from the four DEMs. Upon examination of the stream network it was noticed that the streams derived from the SRTM and ASTER datasets show a marked difference in the accuracy of stream definition due to the pixel size of these datasets. One of the main observed differences was straightening of a stream channel on torturous meander bends (see Figure 6-5). This issue was very likely to cause sinuosity calculations derived from these datasets to be extremely low and therefore not provide an accurate representation of sinuosity. The Otago and Landcare datasets are derived from a very similar base dataset (contour line and spot heights) and therefore comparison between these dataset is not necessary. With this in mind, it was decided to use only the Otago dataset for sinuosity calculations.

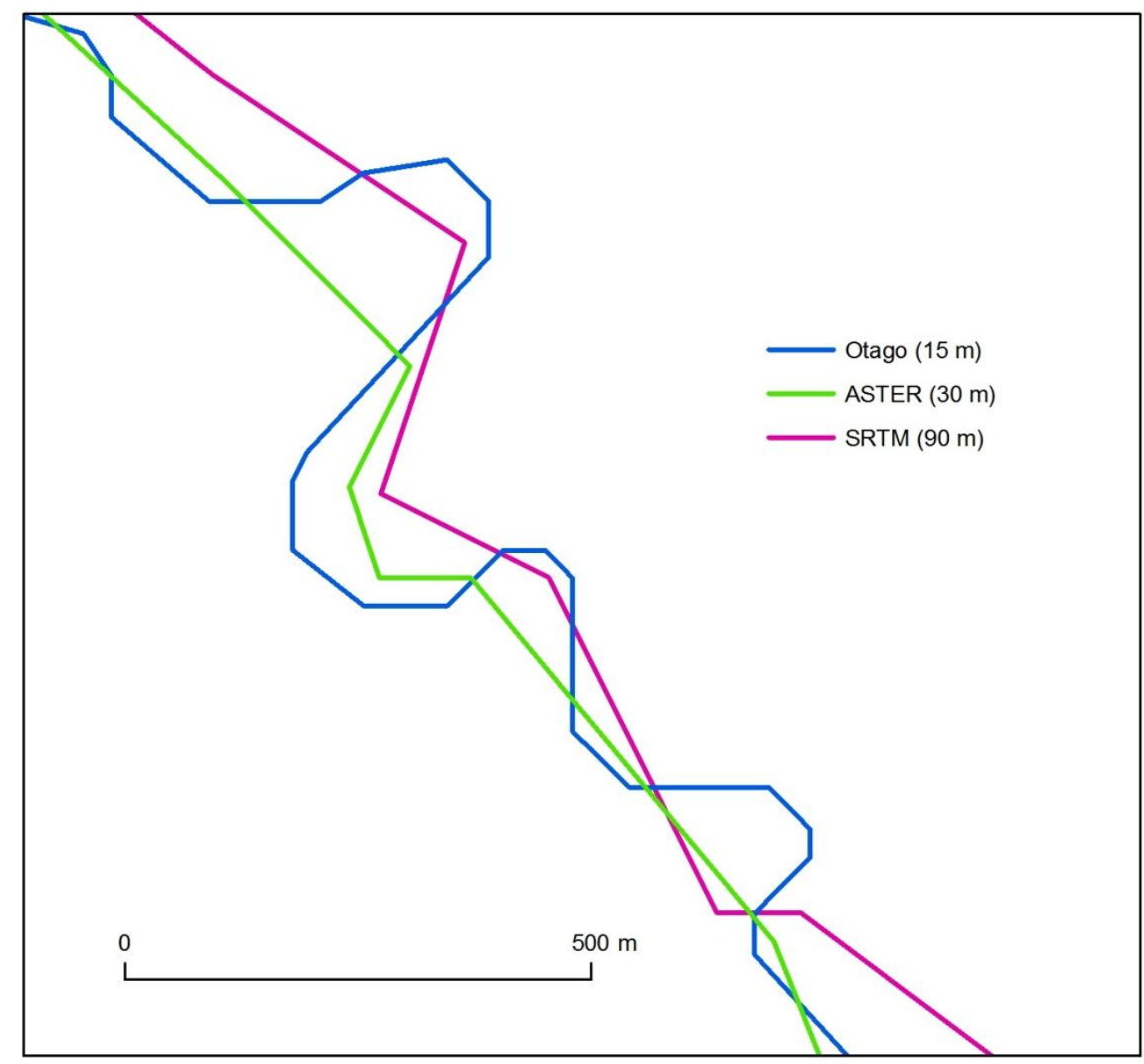

Figure 6-5. Issues with DEM pixel size (horizontal resolution). A larger pixel size causes the straitening of a sinuous channel in the SRTM and ASTER dataset. 
Sinuosity was calculated at a sample distances of $250 \mathrm{~m}, 500 \mathrm{~m}, 750 \mathrm{~m}, 1000 \mathrm{~m}, 1500 \mathrm{~m}$ and $2000 \mathrm{~m}$ using the Otago DEM as outlined in Section 4.3.3. The resulting point layers were interpolated into a $90 \mathrm{~m}$ cell size raster layer using IDW (see Section 4.3.5. for details). The sinuosity raster layers were then visually compared to geological boundaries from Townsend et al. (2008) and Edbrooke (2005), mapped faults extracted from the GNS AFDB and Townsend et al. (2008) and the lineaments layer described in Section 3.3.

Comparing between the six sampling distances has identified that sampling distance does not affect the location of high SI values. The interpolation of larger sample distances produces a larger area of high SI and the converse is true for the smaller sampling distances. This is simply the effect of fewer points being used to interpolate a surface. The amount of detail in the smaller sampling distances (i.e. $250 \mathrm{~m}$ and $500 \mathrm{~m}$ ) suggests these data could be used to identify finer scale processes than the large sampling distances. However, due to the scale of the mapping of geological boundaries and some faults not containing enough detail to ensure the anomalous SI value corresponds to the mapped data. A recommendation of this study would be a detailed analysis of sinuosity in an area where the effects of geology, faulting and sediment deposition can be tested. This would require mapping of geology, faults, sedimentary records and stream channels at a finer scale than used in this study.

Appendix 2 contains maps showing the 6 sampling distances displayed using the above method. Areas of high sinuosity in the maps were considered and assessed as to the most likely causes for high sinuosity values. Ten areas were identified that contained zones of high sinuosity on all of the sinuosity index maps. Figure 6-6 shows the ten areas with the interpolated SI values on top of the $1500 \mathrm{~m}$ sampling distance. Following is a detailed description of each of these areas with a summary of the processes thought to be influencing stream sinuosity. 

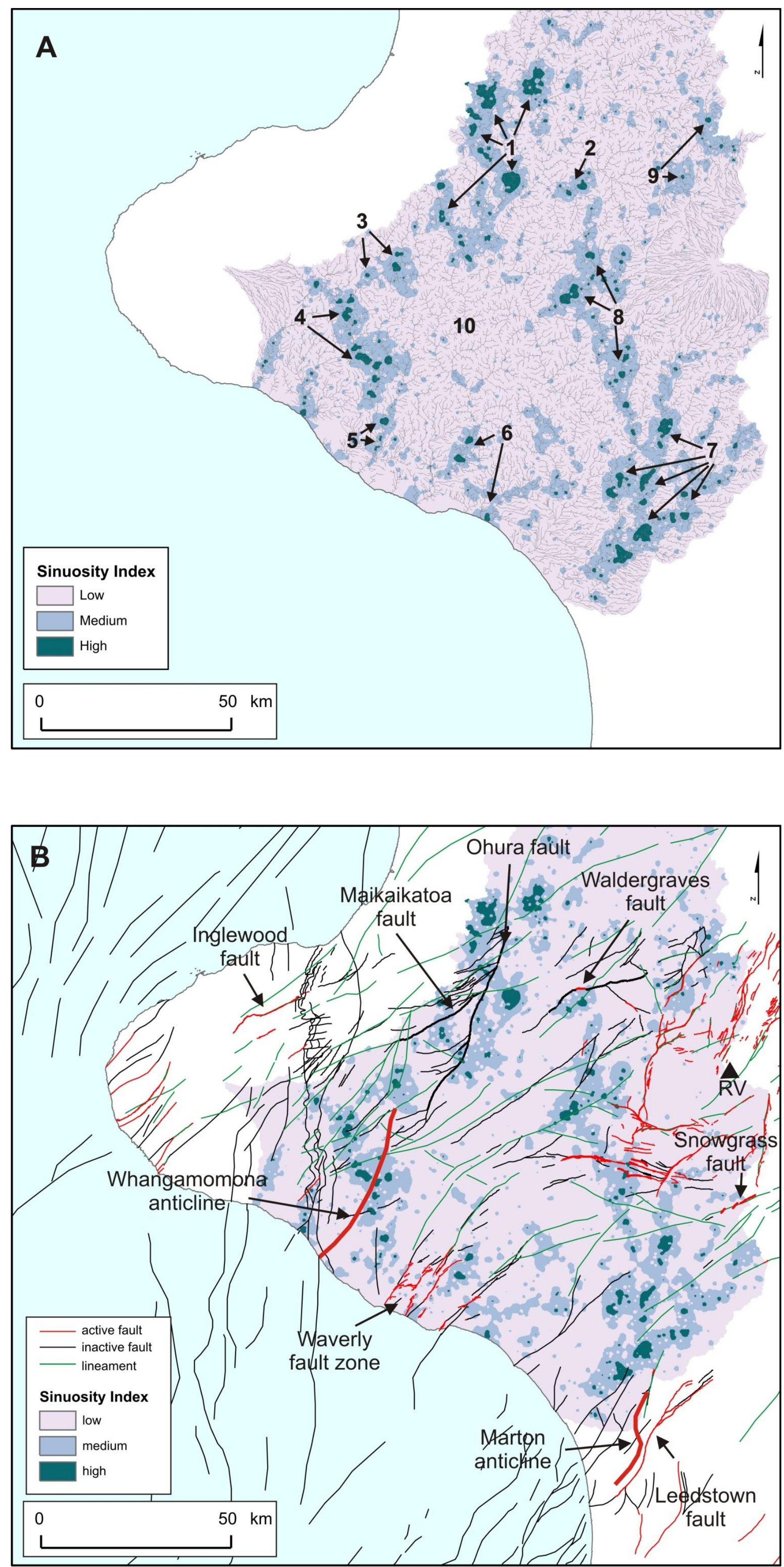

Figure 6-6. The sinuosity index values interpolated from a sample distance of $1500 \mathrm{~m}$. A. The 10 areas of high sinuosity the the stream used to sample the index. B. The 10 areas of high sinuosity with active faults, inactive faults and lineaments. 


\section{Area 1}

The geology of this area consists of Miocene Mount Messenger Formation mudstone and Kiore Formation sandstone. This is a geologically complicated area with several inactive faults traces. In such a complex area, there are many possible causes for high SI values:

\section{Stream interactions with geological formations.}

Over a small area, the streams cross numerous sedimentary rocks with different competency (i.e. resistance to erosion): mudstones, siltstones and limestones. The rock formations consist of bedded units of meters to tens of meters scale. The softer materials could be causing the high SI values.

\section{Previous fault activity.}

In this area, there are multiple examples of possible interaction of mapped inactive faults influencing stream sinuosity. Mapped lineaments also seem to coincide with high sinuosity values. For example, the Ohura fault deflects the Makau stream (see Figure 6-6B). The Makau stream flows to the south east until it reaches the Ohura fault where it follows along strike with the fault for $\sim 12 \mathrm{~km}$. The sinuosity of the Makau stream increases just before crossing the fault. The Ohura fault has uplifted and tilted the block to the west. Tilting could be also responsible for some of the sinuosity to the west of the Ohura fault as streams are forced to flow in a slightly different direction.

The other main structure in this area is the Maikaikatoa fault. The Maikaikatoa fault has a similar strike as other inactive faults, active faults (i.e. Inglewood fault and Waldergraves fault) and mapped lineaments in this area.

\section{Current fault activity.}

If the Ohura and other smaller NW trending faults are still active, they could be causing the high SI values mentioned in point 2 above. Gravity studies across the Ohura fault suggest that the fault underwent large vertical displacements since the Tertiary (Walls, 2004). High SI values associated with the fault suggest that the fault could still be active and further detailed studies on potential recent fault activity are worth pursuing.

The concept of inherited sinuosity values presented in point 2 above is very relevant for areas where the drainage patterns are long established and faults may have shut down activity since the establishment of the drainage. Within the study area, this process may be more likely to occur in the northern half of the area. Further studies of the activity of the Ohura and Maikaikatoa faults will help assessing if sinuosity values may be long lived or may be reset when fault activity shuts down. 


\section{Area 2}

Several inactive fault traces, lineaments and one small active fault trace that have been mapped in the area correspond with high SI values. The high SI values suggest that some of the inactive traces or lineaments may be active and/or the small active trace may be longer. For example, the Waldegraves fault crosses the Retaruke stream in two places with a corresponding increase in sinuosity on the downthrown side of the fault. There is also a lineament that crosses this stream that is along strike with the high sinuosity values. However, some of these points of high SI values could also be influenced by changes in the geology along streams. For example, the Retaruke stream is deflected to the NW when it hits the boundary of the Mount Messenger Formation mudstone and Kiore Formation sandstone. This location is an example of where sinuosity could be due to faulting, topography or geology or a combination of all three. Because of the presence of an active trace in correlation with high SI values, this area is a good candidate for further detailed studies to assess the influence of geology or faulting on localised stream sinuosity.

\section{Area 3}

In this area, high SI values correlate with the location of the boundary between the Kiore Formation (mainly sandstone) and Matemateaonga Formation (mainly mudstone at that contact). Also a mapped lineament runs parallel to the stream channel. Again this is an area where geology and/or tectonics could be a cause for increased SI values.

\section{Area 4}

Increased SI values in this area are located immediately beyond the Taranaki ring plain and in association with the Ngaere swamp. The swamp is likely to be associated with large volcano collapse episodes (Alloway et al., 2005). There are also several inactive faults and lineaments crossing the streams. While it is possible that high SI values could be associated with lineaments, it is more likely the presence of the swamp (i.e. an abrupt change in elevation and a historic deposition of the Ngaere formation) caused the increase in SI values.

\section{Area 5}

High SI values are spatially associated with the active Whangamomona anticline. The axis of the anticline is located at the western edge of the high SI anomaly. In fact high sinuosity along the Patea River is clear from a few kilometres east the axis of the anticline, crossing the axis and all the way to Area 4 (see Townsend et al., 2008). It is not clear what could be the exact mechanism to produce high sinuosity in the uplifted part of the anticline (close to the axis). One would expect to find incision and thus less sinuosity in the uplifted part of the anticline. High SI values are likely to be 
found further away from the axis, upstream of the anticline, at the point where the Patea River runs into the western limb of the anticline. The exact location of the trace of the anticline is only inferred. Therefore is it is possible that the actual trace lies to the east of the current location on the map which would better explain the high SI values found.

An alternative cause for the presence of high SI values in this area would be the presence of unknown active faults. There are some NE trending lineaments in the area crossing the Patea River and other streams. If any of the lineaments were active, high SI values would be expected in the downthrown side of the faults. More detailed studies are required to prove the cause for the high SI values in this area.

\section{Area 6}

Active traces of the Waverly fault with normal sense of movement have been mapped on the marine terraces near the Waverly township (Townsend, 1998). The fault scarps are clearly preserved in the harder marine terrace sediments but they disappear when traces run into the more erodible Pleistocene materials. It is not clear why there are not high SI values associated with where the streams cross the active traces in the marine terraces. However, there are high SI values found in the Pleistocene sediments around where the active traces extend into the softer sediments.

One could interpret that the mapped active traces may be longer than currently mapped and that there could be more active traces to the East of the currently mapped traces based on the presence of high SI values. However, the reasons why high SI values are not mapped across the active traces remain unexplained.

\section{Area 7}

Several active tectonic structures and other structures mapped as inactive but with similar trends as the active ones are located in close proximity to the high SI values in Area 7. For example, the extension of the active Snowgrass faults (Lee et al., 2011) is associated with one of these SI anomalies.

Other high SI anomalies, aligned in a NE trend, are located along the Turakina River. The Turakina River has its headwaters in Tangahoe mudstone and Paparangi group sandstone. At approximately $32 \mathrm{~km}$ downstream the channel has incised through all surrounding lithology and flows over Ohakean alluvium until it reaches the sea. The mapped faults, folds and lineaments (all mapped as 
inactive) in this area run parallel to the stream network. There are high SI index values along the entire length of this stream that do not appear to correlate with any mapped structure or lineament crossing the stream. However, given that the active Marton Anticline and Leedstown Fault (located further east of this anomaly, and outside the study area) are trending in the same direction as the features mapped as inactive and also parallel to the $\mathrm{SI}$ anomaly, it is possible that there is an active NE trending fault in close proximity to the Turakina River.

An alternative explanation for the presence of high SI values along the streams in area 7 is a large sediment supply due to laharic processes. In the last $\sim 150,000$ years, lahars and alluvial deposits derived from the erosion of lahars, have been deposited and reworked along the rivers that drain Mt Ruapehu on its southern and south-eastern sides (Hodgson, 1993). High SI values can be associated with large sediment supply through deposition and thus reducing stream slope. A large pulse of material is likely to persist for a long period after a lahar due to the material being more able to resist erosion than the surrounding Plio-Pleistocene sediments of the Matemateaonga, Tangahoe and other marine formations.

Area 7 has very interesting features and the potential to evaluate the influence of active tectonics on stream sinuosity in the region with further detailed studies. Those studies should also include the area of the active Marton Anticline and Leedstown Fault as a calibration for the geomorphic indices.

\section{Area 8}

This area consists of volcanic derived deposits of the Mt Rupehu ring plain as well as Plio-Pleistocene marine sediment. There are several potential reasons for the high SI values:

1. Influence of volcano topography and change from the harder ring plain laharic surface to softer Miocene to Pliocene deposits.

In the flat areas of the ring plain and within a band of $\sim 6 \mathrm{~km}$ in width extending outside the ring plain, high SI values could relate to the abrupt change in topography from the steep slopes of the volcano to the almost flat topography of the ring plain. Also the change in geology from harder volcanic to softer marine derived sediments may contribute to presence of high SI values. Within this high SI value area, some active faults are mapped. The SI values are higher in association with these mapped faults.

2. Active faults in this area have clear fault scarps in the ring plain while scarps are not observed in the Plio- Pleistocene marine sedimentary rocks.

High SI values are associated with these faults along streams flowing on the ring plain as well as those flowing on the marine sediments. To the south of Mt Ruapehu, anomalous sinuosity values 
occur close to the Waipuna and Oruakukuru faults where they cross the Mangawhero River. The highest SI values occur on the downthrown side of the each of these faults. The Raetihi south and Oruakukuru faults both rupture through homogenous material on the upthrown and downthrown side of the fault. This suggests that the increase in SI values is due to the fault rather than a change in lithology. The Waipuna fault shows increased SI values on the downthrown side. However, this relationship is complicated by a change of lithology from sandstone of the Matemateaonga formation to Tangahoe mudstone. The change in relative strength of the underlying lithology is likely to enhanced the sinuosity of the stream (the Tangahoe mudstone on the downthrown side is highly erodible). This is also complicated further by the presence of the Waimarino formation (hard laharic sediments; Hodgson, 1993). Where the fault crosses the river, the river channel appears to drop off the Waimarino lahar deposits onto the Tangahoe mudstone (see Figure 6-7). Once again this would likely enhance sinuosity values downstream due to the change from harder to softer materials.

\section{Presence of an active fault not mapped previously.}

Further to the south from the Waipuna fault, there are two anomalies that appear to coincide with $\mathrm{E}-\mathrm{W}$ trending mapped lineaments and an inactive fault trace. If these high SI values are associated with faulting, these lineaments would have to be downthrown to the north (see Figure 6-7),

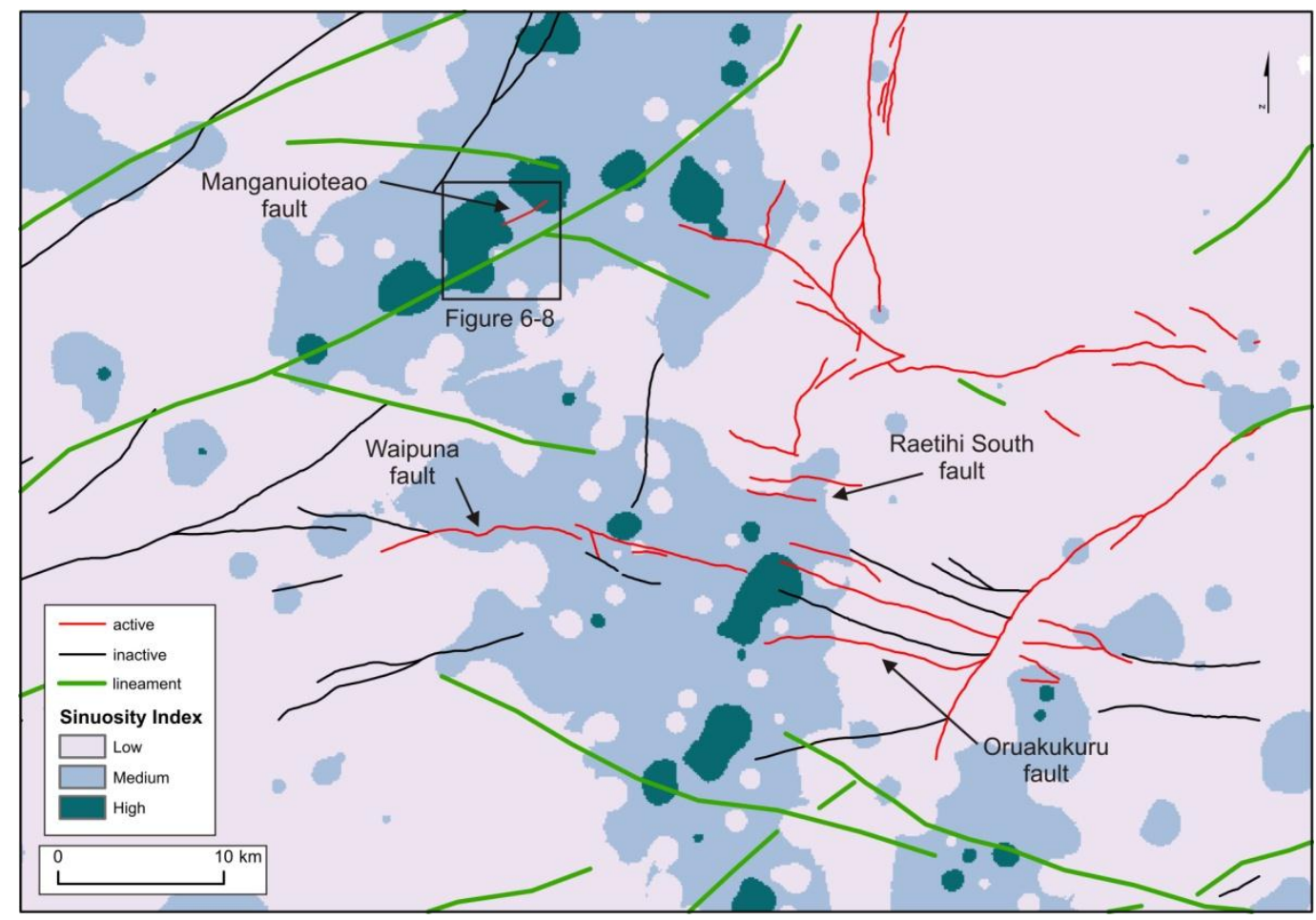

Figure 6-7 Area 8 with the location of active faults inactive faults and lineaments. The black box indicates the location of Figure 6-8. 
producing a graben type structure with the axis of the graben to the south of the Waipuna fault. The mapped inactive fault and lineaments have all been mapped in Tangahoe mudstone and therefore it is likely that if a faulting event did rupture the surface, the fault scarp may have been removed by erosion. These high SI values could be due to faulting of a similar size as the faults to the north. West of Mt Ruapehu, the Manganuioteao Fault along the Manganuioteao stream is not mapped as an active fault. However, high SI values are strongly associated with it. Brief aerial photo review shows potential active traces displacing alluvial terraces of the stream (see Figure 6-8).

In general, this area is very complex but has good potential for focused aerial photographic interpretation, detailed LiDAR studies, and field reconnaissance to assess presence of active faulting.

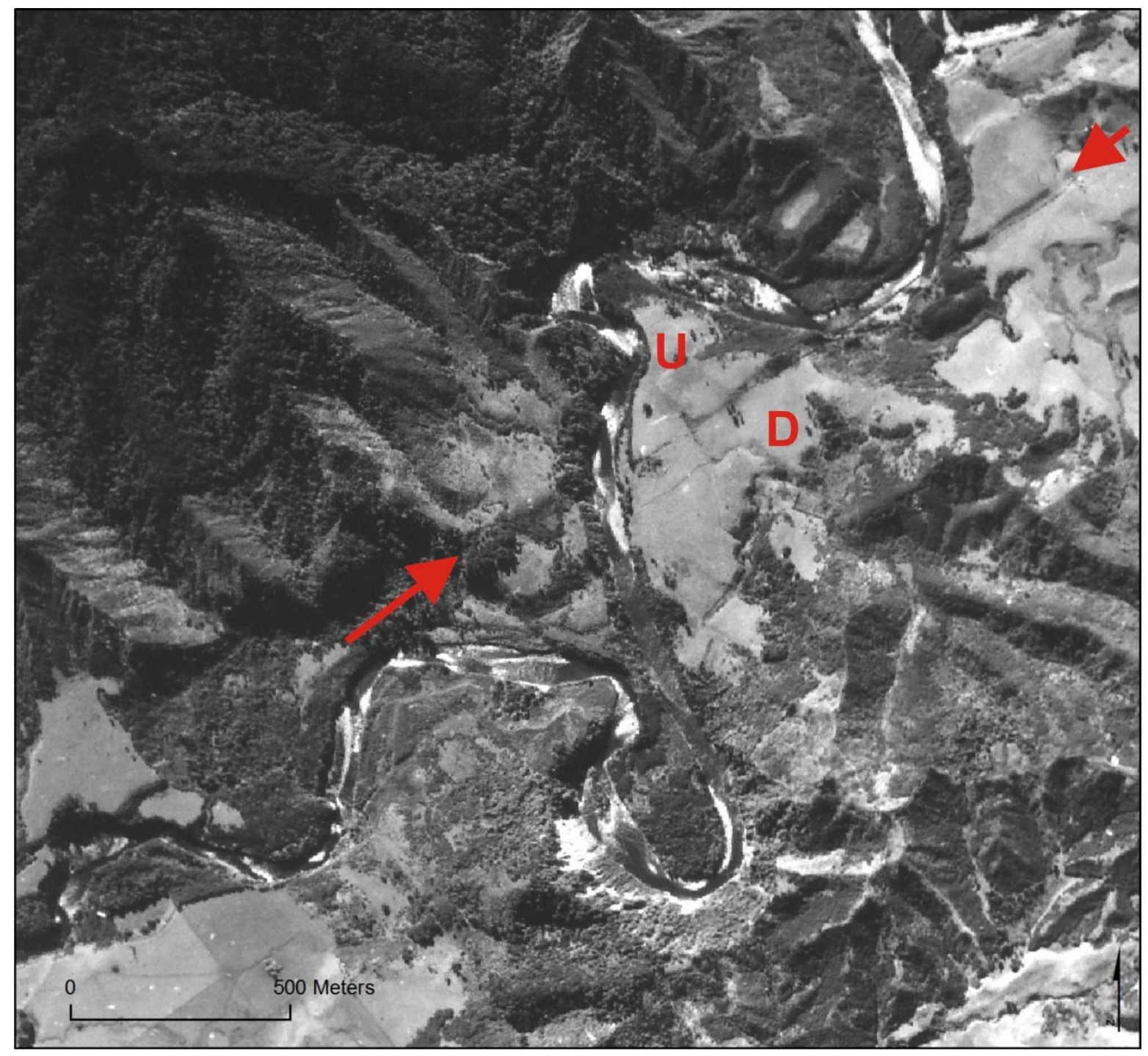

Figure 6-8. Aerial photographic review of an area of high sinuosity has identified a previously unmapped fault. The Manganuioteao fault is indicated by the two red arrows. 


\section{Area 9}

Area 9 has a complicated geology. It straddles the ring plain and Miocene marine sediments but also has exposed basement rocks, lahars and ignimbrite deposit. The area has several faults mapped as inactive; some of them are parallel and in close proximity to active faults (for example to the National Park fault that bounds this are to the east). Therefore, changes in geology along the stream as well as presence of potentially active faults could be causes for elevated SI values. In addition abrupt changes in elevation from the steep slopes of the volcano to the ring plain (similar case to point 1 in area 8) may also influence stream sinuosity.

\section{Area 10}

This area is highlighted due to the absence of streams with high sinuosity values. This area is a topographic high and has been an area of interest for earth scientists. The area has increased shallow seismicity compared to the rest of the region and is associated with an E-W trending gravity gradient. The gravity feature is referred to in the literature as The Taranaki - Ruapehu line and coincides with a change in the thickness of the crust (Sherburn and White, 2005; Reyners et al., 2006). While the deep crustal structure seems to extend $E$ and $W$ beyond area 10 (into Area 3 and 8), the shallow seismicity is mainly located within Area 10.

The SI clearly identifies that this area is different to the rest of the region. Given the elevated topography of Area 10 in comparison to the surrounding region and the lack of high $\mathrm{SI}$, it is possible that Area 10 in undergoing uplift compared to the surrounding regions. Maintained uplift can explain steepening of streams and/or enhanced incision, two processes that will produce low SI values. The reasons for the uplift are unclear. The lack of high SI values in the area could also indicate absence of active faults in this region. 


\subsection{Asymmetry Factor}

As discussed in Section 4.4, asymmetric catchments have been related to active folds in the marine gravel platforms of the Manawatu region, south of the study area (Jackson et al., 1998). One aim of this study was to identify if there is evidence of similar asymmetric catchments further to the northwest within the Taranaki study area. To achieve this aim, the asymmetry factor was calculated for all $3^{\text {rd }}$ and $4^{\text {th }}$ order catchments for all of the four DEMs within the study area using the methods outline in Section 4.4.2. Comparison of asymmetry values between the DEMs showed no discernible difference between catchments as long as care was taken to ensure the main trunk stream was identified correctly and the modelled catchment divide followed a similar path.

A preliminary evaluation of asymmetry values from $3^{\text {rd }}$ order catchments showed no clear correlation with mapped active structure or geological boundaries (cf. maps in Appendix D).

A more detailed analysis is required to assess if maps of low-order catchments can be used to identify active tectonics. Given that the tectonic structures of interest for this study are likely to influence larger catchments, this study will focus only on asymmetry in $4^{\text {th }}$ order catchments to assess presence or absence of active tectonic structures.

Catchment asymmetry was calculated with the ASTER DEM. Asymmetry factor results for $4^{\text {th }}$ order catchments are presented in Figure 6-9 and Table 6. Asymmetry values are displayed using the categories and colouring outlined in Section 4.4.2. What follows are the main observations comparing asymmetry calculation to the mapped tectonic structure.

The majority of the $4^{\text {th }}$ order catchments within the study area are classified as symmetrical. Half of the catchments classified as low asymmetry are within 1-3\% of the threshold of symmetric class. There are no $4^{\text {th }}$ order catchments with high asymmetry and only one extremely asymmetric catchment. The shapes of the catchments vary greatly, with a mix of elongated and round catchments. 

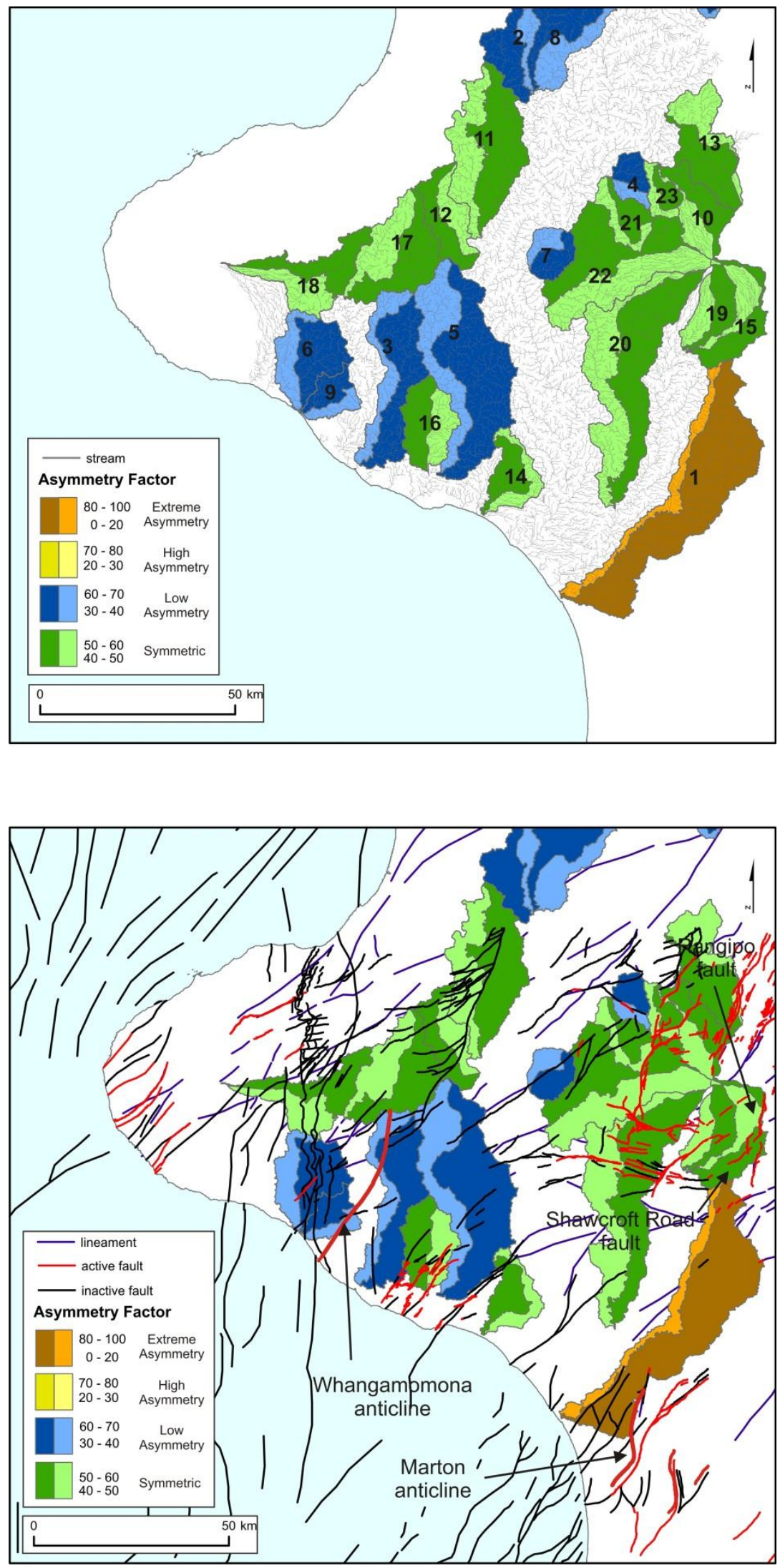

Figure 6-9. Upper figure shows asymmetry factor values for $4^{\text {th }}$ order catchment in the study area. Lower figure shows asymmetry values overlain with active faults from the Actice Faults database, inactive faults and lineaments from Edbrook et al. (2005), Townsend et al. (2008), and Lee et al. (2011). 
Table 6. Asymmetry factor values for $4^{\text {th }}$ order catchments

\begin{tabular}{|l|r|r|}
\hline Catchment Name & Catchment ID & Asymmetry \% \\
\hline Turakina & 1 & 83.1 \\
\hline Waitewhena & 2 & 68.7 \\
\hline Whenakura & 3 & 67.2 \\
\hline Kaitieke & 4 & 65.9 \\
\hline Waitotara & 5 & 65.6 \\
\hline Tangahoe & 6 & 62.8 \\
\hline Mangatiti & 7 & 62.4 \\
\hline Ohura & 8 & 61.3 \\
\hline Ingahape & 9 & 61.0 \\
\hline Whakapapanui & 10 & 59.8 \\
\hline Tangarakau & 11 & 59.2 \\
\hline Whangamomona & 12 & 58.2 \\
\hline Upper Whanganui & 13 & 56.9 \\
\hline Kai Iwi & 14 & 56.9 \\
\hline Whangaehu & 15 & 56.8 \\
\hline Weraweraonga & 16 & 56.8 \\
\hline Mangaehu & 17 & 56.5 \\
\hline Patea & 18 & 56.5 \\
\hline Te Unuunuakapuateariki & 19 & 56.5 \\
\hline Mangawhero & 20 & 55.4 \\
\hline Retaruke & 21 & 52.3 \\
\hline Manganuioteao & 22 & 52.1 \\
\hline Tepure & 23 & 50.7 \\
\hline
\end{tabular}

The Turakina catchment (catchment 1, Figure 6-9), is extremely asymmetrical. This asymmetry has been attributed by Jackson et al. (1998) to uplift associated to the active Marton anticline (i.e. to the tilt of the western anticline limb). Jackson et al.'s (1998) mapping of this structure was based on evidence of increased elevation in the surface of the marine terraces. While the marine terraces consist of gravels that are relatively resistant to erosion, to the $\mathrm{N}$ and NE Plio-Pleistocene mudstones are more erodible. Where this structure crosses into the softer Plio-Pleistocene material to the NE the structure is less clear. The mapping of the anticline has not been able to close the structural contours and therefore the termination of this anticline to the north is unknown.

The currently mapped extent of the Marton anticline does not explain the asymmetry observed in the upper reaches of the Turakina catchment. As shown in Figure 6-9 the mapped extent of the anticline is too short to explain that asymmetry further north. Therefore the following explanations are considered: 
1. The Marton anticline extends further to the north than currently mapped. The Plio-Pleistocene materials are more easily eroded than the marine gravels that preserve the current trace making it hard to identify the extent of this structure.

2. Alternatively there could be two parallel, unmapped, en-echelon structures with similar lengths to the Marton anticline. It is suggested, that if this was the case, the structure would be along strike with other faults, such as the Snowgrass and Leedstown faults and the faults that have been mapped offshore (Lamarche et al., 2005). It could also be possible for this structure to run parallel to the bed of the Turakina River.

The Turakina catchment is extremely asymmetrical and the most likely explanation for this asymmetry is the presence of a large active tectonic structure. While high asymmetry factor values clearly provide some evidence toward an active structure influencing fluvial processes, low asymmetry factor values (40-60) do not exclude the presence of active faulting. This ambiguity is partly due to the simplification of the complexity of the fluvial systems response through the methods used to calculate the asymmetry values. There are many factors that can cause change to a fluvial system toward an increase or decrease in asymmetry, with tectonics being just one factor causing change. This simplification of the fluvial system can be seen in the Whangaehu catchment (number 15 in Figure 6-9). The Whangaehu catchment is a symmetric catchment based on the asymmetry factor values calculated, but it does not have a shape consistent with an idealised dendritic catchment. The lower reaches of the catchment bend strongly from a SE to a NE trend. One possible explanation for the complex change in stream geometry is evident in the complex volcanic and tectonic landforms of the area. If the mapped tectonic structures are considered as the main influence for drainage direction then the following explanation could be inferred.

The drainage is deflected by the N-S striking Rangipo fault to the east, and follows the NE-SW trending Karori and Shawcroft Road faults to the south. In the lower reaches, the river flows within the depression formed by the downthrown side of the Karori fault and the back tilt of the uplifted block of the Shawcroft Road fault. The whole catchment does however still have approximately an equal amount of area either side of the main trunk stream. However, if only the lower section is considered, once the main trunk stream has been deflected to the west, there is a distinct asymmetry.

Catchments 10, 13, 22 and 23 are also similar to the example above. All of these catchments are classed as symmetrical, due to approximately equal area on both sides of main trunk stream, but the shape of the catchments is not symmetrical due to the drainage being deflected by active faulting and volcanic outcrops. These catchment shapes are all related to the complex interaction between a 
stream network and an active volcanic rift, highlighting the issues with using exclusively asymmetry factor values within these environments to assess asymmetry, without also considering catchment shape.

The catchments contained within the Plio-Pleistocene marine sediment all drain in a SSW direction at $\sim 4^{\circ}$, toward the Wanganui basin depo-centre. All of these catchments show very little evidence of tilting relating to mapped tectonic structure. Of note in this area is the lack of asymmetry related to the catchments near the Whangamomona anticline. If the Whangamomona anticline is similar to the anticlines to the southwest (e.g., Marton anticline), the catchments would be expected to drain away from the uplifting area causing the catchment to become asymmetrical. Instead what is observed is catchments 9 and 3 both tilt in the opposite direction to what would be expected if the anticline influences the drainage. Here we consider two possible explanations:

1. The anticline could have been incorrectly mapped at the surface and is in fact further to the east.

2. The Whangamomona anticline could be less active than the anticlines to the south and thus unable to influence the drainage. 


\section{Chapter 7 Discussion}

\subsection{Appropriateness of DEM Data for Geomorphic Index Analysis}

All the data used to calculate the four geomorphic indices relies on elevation data from DEMs. Therefore both the accuracy and resolution of the DEMs are important to understand. The following section discusses the main issues encountered in this study with the extraction of data from the SRTM, ASTER, LC, and Otago DEMs.

It has been shown in section 3.2.2 that the grid size of the DEM is an important factor to consider when calculating a stream network. The grid size of the DEMs used in this study varies from 15 to $90 \mathrm{~m}$. The planar resolution of the extracted stream network will be less detailed with an increase in cell size. This has implications for the sinuosity, SLk and asymmetry calculations. The sinuosity index measures changes in the horizontal geometry of the stream network. A larger cell size has been shown to simplify the geometry to a degree that in some cases meander bends become straight lines. This study recommends that the SRTM DEM is not used for stream analysis at a scale where such a level of detail is required. The simplification of the geometry also potentially influences the SLk calculations. The SLk index uses distance along a stream network and distance to the headwaters of the stream for calculation of the index. A stream extracted from a DEM with a larger cell size and simplified geometry will not provide an accurate representation of a complex sinuous section of the stream channel and potentially underestimate the length of some section of the stream as well as total stream length. Therefore SLk values from stream networks extracted from large cell size DEMs would produce lower values of SLk. The issues related to producing hydrologically correct DEMs has been well documented (Walker and Willgoose, 1999; Finlayson and Montgomery, 2003; Kienzle, 2004). Of particular interest to this study is the significant variation found by Kienzle (2004) when comparing derived elevation data with a ground truth data set, obtained by ground survey. Kienzle (2004) results show catchment sizes and stream networks determined by published DEMs may be significantly different from the ground truth. Kienzle (2004) recommends cartometric and photogrammetric DEMs can be used for determination of catchments and stream networks but with caution and in conjunction with observations from a site inspection. The asymmetry calculation uses the geometry of the main trunk stream to calculate percentage of area on either side. The geometry of the stream could also affect this calculation. A comparison between asymmetry values from the same catchments extracted from all four DEMs showed variation of only $1-2 \%$. This small variation was thought not to be significant. However, catchments with asymmetry values close to the threshold of a classification boundary could be affected by such a small change (i.e. moving a 
medium asymmetric catchment to high asymmetric classification). The asymmetry calculations for the $4^{\text {th }}$ order catchments only contained one catchment that was highly asymmetrical and the rest of the catchments were either symmetrical or low asymmetry. Therefore this $1-2 \%$ did not affect classifications in this study. If this method was to be used at a finer scale (i.e. $2^{\text {nd }}$ or $3^{\text {rd }}$ order catchments) it is suggested that care is taken to ensure stream geometry is extracted from the DEM with the smallest cell size.

The LC and Otago DEMs are not suitable for the calculation of the SLk index with the method used in this study. The calculation of SLk values from the LC and Otago DEMs produced abrupt changes in slope in the extracted stream profiles. These abrupt changes in elevation were mostly detected in areas of low slope, where the contour data used for DEM interpolation was widely spaced. High SLk values were attributed to these changes in slope and thus making it impossible to tell whether anomalous values were due to contour data or a real landscape feature. The method used in this study held length constant and elevation was sampled at this set length. Alternatively elevation could be held constant and distance could be measured. This approach is often used when contour data are the only elevation source. Studies have shown DEMs derived from contour data are problematic for hydrological studies at a stream scale (e.g. Wise, 2000; Barringer et al., 2002; Wise, 2007). However, these datasets are currently the only national DEMs available with a cell size less than $30 \mathrm{~m}$. One simple method to check the accuracy of the extracted stream network is a visual comparison of the extracted network with georeferenced aerial photographs to test how well these data conform to real life. It is thought that the use of high-resolution DEMs would significantly improve the identification of tectonic structures. In the author's opinion, a sub-5m, potentially LiDAR derived, DEM could provide sufficient resolution to accurately mimic the real geometry of the stream network.

The resolution of the four DEMs did not overly influence the hypsometric curve data. A slight difference was detected between statistical moments of the hypsometric curves of the test catchments in the SRTM DEM and the data was therefore excluded. However, this difference was not significant enough to suggest that it is not feasible to calculate hypsometric curves from this DEM. It is also possible that the variation increases with catchment scale. If second order catchments were used, the SRTM data may show increasing variation. This would need to be tested before further research is conducted at a finer scale. 
Table 7. The four DEMs used in this study and their recommended use with the four geomorphic indices.

\begin{tabular}{|l|c|l|c|c|c|c|}
\cline { 3 - 7 } \multicolumn{1}{c|}{} & \multicolumn{4}{c|}{ Cell Size } \\
\cline { 2 - 7 } \multicolumn{1}{c|}{} & $(\mathbf{m})$ & Data Collection Method & Hypsometry & Asymmetry & SLk Index & $\begin{array}{c}\text { Sinuosity } \\
\text { Index }\end{array}$ \\
\hline SRTM & 90 & InSAR & Yes & No & No & No \\
\hline ASTER & 30 & Photogrammetry & Yes & Yes & Yes & No \\
\hline LC & 25 & Contours and spot heights & Yes & Yes & No & No \\
\hline Otago & 15 & Contours and spot heights & Yes & Yes & No & Yes \\
\hline
\end{tabular}

There is not one DEM that is suitable for calculating all four of the geomorphic indices tested in this study. Table 7 shows the recommendations of this study for the suitability of the DEMs in the calculation of each geomorphic index.

\subsection{Interpretation of Fault Activity from Analysis of Geomorphic Indices}

The identification of active faulting within the study area has been difficult and greatly uncertain due to the following reasons:

- The lack of mapped active fault traces within the Tertiary mudstone/sandstone region limiting the potential to calibrate the indices to assess fault activity. This limits analysis to only one or several "appropriate test areas/catchments".

- The Geomorphic indices used in this study can be influenced a myriad of causal factors (i.e. landsliding, lithology) that make it difficult to isolate if tectonics are the main cause.

- The limitation of the DEMs described above.

For these reasons, the fault activity interpretations presented here are tentative. However, it is worth exploring areas of anomalous geomorphic index values where lithology or landsliding, can be ruled out as the cause for the anomaly. These areas could be further explored for fault activity. Also locations that display anomalies of several indices, with uncertain interpretation of the cause of the anomalies, can be highlighted as areas where active faulting is plausible. For these cases I have hypothesised fault activity and explored the impacts on the earthquake hazard of the region if those anomalies do in fact represent presence of active faulting. 


\subsection{Hypsometric Curve}

A convex shape of a hypsometric curve has been interpreted as an indicator for a catchment that has undergone either regional or local uplift (e.g. Ohmori, 1993; Keller and Pinter, 1996; Hurtrez et al., 1999; El Hamdouni et al., 2008; Pérez-Peña et al., 2009a). The catchment classified as convex within the study area could potentially be caused by localised uplift. However, the variation in catchment shape and the respective locations to potential source of uplift make this assertion difficult to prove. There is no easily discernible relationship between the mapped active faults (and thus areas of possible uplift) and the shape of the hypsometric curves calculated for third order catchments.

The variable size of catchment of same order could be a case for the lack of correlation between hypsometric curve shapes and potential fault activity. The convex catchments are on average smaller than the other catchment shapes. This conforms with Hurtrez et al.'s (1999) observation that catchments with a convex shape have a smaller area when compared to other hypsometric shapes. Hurtrez et al. (1999) suggest that the difference in size reflects the varying importance of river and hillslope processes occurring within the catchment. A smaller catchment has a smaller drainage area with low-order streams prevailing (i.e. lower stream power and steeper channel gradients). In these small catchments, erosion is dominated by hillslope processes. Larger catchments contain streams of a higher order and a more defined drainage network. In larger catchments, erosion is dominated by fluvial processes. A more detailed analysis of a range of catchment sizes in an area where processes and geology were well understood would be ideal to test these assumptions.

Strahler's (1952b) classification of hypsometric shape is still used in some studies as an indication of the age of a catchment (cf. Pérez-Peña et al., 2009a). However, the concave catchments in this study are located on relatively young volcanic material. This suggests that the hypsometric shape/catchment age relationship is not valid for the Taranaki region. Other studies have found a relationship between hypsometric shape and the geology within a catchment (e.g. Ohmori, 1993; Hurtrez et al., 1999; El Hamdouni et al., 2008). This study showed a relationship between catchments with a concave shape and geology. This finding is similar to Ohmori (1993) who found concave catchments occur within the mountainous regions of Japan. In this study a majority of concave shaped catchments are located on the slopes of Ruapehu, Tongariro, and Taranaki volcanoes.

The E - W trending Plio-Pleistocene geology, represented by large variety of lithologies from erodible sandstones to harder limestones and calcareous sandstones, do not appear to influence the catchments' hypsometric shape. If it were the case, a N-S change in hypsometric curve shape would have been expected. The majority of the catchments that contain Plio-Pleistocene marine sediments 
are either S-shaped or S-shaped/concave. This suggests that the relative amount of material removed from these catchments is either equal to or greater than the relative amount of material gained through uplift. The shift from an S-shaped hypsometric curve to an S-shaped/concave hypsometric curve could provide a method to quantify the change of relative amount of material gained or lost and therefore be used to inform about the processes occurring within the catchment. One aim of this study was to test if the statistical moments of the hypsometric curve could provide a method to quantify hypsometric curve shape. Building on Lou (2000), this study has found DEN SK might provide an alternative and more informative method for classifying hypsometric shape.

\subsection{Stream Length Gradient Index and Sinuosity Index and Asymmetry}

Correlations between sinuosity index, SLk, and asymmetry factor with geological and other landscape features described in Figure 6-4 and Figure 6-6 suggest that several processes can cause positive anomalies of these indices. Potential influences are: changes in geological materials along stream, active faults crossing or flowing parallel to streams, increased sediment supply, the effects of faults that are currently inactive but have been active during the life of the stream, and abrupt changes in topography.

Several areas of high sinuosity index and SLk index have been identified where a stream crosses a geological boundary. This has been attributed to a change in resistance of the stream bed and banks to erosion. However, one of the most striking results is that the large scale geology does not seem to influence sinuosity or SLk. The marine Plio-Pleistocene sediments have an E-W trend and are represented by a large variety of lithologies from erodible sandstones to harder limestones and calcareous sandstones. One would expect an increase in sinuosity and SLk along some of these long continuous boundaries. However, sinuosity and SLk anomalies do not align E-W across the study area. In view of the lack of correlation between high SI, SLk and large scale geology, interpretations made based on Figure 6-4 and Figure 6-6 for small areas with complicated geology need to be considered with caution.

Three possible scenarios are suggested for when a normal fault crosses obliquely to a stream channel and how it affects SLk and sinuosity index values (see Figure 7-1). 1) The fault is downthrown, downstream. This would increase SLk and sinuosity index values. 2) The fault is downthrown upstream, this would increase sinuosity but is less likely to increase SLk. 3) The stream has a steep gradient and the stream channel is confined. The SLk index is likely to increase but sinuosity is not. 
Active deposition of lahar material within streams also appears to produce high SI values, but is also likely to reduce SLk values. Eruptions from the Ruapehu volcano during recent times have caused a collapse of the crater lake and large lahars have influenced many of the valleys. These valleys have experienced a sudden deposition of large amounts of sediment that completely change the sediment regime of the river and therefore the pattern of the stream channel. This material has the potential to be reworked and is likely to persist within the landscape for a long period. The streams to the south of Ruapehu are all influenced by this increase of material and are anomalous when compared to the rest of the study area. These streams provide an opportunity to investigate and compare streams with differing sediment regimes but with similar tectonic influences and therefore could provide insight into the influence of sediment flux on channel form within the Taranaki region.

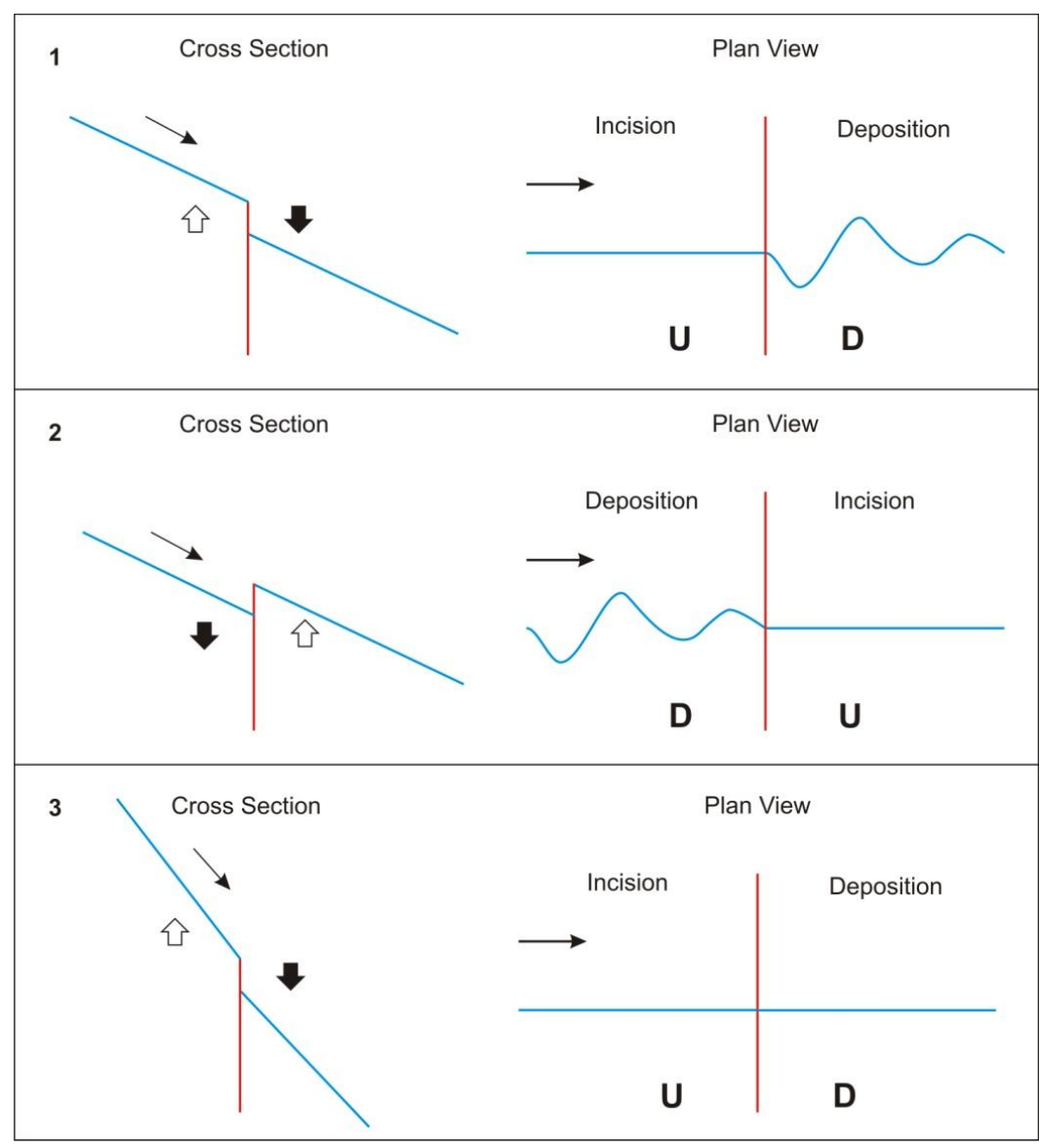

Figure 7-1. The geometry of the fault rupture could affect which indices detect the fault. 1. The fault is downthrown, downstream. This would cause increased SLK and SI. 2. The fault is downthrown upstream, this would cause increase sinuosity but less likely to increase SLk. Arrows show the direction of uplift. $D=$ downthrown side of the fault, $U=$ upthrown side of the fault. 3. The fault is downthrown, downstream and the stream is high gradient with a channel in harder material SLk index is likely to be higher but sinuosity index not increase. 
Many of the faults of the study area have been mapped as inactive. However, in some cases there appears to be an increase in both sinuosity and SLk value where faults cross the stream. This suggests that the faults of this area may be more active than what is currently thought or that streams are still influenced by past activity. This result poses the following question: If these streams have inherited geometry from faults that are now no longer active, then how long is the sinuosity or increased SLk value preserved in the landscape? To answer this question requires a detailed investigation into the activity of these faults.

The relatively soft marine sediments of the central part of the study area are very susceptible to large landslides. Large mass movements have the potential to completely block or alter a stream and thus could affect the drainage of a large area. Not only could a landslide change the stream gradient, but also increase the sediment supply. Either of these factors, or a combination of both, could dramatically change the sinuosity or slope of a stream. The investigation of the effect of large landslides on stream sinuosity in the Taranaki area is suggested for future research.

\subsection{Implications for Seismic Hazards in the Wanganui Region}

The geomorphic indices used in this study provide some evidence for the location of possible active faulting and folding as well as evidence of locations where it is unlikely faulting and folding has occurred. While the results from this study are far from conclusive, if the tentative identification of potential active faulting in the region is real, then the results will have important implications for the seismic hazard of the region. Possible active faulting will need to be supported through more detailed studies, such as geomorphic interpretation of high resolution aerial photographs and detailed DEMs (e.g. LiDAR), field mapping, geophysical studies or paleoseismic trenching.

The newly identified fault activity the earthquake hazard in the region could be affected by the following aspects of active faulting and folding: 1 ) some faults may be longer than currently mapped, 2) there could be some active faults that have not been mapped (or at least not mapped as active), 3) some active structures do not appear to influence geomorphic index values, indicating low activity.

These tentative interpretations of the results show evidence for a possible extension of the mapped length on the Marton anticline and the Snowgrass, Ohakune, Waipuna and Oruakukuru faults. The interpretation from geomorphic index values that led to this proposed increase in length are described in Chapter 6. The fault or fold rupture length, is one of the parameters used in fault scaling relationships, to predict earthquake magnitude assigned to possible fault rupture (Wells and 
Coppersmith, 1994). The rupture length is particularly important where there is no historic rupture and the corresponding earthquake magnitude is unknown, or where there are no paleoseismic investigations that can assess co-seismic displacement (another parameter used in scaling relationships). In New Zealand this has implication for the National Seismic Hazard Model (NHSM) which relies on fault length to calculate earthquake magnitude for numerous fault sources (Stirling et al., 2012).

Based on the interpretation of this study and acknowledging the inconclusive nature of the results, information derived from mapping of potential fault lengths in Figure 7-2 are compared to lengths used to estimate magnitudes ( $\mathrm{Mw}$ ) from the NSHM. Table 8 show the comparison between these data. If these results were proven through more detailed analysis, the strong ground motion from the possibility of $\sim \mathrm{Mw} 7$ earthquakes would substantially increase the hazard for Wanganui, National Park, Ohakune and Marton. This study has also located a previously unmapped fault that has a well-defined scarp in Holocene terraces. The Manganuioteao fault has a mapped length of $2 \mathrm{~km}$ (this length is preliminary, as further detailed mapping is likely to increase the length) however there is strong evidence from interpretation of the geomorphic indices that it could be substantially longer. This interpretation is also included in Table 8.

Table 8. Estimated Magnitudes ( $\mathrm{Mw}$ ) for new fault traces or fault traces modified in this study

\begin{tabular}{|l|c|c|c|c|}
\hline Fault/Fold & $\begin{array}{c}\text { Mapped length } \\
(\mathrm{km})\end{array}$ & $\begin{array}{c}\text { Mw associated with } \\
\text { current fault length }\end{array}$ & $\begin{array}{c}\text { Potential total } \\
\text { length }(\mathrm{km})\end{array}$ & $\begin{array}{c}\text { Mw associated with } \\
\text { potential fault length }\end{array}$ \\
\hline Marton $^{1}$ & 25 & 7.1 & $67^{*}$ & 7.4 \\
\hline Marton Alt $^{1,3}$ & - & - & 40 & 7.8 \\
\hline Ohakune $^{2}$ & 25 & 6.7 & 38 & 6.9 \\
\hline Waipuna $^{2}$ & 26 & 6.7 & 33 & 6.8 \\
\hline Oruakukuru $^{2}$ & 9 & 6.1 & & 6.5 \\
\hline Manganuioteao $^{2}$ & 2 & 5.2 & & 38 \\
\hline
\end{tabular}

${ }^{1}$ Magnitude estimated from scaling relationship for reverse faulting (Stirling et al, 2012)

${ }^{2}$ Magnitude estimated from scaling relationship for normal faulting (Stirling et al, 2012)

${ }^{3}$ Alternative interpretation for the Marton anticline.

* Possibly too long; the extension could be an independent structure. 


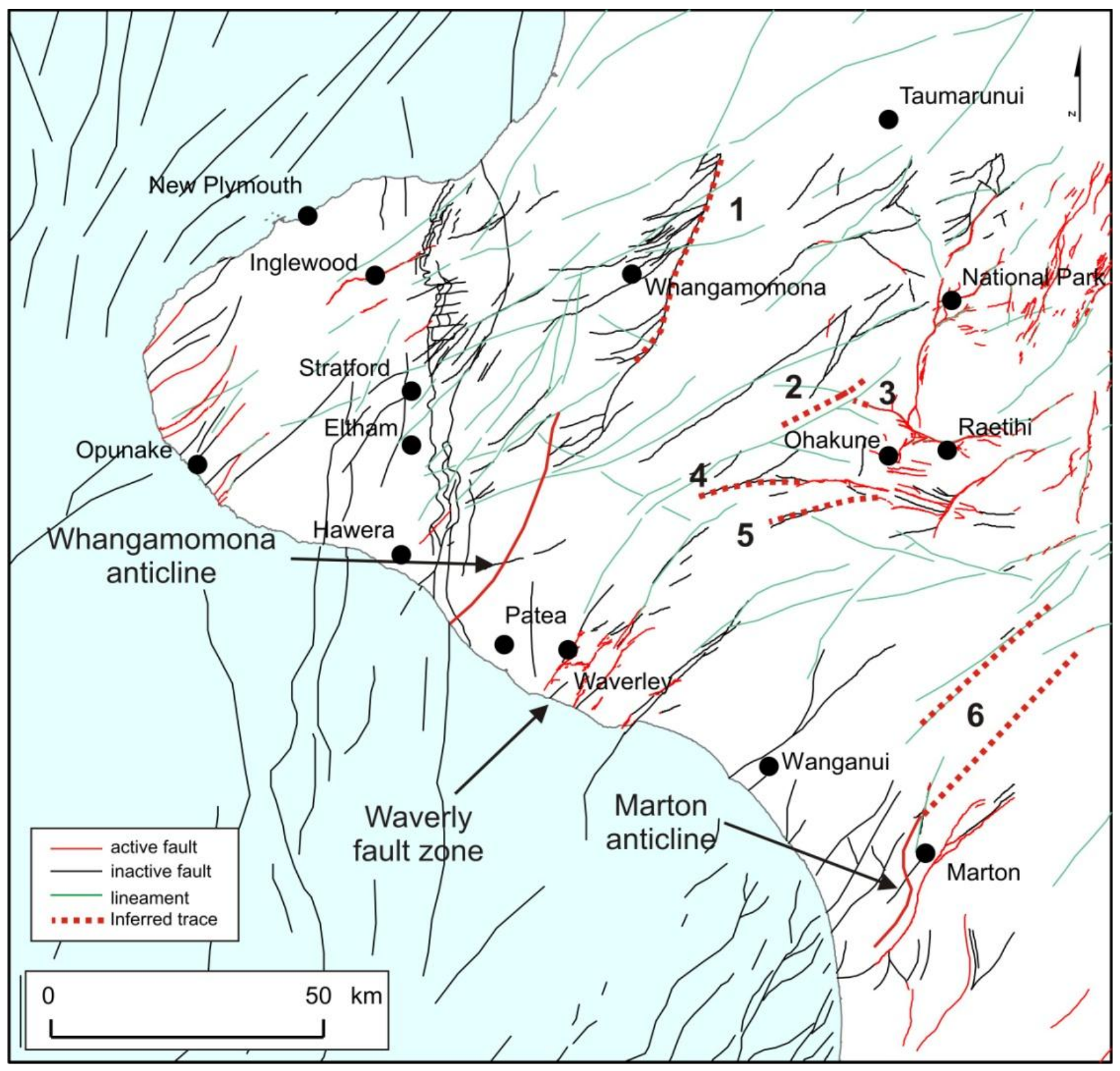

Figure 7-2. Current mapped faults, folds and lineaments with the inferred traces from this study. 1. Ohura fault. 2. Manganuioteao fault and inferred extension. 3. Waipuna fault extension. 4. Ohakune fault extension. 5. Oruakukuru fault extension. 6. Two possible interpretations for the Marton area.

Results of this study suggest that the Marton anticline extends possibly further than currently mapped. An alternative to this is a potentially unmapped fault trace. The high sinuosity values to the north are in strike with the Marton anticline and the Snowgrass fault. This suggests the presence of an en echelon type structure.

The interpretation of geomorphic indices has highlighted some areas that could have active tectonics but are currently mapped as lineaments or inactive faults. This study suggests the E-W trending Ohura fault and the unnamed NE faults to the south of Waipuna fault could be more active 
than currently thought. To test the activity of these faults would require paleoseismic investigations. The seismic hazard of the area around these faults would remain similar to those currently assessed by the NHSM as the model allows for the presence of unknown/unmapped faults to occur in this area. However, the hazard for localities close to those faults may increase slightly.

No evidence has been found for the active traces near the southern coast to extend further onshore into the erodible Pleistocene marine sediments. The Waverley fault for example may extend up to $2 \mathrm{~km}$ onshore, but not further. This implies that the hazard for that area is currently well characterised.

The Whangamomona anticline does not seem to influence the geomorphic indices. Given the large influence that the Marton anticline has on the asymmetry of the Turakina fault, it is likely that the Whagamomona anticline is less active or could be a more recent structure than the Marton anticline. 


\section{Chapter 8 Conclusion}

This study applied geomorphic index analysis (stream length gradient index, sinuosity index, hypsometric curve, and asymmetry factor) to assess potential presence of active faulting in a large remote area of central Taranaki, not easily accessible for field based reconnaissance, using free and readily available national elevation datasets. While the presence active faulting using these methods is not conclusive, the identification of areas with anomalous values for several geomorphic indices or areas where the causes for the anomalies are not clear, suggest that active faulting could be a possibility in those locations and that further detailed studies are recommended. This is supported by a brief inspection of aerial photography of one of those examples, which has shown recent displacement of a Holocene river terrace (Manganuioteao fault).

The identification of active faulting within the study area has been difficult and greatly uncertain due to the following:

- Some of the elevation data used in this study has been shown to be less than ideal for the calculation of some of the geomorphic indices.

- As a consequence of the lack of active fault traces within the Tertiary mudstone/sandstone region, there were hardly any examples of fault activity to test the geomorphic indices against one or several "appropriate test areas/catchments".

- Geomorphic indices in the area of the study can be influenced by several of the parameters different from recent faults activity, such; changes in lithology, landslides, etc. These parameters are often difficult to isolate to study them separately.

The resolution and accuracy of DEMs worthy of consideration and have been highlighted with the following conclusions:

The cell sizes of the SRTM and ASTER DEMs are greater than $30 \mathrm{~m}$, which is larger than the deformation zone of some faults. Therefore, it is unlikely small events will be located by these DEMs. However, these DEMs can be used to identify large and/or frequent active faults or folds and are most useful identifying processes that can affect the landscape at a catchment scale. 
The Otago and LC DEMs were interpolated from contour lines. Both DEMs bias toward these base data and are therefore are not suitable for calculations of the SLk index with the methods used in this study.

The Otago DEM provides the best planar resolution and is recommended for calculations where the horizontal geometry of the stream is required. This DEM is currently the only national DEM this study recommends for sinuosity calculations. Alternatively the mapped streams from national topographic maps could also be used if sinuosity was the only metric being measured and no comparison or integration of metrics was required.

The DEMs used in this study all have advantages and disadvantages when used for calculating geomorphic indices. No single DEM is suitable for calculating all four indices. Therefore, understanding the issues associated with each dataset is essential.

It is likely all four indices tested in this study would produce better results if a higher resolution DEM was available. The best current method available to obtain a DEM over a large area (of sub $5 \mathrm{~m}$ resolution), is airborne LiDAR. DEMs produced from data gathered by LiDAR sensors are becoming more readily available for many areas of New Zealand. However, because of the cost involved in collecting the data for these DEMs, only small areas, often not covering entire catchments, have been acquired.

This study identified locations that can be interpreted as being recently tectonically active using each of the four indices; stream length gradient index, sinuosity index, hypsometric curve, and asymmetry factor. While the fault activity interpretations for each index presented here are tentative, by combining all four of these indices the interpretations are more robust. The indices all use measurements of different aspects of the landscape to provide methods to quantify the processes that occur within these landscapes. This study, in the assessment of the four indices for use in detecting tectonic influences has the following conclusions:

The sinuosity and SLk indices when interpolated into a surface of index values have the potential to provide reconnaissance over large areas at limited cost. The combination of these two indices could provide further insight in to the geometry of the fault rupture. Care needs to be taking when interpreting results as high index values are not solely due to tectonic processes.

The hypsometric curve results show that the density skewness statistical moment could be a better indicator of the equilibrium of a catchment and provide a better method to classify hypsometric curve shape. A study of a larger number of catchments and from a greater range of 
terrains could provide a statistically robust measure of how well this value identifies hypsometric curve shape.

The Hypsometric curve analysis does not provide any evidence of active faulting. This may suggest that this form of geomorphic analysis may not be suited to the landscapes of the study area.

Asymmetry is an efficient method to study large scale processes and could be applied at a national scale with relative ease, and at very little cost. A large tectonic structure similar to the Marton anticline could be identified through this method.

The hypsometric curve and asymmetry factor have both identified catchments that could be interpreted as being influenced by tectonics. The SLk and sinuosity index provide further detail to support the catchment scale finding, as well as identifying tectonic processes at a stream scale. The combination of supporting results from multiple geomorphic indices and the interpretation of geology and geomorphology have identified areas that require further investigation with the following interpretations of tectonic processes occurring within these areas.

This study suggests the Snowgrass, Ohakune, Waipuna and Oruakukuru faults could be longer than currently mapped.

The extent of asymmetry within the Turakina catchment suggests the Marton anticline could be longer that currently mapped or there are other unmapped, but likely to be active, fault traces running parallel to the drainage.

This study identified the Manganuioteao fault as a $2 \mathrm{~km}$ trace that displaces Holocene age alluvium. This trace is likely to be longer and would require detailed mapping or field studies to evaluate the length.

The Whangamomona anticline does not influence the landscape in the same way as the anticlines to the south of the study area.

There is no evidence that the Waverley fault zone extends further inland than currently mapped.

The areas identified above, if proven tectonically active through more detail investigation, have implications for the seismic hazard of the region. The following conclusion have been calculated or inferred from these results: 
The Whangamomona anticline is suggested to be either less active or younger than the structures to the south. In both these cases the modelled earthquake hazard would remain approximately the same.

The Marton anticline could be capable of a Mw 7.4 earthquake if the length is extended to $67 \mathrm{~km}$. The alternative to the extension of the Marton anticline is an en echelon structure with a maximum length of $40 \mathrm{~km}$ capable of producing an Mw of 7.1 earthquake.

The extension of the Ohakune, Waipuna and Oruakukuru faults all increase the possible calculated Mw significantly.

The previously unmapped Manganuioteao fault displaces Holocene alluvium. The length and recurrence interval on this fault is unknown and therefore requires further investigation. The calculated Mw 6.1 on this fault would not overly change the modelled earthquake hazard in this area.

There are large areas of New Zealand where the influence of tectonics on the landscape has not been, or is poorly, defined due to poor preservation of active fault scarps. The strength of this study is the ability to provide a first approximation of likely areas that are potentially influenced by tectonic activity. While these results are far from robust they do provide a method to focus research to a smaller targeted area with very little cost. The erodible geology of the central Taranaki region has proven to be difficult to definitively locate evidence of past fault ruptures. This study has only touched on four methods of quantifying landforms to identify tectonic processes. These methods have also been hindered by the low resolution of the freely available nation data sets. The following section takes the conclusions from this study and uses them to identify areas where the work completed in this study could be advanced.

\subsection{Areas for Future Research}

This study could be expanded upon and the inclusion of supporting evidence from other fields of study could improve or produce more robust results. Apart from undertaking detailed studies in the areas listed above, the following areas of future research are suggested by this study:

- Compare current deformation rates across the area from GPS studies, together with the information on known faults, to help to constrain the possible active rates of new structures. 
- Analyse rates of erosion in the region, in conjunction with active fault rates and landscape evolution rates, to help constraint active tectonic rates for the region and perhaps for individual structures.

- Investigate the influence of landslides on the geomorphic indices.

- Testing methods to normalise SI index by stream order, therefore improving the accuracy of this index in lower order steams.

- Detailed analysis of the hypsometric curve and the statistical moments outside of the Taranaki region in an area where faults are well mapped and fault activity is well constrained. This will provide insight into how the statistical moments of the hypsometric curve can be used to detect faults in a less dynamic erodible landscape and perhaps provide boundary conditions for application within the Taranaki region.

- Testing of geomorphic indices using a LiDAR derived DEM. 


\section{References}

Akar, I., 2009. How geographical information systems and remote sensing are used to determine morphometrical features of the drainage network of Kastro (Kasatura) Bay hydrological basin. International Journal of Remote Sensing, 30(7): 1737-1748.

Alloway, B., McComb, P., Neall, V., Vucetich, C., Gibb, J., Sherburn, S. and Stirling, M., 2005. Stratigraphy, age, and correlation of voluminous debris-avalanche events from an ancestral Egmont Volcano: Implications for coastal plain construction and regional hazard assessment. Journal of the Royal Society of New Zealand, 35(1-2): 229-267.

ASTER, G., 2009. ASTER GDEM Validation Summary Report.

Barrell, D.J.A., Litchfield, N.J., Townsend, D.B., Quigley, M., Van Dissen, R.J., Cosgrove, R., Cox, S.C., Furlong, K., Villamor, P., Begg, J.G., Hemmings-Sykes, S., Jongens, R., Mackenzie, H., Noble, D., Stahl, T., Bilderback, E., Duffy, B., Henham, H., Klahn, A., Lang, E.M.W., Moody, L., Nicol, R., Pedley, K. and Smith, A., 2011. Strike-slip ground-surface rupture (Greendale Fault) associated with the 4 September 2010 Darfield earthquake, Canterbury, New Zealand. Quarterly Journal of Engineering Geology and Hydrogeology, 44(3): 283-291.

Barringer, J., Pairman, D. and McNeil, S.J., 2002. Development of a High-Resolution Digital Elevation Model for New Zealand., Landcare Research, Wellington.

Begg, J.G. and Mouslopoulou, V., 2010. Analysis of late Holocene faulting within an active rift using lidar, Taupo Rift, New Zealand. Journal of Volcanology and Geothermal Research, 190(1-2): 152-167.

Berryman, K., 1990. Late Quaternary movement on the Wellington fault in the Upper Hutt area, New Zealand. New Zealand Journal of Geology and Geophysics, 33(2): 257-270.

Berryman, K., 1994. The Quaternary Tectonic Framework of New Zealand and Relationship to Earthquake Hazard. Journal of Geography, 103(7): 799-808.

Berryman, K. and Beanland, S., 1991. Variation in fault behaviour in different tectonic provinces of New Zealand. Journal of Structural Geology, 13(2): 177-189.

Burbank, D. and Anderson, R., 2001. Tectonic geomorphology. Blackwell Science, 274 pp.

Chen, Y.C., Sung, Q.C. and Cheng, K.Y., 2003. Along-strike variations of morphotectonic features in the Western Foothills of Taiwan: tectonic implications based on stream-gradient and hypsometric analysis. Geomorphology, 56(1-2): 109-137.

Columbus, J., Sirguey, P. and Tenzer, R., 2011a. A free, fully assessed 15-m DEM for New Zealand. Survey Quarterly(66): 16-19. 
Columbus, J., Sirguey, P. and Tenzer, R., 2011b. A High Resolution Digital Elevation Model (DEM) for New Zealand. , University of Otago, Dunedin.

Cooper, A.F. and Norris, R.J., 1994. Anatomy, structural evolution, and slip rate of a plate-boundary thrust: The Alpine fault at Gaunt Creek, Westland, New Zealand. Geological Society of America Bulletin, 106(5): 627-633.

Cox, R.T., 1994. Analysis of drainage-basin symmetry as a rapid technique to identify areas of possible Quaternary tilt-block tectonics: An example from the Mississippi Embayment. Geological Society of America Bulletin, 106(5): 571-581.

Crozier, M.J. and Pillans, B.J., 1991. Geomorphic events and landform response in south-eastern Taranaki, New Zealand. Catena, 18(5): 471-487.

Davis, W.M., 1899. The Geographical Cycle. The Geographical Journal, 14(5): 481-504.

Dehbozorgi, M., Pourkermani, M., Arian, M., Matkan, A.A., Motamedi, H. and Hosseiniasl, A., 2010. Quantitative analysis of relative tectonic activity in the Sarvestan area, central Zagros, Iran. Geomorphology, 121(3-4): 329-341.

Edbrooke, S.W., 2005. Geology of the Waikato area, QMap. GNS Science, Lower Hutt.

El Hamdouni, R., Irigaray, C., Fernandez, T., Chacon, J. and Keller, E.A., 2008. Assessment of relative active tectonics, southwest border of the Sierra Nevada (southern Spain). Geomorphology, 96(1-2): 150-173.

Finlayson, D.P. and Montgomery, D.R., 2003. Modeling large-scale fluvial erosion in geographic information systems. Geomorphology, 53(1-2): 147-164.

Fleming, C.A., 1953. The geology of Wanganui Subdivision. New Zealand Geological Survey Bulletin, 52

Font, M., Amorese, D. and Lagarde, J.-L., 2010. DEM and GIS analysis of the stream gradient index to evaluate effects of tectonics: The Normandy intraplate area (NW France). Geomorphology, 119(3-4): 172-180.

Gonga-Saholiariliva, N., Gunnell, Y., Petit, C. and Mering, C., 2011. Techniques for quantifying the accuracy of gridded elevation models and for mapping uncertainty in digital terrain analysis. Progress in Physical Geography.

Gyasiagyei, Y., Willgoose, G. and Detroch, F.P., 1995. Effects of Vertical Resolution and Map Scale of Digital Elevation Models on Geomorphological Parameters used in Hydrology. Hydrological Processes, 9(3-4): 363-382.

Hack, J.T., 1960. Interpretation of Erosional Topography in Humid Temperate Regions. American Journal of Science, 258: 80-97. 
Hack, J.T., 1973. Stream-Profile analysis and stream-gradient index. Journal of Research of the U.S. Geological Survey, 1(4): 421-429.

Harlin, J., 1978. Statistical moments of the hypsometric curve and its density function. Mathematical Geology, 10(1): 59-72.

Hodgson, K.A., 1993. Late Quaternary lahars from Mount Ruapehu in the Whangaehu River valley, North Island, New Zealand. PhD Thesis, Massey University, Palmerston North, New Zealand.

Holbrook, J. and Schumm, S.A., 1999. Geomorphic and sedimentary response of rivers to tectonic deformation: a brief review and critique of a tool for recognizing subtle epeirogenic deformation in modern and ancient settings. Tectonophysics, 305(1-3): 287-306.

Hurtrez, J.E., Sol, C. and Lucazeau, F., 1999. Effect of drainage area on hypsometry from an analysis of small-scale drainage basins in the Siwalik Hills (Central Nepal). Earth Surface Processes and Landforms, 24(9): 799-808.

Hutchinson, M.F., 1989. A new procedure for gridding elevation and stream line data with automatic removal of spurious pits. Journal of Hydrology, 106(3-4): 211-232.

Jackson, J., Van Dissen, R. and Berryman, K., 1998. Tilting of active folds and faults in the Manawatu region, New Zealand: evidence from surface drainage patterns. New Zealand Journal of Geology and Geophysics, 41(4): 377-385.

Jenks, G.F., 1967. The data model concept in statistical mapping. In: Frenzel, K. (Editor), International Yearbook of Cartography. Rand McNally \& Co, pp. 186.

Jenson, S.K. and Domingue, J.O., 1988. Extracting Topographic Structure from Digital Elevation Data for Geographic Information-System Analysis. Photogrammetric Engineering and Remote Sensing, 54(11): 1593-1600.

Jongens, R. and Dellow, G., 2003. The active faults database of New Zealand: Data dictionary, Institute of Geological and Nuclear Sciences science report.

Keller, E. and Pinter, N., 1996. Active tectonics: earthquakes, uplift, and landscape. Prentice Hall, 338 pp.

Kienzle, S., 2004. The Effect of DEM Raster Resolution on First Order, Second Order and Compound Terrain Derivatives. Transactions in GIS, 8(1): 83-111.

Lamarche, G., Proust, J.-N. and Nodder, S.D., 2005. Long-term slip rates and fault interactions under low contractional strain, Wanganui Basin, New Zealand. Tectonics, 24(4): TC4004.

Langbein, W.B., et al, 1947. Topographic characteristics of drainage basins. U.S. Geological Survey, Water Supply Paper, 968-C: 125-157. 
Langridge, R., Van Dissen, R., Rhoades, D., Villamor, P., Little, T., Litchfield, N., Clark, K. and Clark, D., 2011. Five Thousand Years of Surface Ruptures on the Wellington Fault, New Zealand: Implications for Recurrence and Fault Segmentation. Bulletin of the Seismological Society of America, 101(5): 2088-2107.

Langridge, R.M., Berryman, K.R. and Van Dissen, R.J., 2007. Late holocene paleoseismicity of the pahiatua section of the Wellington fault, New Zealand. New Zealand Journal of Geology and Geophysics, 50(3): 205-226.

Langridge, R.M., Villamor, P., Basili, R., Almond, P., Martinez-Diaz, J.J. and Canora, C., 2010. Revised slip rates for the Alpine fault at Inchbonnie: Implications for plate boundary kinematics of South Island, New Zealand. Lithosphere, 2(3): 139-152.

Lee, J.M., Bland, K.J., Townsend, D.B. and Kamp, P.J.J., 2011. Geology of the Hawke's Bay area : scale 1:250,000. GNS Science, Lower Hutt, 93 pp.

Leopold, L.B. and Maddock, T., 1953. The hydraulic geometry of stream channels and some physiographic implications. U.S. Geological Survey Professional Paper: 252.

Leopold, L.B., Wolman, M.G. and Miller, J.P., 1964. Fluvial Processes in Geomorphology

Lin, C.-W., Liu, S.-H., Lee, S.-Y. and Liu, C.-C., 2006. Impacts of the Chi-Chi earthquake on subsequent rainfall-induced landslides in central Taiwan. Engineering Geology, 86(2-3): 87-101.

Litchfield, N. and Jongens, R., 2006. Active Faults Database of New Zealand, New Zealand Earthquakes and urban development, New Zealand Geotechnical Society 2006 Symposium, pp. 327-340.

Litchfield, N., Van Dissen, R., Sutherland, R., Barnes, P.M., Cox, S., Norris, R., Beavan, J., Langridge, R., Villamor, P., Berryman, K., Stirling, M., Nicol, A., Nodder, S., Lamarche, G., Barrell, D.J.A., Pettinga, J.R., Little, T., Pondard, N., Mountjoy, J. and Clark, K., In Prep. A model of active faulting in New Zealand. New Zealand Journal of Geology and Geophysics.

Little, T.A., Van Dissen, R., Rieser, U., Smith, E.G.C. and Langridge, R.M., 2010. Coseismic strike slip at a point during the last four earthquakes on the Wellington fault near Wellington, New Zealand. Journal of Geophysical Research-Solid Earth, 115.

Lopez-Vicente, M., Navas, A. and Machin, J., 2009. Geomorphic mapping in endorheic catchments in the Spanish Pyrenees: An integrated GIS analysis of karstic features. Geomorphology, 111(12): 38-47.

Luo, W., 1998. Hypsometric analysis with a geographic information system. Computers \& Geosciences, 24(8): 815-821.

Luo, W., 2000. Quantifying groundwater-sapping landforms with a hypsometric technique. J. Geophys. Res., 105(E1): 1685-1694. 
Luo, W., 2002. Hypsometric analysis of Margaritifer Sinus and origin of valley networks. J. Geophys. Res., 107(E10): 5071.

Mackin, J., 1948. Concept of the Graded River. Geological Society of America Bulletin, 59(5): 463512.

Maroukian, H., Gaki-Papanastassiou, K., Karymbalis, E., Vouvalidis, K., Pavlopoulos, K., Papanastassiou, D. and Albanakis, K., 2008. Morphotectonic control on drainage network evolution in the Perachora Peninsula, Greece. Geomorphology, 102(1): 81-92.

Melhuish, A., van Dissen, R. and Berryman, K., 1996. Mount Stewart-Halcombe Anticline: A look inside a growing fold in the Manawatu region, New Zealand. New Zealand Journal of Geology and Geophysics, 39(1): 123-133.

Nathan, S., 1993. Revising the 1:250,000 Geological Map of New Zealand, Institute of Geological \& Nuclear Sciences.

Norris, R.J. and Cooper, A.F., 2001. Late Quaternary slip rates and slip partitioning on the Alpine Fault, New Zealand. Journal of Structural Geology, 23(2-3): 507-520.

Ohmori, H., 1993. Changes in the hypsometric curve through mountain building resulting from concurrent tectonics and denudation. Geomorphology, 8(4): 263-277.

Ouchi, S., 1985. Response of alluvial rivers to slow active tectonic movement. Geological Society of America Bulletin, 96(4): 504-515.

Palacios-Vélez, O.L. and Cuevas-Renaud, B., 1986. Automated River-Course, Ridge and Basin Delineation from Digital Elevation Data. Journal of Hydrology, 86(3-4): 299-314.

Pedrera, A., Pérez-Peña, J.V., Galindo-Zaldivar, J., Azanon, J.M. and Azor, A., 2009. Testing the sensitivity of geomorphic indices in areas of low-rate active folding (eastern Betic Cordillera, Spain). Geomorphology, 105(3-4): 218-231.

Pérez-Peña, J.V., Azanon, J.M. and Azor, A., 2009a. CalHypso: an ArcGIS extension to calculate hypsometric curves and their statistical moments. Applications to drainage basin analysis in SE Spain. Computers \& Geosciences, 35(6): 1214-1223.

Pérez-Peña, J.V., Azanon, J.M., Azor, A., Delgado, J. and Gonzalez-Lodeiro, F., 2009b. Spatial analysis of stream power using GIS: SLk anomaly maps. Earth Surface Processes and Landforms, 34(1): 16-25.

Pérez-Peña, J.V., Azor, A., Azañón, J.M. and Keller, E.A., 2010. Active tectonics in the Sierra Nevada (Betic Cordillera, SE Spain): Insights from geomorphic indexes and drainage pattern analysis. Geomorphology, 119(1-2): 74-87.

Pillans, B., 1983. Upper Quaternary marine terrace chronology and deformation, South Taranaki, New Zealand. Geology, 11(5): 292-297. 
Pillans, B., 1990. Vertical Displacement Rates on Quaternary Faults, Wanganui Basin. New Zealand Journal of Geology and Geophysics, 33(2): 271-275.

Pillans, B., 1994. Direct Marine Terrestrial Correlations, Wanganui Basin, New Zealand - The Last Million Years. Quaternary Science Reviews, 13(3): 189-200.

Quigley, M., Van Dissen, R., Litchfield, N., Villamor, P., Duffy, B., Barrell, D., Furlong, K., Stahl, T., Bilderback, E. and Noble, D., 2012. Surface rupture during the $2010 \mathrm{Mw} 7.1$ Darfield (Canterbury) earthquake: implications for fault rupture dynamics and seismic-hazard analysis. Geology, 40(1).

Rattenbury, M.S. and Heron, D.W., 1997. Revised procedures and specifications for the QMAP GIS, Institute of Geological \& Nuclear Sciences

Rattenbury, M.S., Heron, D.W. and Nathan, S., 1994. Procedures and specifications for the QMAP GIS, . Institute of Geological \& Nuclear Sciences

Raub, M.L., 1987. Seismotectonic hazard analysis of the Mohaka fault, North Island, New Zealand. In: Engineering, N.Z.S.f.E. (Editor), Proceeding of the Pacific Conference, pp. 219-230.

Reuter, H.I., Nelson, A. and Jarvis, A., 2007. An evaluation of void filling interpolation methods for SRTM data. International Journal of Geographic Information Science, 21(9): 983-1008.

Reyners, M., Eberhart-Phillips, D., Stuart, G. and Nishimura, Y., 2006. Imaging subduction from the trench to $300 \mathrm{~km}$ depth beneath the central North Island, New Zealand, with Vp and Vp/Vs. Geophys. J. Int, 165: 565-583.

Rodgers, D.W. and Little, T.A., 2006. World's largest coseismic strike-slip offset: The 1855 rupture of the Wairarapa Fault, New Zealand, and implications for displacement/length scaling of continental earthquakes. J. Geophys. Res., 111(B12): B12408.

Schumm, S.A., Dumont, J.F. and Holbrook, J.M., 2000. Active Tectonics and Alluvial Rivers. Cambridge University Press, Cambridge, $276 \mathrm{pp}$.

Sherburn, S. and White, R.S., 2005. Crustal seismicity in Taranaki, New Zealand, using accurate hypocentres from a dense network. Geophys. J. Int, 162 (494-506).

Snow, R.S. and Slingerland, R.L., 1987. Mathematical Modeling of Graded River Profiles. The Journal of Geology, 95(1): 15-33.

Stirling, M., McVerry, G., Gerstenberger, M., Litchfield, N., Van Dissen, R., Berryman, K., Barnes, P., Wallace, L., Villamor, P., Langridge, R., Lamarche, G., Nodder, S., Reyners, M., Bradley, B., Rhoades, D., Smith, W., Nicol, A., Pettinga, J., Clark, K. and Jacobs, K., 2012. National Seismic Hazard Model for New Zealand: 2010 Update. Bulletin of the Seismological Society of America, 102(4): 1514-1542. 
Stirling, M.W., McVerry, G.H. and Berryman, K.R., 2002. A new seismic hazard model for New Zealand. Bulletin of the Seismological Society of America, 92(5): 1878-1903.

Strahler, A., 1952a. Dynamic Basis of Geomorphology. Geological Society of America Bulletin, 63(9): 923-938.

Strahler, A.N., 1952b. Hypsometric (Area-Altitude) Analysis of Erosional Topography. Geological Society of America Bulletin, 63(11): 1117-1142.

Sutherland, R., Berryman, K. and Norris, R., 2006. Quaternary slip rate and geomorphology of the Alpine fault: Implications for kinematics and seismic hazard in southwest New Zealand. Geological Society of America Bulletin, 118(3-4): 464-474.

Tarboton, D.G., Bras, R.L. and Rodriguez-Iturbe, I., 1991. On Extraction of Channel Networks from Digital Elevation Data. Hydrological Processes, 5: 81-100.

Townsend, D., Nicol, A., Mouslopoulou, V., Begg, J.G., Beetham, R., Clark, D., Giba, M., Heron, D., Lukovic, B., McPherson, A., Seebeck, H. and Walsh, J., 2010. Palaeoearthquake histories across a normal fault system in the southwest Taranaki Peninsula, New Zealand. New Zealand Journal of Geology and Geophysics, 53(4): 375-394.

Townsend, D., Vonk, A. and Kamp, P., 2008. Geology of the Taranaki area. 1:250 000 geological map, 7. GNS Science, Lower Hutt, 1 sheet +77 pp.

Townsend, T., 1998. Paleoseismology of the Waverley Fault Zone and implications for earthquake hazard in South Taranaki, New Zealand. New Zealand Journal of Geology and Geophysics, 41(4): 467-474.

Troiani, F. and Della Seta, M., 2008. The use of the Stream Length-Gradient index in morphotectonic analysis of small catchments: A case study from Central Italy. Geomorphology, 102(1): 159168.

Trustpower Ltd., 2008. Online information on the Patea Hydro Electric Scheme (http://www.trustpower.co.nz/index.php?section=117).

Van Dissen, R., Barrell, D., Litchfield, N., Villamor, P., Quigley, M., King, A., Furlong, K., Begg, J., Townsend, D., Mackenzie, H., Stahl, T., D., N., Duffy, B., Bilderback, E., Claridge, J., Klahn, A., Jongens, R., Cox, S., Langridge, R., Ries, W., Dhakal, R., Smith, A., Hornblow, S., Nicol, R., Pedley, K., Henham, H., Hunter, R., Zajac, A. and Mote, T., 2011. Surface rupture displacement on the Greendale Fault during the Mw 7.1 Darfield (Canterbury) earthquake, New Zealand, and its impact on man-made structures, Proceedings of the Ninth Pacific Conference on Earthquake Engineering - Building an Earthquake-Resilient Society, Auckland, New Zealand.

Villamor, P. and Berryman, K.R., 2006. Late Quaternary geometry and kinematics of faults at the southern termination of the Taupo Volcanic Zone, New Zealand. New Zealand Journal of Geology and Geophysics, 49(1): 1-21. 
Villamor, P., Berryman, K.R., Nairn, I.A., Wilson, K., Litchfield, N. and Ries, W., 2011. Associations between volcanic eruptions from Okataina volcanic center and surface rupture of nearby active faults, Taupo rift, New Zealand: Insights into the nature of volcano-tectonic interactions. Geological Society of America Bulletin, 123(7-8): 1383-1405.

Villamor, P., Litchfield, N., Barrell, D., Van Dissen, R., Hornblow, S., Quigley, M., Levick, S., Ries, W., Duffy, B., Townsend, D., Stahl, T., Bilderback, E., Noble, D., Furlong, K. and Grant, H., 2012. Map of the 4th December 2010 rupture along the Greendale Fault, Canterbury, New Zealand: Application to land use planning. New Zealand Journal of Geology and Geophysics In Press.

Villamor, P., Van Dissen, R., Alloway, B.V., Palmer, A.S. and Litchfield, N., 2007. The Rangipo fault, Taupo rift, New Zealand: An example of temporal sliprate and single-event displacement variability in a volcanic environment. Geological Society of America Bulletin, 119(5-6): 529547.

Walcott, R.C. and Summerfield, M.A., 2008. Scale dependence of hypsometric integrals: An analysis of southeast African basins. Geomorphology, 96(1-2): 174-186.

Walker, J.P. and Willgoose, G.R., 1999. On the effect of digital elevation model accuracy on hydrology and geomorphology. Water Resources Research, 35(7): 2259-2268.

Walls, M., 2004. The geophysical exploration of the Ohura Fault, North Wanganui Basin, New Zealand Victoria University of Wellington.

WDC, 2011. Earthquake risk in Wanganui, Wanganui District Council, Wanganui.

Wells, D.L. and Coppersmith, K.J., 1994. New empirical relationships among magnitude, rupture length, rupture width, rupture area, and surface displacement. Bulletin of the Seismological Society of America, 84(4): 974-1002,A1-A4,B1-B11,C1-C49.

Willgoose, G. and Hancock, G., 1998. Revisiting the hypsometric curve as an indicator of form and process in transport-limited catchment. Earth Surface Processes and Landforms, 23(7): 611623.

Wise, S.M., 2000. Assessing the quality for hydrological applications of digital elevation models derived from contours. Hydrological Processes, 14(11-12): 1909-1929.

Wise, S.M., 2007. Effect of differing DEM creation methods on the results from a hydrological model. Computers \&amp; Geosciences, 33(10): 1351-1365. 


\section{Appendix A}

\section{Visual Basic code used for the calculation of the sinuosity index}

Dim pMxDoc As IMxDocument

Dim pMap As IMap

Dim pFLayer As IFeatureLayer

Dim pFClass As IFeatureClass

Dim pFCursor As IFeatureCursor

Dim pFeat As IFeature

Dim pCurve As ICurve

Dim pSubC As ICurve

Dim pPoint1 As IPoint

Dim pPoint2 As IPoint

Dim MidPoint As IPoint

Dim D As Double

Dim i As Long, j As Long, k As Long

Dim OutFile As String

Dim Sinu As Double

Dim pProx As IProximityOperator

Dim Dist1 As Double

Dim Dist2 As Double

Dim TxtLine As String

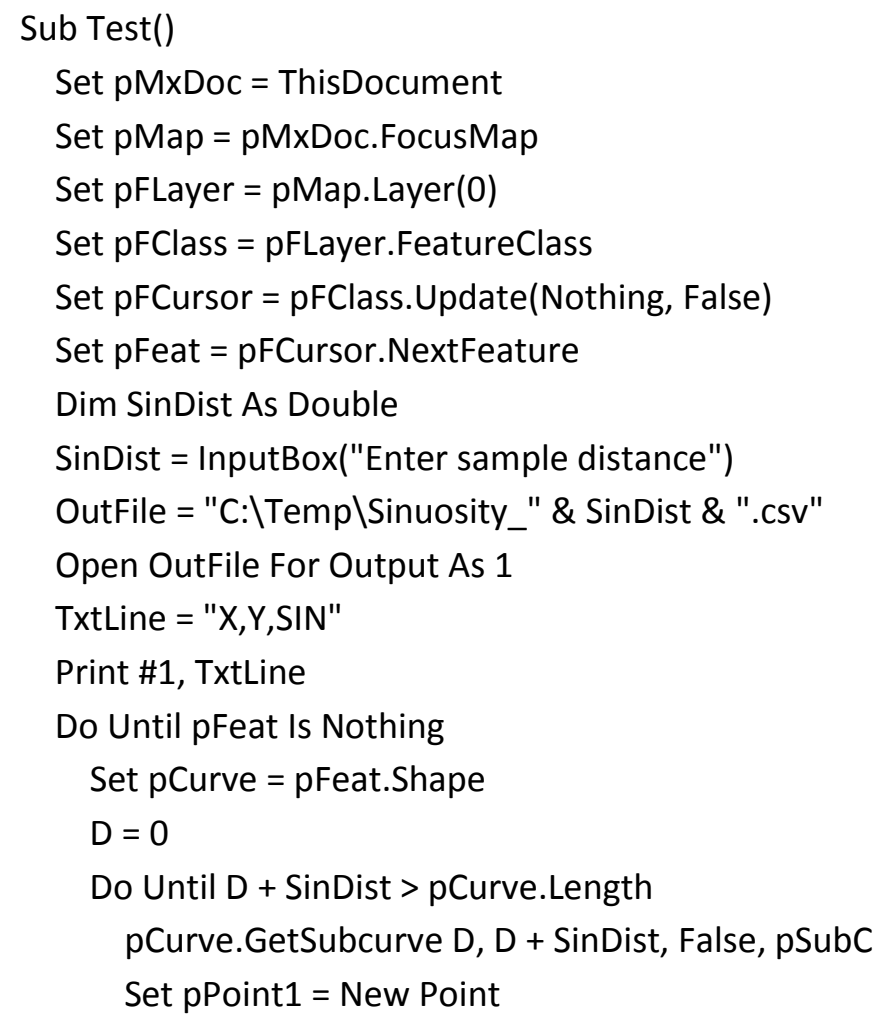


Set $\mathrm{pPoint} 2=$ New Point

Set MidPoint $=$ New Point

pCurve.QueryPoint esriNoExtension, D + SinDist, False, pPoint1

pCurve.QueryPoint esriNoExtension, D, False, pPoint2

pCurve.QueryPoint esriNoExtension, D + SinDist / 2, False, MidPoint

Set $p$ Prox $=$ pPoint 1

Dist1 $=$ Prox. ReturnDistance (pPoint2)

Dist2 $=$ pSubC.Length

TxtLine = MidPoint.X \& "," \& MidPoint.Y \& "," \& Dist2\# / Dist1\#

Print \#1, TxtLine

$\mathrm{D}=\mathrm{D}+$ SinDist

Loop

DoEvents

Set $p F e a t=p F C u r s o r$. NextFeature

Loop

Close

MsgBox "Done"

End Sub 


\section{Appendix B}
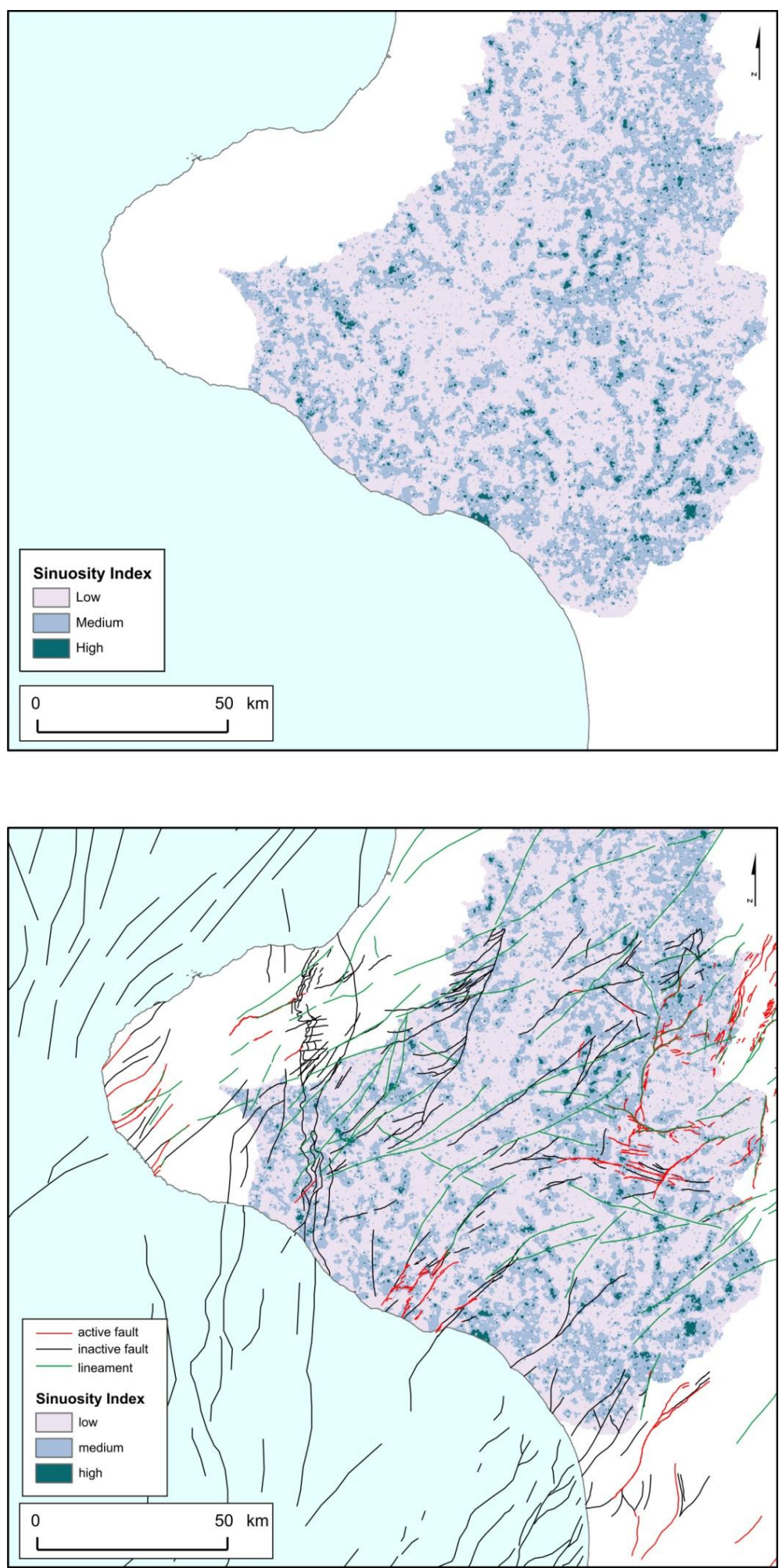

Figure B-1. Upper - The sinuosity index values interpolated from a sample distance of $250 \mathrm{~m}$. Lower - The sinuosity index values interpolated from a sample distance of $250 \mathrm{~m}$ with active faults, inactive faults and lineaments. 

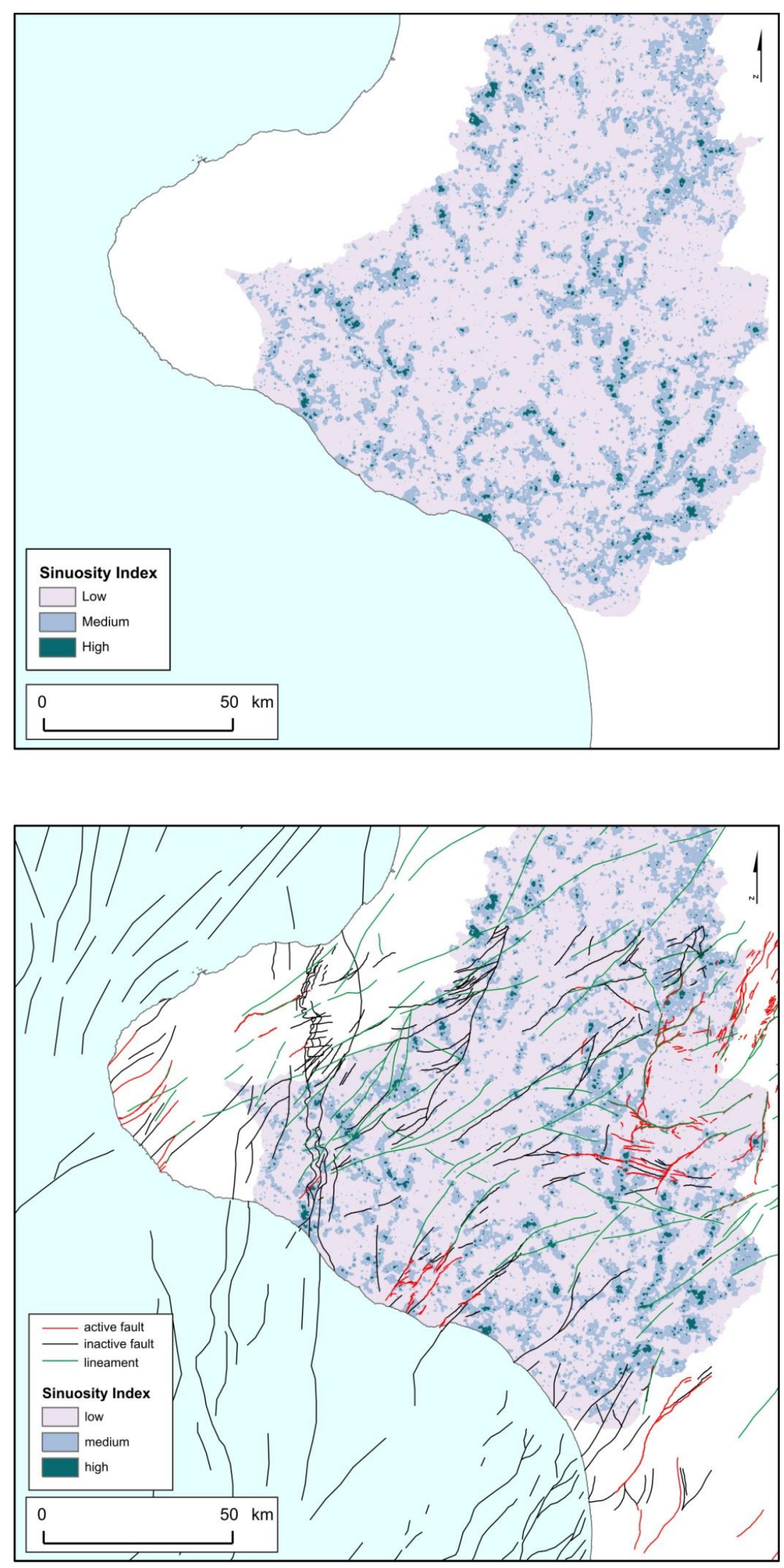

Figure B-2. Upper - The sinuosity index values interpolated from a sample distance of $500 \mathrm{~m}$. Lower - The sinuosity index values interpolated from a sample distance of $500 \mathrm{~m}$ with active faults, inactive faults and lineaments. 

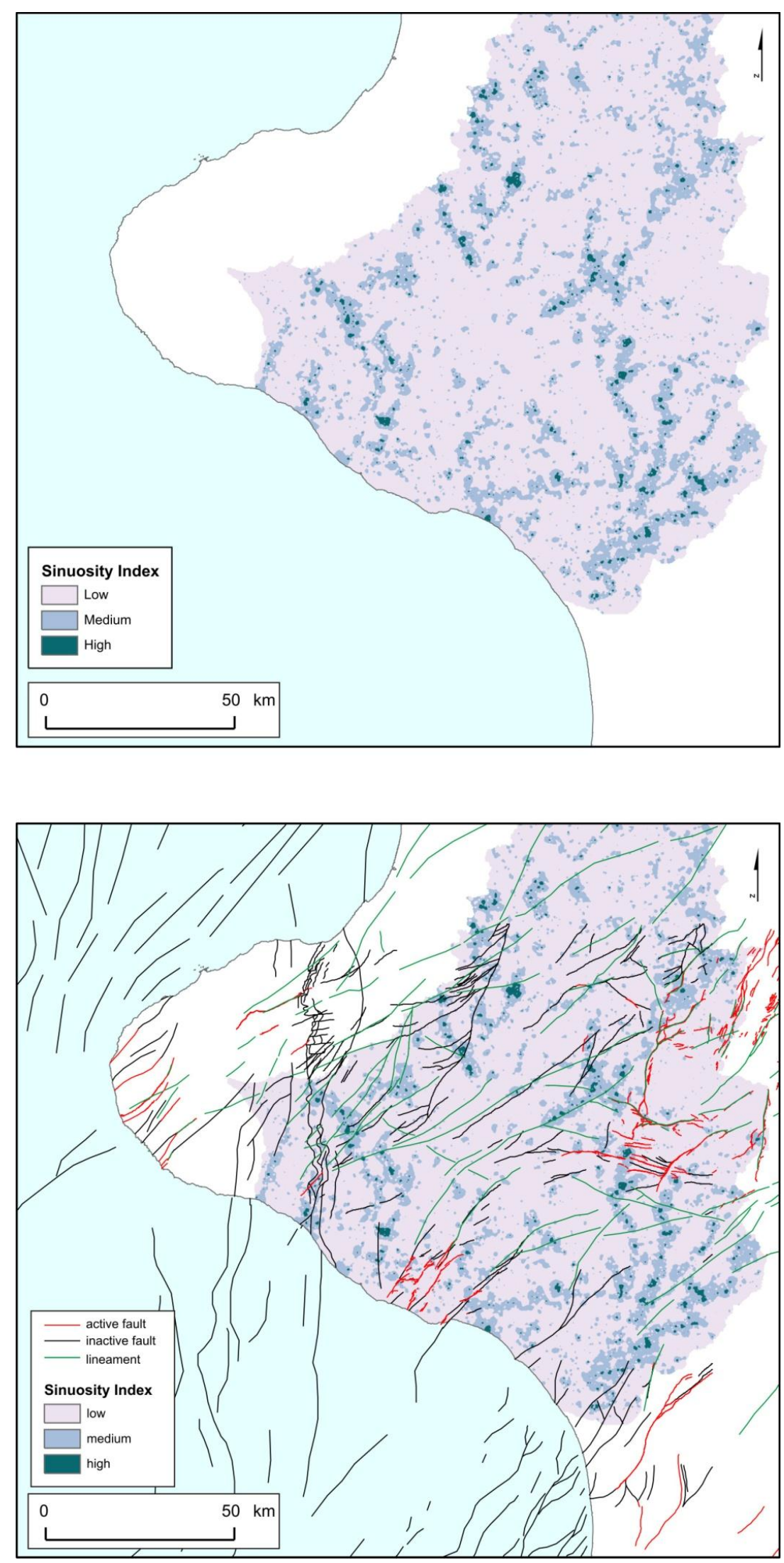

Figure B-3. Upper - The sinuosity index values interpolated from a sample distance of $750 \mathrm{~m}$. Lower - The sinuosity index values interpolated from a sample distance of $750 \mathrm{Om}$ with active faults, inactive faults and lineaments. 

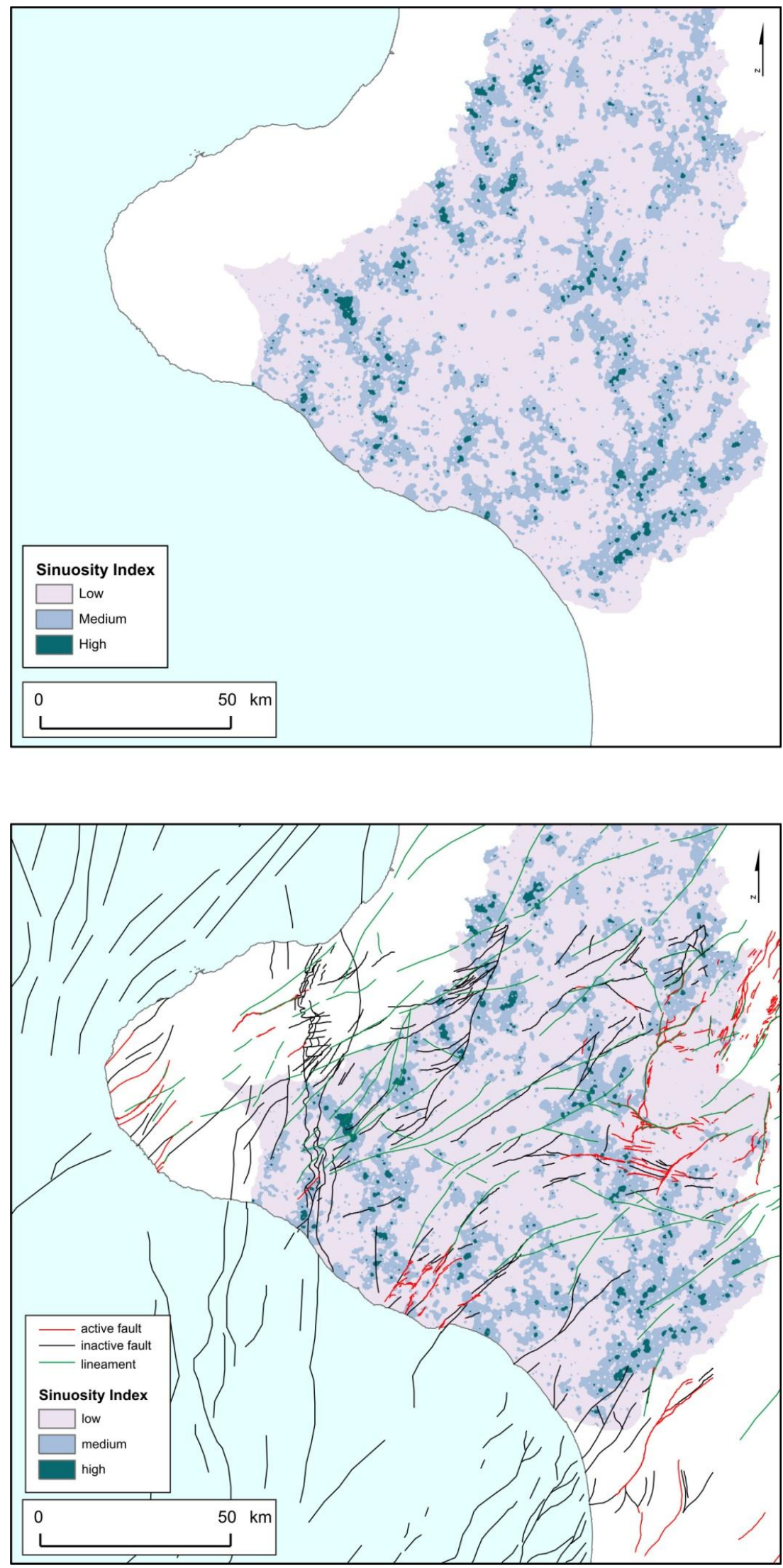

Figure B-4 Upper - The sinuosity index values interpolated from a sample distance of $1000 \mathrm{~m}$. Lower - The sinuosity index values interpolated from a sample distance of $1000 \mathrm{~m}$ with active faults, inactive faults and lineaments. 

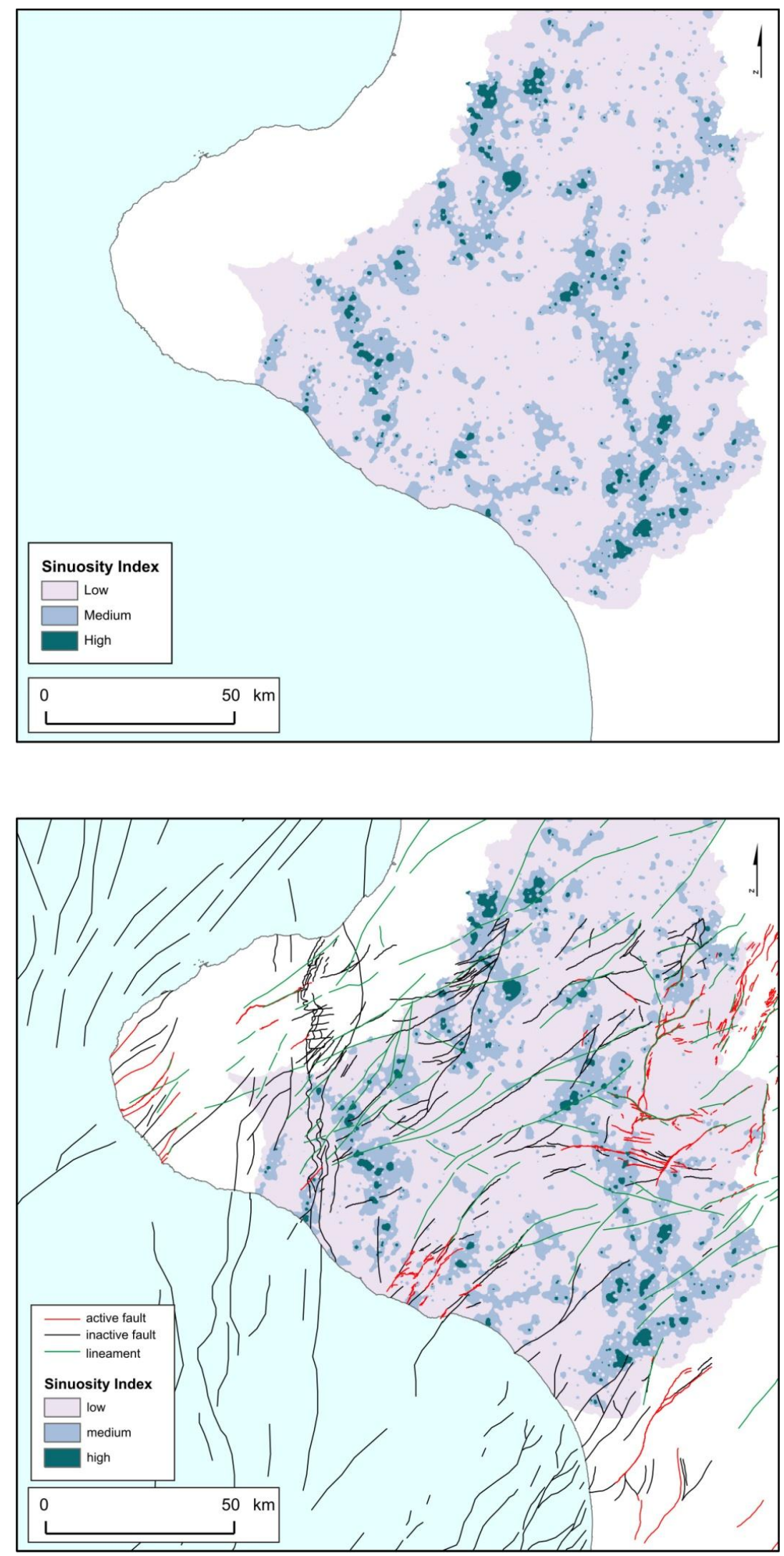

Figure B-5 Upper - The sinuosity index values interpolated from a sample distance of $1500 \mathrm{~m}$. Lower - The sinuosity index values interpolated from a sample distance of $1500 \mathrm{~m}$ with active faults, inactive faults and lineaments. 

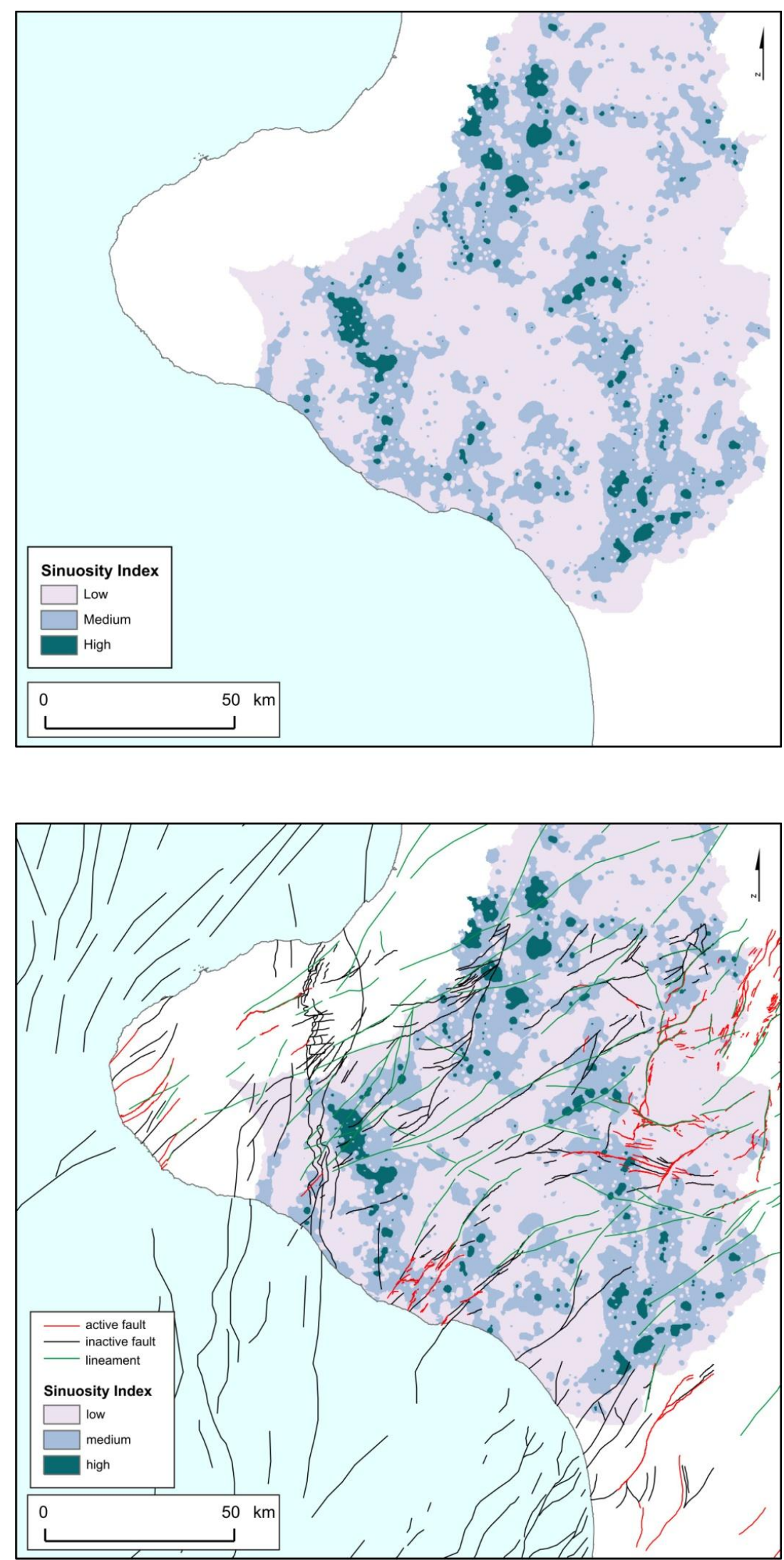

Figure B-6. Upper - The sinuosity index values interpolated from a sample distance of $2000 \mathrm{~m}$. Lower - The sinuosity index values interpolated from a sample distance of $2000 \mathrm{~m}$ with active faults, inactive faults and lineaments. 


\section{Appendix C}
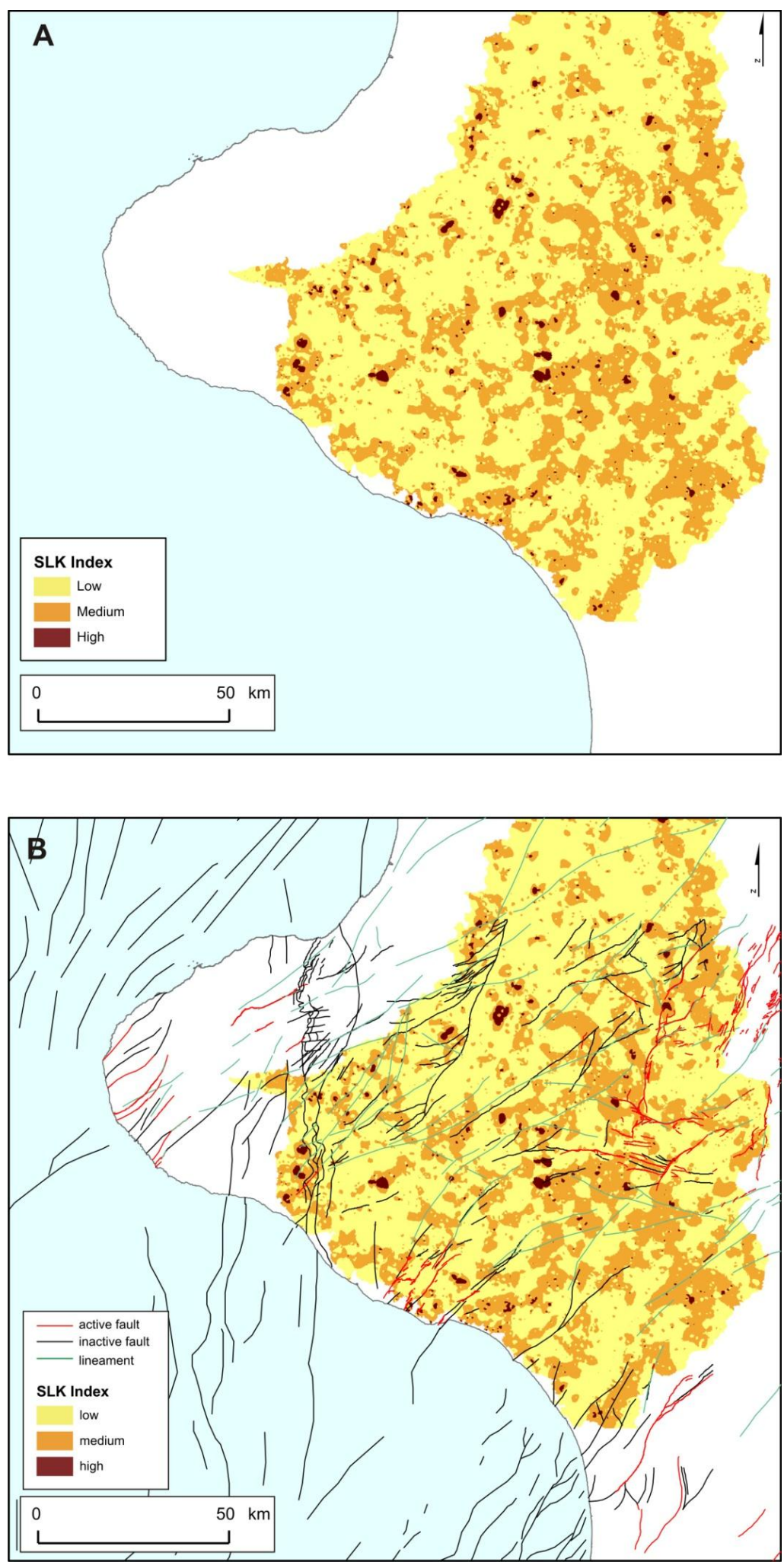

Figure C-1. Upper - The SLk index values interpolated from a sample distance of $500 \mathrm{~m}$. Lower - The SLk index values interpolated from a sample distance of $500 \mathrm{~m}$ with active faults, inactive faults and lineaments 

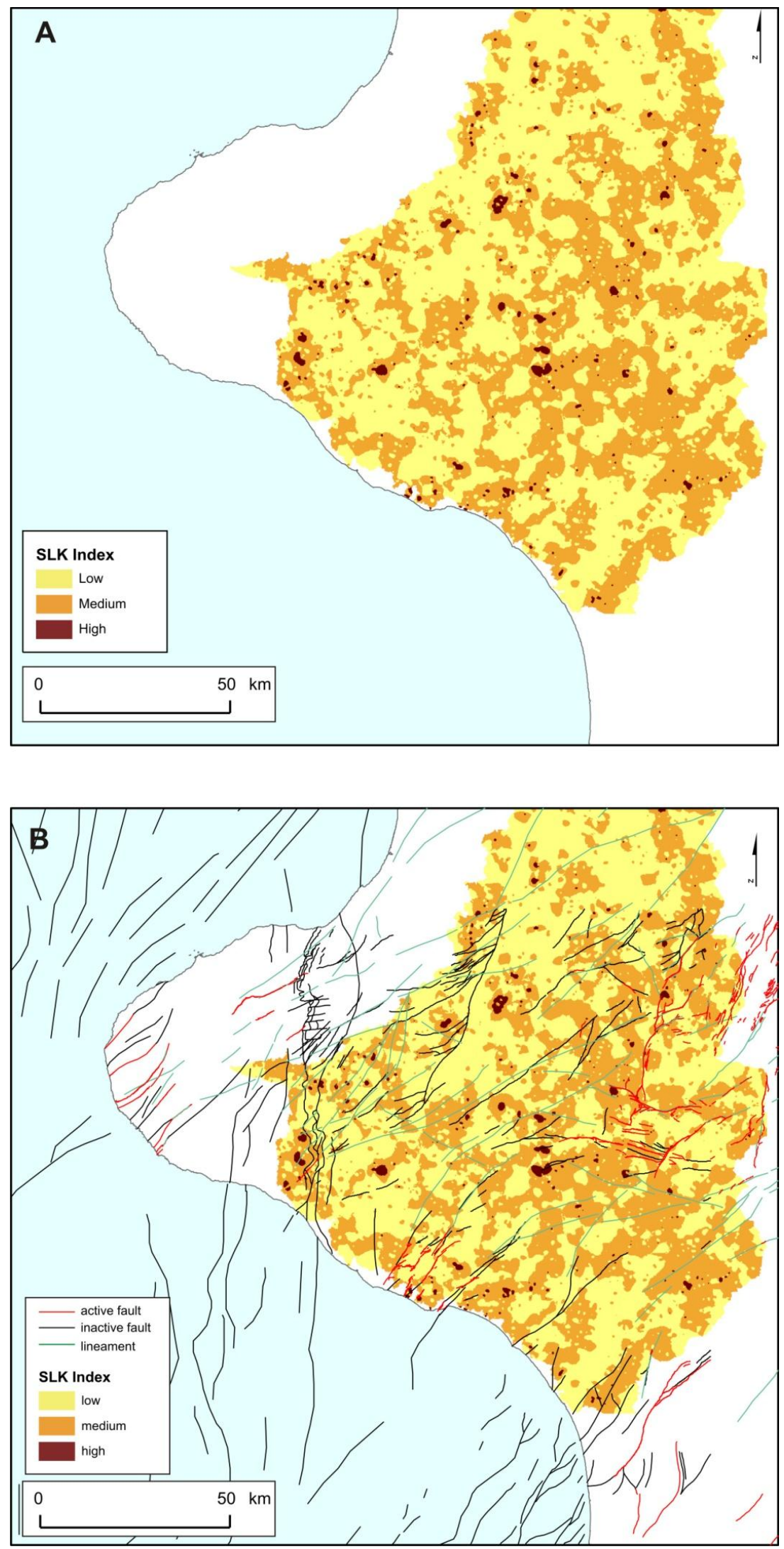

Figure C-2. Upper - The SLk index values interpolated from a sample distance of $750 \mathrm{~m}$. Lower - The SLk index values interpolated from a sample distance of $750 \mathrm{~m}$ with active faults, inactive faults and lineaments 

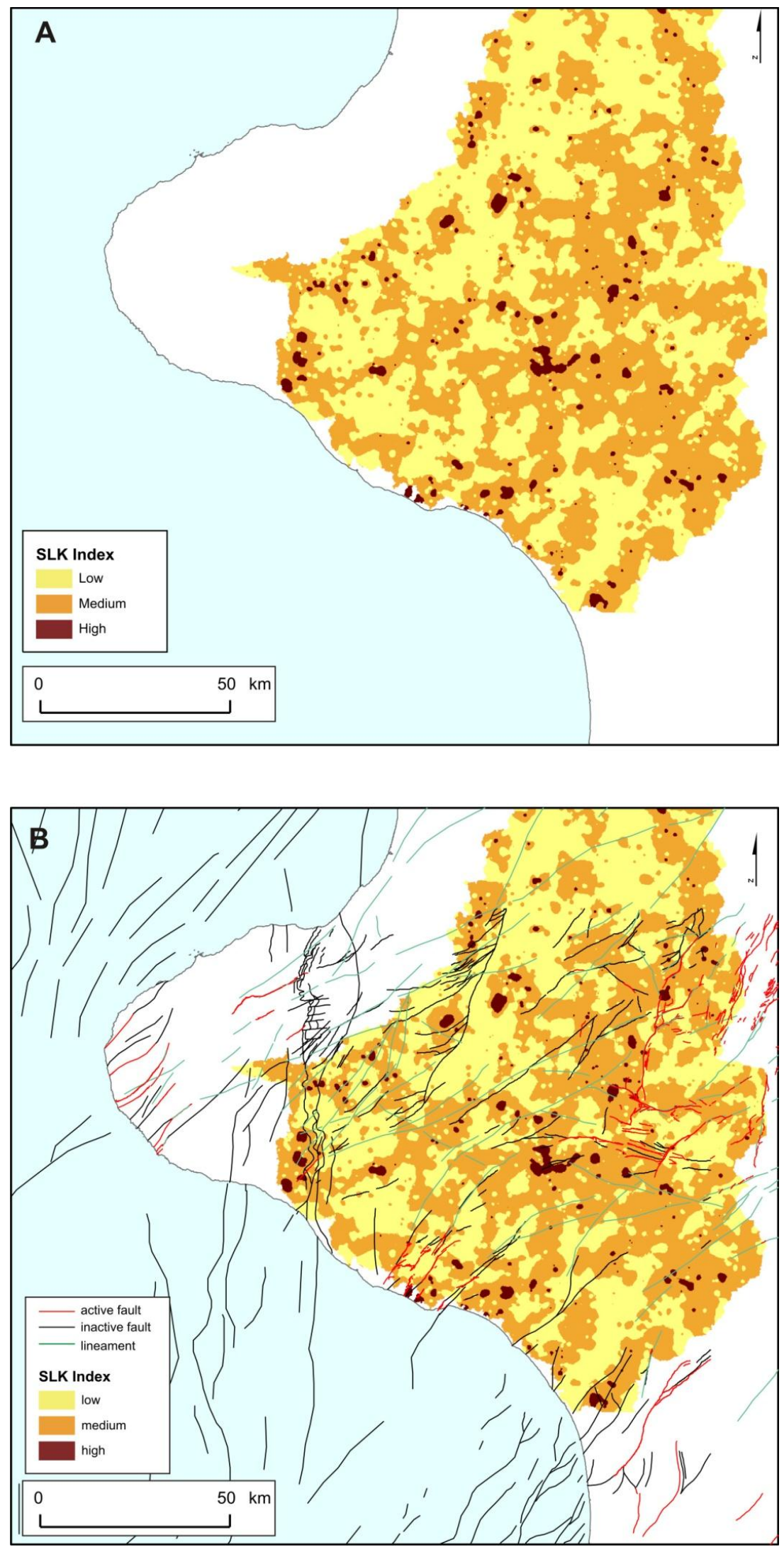

Figure C-3. Upper - The SLk index values interpolated from a sample distance of $1000 \mathrm{~m}$. Lower - The SLk index values interpolated from a sample distance of $1000 \mathrm{~m}$ with active faults, inactive faults and lineaments 

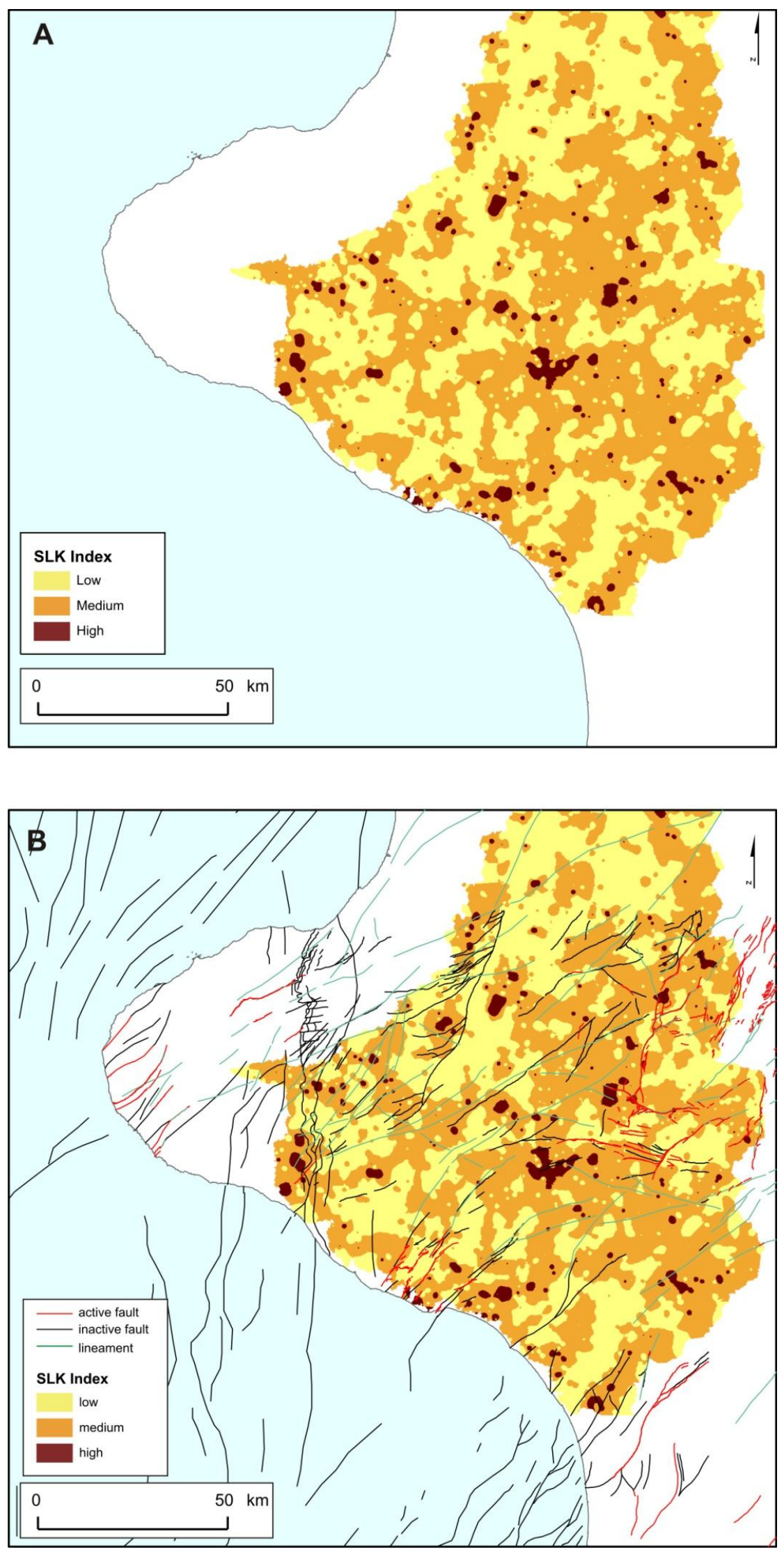

Figure C-4. Upper - The SLk index values interpolated from a sample distance of $1500 \mathrm{~m}$. Lower - The SLk index values interpolated from a sample distance of $1500 \mathrm{~m}$ with active faults, inactive faults and lineaments 


\section{Appendix D}
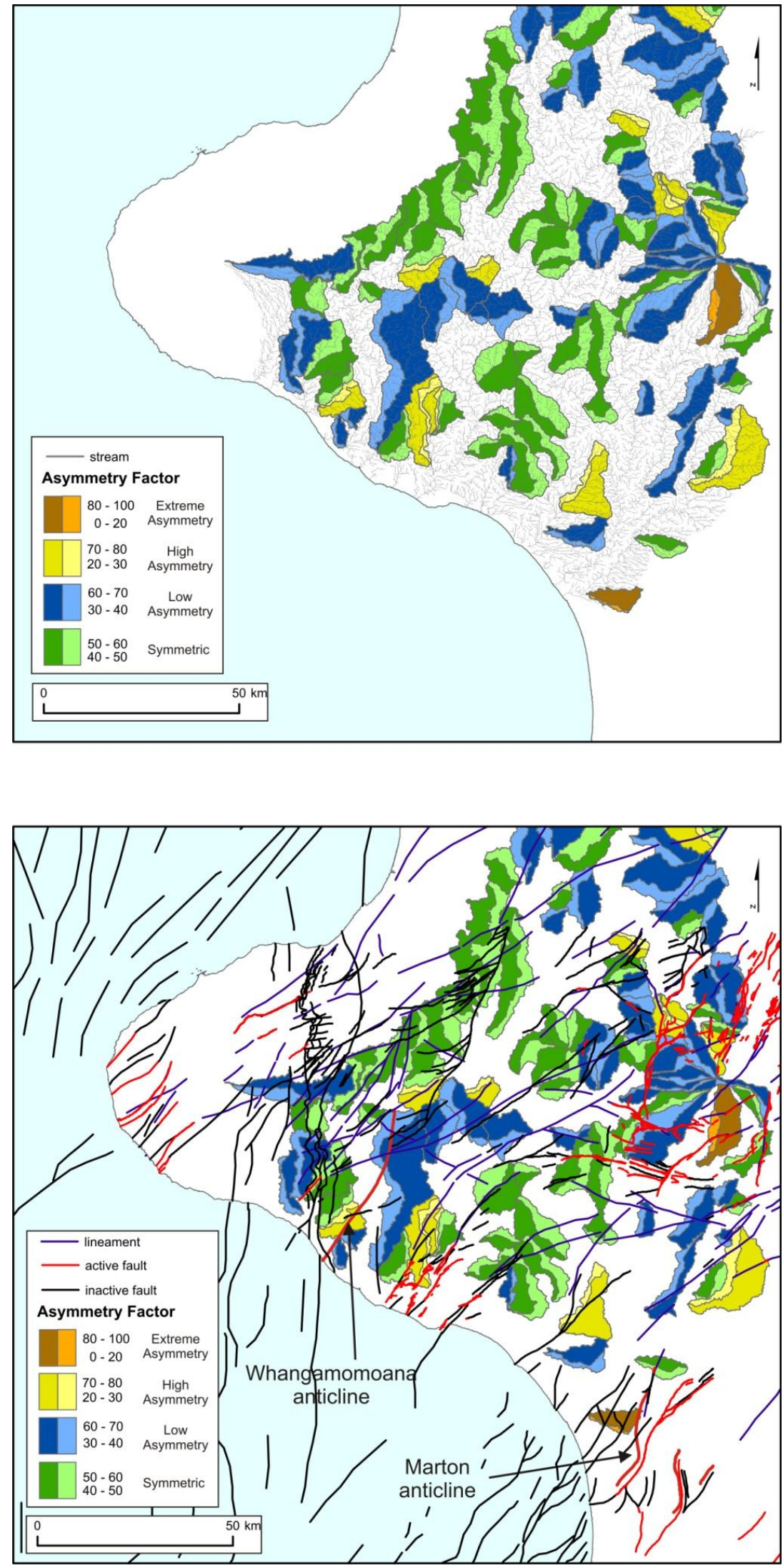

Figure D-1. Upper - The asymmetry factor values for $3^{\text {rd }}$ order catchments. Lower - The asymmetry factor values for $3^{\text {rd }}$ order catchments with active faults, inactive faults and lineaments 